\author{
UNIVERSIDADE DE SÃO PAULO \\ FACULDADE DE ECONOMIA, ADMINISTRAÇÃO E CONTABILIDADE \\ DEPARTAMENTO DE ADMINISTRAÇÃO \\ PROGRAMA DE PÓS-GRADUAÇÃO EM ADMINISTRAÇÃO
}

\title{
RESPONSABILIDADE SOCIAL E DESEMPENHO FINANCEIRO DAS EMPRESAS: UM ESTUDO EMPÍRICO UTILIZANDO O BALANÇO SOCIAL PADRÃO IBASE
}

\author{
José Renato Kitahara
}

Orientador: Prof. Dr. José Augusto Giesbrecht da Silveira

SÃO PAULO 
Profa. Dra. Suely Vilela

Reitor da Universidade de São Paulo

Prof. Dr. Carlos Roberto Azzoni

Diretor da Faculdade de Economia, Administração e Contabilidade

Prof. Dr. Eduardo Pinheiro Gondim de Vasconcellos

Chefe do Departamento de Administração

Prof. Dr. Isak Kruglianskas

Coordenador do Programa de Pós-Graduação em Administração 


\title{
JOSÉ RENATO KITAHARA
}

\section{RESPONSABILIDADE SOCIAL E DESEMPENHO FINANCEIRO DAS EMPRESAS: UM ESTUDO EMPÍRICO UTILIZANDO O BALANÇO SOCIAL PADRÃO IBASE}

\author{
Dissertação apresentada ao Departamento de \\ Administração da Faculdade de Economia, \\ Administração e Contabilidade da Universidade de \\ São Paulo como requisito para a obtenção do título \\ de Mestre em Administração.
}

Orientador: Prof. Dr. José Augusto Giesbrecht da Silveira

\section{SÃO PAULO}




\section{FICHA CATALOGRÁFICA}

\section{Elaborada pela Seção de Processamento Técnico do SBD/FEA/USP}

\section{Kitahara, José Renato}

Responsabilidade social e desempenho financeiro das empresas : um estudo empírico utilizando o balanço social padrão IBASE / José Renato Kitahara - São Paulo, 2007.

$178 \mathrm{p}$.

Dissertação (Mestrado) - Universidade de São Paulo, 2007

Bibliografia

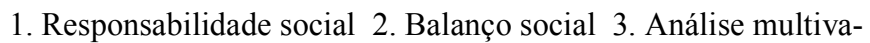
riada 4. Análise estatística I. Universidade de São Paulo. Faculdade de Economia, Administração e Contabilidade II. Título.

$$
\text { CDD - } 658.408
$$


Dedico esse trabalho a

meus pais Cirene e Yaemi, a

minha esposa Maria Inês, a

meus filhos Fernanda e Rodrigo e a meus irmãos Silvia e Choji. 


\section{AGRADECIMENTO}

Agradeço a Deus pela graça de poder realizar mais esse sonho e que me tem dado força e inspiração em todos os momentos da minha vida.

Agradeço a meus pais, Cirene e Yaemi, que me trouxeram ao mundo, me cobriram de amor, forjaram meu caráter, sempre me incentivaram e que me ensinaram a ajudar o próximo com dedicação e honestidade.

Agradeço a minha amada esposa Maria Inês pelo amor, companheirismo, paciência e total apoio em todos os momentos de nossa convivência. Sem ela nada teria acontecido. Aos meus filhos, Fernanda e Rodrigo, pelo apoio e compreensão do pouco tempo que dediquei a eles por conta desse trabalho e tantos outros.

Agradeço aos professores Boris Schneiderman, Adolpho Canton e Maria Aparecida Gouvea, que me ajudaram a conhecer, admirar e gostar da estatística, e aos colegas Cristiane Karcher e Newton Ribeiro pelas longas e frequentes discussões sobre o mesmo tema. Todos contribuíram para que esse trabalho atingisse os objetivos esperados.

Agradeço aos srs. Ciro Torres e Cláudia Mansur do IBASE, Peter Nadas do FIDES, Roberto Gonzales da APIMEC e José Chehebe do IBS, pelo tempo, apoio e oportunidade de conhecer mais sobre Responsabilidade Social.

Agradeço ao IBASE pela iniciativa de administrar e disponibilizar os Balanços Sociais, cuja riqueza de informações permitiu o desenvolvimento desse trabalho.

Agradeço aos professores Isak Kruglianskas e Vicente Plantullo pelas valiosas sugestões no exame de qualificação.

Agradeço ao Prof. Silveira, meu orientador, por toda a dedicação e condução do trabalho. Sua experiência e amizade tornaram o desenvolvimento do trabalho uma tarefa desafiante, motivadora e muito agradável. 
“Nada te perturbe, nada te assuste, pois tudo passa. Só Deus não muda. Com paciência tudo se alcança. Quem a Deus tem, nada lhe falta, só Deus basta !” Santa Teresa de Jesus 


\section{RESUMO}

Existe uma polêmica sobre qual deve ser o papel social das empresas. De um lado, considera-se que a responsabilidade de seus gestores é maximizar os resultados em favor de seus acionistas e proprietários e, de outro, que a ação social empreendida pelas empresas traz benefícios à sociedade e também a seus stakeholders. Além disso, alguns autores admitem, inclusive, que não basta seguir as leis e pagar os impostos, mas também ter atitudes éticas e filantrópicas.

Essa dissertação é um estudo empírico, de caráter exploratório, que objetiva identificar a existência de relações significativas entre o desempenho financeiro das empresas e o seu nível de investimento em ações de responsabilidade social. A pesquisa envolveu a análise de uma amostra de 897 balanços sociais publicados pelo IBASE no período de 2000 a 2004, por 298 empresas de diversos portes, nacionais e multinacionais, que atuavam no Brasil.

Estudos científicos que buscam identificar relacionamentos entre ação social empresarial e seu impacto sobre o desempenho financeiro têm procurado responder, mas ainda não encontraram uma resposta definitiva para essa questão. Algumas dessas pesquisas foram abordadas na revisão bibliográfica demonstrando que o tema ainda carece de mais investigação.

O presente estudo avaliou esse relacionamento sob várias condições: influência da situação financeira de lucro ou prejuízo das empresas, setor de atuação, seu porte e a conjuntura econômica e social em que elas operaram, refletida no ano de publicação de seu balanço social. O resultado da análise encontrou significância estatística que confirmou algumas das pesquisas científicas publicadas e também apresentou resultados que responderam questões em aberto de outras pesquisas sobre o mesmo tema. Portanto, apesar da dificuldade natural de percepção integrada dos resultados dos 68 modelos matemáticos envolvidos no estudo, as conclusões são uma oportuna contribuição científica ao tema.

Palavras-chave: Responsabilidade Social, Balanço Social, Análise Estatística, Análise Multivariada 


\begin{abstract}
There is a polemic about which should be the social role of companies. At one side, it is considered that the managers' responsibility is to maximize the results for stockholders and owners, and at the other, the social action undertaken by companies to bring benefits to the society and also to the stakeholders. Besides, some authors admit that is not enough to abide to the laws and to pay taxes, but the firm must also have ethical and philanthropical attitudes.

This dissertation is an empiric study, of exploratory nature, aiming at identifying the existence of significant relationships between financial performance of the companies and their investment level in social responsibility. The research involved the analysis of a sample of 897 social accounts published by IBASE in the period of 2000 to 2004, by 298 companies of several sizes, owned by national and multinational capital and operating in Brazil.

Scientific studies that seek to identify relationships between managerial social action and their impact on the financial performance have searched to answer this question, but they did not find a definitive answer yet. Some of these researches were mentioned in the bibliographic revision demonstrating that the theme still needs more investigation.

The present study evaluated this relationship under several conditions: companies having profit or loss, the business sector where they act, the firm size and the economic and social conjuncture in which they operated, reflected in the year of publication of their social accounting. The result of this analysis found statistical significance that confirmed some of the published scientific researches and also presented original results that answered open matters of other researches about the subject. Therefore, although the natural difficulty of integrated perception of the results of 68 mathematical models involved in the study, the conclusions are an opportune scientific contribution to the theme.
\end{abstract}

Keywords: Social Responsibility, Social Accounting, Multivariate Analysis, Statistical Analysis. 


\section{SUMÁRIO}

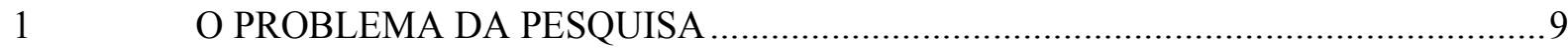

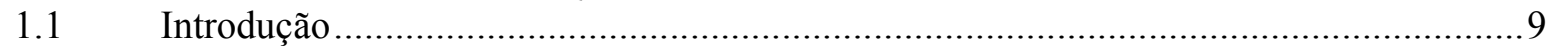

1.2 Descrição da Situação Problema............................................................................... 13

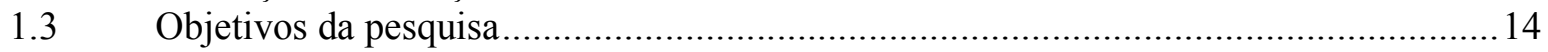

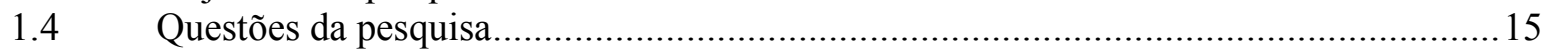

1.5 Definição teórica e operacional dos conceitos......................................................... 15

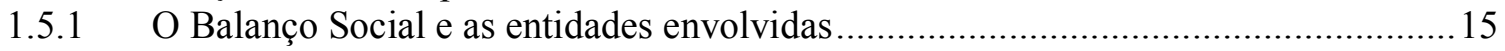

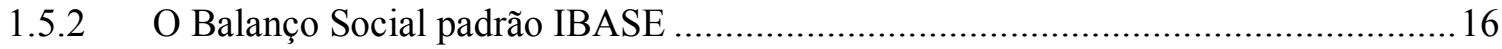

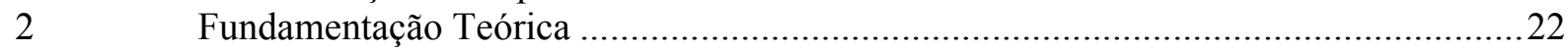

2.1 RSE - Responsabilidade Social Empresarial ....................................................22

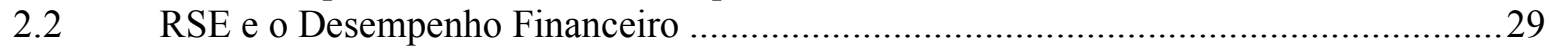

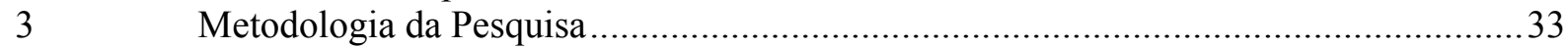

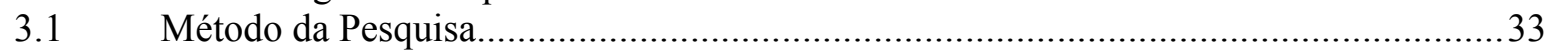

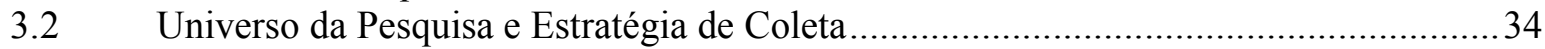

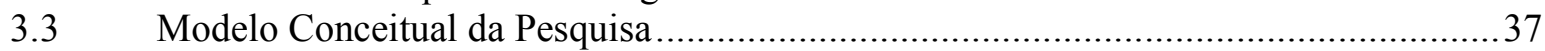

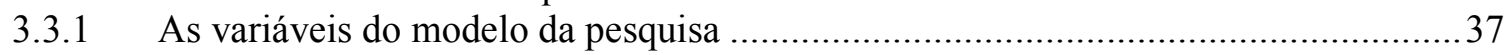

3.3.2 Construção dos modelos estatísticos ............................................................40

Exame dos Dados Coletados ......................................................................... 43

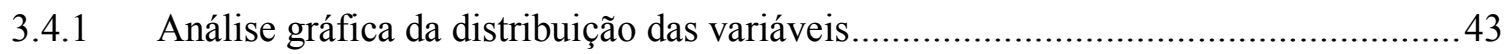

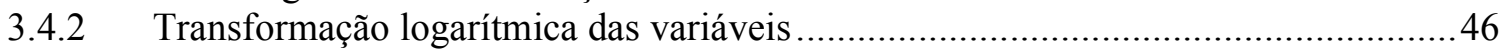

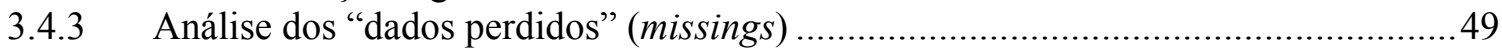

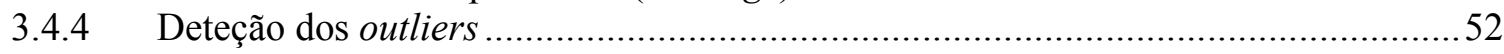

Estratégia de seleção das ferramentas estatísticas ..............................................56

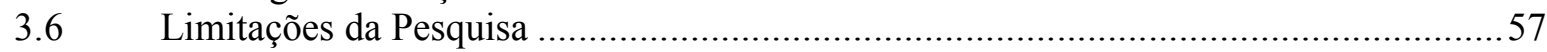

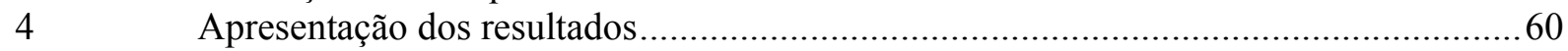

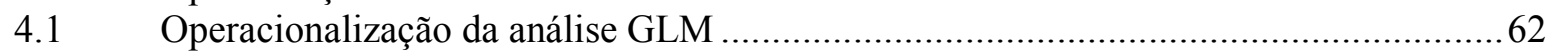

4.2 Análise dos modelos referentes às empresas que operaram com RO negativo.............63

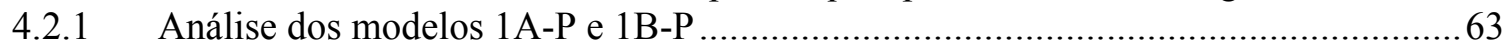

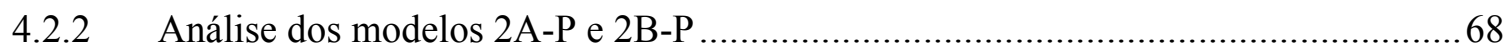

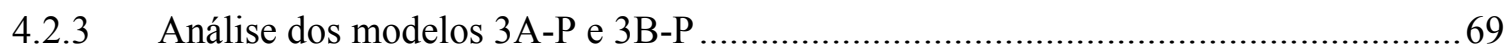

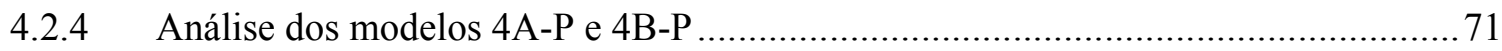

4.2.5 Conclusão sobre os modelos das empresas que operaram com RO negativo ............73

4.3 Análise dos modelos referentes às empresas que operaram com RO positivo..............75

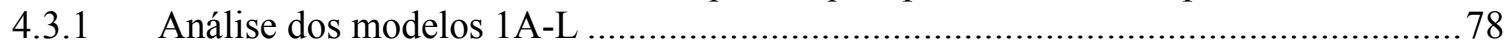

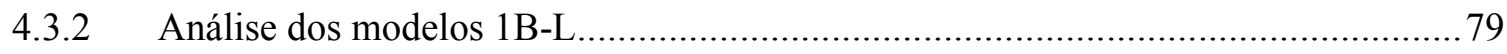

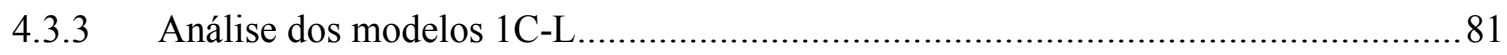

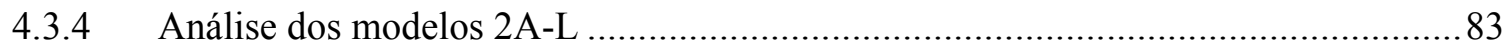

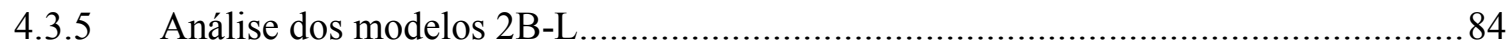

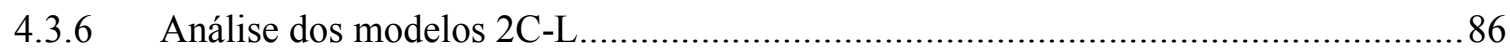

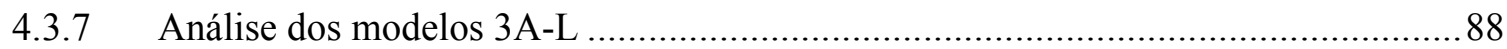

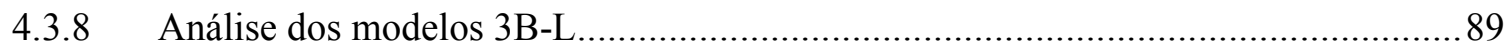

4.3.9 Análise dos modelos 3C-L...................................................................... 91

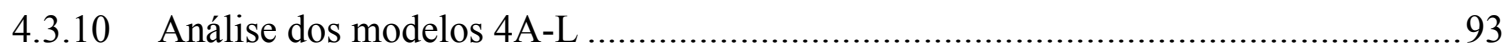

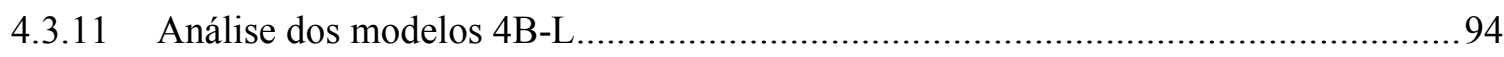

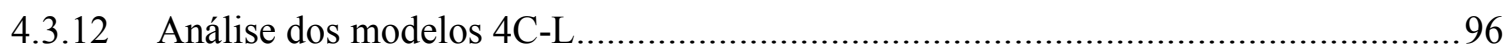


4.3.13 Conclusão sobre os modelos das empresas que operaram com RO positivo .98

4.4 Respostas às perguntas da pesquisa referentes ao grupo de empresas com RO negativo

4.5 Respostas às perguntas da pesquisa referentes ao grupo de empresas com RO positivo 100

5
6
7 Conclusões e Recomendações 103 Referências 109

7.1 Balanço Social - Modelo Empresas - IBASE

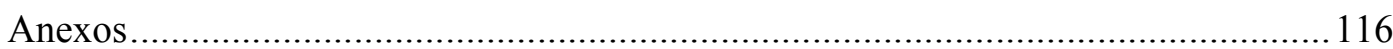

7.2 Tabela outliers pela Distância de Mahalanobis 116

Teste de normalidade das variáveis escala razão

7.4 Gráficos Normal Q-Q

7.4.2 Variáveis Indicadores Sociais Internos considerando o porte das empresas............125

7.4.3 Variáveis Indicadores Sociais Externos considerando o porte das empresas...........130

7.4.4 Variáveis Indicadores Ambientais considerando o porte das empresas................... 135

7.4.5 Variáveis Investimentos Totais considerando o porte das empresas .......................137

7.4.6 Variável Resultado Operacional dessensibilizada do porte das empresas ............... 138

7.4.7 Variáveis Indicadores Sociais Internos dessensibilizadas do porte das empresas.... 138

7.4.8 Variáveis Indicadores Sociais Externos dessensibilizadas do porte das empresas...143

7.4.9 Variáveis Indicadores Ambientais dessensibilizadas do porte das empresas ........... 148

7.4.10 Variáveis Investimentos Totais dessensibilizadas do porte das empresas ...............150

7.5 Resultados da análise GLM dessensibilizada do porte das empresas e utilizando fator de escala igual a 1000

7.6 Resultados completos da análise GLM referente às empresas que operaram com RO negativo

7.7 Resultados completos da análise GLM referente às empresas que operaram com RO positivo, sem homocedasticidade

7.8 Resultados completos da análise GLM referente às empresas que operaram com RO

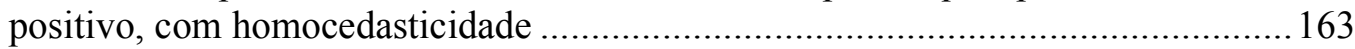

7.9 Mapa dos BSs da amostra por ano de publicação............................................... 169

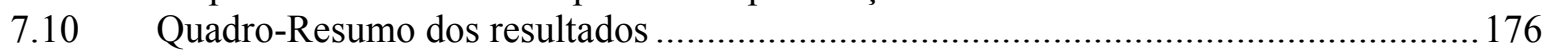




\title{
LISTA DE ABREVIATURAS E SIGLAS
}

\author{
ABERJE: Associação Brasileira de Comunicação Empresarial \\ AGI: $\quad$ Setor Agro-Industrial \\ Ano: $\quad$ Ano de publicação do BS \\ APIMEC: Associação dos Analistas e Profissionais de Investimento do Mercado de Capitais \\ BS: $\quad$ Balanço Social \\ D $\mathrm{D}^{2}$ : $\quad$ Distância de Mahalanobis (definição p. 52) \\ df: $\quad$ Grau de Liberdade (Degree of Freedom) (definição p. 53) \\ DJSI: $\quad$ Dow Jones Sustainability Indexes \\ DVA: $\quad$ Distribuição do Valor Adicionado \\ ELE: $\quad$ Setor Elétrico \\ EQP: $\quad$ Eta Quadrado Parcial, Partial Eta Square (definição p. 65) \\ FIDES: $\quad$ Fundação Instituto de Desenvolvimento Empresarial e Social \\ FIN: $\quad$ Setor de Serviços Financeiros \\ IA: Indicadores Ambientais \\ IBASE: Instituto Brasileiro de Análises Sociais e Econômicas \\ IND: $\quad$ Setor Industrial \\ ISE: $\quad$ Indicadores Sociais Externos \\ ISI: Indicadores Sociais Internos \\ Ln: $\quad$ Logaritmo natural (base e $=2,718$ ) \\ LnR_RSE_Total: Variável R_RSE_Total transformada log natural \\ LnR_RSE_Voluntario: Variável $\overline{\mathrm{R}}$ _RSE_Voluntario transformada log natural \\ LnRLVnnn: Variável RLVnnn transformada log natural \\ LnRSE_Total:Variável RSE_Total transformada log natural \\ LnRSE_Voluntario: Variável RSE_Voluntario transformada log natural \\ LnVnnn: Variável Vnnn transformada log natural
}

Modelo 1A-L:modelo de investimento Voluntário Total em RSE considerando o porte da empresa com lucro (RO positivo)

Modelo 1B-L: modelo de investimento Voluntário segmentado por natureza em RSE considerando o porte da empresa com lucro (RO positivo)

Modelo 1C-L: modelo de investimento Voluntário detalhado conforme BS padrão IBASE em RSE considerando o porte da empresa com lucro (RO positivo)

Modelo 2A-L:modelo de investimento Total em RSE considerando o porte da empresa com lucro (RO positivo)

Modelo 2B-L: modelo de investimento Total segmentado por natureza em RSE considerando o porte da empresa com lucro (RO positivo)

Modelo 2C-L: modelo de investimento Total detalhado conforme BS padrão IBASE em RSE considerando o porte da empresa com RO positivo

Modelo 3A-L:modelo de investimento Voluntário Total em RSE dessensibilizando o porte da empresa com lucro (RO positivo)

Modelo 3B-L:modelo de investimento Voluntário segmentado por natureza em RSE dessensibilizando o porte da empresa com lucro (RO positivo)

Modelo 3C-L: modelo de investimento Voluntário detalhado conforme BS padrão IBASE em RSE dessensibilizando o porte da empresa com lucro (RO positivo)

Modelo 4A-L:modelo de investimento Total em RSE dessensibilizando o porte da empresa com lucro (RO positivo) 
Modelo 4B-L: modelo de investimento Total segmentado por natureza em RSE dessensibilizando o porte da empresa com lucro (RO positivo)

Modelo 4C-L: modelo de investimento Total detalhado conforme BS padrão IBASE em RSE dessensibilizando o porte da empresa com lucro (RO positivo)

Modelo 1A-P: modelo de investimento Voluntário Total em RSE considerando o porte da empresa com prejuízo (RO negativo)

Modelo 1B-P: modelo de investimento Voluntário segmentado por natureza em RSE considerando o porte da empresa com prejuízo (RO negativo)

Modelo 1C-P: modelo de investimento Voluntário detalhado conforme BS padrão IBASE em RSE considerando o porte da empresa com prejuízo (RO negativo)

Modelo 2A-P:modelo de investimento Total em RSE considerando o porte da empresa com prejuízo (RO negativo)

Modelo 2B-P: modelo de investimento Total segmentado por natureza em RSE considerando o porte da empresa com prejuízo (RO negativo)

Modelo 2C-P: modelo de investimento Total detalhado conforme BS padrão IBASE em RSE considerando o porte da empresa com prejuízo (RO negativo)

Modelo 3A-P:modelo de investimento Voluntário Total em RSE dessensibilizando o porte da empresa com prejuízo (RO negativo)

Modelo 3B-P: modelo de investimento Voluntário segmentado por natureza em RSE dessensibilizando o porte da empresa com prejuízo (RO negativo)

Modelo 3C-P: modelo de investimento Voluntário detalhado conforme BS padrão IBASE em RSE dessensibilizando o porte da empresa com prejuízo (RO negativo)

Modelo 4A-P: modelo de investimento Total em RSE dessensibilizando o porte da empresa com prejuízo (RO negativo)

Modelo 4B-P: modelo de investimento Total segmentado por natureza em RSE dessensibilizando o porte da empresa com prejuízo (RO negativo)

Modelo 4C-P: modelo de investimento Total detalhado conforme BS padrão IBASE em RSE dessensibilizando o porte da empresa com prejuízo (RO negativo)

PO: $\quad$ Poder Observado (definição p. 66)

RL: $\quad$ Receita Líquida (definição p. 18)

RLVnnn: Variável Vnnn dessensibilizada do porte da empresa

RO: $\quad$ Resultado Operacional (definição p. 18)

R_RSE_Total:Variável referente ao total dos investimentos voluntários e compulsórios em RSE, dessensibilizada do porte da empresa

R_RSE_Voluntario: Variável referente ao total dos investimentos voluntários em RSE, dessensibilizada do porte da empresa

RSE: $\quad$ Responsabilidade Social Empresarial

RSE_Total: Variável referente ao total dos investimentos voluntários e compulsórios em RSE

RSE_Voluntario: Variável referente ao total dos investimentos voluntários em RSE

SAM: $\quad$ Sustainable Asset Management

Setor: $\quad$ Setor de atuação da empresa: Agro-Industrial, Elétrico, Financeiro, Industrial ou Outros Serviços

Sig: $\quad$ Significância calculada

SPSS: $\quad$ Statistical Package for the Social Sciences

SRCB: Comportamento do Consumidor Socialmente Responsável, Socially Responsible Consumer Behaviour

SRV: $\quad$ Setor referente a Outros Serviços que não do Setor Financeiro ou Setor Elétrico

V201: $\quad$ Variável do BS-Alimentação 
V202: Variável do BS ISI-Encargos sociais compulsórios

V203: $\quad$ Variável do BS ISI-Previdência privada

V204: Variável do BS ISI-Saúde

V205: Variável do BS ISI-Segurança e medicina no trabalho

V206: Variável do BS ISI-Educação

V207: Variável do BS ISI-Cultura

V208: Variável do BS ISI-Capacitação e desenvolvimento profissional

V209: Variável do BS ISI-Creche ou auxílio-creche

V210: Variável do BS ISI-Participação nos lucros ou resultados

V211: Variável do BS ISI-Outros benefícios

V213: Variável do BS ISI-Investimentos Sociais Internos Voluntários

V214: Variável do BS ISI-Investimentos Sociais Internos Totais

V301: $\quad$ Variável do BS ISE-Educação

V302: Variável do BS ISE-Cultura

V303: Variável do BS ISE-Saúde e saneamento

V304: $\quad$ Variável do BS ISE-Habitação

V305: Variável do BS ISE-Esporte

V306: Variável do BS ISE-Lazer e diversão

V307: $\quad$ Variável do BS ISE-Creches

V308: $\quad$ Variável do BS ISE-Alimentação

V309: Variável do BS ISE-Combate à fome e segurança alimentar

V310: Variável do BS ISE-Outros programas

V311: Variável do BS ISE-Indicadores Sociais Externos agregados

V312: $\quad$ Variável do BS ISE-Total das contribuições para a sociedade

V313: $\quad$ Variável do BS ISE-Impostos excluídos encargos sociais

V401: Variável do BS IA-Investimentos relacionados com a produção/operação da empresa

V402: Variável do BS IA-Investimentos em programas/projetos externos

V403: Variável do BS IA-Indicadores Ambientais agregados

V404: $\quad$ Variável do BS IA-Total dos investimentos em meio ambiente 


\section{LISTA DE TABELAS}

Tabela 1 - Base de Cálculo $\quad 18$

Tabela 2 - Indicadores Sociais Internos $\quad 18$

Tabela 3 - Indicadores Sociais Externos $\quad 19$

Tabela 4 - Indicadores Ambientais 20

Tabela 5 - Indicadores do Corpo Funcional 20

Tabela 6 - Informações Relevantes quanto ao Exercício da Cidadania Empresarial 21

Tabela 7 - Países e quantidade de empresas que participam do DJSI (2004) 25

Tabela 8 - Distribuição anual e por setor dos BSs da amostra 35

Tabela 9 - Distribuição anual e setorial de BSs de empresas com RO positivo (Lucro) 36

Tabela 10 - Distribuição anual e setorial de BSs de empresas com RO negativo (Prejuízo)

Tabela 11 - Variáveis adicionais ao BS padrão IBASE

Tabela 12 - Modelos específicos testados e respectivas variáveis $\quad 42$

Tabela 13 - Variáveis transformadas log natural 49

Tabela 14 - Sumário dos casos para variáveis dependentes e independentes do modelo (2000-2004)

Tabela 15 - Sumário dos casos para variáveis que não foram selecionadas para o modelo (2000-2004) 51

Tabela 16 - Outliers pela deteção multivariada da Distância de Mahalanobis 54

Tabela 17 - Outliers pela deteção univariada $\quad 55$

Tabela 18 - Casos de outliers "comportamentais" retirados da amostra 56

Tabela 19 - Modelo 1A-P considera o porte das empresas, investimentos voluntários em RSE e operação com prejuízo

Tabela 20 - Modelo 1B-P considera o porte das empresas, investimentos voluntários segmentados por natureza de RSE e operação com prejuízo

Tabela 21 - Modelo 2A-P considera o porte das empresas, investimentos totais de RSE e operação com prejuízo

Tabela 22 - Modelo 2B-P considera o porte das empresas, investimentos totais segmentados por natureza de RSE e operação com prejuízo

Tabela 23 - Modelo 3A-P considera investimentos voluntários de RSE, operação com prejuízo e dessensibiliza o porte das empresas

Tabela 24 - Modelo 3B-P considera investimentos voluntários segmentados por programas de RSE, operação com prejuízo e dessensibiliza o porte das empresas

Tabela 25 - Modelo 4A-P considera os investimentos totais de RSE, operação com prejuízo e dessensibiliza o porte das empresas

Tabela 26 - Modelo 4B-P considera investimentos totais segmentados por programas de RSE, operação com prejuízo e dessensibiliza o porte das empresas

Tabela 27 - Empresas retiradas da amostra para ajuste de homocedasticidade referente ao setor AGI

Tabela 28 - Modelo 1A-L considera o porte das empresas, investimentos voluntários em RSE e operação com lucro

Tabela 29 - Modelo 1B-L considera o porte das empresas, investimentos voluntários segmentados por natureza de RSE e operação com lucro 
Tabela 30 - Modelo 1C-L considera o porte das empresas, investimentos voluntários individualizados por ação em RSE do BS padrão IBASE e operação com lucro

Tabela 31 - Modelo 2A-L considera o porte das empresas, investimentos totais em RSE e operação com lucro

Tabela 32 - Modelo 2B-L considera o porte das empresas, investimentos totais segmentados por natureza de RSE e operação com lucro

Tabela 33 - Modelo 2C-L considera o porte das empresas, investimentos totais individualizados por ação em RSE do BS padrão IBASE e operação com lucro

Tabela 34 - Modelo 3A-L considera investimentos voluntários em RSE, operação com lucro e dessensibiliza o porte das empresas

Tabela 35 - Modelo 3B-L considera investimentos voluntários segmentados por programas de RSE, operação com lucro e dessensibiliza o porte das empresas

Tabela 36 - Modelo 3C-L considera os investimentos totais individualizados por ação em RSE do BS padrão IBASE, operação com lucro e dessensibiliza o porte das empresas

3

85

88

Tabela 42 - Quadro-resumo do poder de explicação das variáveis do RO negativo significativas dos modelos estudados

Tabela 43 - Poder de explicação da variância do RO positivo considerando o porte das empresas

Tabela 44 - Poder de explicação da variância do RO positivo dessensibilizado do porte das empresas

Tabela 45 - Quantidade de ações em RSE preconizadas pelo BS padrão IBASE que se mostraram significativas no caso de empresas com RO positivo 


\section{LISTA DE FIGURAS}

Figura 1 - Modelo de Desempenho Social Corporativo 27

Figura 2 - Pirâmide da RSE $\quad 28$

Figura 3 - Modelo conceitual da pesquisa

Figura 4 - Gráficos Boxplot das variáveis dependentes e independentes originais 45

Figura 5 - Exemplo do resultado da transformação logarítmica da variável V201 (antes/ depois) 47

Figura 6 - Modelos GLM propostos 61 


\section{O PROBLEMA DA PESQUISA}

\subsection{Introdução}

Apesar da crescente preocupação mundial pela definição do papel social das empresas, não existe um consenso sobre qual seria esse papel no que se refere aos investimentos não diretamente aplicados em seus processos de negócios.

O desempenho financeiro das empresas não é explicado completamente pelo aumento da qualidade e da eficiência de seus processos produtivos ou pela diferenciação de seus produtos e serviços. Além dos acionistas, a empresa precisa se posicionar adequadamente perante seus consumidores, fornecedores e governo, cujas interações são marcadas, por vezes, por relações de poder assimétrico e, por vezes, conflitantes, isso é, os objetivos de maximização individual dos interesses de cada um dos grupos admite uma vasta gama de variantes, sem contudo existir uma que possa maximizar todos eles simultaneamente.

Ademais, outro fator que até então aparecia com menor destaque na convivência de todos esses atores na busca de atendimento a suas necessidades é o próprio ambiente, com seus recursos limitados e nem todos eles renováveis. Os aspectos ambientais têm participado intensamente da agenda de discussão de governo e sociedade, como, por exemplo, na Convenção Marco sobre Mudança Climática na ECO-92 em 1992, no Protocolo de Kyoto em 1997 e no Pacto Global lançado pela ONU no Fórum Econômico de Davos em 1999.

Por um lado, temos a abordagem neoclássica defendida por Friedman (1975, p. 133) que define sua concepção do caráter e natureza da livre economia e a Responsabilidade Social Empresarial, daqui em diante referenciada como RSE:

Nessa economia existe uma e somente uma responsabilidade social do negócio - usar seus recursos e engajar-se em atividades designadas a aumentar seus lucros dentro das regras do jogo, que significa engajar na competição aberta e livre, sem iludir ou fraudar [...] Poucas tendências podem minar tão completamente as fundações da nossa sociedade livre como a aceitação pelos dirigentes corporativos de 
uma responsabilidade social diferente da de ganhar o máximo de dinheiro possível para seus acionistas. [...] A empresa é um instrumento dos seus acionistas. Se a empresa faz uma contribuição, ela frustra o acionista individual por ele mesmo decidir como poderia dispor de seus proventos. ${ }^{1}$

De outro lado, Freeman (2004, p. 228) menciona a Teoria do Stakeholder ${ }^{2}$, na qual a administração visando os stakeholders é uma boa prática gerencial, ainda que freqüentemente encontre a crítica de que empresas que investem na gestão do stakeholder e melhoram seu desempenho social são penalizadas pelos investidores que estão interessados somente no retorno financeiro. Para apoiar seus argumentos, ele apresenta o resultado de pesquisas desenvolvidas nos últimos 20 anos, que indicam que a gestão visando os stakeholders tem crescido e que as empresas que demonstraram um alto nível de desempenho da RSE tiveram aumentado o interesse em suas ações por um número crescente de instituições. Apesar dos resultados das investigações sobre a relação entre RSE e desempenho financeiro não terem estabelecido uma medida definitiva, eles já demonstraram, com os dados utilizados, que um desempenho ruim de RSE prejudica financeiramente as empresas. Freeman menciona também que esse pensamento ainda é incompleto e que oferece novas e promissoras direções para o desenvolvimento da Teoria do Stakeholder.

A responsabilidade social é o reconhecimento da responsabilidade de todos os partícipes da sociedade em preservar o ambiente e seus recursos para si e para as futuras gerações, produzindo e consumindo bens e serviços, sob o conceito de desenvolvimento sustentável e sua transformação em ações concretas. Observa-se que o entendimento do escopo e das próprias ações de responsabilidade social por parte dos diversos grupos da sociedade têm se alterado significativamente ao longo do tempo, mas nota-se que têm uma direção bastante definida que é a de suprir, principalmente, as deficiências do serviço prestado pelo poder público à sociedade.

\footnotetext{
${ }^{1}$ In such an economy, there is one and only one social responsibility of business - to use its resources and engage in activities designed to increase its profits so long as it stays within the rules of the game, which is to say, engages in open and free competition, without deception or fraud [...] Few trends could so thoroughly undermine the very foundations of our free society as the acceptance by corporate officials of a social responsibility other than to make as much money for their stockholders as possible. [...] The corporation is an instrument of the stockholders who own it. If the corporation makes a contribution, it prevents the individual stockholder from himself deciding how he should dispose of his funds.

${ }^{2}$ Stakeholder: é o grupo formado pelos acionistas, empregados e outros grupos ou indivíduos com uma estaca na empresa (BESANKO et al, 2000, p. 212). Isso é, são grupos ou indivíduos que têm interesse no desempenho financeiro de uma organização na entrega dos resultados pretendidos e manutenção da viabilidade dos produtos e serviços da mesma.
} 
Ainda, o tema da responsabilidade social, que engloba a interação dos fatores já mencionados, tem ganhado destaque e se deslocado cada vez mais para o centro das discussões da sociedade. As atitudes que contribuem para o bem estar e qualidade de vida das pessoas que constituem a sociedade são características reconhecidas como sendo do escopo da responsabilidade social. Como exemplos, pode-se citar os processos ditados pelos conceitos legais, políticos, econômicos, filantrópicos, éticos, ambientais e comunitários que regem as relações sociais e empresariais.

Carroll (1999, p. 268) considera que, a partir dos anos 1950, iniciou-se a era moderna da RSE. Naquela época, ela era percebida como os benefícios decorrentes das ações de produzir e comercializar bens e serviços que traziam concomitantemente o poder de desenvolver a região onde as atividades empresariais ocorriam. A base desse conceito foi dinamizar a economia por intermédio da geração de emprego, circulação de dinheiro e ensejar novas empresas em sua cadeia de negócios. Naquele período os proprietários e acionistas das empresas eram os maiores beneficiários de todo esse dinamismo.

Posteriormente as ações de RSE passaram a ser consideradas obrigações e outros stakeholders passaram a receber parte das disponibilidades de recursos pessoais, materiais e financeiros das empresas até então dos proprietários e acionistas das mesmas. Por ser de caráter não plenamente regulamentado, muitos desses benefícios são características da estratégia de negócios de cada empresa.

Os movimentos trabalhistas apoiados pelos sindicatos conseguiram avanços na forma de mais benefícios a seus trabalhadores e familiares na forma de investimentos das empresas em programas e benefícios de alimentação, saúde, segurança e medicina do trabalho, educação, cultura, lazer, diversão e outros. Alguns trabalhadores também passaram a receber participação nos lucros e resultados, previdência privada complementar e a participar em algumas das decisões da empresa.

A sociedade, além de consumir os produtos e serviços fornecidos pelas empresas, passou a demandar outros serviços das mesmas, agora sob a égide de ações de RSE, não necessariamente alinhados à natureza do negócio das empresas, como, por exemplo, os patrocínios em programas de educação, cultura, saúde e saneamento, habitação, esporte, lazer e outros. 
Outros benefícios para a sociedade se materializaram na forma de ações de RSE voltadas ao uso dos recursos da natureza. As empresas passaram a se preocupar com o impacto de seu processo produtivo sobre o ambiente e efetuaram alterações em seus processos produtivos, otimizando o uso de insumos de produção, reduzindo o volume de seus resíduos e também o nível de periculosidade dos mesmos (poluição). Além dessas ações internas ao seu processo produtivo, as empresas também passaram a apoiar programas de ação ambiental externa a si, como despoluição ambiental, conservação de recursos naturais, educação sócio-ambiental e ecológica e outros.

Carroll (1999, p. 268) reforça essas argumentações manifestando sua percepção sobre o futuro da RSE quando conclui em seu artigo:

[...] veremos novos campos de ação sobre responsabilidades dos negócios à sociedade, particularmente de abrangência global e nas novas e emergentes tecnologias, setores e aplicações comerciais. Nesse contexto, o conceito de RSE tem um futuro brilhante porque em seu núcleo ele endereça e captura as preocupações mais importantes do público no que se refere aos negócios e seu relacionamento com a sociedade ${ }^{3}$.

Dessa feita, todas as ações de RSE, assumidas integral ou parcialmente pelas empresas, passaram a fazer parte dos planos estratégicos e operacionais das mesmas, como parte da criação e manutenção dos seus fatores competitivos.

Para divulgar toda essa interação social, algumas empresas entendem ser necessária a existência de um relato das ações sociais empreendidas e, voluntariamente, elas produzem e divulgam seu Balanço Social, a partir daqui, denominado sob a sigla BS. Gonçalves (1980, p. 55) define BS como o conjunto de informações quantificadas com as quais a empresa pode acompanhar, de maneira objetiva, o desenvolvimento de suas atividades no campo dos recursos humanos, bem como medir seu desempenho na implementação de programas de caráter social.

Gonçalves (1980, p. 40) também caracteriza o BS como instrumento de medição junto aos stakeholders. Ele assinala que o BS é utilizado pelos dirigentes da empresa onde os seus elementos numéricos são essenciais ao seu processo de tomada de decisão; onde os investidores e fornecedores

\footnotetext{
${ }^{3}$ [...] we will see new realms in which to think about businesses responsibilities to our stakeholder society, particularly at the global level, and in new and emerging technologies, fields, and commercial applications. In this context, it appears that the CSR concept has a bright future because at its core, it addresses and captures the most important concerns of the public regarding business and society relationships.
} 
podem conhecer o modo como a empresa encara suas responsabilidades sociais; onde os

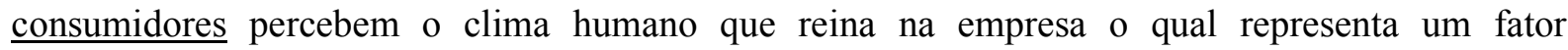
dominante da qualidade do produto que a empresa oferece e, finalmente, o Estado, que analisa o BS para subsidiar a elaboração de normas legais que regulem as atividades das empresas.

Mohr et al (2001, p. 47) destacam que os consumidores precisam ter conhecimento e consciência do nível de responsabilidade social da empresa, antes que esse fator possa ter algum efeito na sua decisão de compra. Webb e Mohr (1998 apud Mohr 2001, p. 48) encontraram que 79\% das pessoas da amostra de sua pesquisa poderiam descrever uma específica relação causal de uma campanha de marketing, após o conceito da campanha ter sido explicado a elas. Portanto, o BS é um canal importante para a divulgação das ações sociais das empresas.

Ao contrário do que acontece com o balanço financeiro clássico, cujo conteúdo, forma e modo de analisar já faz parte do dia-a-dia das empresas, os BSs apresentam uma boa oportunidade de exploração científica e justificada por ser um tema com reduzida produção acadêmica relativamente a sua importância para a sociedade. Especificamente neste trabalho, as informações quantitativas dos BSs são utilizadas na identificação de perfis de comportamento das empresas. O que diferencia o presente trabalho é a análise estatística de comportamento com base nas informações quantitativas dos BSs, sem o enfoque de análise do impacto social utilizando variáveis de opinião ou da análise do desempenho financeiro com visão puramente contábil.

\subsection{Descrição da Situação Problema}

A atual realidade do mercado mundial é reconhecer que as empresas passam a desempenhar um papel social ativo, seja para suprir o espaço não atendido pelo governo e outras entidades assistenciais ou para se destacar de seus competidores perante seus clientes e fornecedores. De qualquer forma, os proprietários e acionistas percebem que parte de seus ganhos serão reduzidos pelos custos incorridos pelas suas ações de RSE, mas entendem que essa decisão deve fazer parte da estratégia empresarial (DRUCKER, 1991, p. 71). 
Há muito tempo, as empresas se defrontam com as decisões estratégicas sobre investimentos em Pesquisa e Desenvolvimento, Produção, Logística, Operações e Vendas e muito ferramental da administração suporta esse processo. No entanto, a análise estratégica das decisões no âmbito da RSE ainda é objeto de posicionamentos com menor arcabouço conceitual e prático. Os estudos acadêmicos têm apresentado conclusões variadas, por vezes divergentes, o que enseja a oportunidade de estudos empíricos com o propósito de enriquecer a base de conhecimento sobre o assunto.

O problema da pesquisa é identificar se as informações do BS das empresas estão relacionadas com o desempenho financeiro das mesmas, isso é, quais variáveis presentes nos BSs têm poder explicativo da variação do desempenho financeiro das empresas que investem em RSE. A existência de um relacionamento estatisticamente significativo pode ser considerada uma evidência de que as ações estratégicas da empresa estejam sintonizadas com a RSE.

\section{Objetivos da pesquisa}

O objetivo da pesquisa é identificar se as variáveis presentes no BS padrão IBASE (Instituto Brasileiro de Análises Sociais e Econômicas) estão relacionadas com o desempenho financeiro das empresas que investem em projetos de RSE, isso é, se os investimentos e políticas de RSE, refletidos nas informações prestadas pelas empresas em seus BSs, têm uma associação estatisticamente relevante com seu nível de lucratividade.

No caso de existência de poder explicativo das variáveis do BS padrão IBASE sobre o desempenho financeiro das empresas, será possível identificar quais são elas e em que nível de significância estatística se apresenta tal relação. 


\subsection{Questões da pesquisa}

Pergunta 1: Com base nas informações dos BSs padrão IBASE publicados pelas empresas, cuja estrutura está detalhada no item 1.5.2 (O Balanço Social padrão IBASE), existem evidências de que o desempenho financeiro refletido no Resultado Operacional esteja correlacionado às ações socialmente responsáveis das empresas que atuam no Brasil?

Pergunta 2: No caso de existirem evidências neste sentido, quais são os fatores que mais contribuíram para explicar essa relação?

Pergunta 3: Existem variáveis que, agrupadas, podem identificar características singulares de um comportamento de gestão empresarial?

\subsection{Definição teórica e operacional dos conceitos}

Este item apresenta um breve histórico do BS padrão IBASE, seguido do detalhamento das informações contidas no mesmo.

\subsubsection{O Balanço Social e as entidades envolvidas}

Complementando o conceito introduzido no item anterior, no entendimento do IBASE (2004), BS é um demonstrativo publicado anualmente pela empresa que reúne um conjunto de informações sobre os projetos, benefícios e ações sociais, dirigido aos empregados, investidores, analistas de mercado,

acionistas e à comunidade. É também um instrumento estratégico para avaliar e multiplicar o exercício da RSE. No BS, a empresa mostra o que faz por seus empregados e seus dependentes, colaboradores e comunidade, dando transparência às atividades que buscam melhorar a qualidade de vida de todos. Ou seja, sua função principal é tornar pública a RSE, construindo maiores vínculos entre a empresa, a sociedade e o meio ambiente. 
O IBASE (2004), criado em 1981, é uma instituição de utilidade pública federal, sem fins lucrativos e sem vinculação religiosa ou política. Sua missão é a construção da democracia, combatendo desigualdades e estimulando a participação cidadã. O objetivo de sua linha programática de

"Responsabilidade Social e Ética nas Organizações" é consolidar parcerias com organizações sociais no Brasil e nos demais países da América Latina e também cobrar uma postura ética, práticas responsáveis e transparência no meio empresarial e nas organizações da sociedade civil.

O Instituto Ethos de Empresas e Responsabilidade Social (ETHOS, 2004) é uma organização nãogovernamental criada com a missão de mobilizar, sensibilizar e ajudar as empresas a gerir seus negócios de forma socialmente responsável, tornando-as parceiras na construção de uma sociedade sustentável e justa. O Instituto Ethos lançou o Guia de Elaboração de Relatório Anual de RSE em 2001 (ETHOS, 2004), no qual um dos tópicos que comparece é um resumo quantitativo das ações sociais empreendidas pelas empresas, que é o padrão IBASE, cujo detalhamento está apresentado no próximo item.

Outra iniciativa incentivadora à adoção da publicação do Relatório Anual de RSE é o PRÊMIO BALANÇO SOCIAL (2006), uma iniciativa conjunta da Associação Brasileira de Comunicação Empresarial - ABERJE, da Associação dos Analistas e Profissionais de Investimento do Mercado de Capitais - APIMEC, do Instituto ETHOS de Empresas e Responsabilidade Social, da Fundação Instituto de Desenvolvimento Empresarial e Social - FIDES e do Instituto Brasileiro de Análises Sociais e Econômicas - IBASE. Iniciado em 2002, a edição de número 4 desse prêmio ocorreu em 2005.

Como resultado dessas ações, mais e mais empresas estão publicando seus BSs como parte de suas políticas de transparência e governança corporativa.

\subsubsection{O Balanço Social padrão IBASE}

A partir de 1997, o IBASE, em parceria com diversos representantes de empresas públicas e privadas, ao longo de inúmeras reuniões e debates com vários setores da sociedade, desenvolveu um modelo de BS que estimula as empresas a divulgar essa informação, independentemente de seu 
porte e setor de atuação. Os objetivos eram sensibilizar e estimular a noção de co-responsabilidade das empresas na busca de soluções para os profundos desequilíbrios da estrutura social do país.

A estratégia da adoção de um padrão mínimo foi facilitar a análise adequada da função social da empresa ao longo dos anos. Sua configuração se caracteriza pela predominância de dados expressos em valores quantitativos, financeiros ou não, que possam ajudar nas análises comparativas da própria empresa ao longo do tempo ou entre outras empresas.

No modelo padrão IBASE, a sociedade e o mercado são os grandes auditores do processo e dos resultados alcançados e, para tal, se utilizam da divulgação interna pelas empresas emitentes e pelo site do BS padrão IBASE na Internet (BALANÇO SOCIAL IBASE, 2004, 2005).

Em 1998, para estimular a participação de um maior número de empresas, o IBASE lançou o Selo Balanço Social IBASE/Betinho, conferido anualmente a todas as empresas que publicam o BS no modelo sugerido por ele. A empresa pode mostrar esse selo em seus anúncios, embalagens, site Internet e campanhas publicitárias, sinalizando que ela investe em programas sociais e está comprometida com a qualidade de vida dos empregados, da comunidade e do meio ambiente. Entretanto, o selo não é fornecido às empresas de cigarro/fumo/tabaco, armas de fogo/munições, bebidas alcoólicas ou que estejam envolvidas em denúncias e/ou processos judiciais relativos à exploração de trabalho infantil e/ou qualquer forma de trabalho forçado, além de prostituição ou exploração sexual de criança ou adolescente.

O Modelo de BS padrão IBASE está dividido em seis seções que estão detalhadas nas tabelas 1 a 6 que seguem: Base de Cálculo, Indicadores Sociais Internos, Indicadores Sociais Externos, Indicadores Ambientais, Indicadores do Corpo Funcional e Informações Relevantes quanto ao Exercício da Cidadania Empresarial.

A Tabela 1 denominada Base de Cálculo é composta pelas informações financeiras da empresa, cujas definições estão de acordo com os conceitos utilizados na contabilidade financeira e resumidos na coluna de Descrição da Variável. A coluna "Código da Variável” corresponde ao nome definido pelo autor para a identificação resumida de cada uma das informações presentes no BS padrão IBASE. 
Tabela 1 - Base de Cálculo

\begin{tabular}{|c|c|c|}
\hline Descrição da variável & Unidade & $\begin{array}{c}\text { Código da } \\
\text { variável }\end{array}$ \\
\hline $\begin{array}{l}\text { Receita Líquida (RL) } \\
\text { Receita bruta excluída dos impostos, contribuições, devoluções, abatimentos e descontos } \\
\text { comerciais }\end{array}$ & $\begin{array}{c}\mathrm{R} \$ \mathrm{x} \\
1000\end{array}$ & V101 \\
\hline $\begin{array}{l}\text { Resultado Operacional (RO) } \\
\text { Resultado que se encontra entre o Lucro Bruto e o LAIR -Lucro Antes do Imposto de Renda, ou } \\
\text { seja, antes das receitas e despesas não operacionais }\end{array}$ & $\begin{array}{l}\mathrm{R} \$ \mathrm{x} \\
1000\end{array}$ & V102 \\
\hline $\begin{array}{l}\text { Folha de Pagamento Bruta } \\
\text { Soma da remuneração tais como salários, gratificações, comissões e abonos, } 13^{\circ} \text { salário, férias e } \\
\text { encargos sociais compulsórios como INSS, FGTS e contribuição social }\end{array}$ & $\begin{array}{c}\mathrm{R} \$ \mathrm{x} \\
1000\end{array}$ & V103 \\
\hline
\end{tabular}

Fonte: Balanço Social IBASE (2004, 2005)

A Tabela 2 apresenta os Indicadores Sociais Internos, que são os investimentos da empresa em programas sociais que atendem a comunidade interna da empresa, constituída pelos seus empregados e dependentes, também denominados como benefícios.

Tabela 2 - Indicadores Sociais Internos

\begin{tabular}{|c|c|c|}
\hline Descrição da variável & Unidade & $\begin{array}{c}\text { Código da } \\
\text { variável }\end{array}$ \\
\hline $\begin{array}{l}\text { Alimentação } \\
\text { Gastos com restaurante, vale-refeição, lanches, cestas básicas e outros relacionados à } \\
\text { alimentação dos empregados }\end{array}$ & $\mathrm{R} \$ \times 1000$ & V201 \\
\hline Encargos sociais compulsórios & $\mathrm{R} \$ \times 1000$ & V202 \\
\hline $\begin{array}{l}\text { Previdência privada } \\
\text { Planos especiais de aposentadoria, fundações previdenciárias e complementações de } \\
\text { benefícios a aposentados e seus dependentes }\end{array}$ & $\mathrm{R} \$ \times 1000$ & V203 \\
\hline $\begin{array}{l}\text { Saúde } \\
\text { Plano de saúde, assistência médica, programas de medicina preventiva, programas de } \\
\text { qualidade de vida e outros gastos com saúde, inclusive dos aposentados }\end{array}$ & $\mathrm{R} \$ \times 1000$ & V204 \\
\hline Segurança e medicina no trabalho & $\mathrm{R} \$ \times 1000$ & V205 \\
\hline $\begin{array}{l}\text { Educação } \\
\text { Gastos com ensino regular em todos os níveis, reembolso de educação, bolsas, assinaturas } \\
\text { de revistas, gastos com biblioteca (excluído pessoal) e outros gastos com educação }\end{array}$ & $\mathrm{R} \$ \times 1000$ & V206 \\
\hline $\begin{array}{l}\text { Cultura } \\
\text { Gastos com eventos e manifestações artísticas e culturais, como música, teatro, cinema, } \\
\text { literatura e outras artes }\end{array}$ & $\mathrm{R} \$ \mathrm{x} 1000$ & V207 \\
\hline $\begin{array}{l}\text { Capacitação e desenvolvimento profissional } \\
\text { Recursos investidos em treinamentos, cursos, estágios (excluído os salários) e gastos } \\
\text { voltados especificamente para capacitação relacionada com a atividade desenvolvida por } \\
\text { empregados }\end{array}$ & $\mathrm{R} \$ \times 1000$ & V208 \\
\hline $\begin{array}{l}\text { Creche ou auxílio-creche } \\
\text { Creche no local ou auxílio-creche a empregados }\end{array}$ & $\mathrm{R} \$ \times 1000$ & V209 \\
\hline $\begin{array}{l}\text { Participação nos lucros ou resultados } \\
\text { Participações que não caracterizem complemento de salários }\end{array}$ & $\mathrm{R} \$ \times 1000$ & V210 \\
\hline $\begin{array}{l}\text { Outros benefícios } \\
\text { Seguros (parcela paga pela empresa), empréstimos (só o custo), gastos com atividades } \\
\text { recreativas, transportes, moradia e outros benefícios oferecidos a empregados }\end{array}$ & $\mathrm{R} \$ \times 1000$ & V211 \\
\hline $\begin{array}{l}\text { Total - Indicadores Sociais Internos } \\
\text { Soma dos valores investidos nesse grupo }\end{array}$ & $R \$ \times 1000$ & V213 \\
\hline
\end{tabular}

Fonte: Balanço Social IBASE (2004, 2005) 
A Tabela 3 apresenta os Indicadores Sociais Externos, que são os investimentos da empresa em programas sociais que atendem a comunidade externa da empresa, também conhecidos como patrocínios.

Tabela 3 - Indicadores Sociais Externos

\begin{tabular}{l|c|c}
\hline \multicolumn{1}{c|}{ Descrição da variável } & Unidade & Código da variável \\
\hline Educação & $\mathrm{R} \$ \times 1000$ & $\mathrm{~V} 301$ \\
\hline Cultura & $\mathrm{R} \$ \times 1000$ & $\mathrm{~V} 302$ \\
\hline Saúde e saneamento & $\mathrm{R} \$ \times 1000$ & $\mathrm{~V} 303$ \\
\hline Habitação & $\mathrm{R} \$ \times 1000$ & $\mathrm{~V} 304$ \\
\hline Esporte & $\mathrm{R} \$ \times 1000$ & $\mathrm{~V} 305$ \\
\hline Lazer e diversão & $\mathrm{R} \$ \times 1000$ & $\mathrm{~V} 306$ \\
\hline Creches & $\mathrm{R} \$ \times 1000$ & $\mathrm{~V} 307$ \\
\hline Alimentação & $\mathrm{R} \$ \times 1000$ & $\mathrm{~V} 308$ \\
\hline Combate à fome e segurança alimentar & $\mathrm{R} \$ \times 1000$ & $\mathrm{~V} 309$ \\
\hline Outros programas & $\mathrm{R} \$ \times 1000$ & $\mathrm{~V} 310$ \\
\hline $\begin{array}{l}\text { Total das contribuições para a sociedade } \\
\text { Soma dos valores investidos nesse grupo }\end{array}$ & $\mathrm{R} \$ \times 12$ \\
\hline $\begin{array}{l}\text { Impostos excluídos encargos sociais } \\
\text { Impostos, contribuições e taxas federais, estaduais e municipais }\end{array}$ & $\mathrm{R} \$ \times 1000$ & $\mathrm{~V} 313$ \\
\hline $\begin{array}{l}\text { Total - Indicadores sociais externos } \\
\text { Soma do total das contribuições para a sociedade e os impostos, } \\
\text { excluídos desses, os encargos sociais }\end{array}$ & $\mathrm{R} \$ \times 1000$ & $\mathrm{~V} 314$ \\
\hline
\end{tabular}

Fonte: Balanço Social IBASE $(2004,2005)$

A Tabela 4 apresenta os Indicadores Ambientais, que são os investimentos da empresa em programas sociais que se refletem sobre o ambiente interno e externo à empresa, isso é, esforços relacionados ao meio ambiente e seus recursos naturais. 
Tabela 4 - Indicadores Ambientais

\begin{tabular}{|c|c|c|}
\hline Descrição da variável & Unidade & $\begin{array}{c}\text { Código da } \\
\text { variável } \\
\end{array}$ \\
\hline $\begin{array}{l}\text { Investimentos relacionados com a produção/operação da empresa } \\
\text { Tais como investimentos no monitoramento da qualidade dos resíduos/efluentes, na } \\
\text { despoluição, nos gastos com a introdução de métodos não-poluentes, nas auditorias } \\
\text { ambientais, em programas de educação ambiental para os empregados e outros gastos } \\
\text { com o objetivo de incrementar e buscar o melhoramento contínuo da qualidade ambiental } \\
\text { na produção/operação da empresa }\end{array}$ & $\mathrm{R} \$ \times 1000$ & V401 \\
\hline $\begin{array}{l}\text { Investimentos em programas/projetos externos } \\
\text { Tais como investimentos na despoluição do ambiente externo não relacionado aos } \\
\text { processos produtivos da empresa, na conservação de recursos ambientais, em campanhas } \\
\text { ecológicas e educação sócio-ambiental para a comunidade externa e para a sociedade em } \\
\text { geral }\end{array}$ & $\mathrm{R} \$ \times 1000$ & V402 \\
\hline $\begin{array}{l}\text { Total dos investimentos em meio ambiente } \\
\text { Soma dos dois itens acima }\end{array}$ & $\mathrm{R} \$ \times 1000$ & V404 \\
\hline $\begin{array}{l}\text { Cumprimento das metas anuais } \\
\text { Quanto ao estabelecimento de metas anuais para minimizar a produção de resíduos, o } \\
\text { consumo em geral na produção/operação e para aumentar a eficácia na utilização de } \\
\text { recursos naturais, a empresa: } 1 \text { = "Não possui metas", } 2 \text { = "Cumpre de } 0 \% \text { a } 50 \% ", 3= \\
\text { "Cumpre de } 51 \% \text { a } 75 \% \text { " ou } 4 \text { = "Cumpre de } 76 \% \text { a } 100 \% " \text { ". } \\
\text { Indica o resultado médio percentual alcançado pela empresa no cumprimento de metas } \\
\text { ambientais estabelecidas por ela mesma, por organizações da sociedade civil e/ou por } \\
\text { parâmetros internacionais como o GLOBAL REPORTING INITIATIVE (GRI) dentre as } \\
\text { quatro alternativas mencionadas }\end{array}$ & Categorias & V405 \\
\hline
\end{tabular}

Fonte: Balanço Social IBASE $(2004,2005)$

A Tabela 5 apresenta os Indicadores do Corpo Funcional e mostra o perfil de constituição dos recursos humanos envolvidos nos processos de negócio da empresa. Nesse grupo de indicadores são considerados os empregados, estagiários e terceiros e suas respectivas métricas referentes ao perfil desse contingente.

Tabela 5 - Indicadores do Corpo Funcional

\begin{tabular}{l|c}
\multicolumn{1}{c|}{ Descrição da variável } & $\begin{array}{c}\text { Código da } \\
\text { variável }\end{array}$ \\
\hline $\mathbf{N}^{\mathbf{0}}$ de empregados ao final do período & V501 \\
\hline $\mathbf{N}^{\mathbf{0}}$ de admissões durante o período & $\mathrm{V} 502$ \\
\hline $\mathbf{N}^{\mathbf{0}}$ de empregados terceirizados & $\mathrm{V} 503$ \\
\hline $\mathbf{N}^{\mathbf{0}}$ de estagiários & $\mathrm{V} 504$ \\
\hline $\mathbf{N}^{\mathbf{0}}$ de empregados acima de 45 anos & $\mathrm{V} 505$ \\
\hline $\mathbf{N}^{\mathbf{0}}$ de mulheres que trabalham na empresa & $\mathrm{V} 506$ \\
\hline$\%$ de cargos de chefia ocupados por mulheres & $\mathrm{V} 507$ \\
\hline $\begin{array}{l}\text { No de negros que trabalham na empresa } \\
\text { Considerar como trabalhadores negros o somatório de indivíduos classificados/auto- }\end{array}$ & $\mathrm{V} 508$ \\
\hline declarados como de pele preta e parda, conforme o declarado na RAIS & \\
\hline $\mathbf{N}^{\mathbf{0}}$ de portadores de deficiência ou necessidades especiais & $\mathrm{V} 509$ \\
\hline
\end{tabular}

Fonte: Balanço Social IBASE (2004, 2005) 


\section{A Tabela 6 apresenta as Informações Relevantes quanto ao Exercício da Cidadania}

Empresarial, destacando os aspectos da postura da empresa perante a sociedade. São métricas que refletem as políticas de recursos humanos, relação com seus consumidores e a riqueza produzida.

Tabela 6 - Informações Relevantes quanto ao Exercício da Cidadania Empresarial

\begin{tabular}{|c|c|}
\hline Descrição da Variável & Código da variável \\
\hline $\begin{array}{l}\text { Relação entre a maior e a menor remuneração da empresa } \\
\text { Resultado da divisão da maior remuneração da empresa pela menor }\end{array}$ & V601 \\
\hline $\begin{array}{l}\text { Número total de acidentes de trabalho } \\
\text { Quantidade dos acidentes de trabalho registrados durante o ano }\end{array}$ & V602 \\
\hline $\begin{array}{l}\text { Os projetos sociais ambientais desenvolvidos pela empresa foram definidos por: } \\
\text { "Direção" ou "Direção e Gerências" ou "Todos os empregados" }\end{array}$ & V603 \\
\hline $\begin{array}{l}\text { Os padrões de segurança e salubridade no ambiente de trabalho foram definidos por: } \\
\text { "Direção e Gerências" ou "Todos os empregados" ou "Todos + CIPA" }\end{array}$ & V604 \\
\hline $\begin{array}{l}\text { Quanto à liberdade sindical, ao direito de negociação coletiva e à representação } \\
\text { interna dos trabalhadores, a empresa: } \\
\text { "Não se envolve" ou "Segue as normas da Organização Internacional do Trabalho - OIT" } \\
\text { ou "Incentiva e segue a OIT" }\end{array}$ & V605 \\
\hline $\begin{array}{l}\text { A previdência privada contempla: } \\
\text { "Direção" ou "Direção e Gerências" ou "Todos os empregados" }\end{array}$ & V606 \\
\hline $\begin{array}{l}\text { A participação nos lucros ou resultados contempla: } \\
\text { "Direção" ou "Direção e Gerências" ou "Todos os empregados" }\end{array}$ & V607 \\
\hline $\begin{array}{l}\text { Na seleção dos fornecedores são considerados os mesmos padrões éticos e de } \\
\text { responsabilidade social e ambiental adotados pela empresa: } \\
\text { "Não são considerados" ou "São sugeridos" ou "São exigidos" }\end{array}$ & V608 \\
\hline $\begin{array}{l}\text { Quanto à participação dos empregados em programas de trabalho voluntário, a } \\
\text { empresa: } \\
\text { "Não se envolve" ou "Apóia" ou "Organiza e incentiva" }\end{array}$ & V609 \\
\hline $\begin{array}{l}\text { Número total de reclamações e críticas de consumidores: } \\
\text { "Na empresa", "No Procon" e "Na justiça" }\end{array}$ & V610 a V612 \\
\hline $\begin{array}{l}\text { \% de reclamações e críticas solucionadas: } \\
\text { "Na empresa", "No Procon" e "Na justiça" }\end{array}$ & V613 a V615 \\
\hline $\begin{array}{l}\text { Valor Adicionado Total a distribuir (em mil R\$): } \\
\text { A Demonstração do Valor Agregado fornece uma visão abrangente sobre a real capacidade } \\
\text { de uma entidade na produção de riqueza para o país (DALMÁCIO, 2004) }\end{array}$ & V616 \\
\hline $\begin{array}{l}\text { Distribuição do Valor Adicionado (DVA): } \\
\text { "\% Governo", “\% Colaboradores", “\% Acionistas”, “\% Terceiros" e “\% Retido" } \\
\text { (DALMÁCIO, 2004) } \\
\text { (valor percentual que coube a cada um dos cinco componentes citados) }\end{array}$ & V617 a V621 \\
\hline
\end{tabular}

Fonte: Balanço Social IBASE (2004, 2005) 


\section{FUNDAMENTAÇÃO TEÓRICA}

A fundamentação teórica explora uma visão histórica da evolução do conceito de RSE a partir da segunda metade do século XX e apresenta alguns aspectos de trabalhos científicos já desenvolvidos na mesma linha de pesquisa do presente trabalho, evidenciando a relevância do tema e o direcionamento dado à pesquisa.

\subsection{RSE - Responsabilidade Social Empresarial}

Segundo Shayon (2003, p. 14-15), o conceito contemporâneo de RSE surgiu no final dos anos 1960. Naquela época os executivos norte-americanos estavam buscando um posicionamento sobre a responsabilidade das empresas perante a sociedade e de que forma os problemas sociais poderiam ser tratados pelo setor privado. Essa primeira onda basicamente atendeu a programas sociais sem perspectiva de adicionar valor à empresa e eram pequenas atividades comunitárias onde se buscava estimular, com a participação voluntária, os programas de limpeza ambiental, tutoria de jovens, alfabetização e projetos de desenvolvimento comunitário.

A partir da segunda metade dos anos 1970, estes programas perderam o apoio das empresas por causa do declínio econômico que ocorreu nos Estados Unidos. Surgiu então o que se poderia chamar de uma segunda onda no início dos anos 80 . O fato direcionador foi a forte pressão de desregulamentação do Presidente Reagan e do corte nos gastos federais referentes aos programas sociais. Em conseqüência, ocorreu um aumento da regulamentação estadual que buscava canalizar dinheiro das empresas aos programas dos governos estaduais e o vácuo assistencial passou a ser atendido por um movimento nacional de voluntariado corporativo. Entretanto, no final dos anos 1980, o ambiente empresarial se viu envolto na turbulência das mega-fusões, os take-overs hostis ${ }^{4}$ e os drásticos cortes de custo nas empresas, novamente arrefecendo o movimento voluntário. Este cenário conjuntural, combinado com a incapacidade de vincular e contabilizar os esforços da RSE e

\footnotetext{
4 "take-over" hostil - É a tomada de controle não solicitado da empresa, resultando na substituição da sua administração. É um tipo de aquisição em que a empresa compradora faz uma oferta diretamente aos acionistas-alvo da empresa, porque a administração-alvo se opõe à compra (BATEMAN e SNELL, 1998).
} 
refleti-los no valor das empresas, reduziu novamente o engajamento das empresas nos programas assistenciais.

No início dos anos 2000, começou a se formar uma terceira onda da RSE, dessa vez na Europa, com os ativistas das questões ambientais, comunitárias, de direitos humanos e de consumo, em uma abordagem mais politizada que a visão americana de até então. As discussões estavam focadas sobre a definição da RSE, como a empresa podia demonstrá-la e comunicá-la, além de como se podia avaliar o impacto social dessas ações (SHAYON, 2003, p. 14-15).

Para entender o impacto dessa nova onda da RSE, aparentemente mais politizada e com maior abrangência, buscou-se identificar no comportamento do consumidor uma explicação sobre as mudanças das motivações que passaram a impulsionar as empresas na direção da RSE. Mohr et al (2001, p. 45, 61) pesquisaram o impacto da RSE no comportamento do consumidor americano. Utilizando a técnica de entrevista em profundidade com 44 pessoas, foram identificados e caracterizados oito perfis de consumidores que guardavam uma distribuição ordinal entre si. Em um extremo dessa escala caracterizaram-se os consumidores que não consideravam RSE nas suas compras, esperavam que as empresas maximizassem seus lucros e não necessitavam estar envolvidas com ações de responsabilidade social, bastando que os produtos fossem de qualidade. No outro extremo foram posicionados os consumidores que praticavam o que Mohr definiu como $\mathrm{SRCB}^{5}$ - Comportamento do Consumidor Socialmente Responsável, tendo conhecimento sobre a abrangência da RSE e também sobre os comportamentos específicos da empresa. Apesar de acreditar que grandes empresas têm muito poder e estão freqüentemente preocupadas somente com lucros e acionistas, esse grupo vê o SRCB como o caminho principal para obter algum controle sobre as empresas, pressionando-as a serem mais responsáveis com suas comunidades.

A pesquisa de Mohr et al (2001, p. 45, 68) concluiu que existem dois fatores relevantes para explicar a falta de SRCB detectada na mesma: i) Considerações pelos critérios tradicionais de preço, qualidade e conveniência, combinado com a premissa que as considerações da RSE poderiam comprometer a otimização dos fatores citados e ii) Baixo nível de conhecimento e dificuldade em obter informações sobre os registros das ações de RSE das empresas.

\footnotetext{
${ }^{5}$ SRCB: Socially Responsible Consumer Behaviour.
} 
Uma outra vertente que impulsiona as empresas para a RSE foi identificada na criação de valor da empresa refletida no valor de suas ações em bolsa de valores. Seguem alguns exemplos que interpretam a valorização das ações relacionados às ações de RSE.

Em 1999 foram lançados os Dow Jones Sustainability Indexes - DJSI (2004), os primeiros índices globais que acompanham o desempenho financeiro das companhias, em nível mundial, que também levam em conta a sustentabilidade, isso é, o equilíbrio ecológico e a preservação da qualidade de vida das populações humanas em escala global, implicando, por exemplo, a gestão equilibrada dos recursos minerais e ecológicos do planeta. Ele está baseado na cooperação dos grupos que produzem o Dow Jones Indexes, do STOXX Ltd (2004) e Sustainable Asset Management - SAM (2004), que fornecem aos gestores de recursos financeiros os benchmarks ${ }^{6}$ confiáveis e objetivos para a gestão de portfolios de empresas que atuam de forma sustentável. Tal gestão é necessária tendo em vista que os recursos das empresas são limitados e não é possível fazer tudo o que é preciso, ao mesmo tempo. Em 2004 existiam 52 licenças DJSI mantidas por gestores de recursos em 14 países administrando uma variedade de produtos financeiros incluindo fundos ativos e passivos, certificados e contas segregadas. No total, esses licenciados controlavam 2,8 bilhões de euros baseados no DJSI. O DJSI considera vários quesitos de análise da sustentabilidade corporativa, que estão agrupados em critérios econômicos, ambientais e sociais.

Em caráter ilustrativo do cenário mundial da preocupação das empresas perante a RSE, a Tabela 7 apresenta, em uma compilação pelo autor, a lista apresentada na página Internet do DOW JONES SUSTAINABILITY INDEXES (2004) e resume a situação, em 31/08/2004, da distribuição por país, das 312 empresas que faziam parte do índice, na qual se destaca a presença de quatro empresas brasileiras: Banco Itaú Holding Financeira S.A., Companhia Energética de Minas Gerais (CEMIG), Embraer - Empresa Brasileira de Aeronáutica S.A. e Itausa - Investimentos Itaú S.A.

\footnotetext{
${ }^{6}$ Benchmarking: processo de comparar práticas organizacionais e de tecnologia com as de outras empresas
} (BATEMAN e SNELL, 1998, p. 526). 
Tabela 7 - Países e quantidade de empresas que participam do DJSI (2004)

\begin{tabular}{l|c}
\hline \multicolumn{1}{c|}{ Países } & $\begin{array}{c}\text { Qtdd. de } \\
\text { empresas }\end{array}$ \\
\hline Reino Unido & 69 \\
\hline Estados Unidos & 65 \\
\hline Japão & 35 \\
\hline Alemanha & 23 \\
\hline Austrália & 16 \\
\hline Canadá & 14 \\
\hline França & 14 \\
\hline Suíça & 13 \\
\hline Holanda & 12 \\
\hline Suécia & 9 \\
\hline Finlândia & 7 \\
\hline
\end{tabular}

\begin{tabular}{l|c}
\hline \multicolumn{1}{c|}{ Países } & $\begin{array}{c}\text { Qtdd. de } \\
\text { empresas }\end{array}$ \\
\hline Dinamarca & 6 \\
\hline Espanha & 6 \\
\hline Noruega & 5 \\
\hline Brasil & 4 \\
\hline Hong Kong & 4 \\
\hline África do Sul & 3 \\
\hline Itália & 2 \\
\hline Malásia & 2 \\
\hline Bélgica & 1 \\
\hline Irlanda & 1 \\
\hline Taiwan & 1 \\
\hline
\end{tabular}

Fonte: Adaptada pelo autor a partir do Dow Jones Sustainability Indexes (2004)

Segundo Leenson (2004), um dos pioneiros na administração de fundos de investimento socialmente responsáveis ${ }^{7}$ :

[...] os americanos estão aprendendo que é estúpido avaliar uma empresa só pelos critérios financeiros. Por exemplo, não é possível fazer um investimento sem saber o que se passa com o meio ambiente e os trabalhadores. O investimento ético é uma maneira mais sofisticada de se investigar uma empresa e seus resultados [...] Nesse momento, mais de $10 \%$ de todo o capital investido no mercado financeiro mundial está em fundos voltados à promoção de empresas socialmente responsáveis. Há um crescimento muito forte $[\ldots]$

O Banco ABN Amro Real criou, em novembro de 2001, o primeiro fundo de investimento em empresas socialmente responsáveis, o Real Ethical (2006). Nele foram eliminadas as empresas de bebidas alcoólicas, fumo, armamentos e jogos de azar e considerados os aspectos de governança corporativa e responsabilidade social e ambiental como fatores importantes na composição do portfolio desse fundo.

Em contraposição a essa abordagem da RSE, Coelho (2003, p. 15) defende os méritos intelectual e ético da primazia dos acionistas e que a doutrina da RSE voltada aos stakeholders remove os capitalistas de sua posição de destaque e, apesar do sentido de "melhoria" que isso traduz, seu efeito é profundamente corrosivo aos fundamentos éticos e práticos do capitalismo.

\footnotetext{
${ }^{7}$ Eric Leenson proferiu esse comentário quando entrevistado pelo Instituto Ethos, por ocasião de sua participação na Conferência Nacional 2004, no painel temático 7: "Responsabilidade social empresarial na visão dos investidores, fundos de pensão e fundos internacionais".
} 
As "melhorias", que atenuam as responsabilidades dos gerentes perante os acionistas, também reduzem os incentivos para a prosperidade da sociedade, cria ambigüidade ao que o gerente ético deve fazer e agrava os problemas da relação agente-principal (agency) ${ }^{8}$ entre os acionistas e gerentes, criando oportunidades virtualmente ilimitadas para situações eticamente suspeitas ou de completa corrupção.

A abordagem neo-clássica defendida por Friedman (1975) e apoiada por Coelho (2003, p. 15) é contrastada por Post (2003, p. 25), que argumenta que, por vezes, decisões corporativas são tomadas com base em considerações éticas em favor dos stakeholders, ainda que elas não aumentem o lucro ou o ganho dos acionistas. Tais comportamentos, além de apropriados, são desejáveis. A lógica é que a empresa é o fórum da interação dos stakeholders e seus interesses suplantam os de um grupo específico de stakeholders.

Post (2003, p. 25) apóia que a Teoria do Stakeholder tem problemas quando não existe um acordo na definição de como estão agrupados os stakeholders, que poderia incluir cachorros, árvores, baleias, prisioneiros políticos e terroristas, mas que se considerasse somente empregados, gerentes, acionistas, fornecedores, clientes e a comunidade local. É ilógico assumir que quaisquer desses grupos irão pressionar por novas direções radicais no processo decisório corporativo ou estabelecer uma coalizão de grupos para obter tais objetivos, acrescentando também que os gerentes decidem com base nos melhores interesses de sobrevivência de longo-prazo da empresa.

Hillman e Keim (2001, p. 125) reforçam a argumentação anterior quando mencionam que a construção de melhores relações com stakeholders primários como empregados, clientes, fornecedores e comunidade pode levar ao aumento da prosperidade dos acionistas ajudando a desenvolver ativos valiosos e intangíveis que podem ser fonte de vantagem competitiva como fidelidade do cliente ou do fornecedor, redução da rotatividade dos empregados e melhora da reputação da empresa. Por outro lado, utilizar recursos corporativos em ações sociais não relacionadas aos stakeholders primários pode não criar valor aos acionistas ou mesmo ter uma

\footnotetext{
${ }^{8}$ Problema da relação agente-principal (agency) surge quando os administradores (agentes) perseguem suas próprias metas, mesmo que essa atitude diminua os lucros dos donos da empresa (principais) (PINDYCK e RUBINFELD, 2004, p. 617).
} 
correlação negativa entre RSE e o valor ao acionista. Isso é, o valor para o acionista pode ser afetado diferentemente, dependendo da natureza do escopo da estratégia e das ações de RSE.

O BS padrão IBASE está estruturado de modo a informar quantitativamente as ações de RSE e identificar os grupos de stakeholders afetados por elas, sem contudo qualificar ou quantificar o impacto social dessas ações. A decisão pelo uso de informações quantitativas proposto nesse trabalho de pesquisa tem a vantagem de reduzir a influência dos aspectos subjetivos inerentes ao uso de variáveis de opinião. Dessa feita, os aspectos de confiabilidade dos resultados é reforçada. Como exemplo, Dentchev (2004, p. 7) em seu estudo sobre os efeitos da RSE sobre a competitividade das empresas, buscando identificar uma correlação entre RSE e desempenho financeiro, definiu a condução por estudos de casos com base na opinião dos stakeholders e explicou como possível causa da variabilidade de resultados dos estudos, a possibilidade de que cada respondente tem diferentes posições sobre os efeitos positivos e negativos da RSE, ainda que pertencentes a grupos característicos como, por exemplo, empregados e gerentes, pois os interesses e experiências pessoais são diversos, como preconizado por Yin (1989, p. 41).

Wood (1991, p. 691) desenvolveu o modelo de desempenho social corporativo que incorpora a medição da receptividade social corporativa. O modelo é uma referência para a literatura da RSE em uma empresa centrada na perspectiva do stakeholder. A adoção desse conceito pressupõe um comportamento social corporativo porque ele se relaciona ao negócio e existe retorno financeiro ao mesmo. A figura 1 representa o modelo de Wood (1991, p. 691) apresentado por Moir (2001, p. 16).

\begin{tabular}{|c|c|c|}
\hline Legitimidade & $\begin{array}{c}\text { Avaliação ambiental } \\
\text { (scanning) }\end{array}$ & Impactos sociais \\
\hline $\begin{array}{l}\text { Responsabilidade } \\
\text { Pública }\end{array}$ & $\begin{array}{l}\text { Gerenciamento do } \\
\text { stakeholder }\end{array}$ & Políticas sociais \\
\hline Critério gerencial & Questões gerenciais & Programas sociais \\
\hline Princípios da RSE & $\begin{array}{l}\text { Processos da } \\
\text { receptividade social }\end{array}$ & $\begin{array}{l}\text { Resultados do } \\
\text { comportamento } \\
\text { corporativo }\end{array}$ \\
\hline
\end{tabular}

Figura 1 - Modelo de Desempenho Social Corporativo

Fonte: Moir (2001, p. 16) 
Resumindo os aspectos presentes na Figura 1 que foram apresentados por Wood (1991, p. 691): Como princípio da RSE, na dimensão institucional, a sociedade outorga "legitimidade" e poder à empresa que, se não for exercida na forma de RSE, tende a se perder. Na dimensão organizacional, as empresas são responsáveis pelos resultados relacionados às suas atividades envolvendo a sociedade ("responsabilidade pública"). Na dimensão individual, os gerentes são atores morais e exercem o arbítrio em direção aos resultados da RSE ("critério gerencial"). Nos processos da receptividade social, a "avaliação ambiental" é o conceito ecológico que sugere a adaptação da empresa às condições ambientais. O "gerenciamento dos stakeholders" envolve a gestão dos diversos grupos de interesse e as "questões gerenciais" se referem aos processos internos que respondem pelos assuntos sociais como, por exemplo, os programas éticos, e refletirão sobre o desempenho corporativo. O "impacto social” do comportamento corporativo é o resultado das ações empresariais e refletem na avaliação do desempenho da RSE. Uma "política social" abrangente, institucionalizada e operacionalizada por meio dos "programas sociais" é o resultado lógico do comportamento empresarial motivado pelos princípios da RSE.

O modelo conceitual da pirâmide de RSE proposto por Carroll (1991, p. 39) e apresentado na Figura 2 está alinhado a esses últimos posicionamentos que se contrapõem à Teoria do Acionista e, portanto, defende os méritos éticos e intelectuais da Teoria do Stakeholder. O modelo integra as quatro dimensões da RSE: responsabilidade econômica, legal, ética e filantrópica. Isso é, a expectativa da sociedade é que as empresas produzam bens ou serviços e deles extraiam seu lucro; mas que nessa empreitada respeitem as leis e tenham atitudes éticas honrando direitos e cumprindo deveres. E, finalmente, também possam executar ações sociais filantrópicas voluntárias.

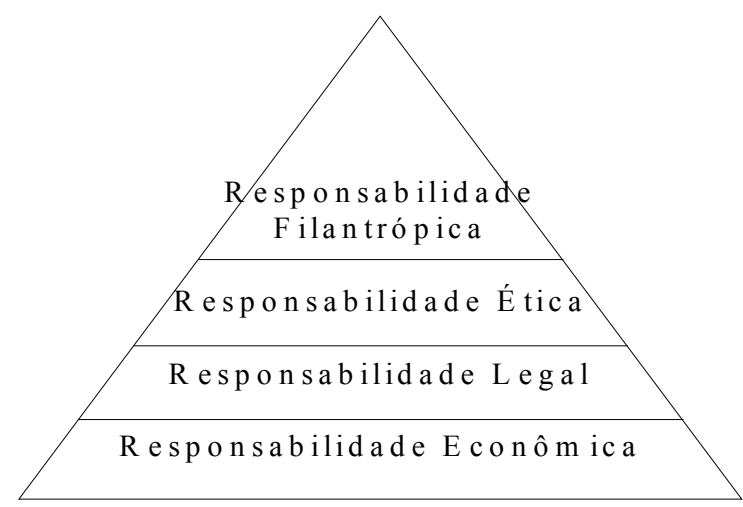

Figura 2 - Pirâmide da RSE

Fonte: Carroll (1991) 


\subsection{RSE e o Desempenho Financeiro}

A seguir são apresentadas as conclusões de algumas pesquisas empíricas que buscavam responder a mesma questão de pesquisa, que é a relação entre o desempenho da RSE e o desempenho financeiro das empresas. Como se pode observar, seus resultados não são plenamente conclusivos, o que reforça a necessidade da continuidade nesse ramo de pesquisa, buscando aumentar o conhecimento existente.

Não existe consenso sobre qual a medida mais apropriada para medição de desempenho financeiro ou da RSE, contudo Roman (1999, p.109) revisou a relação entre RSE e desempenho financeiro nas pesquisas tratadas por Griffin e Mahon (1997, p. 5). Elas tratavam do mesmo tema, mas com ênfase em inconsistências metodológicas, com foco na indústria química e usando dados de fontes múltiplas. Eram 62 pesquisas produzidas ao longo de 25 anos. A contribuição de Roman (1999, p. 109) foi re-categorizar os resultados dessas pesquisas, apresentando 26 reclassificações ou remoções da tabela. Ao final, ele classificou 33 estudos sugerindo uma relação positiva entre RSE e desempenho financeiro, 5 com essa relação negativa, 14 sem relação ou relação não conclusiva e as demais pesquisas foram removidas da tabela original por apresentarem medidas inválidas ou inexistentes (missings). Tais pesquisas estavam baseadas em variáveis de opinião dos respondentes.

Preston e O'Bannon (1997, p. 419) analisaram o relacionamento entre indicadores de RSE e desempenho financeiro de 67 grandes empresas americanas no período de 1982 a 1992. A análise longitudinal dos dados evidenciaram uma correlação positiva entre os indicadores de desempenho social e o financeiro, isso é, bons desempenhos financeiros estavam presentes em empresas com bom desempenho de RSE, um resultado consistente com a Teoria do Stakeholder. Adicionalmente, os resultados revelaram que o desempenho financeiro antecedeu ou ocorreu na mesma época de melhoria dos aspectos de RSE.

Stanwick e Stanwick (1998a, p. 86) consideraram em seu estudo que existiam componentes críticos para criar um alto nível de desempenho da RSE, tais como a lucratividade da empresa, nível de filantropia, nível de emissões ambientais, existência de mulheres e minorias étnicas no grupo dos diretores e em outros níveis da empresa e remuneração do presidente, aí inclusos salário e bônus. Eles encontraram evidências de que o desempenho da RSE é um conceito multidimensional e que 
os níveis ocupados por mulheres e minorias étnicas têm impacto significativo, enquanto o percentual de mulheres e minorias étnicas no grupo de diretores não têm. Os resultados também indicaram que os presidentes estão pouco motivados para agir de forma socialmente responsável, pelas razões defendidas pela Teoria dos Acionistas de que RSE representa custos que prejudicam o desempenho financeiro da empresa. O pagamento do presidente estava positivamente relacionado à redução de emissões ambientais e inversamente relacionados ao percentual de mulheres e minorias entre os empregados. Outras correlações foram calculadas com os seguintes resultados: a percentagem de minorias no alto escalão das empresas é positivamente correlacionada ao percentual de contribuições filantrópicas; o percentual de empregados do sexo feminino é positivamente correlacionado ao percentual de minorias no alto escalão da empresa e inversamente relacionado à redução de emissões ambientais. Uma limitação do estudo de Stanwick e Stanwick (1998a, p. 86) foi o tamanho da amostra. Apesar dos resultados com significância estatística, eles propõem o uso de uma amostra maior de empresas. Outro fator criticado na pesquisa é que $94 \%$ das empresas da amostra do estudo tinham, no mínimo, 1000 empregados e sugerem futuros estudos examinando as relações em empresas menores.

Stanwick e Stanwick (1998b, p. 195) examinaram a relação entre o desempenho da RSE de uma organização e três de suas variáveis: tamanho, desempenho financeiro e desempenho ambiental, estes significando a quantidade de emissão poluente da organização. O estudo empírico com dados do período de 1987 a 1992 apresentou uma correlação positiva entre o desempenho da RSE e as três variáveis de estudo. As empresas participantes da amostra estavam entre as 500 listadas pela Revista Fortune e também entre as 500 maiores emissoras de poluentes segundo o United States Environmental Protection Agency's Toxic Release Inventory Report. O tamanho da empresa foi medido pelo seu faturamento anual e o desempenho financeiro foi considerado como a relação entre o lucro e o faturamento anuais. O desempenho ambiental estava baseado no nível de emissão de poluentes, cujo valor estava disponível no EPA's Toxic Release Inventory Report e para considerar o tamanho da empresa, ele também foi dividido pelo faturamento anual. O nível de desempenho da RSE foi retirado da publicação Fortune Corporate Reputation Index. Entretanto, Wood (1995, p. 197) não concordou com o uso desse índice como medida verdadeira do desempenho da RSE para avaliar o desempenho comunitário e ambiental, mas entende que ele é potencialmente útil como um indicador da reputação da organização entre a comunidade de negócios. Sua crítica se baseou no 
fato de que a montagem do índice utilizou a opinião de executivos e analistas financeiros e foi coletada pela revista Fortune, o que em si deixa de caracterizar a opinião de toda a sociedade.

Orlitzky (2001, p. 167) mencionou que têm existido debates teóricos e empíricos sobre a correlação positiva entre o desempenho da RSE e o desempenho financeiro e que ela é espúria e causada, de fato, por um terceiro fator, o tamanho da empresa. Seu estudo não confirmou que o tamanho da empresa é um terceiro fator que possa confundir a correlação entre os desempenhos da RSE e o financeiro e o resultado de seu estudo encontrou uma correlação positiva entre essas variáveis.

Margolis e Walsh (2003 apud DENTCHEV, 2004, p. 398) contaram 127 estudos destinados a relacionar a RSE e o desempenho financeiro no período de 1972 a 2002. Eles encontraram uma relação positivamente significante na maioria dos estudos, mas em vista da ocorrência de correlação negativa ou inexistente também observada, sugeriram considerar esta relação ainda como complexa e não totalmente caracterizada e que as evidências contribuíram pouco para o conhecimento do desempenho social corporativo.

Considerando que altos níveis de desempenho social demandam recursos, Ullmann (1985, p. 540) mencionou que alguns estudos pressupunham uma correlação negativa entre desempenho social e o econômico, mas destacaram que outra linha de pesquisa assumiu um posicionamento intermediário considerando existir uma correlação com formato de $\mathrm{U}$ invertido e sugerindo que existe um nível ótimo de desempenho social correspondente aos recursos alocados, isso é, o desempenho financeiro seria menor nos casos onde houvesse escasso ou excessivo investimento em ações sociais. Ainda, em períodos de baixa lucratividade, as decisões sobre investimentos em RSE poderiam ter sua prioridade reduzida, o que poderia sugerir uma correlação entre a desempenho financeiro passado e o nível de desempenho da RSE.

Wu (2006, p. 163) investigou a relação da RSE e o desempenho financeiro com a inclusão do porte da empresa. Os resultados não apresentaram evidências de que o porte da empresa refletia no seu desempenho financeiro e ele concluiu que os estudos nessa direção deveriam continuar, sugerindo analisar subgrupos e adicionar outros fatores que pudessem influenciar a relação entre porte e desempenho. 
A esperança preponderante de impacto positivo ou neutro da RSE sobre o desempenho financeiro se deve a que a maioria dos estudos suportam a idéia de que bom desempenho social não leva a pobre desempenho financeiro, isso é, mesmo que não exista uma relação direta significativa entre a RSE e o desempenho financeiro das empresas, as investigações levadas a cabo até o momento não identificaram que empresas que investiram em RSE tenham tido desempenho financeiro negativo. Ainda, à medida que as pesquisas progridem, o desafio dos pesquisadores também é o de encontrar um construto de medida multidimensional de RSE. 


\section{METODOLOGIA DA PESQUISA}

Esse item apresenta as características metodológicas utilizadas no trabalho, o universo da pesquisa descrevendo a origem dos dados amostrais e a distribuição das quantidades dos casos (cross tables), o modelo conceitual da pesquisa e suas variáveis, os critérios de construção dos modelos estatísticos, o exame dos dados coletados, as transformações matemáticas das variáveis e conclui com os comentários das limitações da pesquisa.

\subsection{Método da Pesquisa}

A pesquisa é classificada como exploratória ex-post-facto, isso é, busca percepções dentro da natureza geral do problema, onde as possíveis decisões alternativas e as variáveis relevantes precisam ser consideradas (AAKER et al, 1995, p. 73). Kerlinger (1979) define que é pesquisa na qual a variável independente é manipulada em seu meio natural, sem interferência do pesquisador, na qual o fato a ser estudado já ocorreu e se busca verificar quais elementos geraram determinado acontecimento, ou quais prováveis caminhos surgirão devido ao ocorrido.

As informações dos BSs padrão IBASE que foram coletadas para essa pesquisa compreendem 304 empresas no período de 1996 a 2004. Os dados de 2005 e 2006 não foram considerados no estudo por não estarem disponíveis no momento da montagem do banco de dados da pesquisa, concluído no início de 2006.

As informações da pesquisa são caracterizadas como dados secundários, que são dados existentes e que foram coletados por pessoas ou agências para outros propósitos (AAKER et al, 1995, p. 77), cujas características são relevantes para a abordagem quantitativa da pesquisa. Aaker $(1995$, p. 115) aponta o benefício de que alguns dados podem ser disponíveis somente de fontes secundárias e eventualmente podem ser mais precisos que dados primários. Então, apoiado pelos pressupostos de Aaker, o autor tem convicção de que o uso de variáveis quantitativas, ainda que somente aquelas presentes no BS padrão IBASE, podem ensejar uma investigação destacada das análises puramente baseadas em variáveis de opinião e obtidas em curto lapso temporal, que caracterizam algumas das pesquisas citadas na bibliografia desse trabalho. 
Os processos estatísticos que são aplicados permitem obter, de conjuntos complexos, representações simples e, a partir dessas, verificações simplificadas que tenham relações entre si (LAKATOS, 2003, p. 108). Pela conveniência dos dados secundários, serão empregadas técnicas estatísticas com a finalidade de descobrir e classificar as relações entre as variáveis do estudo e identificar aquelas que determinaram ou contribuíram para a ocorrência do fenômeno sob análise (MATTAR, 1994).

\subsection{Universo da Pesquisa e Estratégia de Coleta}

A amostra obtida de forma não probabilística é composta pelos BSs publicados pelo IBASE e também disponibilizados pelas próprias empresas, sendo acessíveis por intermédio de seus sites na Internet. A distribuição proporcional por porte está estratificada com praticamente 1/3 de empresas de grande porte e $2 / 3$ delas de médio e pequeno porte. A escolha deliberada dos elementos da amostra se deve ao fato que empresas nacionais e multinacionais de vários portes e setores da economia estão representadas nesse elenco amostral, não sendo caracterizado um vício amostral. O vício ocorre quando existe uma tendência na composição da amostra que favoreça uma característica particular.

As empresas presentes na amostra pertencem a mais de 30 setores da economia, com vários setores industriais (como, por exemplo, automotivo, farmacêutico, químico, siderúrgico e agro-indústrial), de serviço (como, por exemplo, comércio varejista e atacadista, financeiros e transporte), concessionárias de serviços públicos e governamentais. A utilização de tal diversidade de setores pode fazer com que os agrupamentos por esse critério tenham uma quantidade pouco relevante às análises estatísticas, portanto, para efeito da pesquisa, o autor estabeleceu para essa fase ainda exploratória de estudos, o enquadramento dos setores nos seguintes agrupamentos: Industrial, Agroindustrial, Serviços Financeiros, Serviço Elétrico e Energia e Outros Serviços.

A escolha dos agrupamentos setoriais foi norteada pela própria realidade das empresas presentes na amostra. O setor financeiro foi destacado por apresentar a característica de ter um porte muito grande perante os demais setores de serviço, podendo acarretar fortes distorções caso fosse mantido dentro do setor de serviços. A partir de 2000, o setor elétrico e energia se fez representar na amostra por mais de 40 empresas. Por ser uma atividade altamente regulamentada e com atividades bastante 
peculiares e diferenciadas tais como geração, transmissão e distribuição de energia elétrica, sua segregação em um setor específico resolveu o dilema da mesma pertencer ao setor de serviços e, de certa forma, industrial. Finalmente, motivado em investigar o comportamento do setor agroindustrial pela sua importância no cenário brasileiro e mundial e considerando que a partir de 2000 ele se fez representar por 30 empresas, uma quantidade razoável de casos para fins de análise estatística, o autor estabeleceu esse agrupamento destacado do setor industrial ou dos serviços. Dessa maneira, cada um desses cinco grupos possuem uma quantidade mais significativa de casos em relação ao seu setor original, sem contudo perder o conceito da natureza de sua atuação, o que poderá beneficiar a significância dos resultados das análises estatísticas.

O período de 1996 a 2004 apresentou 1024 BSs e eles se referiram aos dados de 304 empresas. A cada ano novas empresas publicam seus BSs e outras deixam de fazê-lo, o que explica a variação das quantidades anuais apresentadas na Tabela 8.

Tabela 8 - Distribuição anual e por setor dos BSs da amostra

\begin{tabular}{l|c|c|c|c|c|c|c|c|c}
\hline \multicolumn{1}{c|}{ Setor } & $\mathbf{1 9 9 6}$ & $\mathbf{1 9 9 7}$ & $\mathbf{1 9 9 8}$ & $\mathbf{1 9 9 9}$ & $\mathbf{2 0 0 0}$ & $\mathbf{2 0 0 1}$ & $\mathbf{2 0 0 2}$ & $\mathbf{2 0 0 3}$ & $\mathbf{2 0 0 4}$ \\
\hline Industrial & 2 & 4 & 10 & 27 & $\mathbf{4 4}$ & $\mathbf{6 1}$ & $\mathbf{7 0}$ & $\mathbf{7 1}$ & $\mathbf{5 9}$ \\
\hline Serviços & 1 & 3 & 6 & 16 & $\mathbf{3 0}$ & $\mathbf{4 2}$ & $\mathbf{4 0}$ & $\mathbf{5 9}$ & $\mathbf{4 4}$ \\
\hline Elétrico & 5 & 13 & 15 & 15 & $\mathbf{4 1}$ & $\mathbf{4 4}$ & $\mathbf{3 4}$ & $\mathbf{4 6}$ & $\mathbf{3 6}$ \\
\hline Agroindustrial & 0 & 0 & 1 & 1 & $\mathbf{7}$ & $\mathbf{2 1}$ & $\mathbf{3 0}$ & $\mathbf{3 2}$ & $\mathbf{3 0}$ \\
\hline Financeiro & 1 & 2 & 3 & 2 & $\mathbf{7}$ & $\mathbf{9}$ & $\mathbf{1 1}$ & $\mathbf{1 3}$ & $\mathbf{1 0}$ \\
\hline Total & 9 & 22 & 35 & 61 & $\mathbf{1 2 9}$ & $\mathbf{1 7 7}$ & $\mathbf{1 8 5}$ & $\mathbf{2 2 1}$ & $\mathbf{1 7 9}$ \\
\hline
\end{tabular}

Fonte: Adaptado pelo autor a partir das informações do site IBASE (2004, 2005).

A distribuição dos BSs por setor ao longo do período da amostra sugere que seja feito um corte a partir de 2000. Desse modo, observa-se uma distribuição mais homogênea tanto ao longo dos anos quanto da participação nos diversos setores considerados. Nessa condição, para efeito da análise da pesquisa no período 2000 a 2004, a amostra resultante está constituída por 891 BSs $^{9}$ de 295 empresas.

\footnotetext{
${ }^{9}$ A amostra referente ao período 2000 a 2004 totalizou 897 BSs, correspondentes a 298 empresas, entretanto, por ocorrência de missings, a quantidade de casos úteis para a análise foi de 891 BSs de 295 empresas.
} 
As Tabelas 9 e $\mathbf{1 0}$ apresentam a distribuição anual das empresas que tiveram respectivamente Resultados Operacionais positivos (Lucro) e negativos (Prejuízo) $^{10}$, por setor econômico de atuação. Notar que o setor financeiro está representado por um único BS e que a maior incidência de BSs com resultados financeiros negativos ocorreu em 2002. A menor participação percentual do setor financeiro perante os demais desse estudo reflete a realidade de serem empresas caracteristicamente de grande porte e portanto participarem em menor quantidade na amostra.

Tabela 9 - Distribuição anual e setorial de BSs de empresas com RO positivo (Lucro)

\begin{tabular}{l|c|c|c|c|c|c|c}
\hline \multicolumn{1}{c|}{ Lucro } & $\mathbf{2 0 0 0}$ & $\mathbf{2 0 0 1}$ & $\mathbf{2 0 0 2}$ & $\mathbf{2 0 0 3}$ & $\mathbf{2 0 0 4}$ & Total & Total (\%) \\
\hline Industrial & 32 & 47 & 45 & 55 & 52 & 231 & $33,4 \%$ \\
\hline Serviços & 19 & 30 & 32 & 48 & 36 & 165 & $23,9 \%$ \\
\hline Elétrico & 30 & 35 & 15 & 33 & 32 & 145 & $21,0 \%$ \\
\hline Agroindustrial & 5 & 16 & 25 & 28 & 27 & 101 & $14,6 \%$ \\
\hline Financeiro & 7 & 9 & 11 & 12 & 10 & 49 & $7,1 \%$ \\
\hline Total & 93 & 137 & 128 & 176 & 157 & 691 & \\
\hline Total (\%) & $13,5 \%$ & $19,8 \%$ & $18,5 \%$ & $25,5 \%$ & $22,7 \%$ & & $100,0 \%$ \\
\hline
\end{tabular}

Fonte: Adaptado pelo autor a partir das informações do site IBASE $(2004,2005)$.

Tabela 10 - Distribuição anual e setorial de BSs de empresas com RO negativo (Prejuízo)

\begin{tabular}{l|c|c|c|c|c|c|c}
\hline \multicolumn{1}{c|}{ Prejuízo } & $\mathbf{2 0 0 0}$ & $\mathbf{2 0 0 1}$ & $\mathbf{2 0 0 2}$ & $\mathbf{2 0 0 3}$ & $\mathbf{2 0 0 4}$ & Total & Total (\%) \\
\hline Industrial & 6 & 8 & 17 & 9 & 4 & 44 & $29,9 \%$ \\
\hline Serviços & 8 & 7 & 7 & 10 & 8 & 40 & $27,2 \%$ \\
\hline Elétrico & 9 & 7 & 16 & 10 & 3 & 45 & $30,6 \%$ \\
\hline Agroindustrial & 2 & 4 & 5 & 4 & 2 & 17 & $11,6 \%$ \\
\hline Financeiro & 0 & 0 & 0 & 1 & 0 & 1 & $0,7 \%$ \\
\hline Total & 25 & 26 & 45 & 34 & 17 & 147 & \\
\hline Total (\%) & $17,0 \%$ & $17,7 \%$ & $30,6 \%$ & $23,1 \%$ & $11,6 \%$ & & $100,0 \%$ \\
\hline
\end{tabular}

Fonte: Adaptado pelo autor a partir das informações do site IBASE $(2004,2005)$.

Verifica-se que a soma dos valores das Tabelas 9 e 10 não resultam nos totais da Tabela 8 , pois essa considerou todos os BSs da amostra e aquelas, somente os BSs que informaram os Resultados Operacionais. Observou-se que, algumas empresas deixaram de prestar essa e outras informações constantes do BS padrão IBASE, acarretando as diferenças já apontadas. As conseqüências dessa postura é detalhada no item 3.4.3 (Análise dos “dados perdidos")

\footnotetext{
${ }^{10}$ Os termos Prejuízo e Lucro se referem à condição de Resultado Operacional respectivamente negativo e positivo e não ao seu significado exato do ponto de vista financeiro.
} 


\subsection{Modelo Conceitual da Pesquisa}

Para responder as questões da pesquisa enunciadas no item 1.4 (Questões da pesquisa), o autor desenvolveu o modelo da pesquisa apresentado na Figura 3, no qual as variáveis estatísticas correspondentes estão descritas no item 1.5.2 (O Balanço Social padrão IBASE) e foram complementadas pelas variáveis definidas e justificadas na Tabela 11.

O modelo conceitual pretende identificar de que forma os investimentos em projetos sociais internos, externos e ambientais, que são as variáveis independentes, conseguem explicar a variância do desempenho financeiro traduzido pelo Resultado Operacional, doravante também denominado RO, que é a variável dependente do BS. O RO, conforme especificado pelo IBASE, corresponde ao lucro antes das receitas e despesas não operacionais. As demais variáveis do BS estão sendo alocadas como variáveis intervenientes, isto é, aquelas que ampliam, diminuem ou anulam o efeito das variáveis independentes sobre as dependentes e não podem ser controladas (AAKER, 1995).

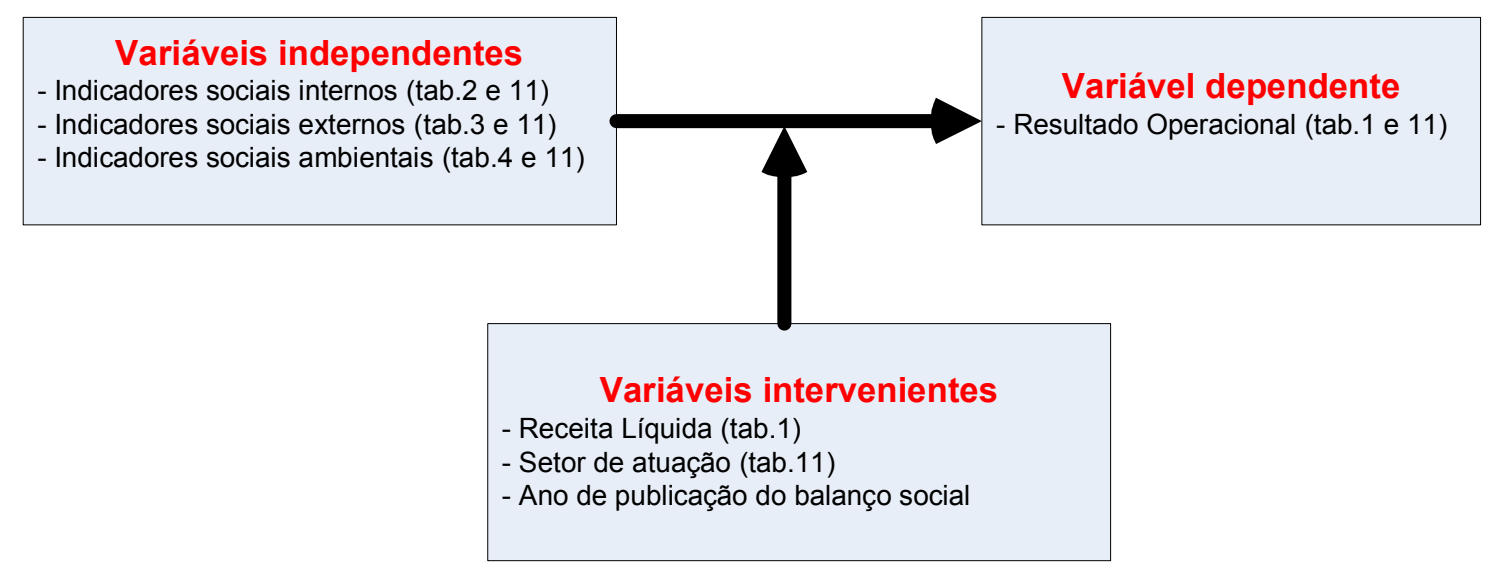

Figura 3 - Modelo conceitual da pesquisa

\subsubsection{As variáveis do modelo da pesquisa}

A variável dependente é o $\mathrm{RO}$ e as variáveis independentes do modelo da pesquisa são aquelas que representam os investimentos em RSE e estão separadas em três grupos: i) ISI - Indicadores Sociais 
Internos, identificadas com números da série 200; ii) ISE - Indicadores Sociais Externos, identificadas com números da série 300 e iii) IA - Indicadores Ambientais, com a série 400.

As variáveis da Tabela $\mathbf{1 1}$ foram criadas pelo autor a partir dos dados do BS e incorporadas ao banco de dados para melhor evidenciar o fenômeno sob estudo.

O autor considera que a análise das contribuições sociais voluntárias e totais, separadamente, pode apresentar resultados relevantes ao entendimento dos impactos das ações estratégicas e da influência da legislação sobre as decisões de investimento em RSE, pelas seguintes razões: i) as contribuições compulsórias por lei podem não refletir decisões estratégicas empresariais e ii) alguns desses encargos, por conta da legislação brasileira, podem ter um valor maior que alguns investimentos voluntários das empresas, o que pode mascarar a influência das ações voluntárias de RSE. Portanto, o estudo considerou dois cenários separados de análise do modelo da pesquisa: o do investimento Voluntário em RSE e o Total, que engloba os valores voluntários e compulsórios. Não é possível analisar, separadamente, as parcelas voluntárias das compulsórias, pois alguns dos itens definidos no BS padrão do IBASE não discriminam essas verbas; portanto, o autor somente considerou no agrupamento de investimentos voluntários, aqueles que claramente não são compulsórios, retirando, por exemplo, itens de impostos e encargos sociais.

Apesar das orientações do IBASE para que a empresa discrimine seus investimentos em RSE em cada uma das suas iniciativas sociais listadas no formulário do BS padrão IBASE, algumas empresas informaram somente os valores totais correspondentes aos investimentos em Indicadores Sociais Externos e Ambientais. Para contornar essa característica, o autor criou as variáveis agregadoras V311 e V403 cuja regra de formação está detalhada na Tabela 11. Nessas condições, é possível perceber a influência dessa característica comportamental das empresas no modelo, isso é, o comportamento de empresas detalhistas no seu BS daquelas que preferem relatar valores mais agregados. Esse comportamento não foi observado em relação aos Indicadores Sociais Internos. Nesse grupo de variáveis, as empresas destacaram seus investimentos conforme orientação do IBASE. 
Tabela 11 - Variáveis adicionais ao BS padrão IBASE

\begin{tabular}{|c|c|c|}
\hline Denominação & Descrição & $\begin{array}{l}\text { Código da } \\
\text { variável }\end{array}$ \\
\hline Empresa & $\begin{array}{l}\text { Código da empresa: Código numérico definido pelo autor para fins de } \\
\text { identificação da empresa. Foi atribuído um código numérico a cada razão } \\
\text { social identificada nos BSs }\end{array}$ & V10 \\
\hline Setor & $\begin{array}{l}\text { Código do setor econômico no qual a empresa atua (código atribuído pelo } \\
\text { autor): Industrial (1), Serviços Financeiros (5), Outros Serviços (2), } \\
\text { Elétrico/ Energia (3) e Agroindustrial (4). } \\
\text { Dos mais de } 30 \text { setores originais, o autor, por meio dos critérios } \\
\text { mencionados no item } 3.2 \text { (Universo da Pesquisa e Estratégia de Coleta), } \\
\text { agrupou-os em 5, já que pequenas quantidades de casos ou quantidades } \\
\text { distribuídas de forma desbalanceada nas diversas categorias da variável } \\
\text { podem introduzir distorções nos resultados e, conseqüentemente, nas } \\
\text { conclusões }\end{array}$ & V25 \\
\hline $\begin{array}{l}\text { Investimentos } \\
\text { Sociais Internos } \\
\text { Voluntários }\end{array}$ & $\begin{array}{l}\text { Total do investimento voluntário em RSE no programas sociais internos: } \\
\text { Representa o Total dos Indicadores Sociais Internos subtraídos dos } \\
\text { Encargos Sociais Compulsórios. } \\
\text { Será utilizado para análises nas quais se desejam somente valores } \\
\text { estabelecidos pela empresa, sem a obrigatoriedade governamental: } \\
\text { V214 = V213 - V202 }\end{array}$ & V214 \\
\hline $\begin{array}{l}\text { Indicadores } \\
\text { Sociais Externos } \\
\text { agregados }\end{array}$ & $\begin{array}{l}\text { Valor total investido em programas sociais externos no caso em que a } \\
\text { empresa não informou os investimentos discriminados pelos itens } \\
\text { preconizados pelo BS padrão IBASE, mas somente o valor total: } \\
\text { V311 = V312 (quando V301 a V310 forem todos iguais a Zero) }\end{array}$ & V311 \\
\hline $\begin{array}{l}\text { Indicadores } \\
\text { Ambientais } \\
\text { agregados }\end{array}$ & $\begin{array}{l}\text { Valor total investido em programas ambientais no caso em que a empresa } \\
\text { não informou os investimentos discriminados pelos itens preconizados pelo } \\
\text { BS padrão IBASE, mas somente o valor total: } \\
\text { V403 = V404 (quando V401 e V402 forem todos iguais a Zero) }\end{array}$ & V403 \\
\hline $\begin{array}{l}\text { Investimento } \\
\text { Total em RSE }\end{array}$ & $\begin{array}{l}\text { Total dos investimentos em RSE, inclusos os voluntários e os compulsórios: } \\
\text { RSE_Total = V } 213+\mathrm{V} 314+\mathrm{V} 404\end{array}$ & RSE_Total \\
\hline $\begin{array}{l}\text { Investimento } \\
\text { voluntário total } \\
\text { em RSE }\end{array}$ & $\begin{array}{l}\text { Total dos investimentos voluntários em RSE. É o total dos investimentos } \\
\text { em RSE descontados dos investimentos compulsórios: } \\
\text { RSE_Voluntario = V214 + V312+V404 }\end{array}$ & $\begin{array}{c}\mathrm{RSE}_{-} \\
\text {Voluntario }\end{array}$ \\
\hline $\begin{array}{l}\text { Dessensibilização } \\
\text { do efeito do Porte } \\
\text { da empresa }\end{array}$ & $\begin{array}{l}\text { Ajuste de escala pelo porte da empresa (dessensibilização do porte da } \\
\text { empresa): } \\
\text { Foi considerada a variável V101 (Receita Líquida - RL) como parâmetro } \\
\text { definidor do porte da empresa. } \\
\text { A dessensibilização do porte foi obtida pelo uso de um índice resultante da } \\
\text { relação entre a variável original Vnnn e a RL. O resultado foi ainda } \\
\text { multiplicado por } 1.000 .000 \text {, como um fator de escala. para tornar os valores } \\
\text { dos índices acima de } 1 \text {, melhorando a linearidade da variável transformada } \\
\text { log normal }{ }^{11} \text { : } \\
\text { RLVnnn = Vnnn / V101 x } 1.000 .000 \\
\text { R_RSE_Total = RSE_Total / V101 x } 1.000 .000 \\
\text { R RSE Voluntario = RSE Voluntario / V101 x } 1.000 .000\end{array}$ & $\begin{array}{l}\text { RLVnnn } \\
\text { R_RSE_- } \\
\text { Total } \\
\text { R_RSE_- } \\
\text { Voluntario }\end{array}$ \\
\hline
\end{tabular}

${ }^{11} \mathrm{O}$ fator de escala foi arbitrado pelo autor. A transformação logarítmica destas variáveis, descrita no item 3.4 .2 (Transformação logarítmica das variáveis), apresentou melhor linearidade quando utilizado o fator de escala 1.000.000 comparativamente ao fator 1.000. Desse modo, a pequena distorção que se observou na região dos valores dos índices no entorno de zero, decorrente da transformação log natural, pode ser eliminada. A confirmação da conveniência da adoção do valor 1.000 .000 foi constatada pela comparação dos resultados processados para cada um desses valores. $\mathrm{O}$ Anexo 7.5 apresenta as tabelas da análise do modelo com o fator 1.000, que confirmou a maior linearidade do modelo de regressão utilizado. 
Em favor da parcimônia na elaboração dos modelos estatísticos, a quantidade de variáveis dos modelos será reduzida e, por ser uma análise ainda exploratória, as variáveis intervenientes correspondentes às séries V500 (Tabela 5) e V600 (Tabela 6) dos BSs padrão IBASE não serão abordadas no estudo. Portanto, o estudo focaliza principalmente as variáveis financeiras da RSE. Outra razão que reforça essa decisão é que a incidência de missings (ver considerações detalhadas no item 3.4.3 - Análise dos “dados perdidos”) é bastante alta nas variáveis dessas séries, o que acarreta uma redução da quantidade de casos úteis da amostra para fins das análises estatísticas.

\subsubsection{Construção dos modelos estatísticos}

O autor considerou que a análise pautada por uma única visão que utilizasse diretamente os investimentos como apresentados no BS poderiam não evidenciar o comportamento empresarial perante a RSE e propôs uma análise em profundidades progressivas, iniciando por uma abordagem com visão agregada dos investimentos em RSE que avaliou o total geral dos mesmos, seguida por uma segunda visão, por natureza de investimento em RSE e nela se buscou perceber o foco nos Indicadores Internos, Externos e/ou Ambientais separadamente e, finalmente, a visão detalhada que pode perceber cada programa em RSE preconizado pelo BS padrão IBASE. A exploração sistematizada dessas visões permitiu perceber a significância e relevância das decisões estratégicas das empresas em RSE. Cada uma das visões foi analisada perante alguns recortes, visando segmentar a influência das variáveis intervenientes.

O primeiro recorte do modelo da pesquisa considerou o porte da empresa e o objetivo foi identificar se ele foi fator discriminante das estratégias de investimento em RSE e qual seria o reflexo nos resultados financeiros. Para tal, existem vários critérios para definir o porte da empresa, como por exemplo, a Receita Líquida, o valor da Folha de Pagamento ou mesmo a quantidade de empregados da empresa como tradutores do porte da empresa. O autor entende que esses dois últimos fatores podem trazer um viés ao índice, pois a amostra em estudo contém empresas de diversas naturezas e setores, nos quais a força de trabalho pode ter perfis de especialização ou mesmo de atividades de uso intensivo de mão-de-obra que podem distorcer os resultados dos modelos. Stanwick e Stanwick (1998b, p. 195) utilizaram o critério de Vendas Anuais para medir o porte da empresa e esse 
também será o critério utilizado nesse trabalho e que, no caso do BS padrão IBASE, correspondeu à Receita Líquida (RL), que é a receita bruta excluída dos impostos, contribuições, devoluções, abatimentos e descontos comerciais. O autor acredita que uma variável escala razão que traduzisse o porte ou que o desconsiderasse teria melhor representatividade no modelo selecionado. Para o caso da percepção do porte, o entendimento do autor é que o valor absoluto das variáveis originais da amostra já embutem o porte da empresa. No caso de se eliminar a influência do porte, a RL foi utilizada para criar um índice que correspondeu ao valor de cada variável fornecido pelo BS, dividido pelo valor da RL respectiva; dessa forma, foi possível efetuar a análise dessensibilizada do porte da empresa.

O segundo recorte considerou as condições compulsórias estabelecidas pela legislação brasileira nos seus capítulos fiscal, trabalhista e ambiental e que são consideradas como investimentos em RSE pelo IBASE. Apesar desse padrão não discriminar precisamente as verbas voluntárias das compulsórias, o autor estabeleceu dois cenários para acomodar essa realidade ao estudo que são: i) o modelo com os investimentos que são estabelecidos principalmente pela iniciativa das empresas e que foram consignados ao modelo "Voluntário" e ii) o modelo "Total", cujos investimentos em RSE incluem tanto os valores voluntários quanto os obrigatórios por lei. A Tabela 11 indica as variáveis que foram consideradas para originar essa segmentação.

A combinação desses dois recortes, ou critérios, sugeriu a consecução de quatro famílias de modelos:

Modelo 1 = função (investimento Voluntário em RSE considerando o porte da empresa)

Modelo 2 = f unção (investimento Total em RSE considerando o porte da empresa)

Modelo 3 = função (investimento Voluntário em RSE dessensibilizado do porte da empresa)

\section{Modelo 4 = função ( investimento Total em RSE dessensibilizado do porte da empresa)}

Conforme mencionado no início desse item, cada um dos quatro modelos mencionados foram subcategorizados em três visões: i) Visão agregada na qual se analisou o investimento total em RSE que foi a soma de todos os investimentos do BS em uma única variável independente; ii) $\underline{\text { Visão }}$ 
agregada por natureza do investimento em RSE na qual foram considerados no modelo o total dos Indicadores Sociais Internos (que focaram a comunidade interna da empresa, como por exemplo, os funcionários), dos Indicadores Sociais Externos (que focaram a comunidade externa à empresa) e dos Indicadores Ambientais (que foram destinados tanto aos programas internos quanto aos externos ligados aos processos de produção e ao meio ambiente), cada um deles representados por uma variável independente do modelo; iii) Visão detalhada na qual cada variável do modelo correspondeu a um dos programas em RSE do BS.

A Tabela 12 apresenta as doze funções que foram modeladas para a investigação proposta. As variáveis que compuseram cada um dos modelos correspondem à codificação mencionada nas Tabelas 1 a 6 do item 1.5.2 (O Balanço Social padrão IBASE) e Tabela 12.

Tabela 12 - Modelos específicos testados e respectivas variáveis

\begin{tabular}{|c|c|c|c|c|}
\hline & & $\begin{array}{c}\text { Investimento total } \\
\text { em RSE }\end{array}$ & $\begin{array}{c}\text { Investimentos Internos, } \\
\text { Externos e Ambientais } \\
\text { em separado }\end{array}$ & $\begin{array}{c}\text { Investimento } \\
\text { conforme programas } \\
\text { sociais do BS padrão } \\
\text { IBASE }\end{array}$ \\
\hline & & $\bar{A}$ & B & $\mathrm{C}$ \\
\hline Modelo 1 & $\begin{array}{l}\text { f (investimento } \\
\text { Voluntário em } \\
\text { RSE } \\
\text { considerando o } \\
\text { porte da } \\
\text { empresa) }\end{array}$ & $\begin{array}{l}\text { V102 = f } \\
\text { (RSE_Voluntario) }\end{array}$ & $\begin{array}{l}\text { V102 = } \mathrm{f}(\mathrm{V} 214, \mathrm{~V} 312, \\
\text { V404) } \\
\text { (3 variáveis } \\
\text { independentes) }\end{array}$ & $\begin{array}{l}\text { V102 = f(V201, } \\
\text { V203 a V211, V301 a } \\
\text { V311, V401 a V403) } \\
\text { (24 variáveis } \\
\text { independentes) }\end{array}$ \\
\hline Modelo 2 & $\begin{array}{l}\text { f (investimento } \\
\text { Total em RSE } \\
\text { considerando o } \\
\text { porte da } \\
\text { empresa) }\end{array}$ & $\begin{array}{l}\text { V102 = f } \\
(\text { RSE_Total) }\end{array}$ & $\begin{array}{l}\text { V102 = f (V213, V314, } \\
\text { V404) } \\
\text { (3 variáveis } \\
\text { independentes) }\end{array}$ & $\begin{array}{l}\text { V102 = f(V201 a } \\
\text { V211, V301 a V311, } \\
\text { V313, V401 a V403) } \\
\text { (26 variáveis } \\
\text { independentes) }\end{array}$ \\
\hline Modelo 3 & $\begin{array}{l}\text { f (investimento } \\
\text { Voluntário em } \\
\text { RSE } \\
\text { dessensibilizado } \\
\text { do porte da } \\
\text { empresa) }\end{array}$ & $\begin{array}{l}\text { RLV102 = f } \\
(\mathrm{R} \text { RSE_Voluntario) }\end{array}$ & $\begin{array}{l}\text { RLV102 = f(RLV214, } \\
\text { RLV312, RLV404) } \\
\text { (3 variáveis } \\
\text { independentes) }\end{array}$ & $\begin{array}{l}\text { RLV102 = f } \\
\text { (RLV201, RLV203 a } \\
\text { RLV211, RLV301 a } \\
\text { RLV311, RLV401 a } \\
\text { RLV403) } \\
\text { (24 variáveis } \\
\text { independentes) }\end{array}$ \\
\hline Modelo 4 & $\begin{array}{l}\text { f (investimento } \\
\text { Total em RSE } \\
\text { dessensibilizado } \\
\text { do porte da } \\
\text { empresa) }\end{array}$ & $\begin{array}{l}\text { RLV102 = f } \\
(\mathrm{R} \text { _RSE_Total) }\end{array}$ & $\begin{array}{l}\text { RLV102 = f(RLV213, } \\
\text { RLV314, RLV404) } \\
\text { (3 variáveis } \\
\text { independentes) }\end{array}$ & $\begin{array}{l}\text { RLV102 = f (RLV201 } \\
\text { a RLV211, RLV301 a } \\
\text { RLV311, RLV313, } \\
\text { RLV401 a RLV403) } \\
\text { (26 variáveis } \\
\text { independentes) }\end{array}$ \\
\hline
\end{tabular}




\subsection{Exame dos Dados Coletados}

A aplicação das técnicas estatísticas de análise do modelo da pesquisa foi antecedida pela fase de preparação sugerida por Hair (2005, p. 47). Um esforço significativo foi dispendido no exame e tratamento dos dados e esse refinamento está detalhado nesse item.

O exame dos dados permitiu uma visão crítica das características dos mesmos e das relações entre as variáveis e esse conhecimento das interrelações de variáveis foi útil na especificação e no refinamento do modelo estatístico, assim como na seleção das técnicas e na condução das análises.

Para a operacionalização das análises estatísticas foi utilizado o software SPSS, Statistical Package for the Social Sciences, na sua versão 13.

As técnicas estatísticas que foram utilizadas nessa pesquisa estão apresentadas em Hair (2005, p. 49). Inicialmente os dados coletados foram examinados buscando obter uma visão básica dos mesmos e das relações entre as variáveis. $\mathrm{O}$ resultado deu suporte à escolha e especificação do modelo estatístico e forneceu uma perspectiva racional para a interpretação dos resultados.

Essa etapa incluíu exames gráficos dos dados visando perceber a forma de distribuição dos mesmos e indicar indícios para a produção de variáveis transformadas que se tornaram necessárias para melhor representar o fenômeno em estudo e também melhorar a adequação dos dados aos requisitos técnicos demandados pelos modelos estatísticos.

\subsubsection{Análise gráfica da distribuição das variáveis}

A Figura 4 apresenta um exemplo compacto com algumas das variáveis do estudo e seus valores originais da coleta apresentados nos gráficos de caixas e wiskers, mais conhecidos como Boxplots e assim denominados daqui em diante. Para uma melhor visualização do comportamento relativo das variáveis do exemplo, os dois gráficos agrupam variáveis com escalas semelhantes, no caso, aquelas cujos valores estiveram acima e abaixo de $\mathrm{R} \$ 200$ milhões, respectivamente. Os valores no eixo horizontal indicam os códigos correspondentes às variáveis do estudo e os números no interior do 
gráfico correspondem ao número dos casos amostrais. Essa separação se mostrou conveniente já que os valores de investimentos variaram de zero até $\mathrm{R} \$ 2,5$ bilhões. $\mathrm{O}$ objetivo dessa figura não foi permitir uma percepção detalhada, mas sim uma visão panorâmica das distribuições das variáveis.

A distribuição dos valores originais dos investimentos em RSE e do desempenho financeiro das empresas da amostra apresentaram uma forte assimetria e a presença de muitos outliers ${ }^{12}$. O autor acredita que ela foi devida principalmente à presença de empresas de vários portes e setores da economia na amostra.

Nesse caso, Hair (2005, p. 51) indica procedimentos de ajuste, como, por exemplo, transformações matemáticas das variáveis originais da amostra. A variável transformada pode ser mais adequada para descrever a relação entre as variáveis do modelo, mas é importante destacar que tal procedimento não garante que a transformação produzirá variáveis com o comportamento desejado pelo pesquisador e adequado à técnica de análise selecionada. Essas transformações das variáveis de estudo podem remediar a assimetria e também a presença de outliers, falhas de normalidade, linearidade e homocedasticidade, mas também poderão acarretar o aumento do nível de dificuldade de interpretação dos resultados por conta dessas transformações.

A suposição de normalidade indica que a variável segue o comportamento da Distribuição Normal, que é requisito de várias técnicas multivariadas. Existem vários procedimentos de teste de normalidade, tais como: métodos gráficos, Shapiro-Wilks e Kolmogorov-Smirnov modificado. A falta de normalidade não impede que se possa utilizar métodos estatísticos multivariados, principalmente no caso de amostras grandes. Nesse caso, sugere-se considerar esse comportamento nas conclusões decorrentes dos resultados obtidos das análises estatísticas ou mesmo usar somente testes não-paramétricos que não demandam tal característica.

${ }^{12}$ Outliers são valores muito diferentes das demais observações correspondentes na amostra e serão detalhados no item 3.4.4 (Deteção dos outliers). 

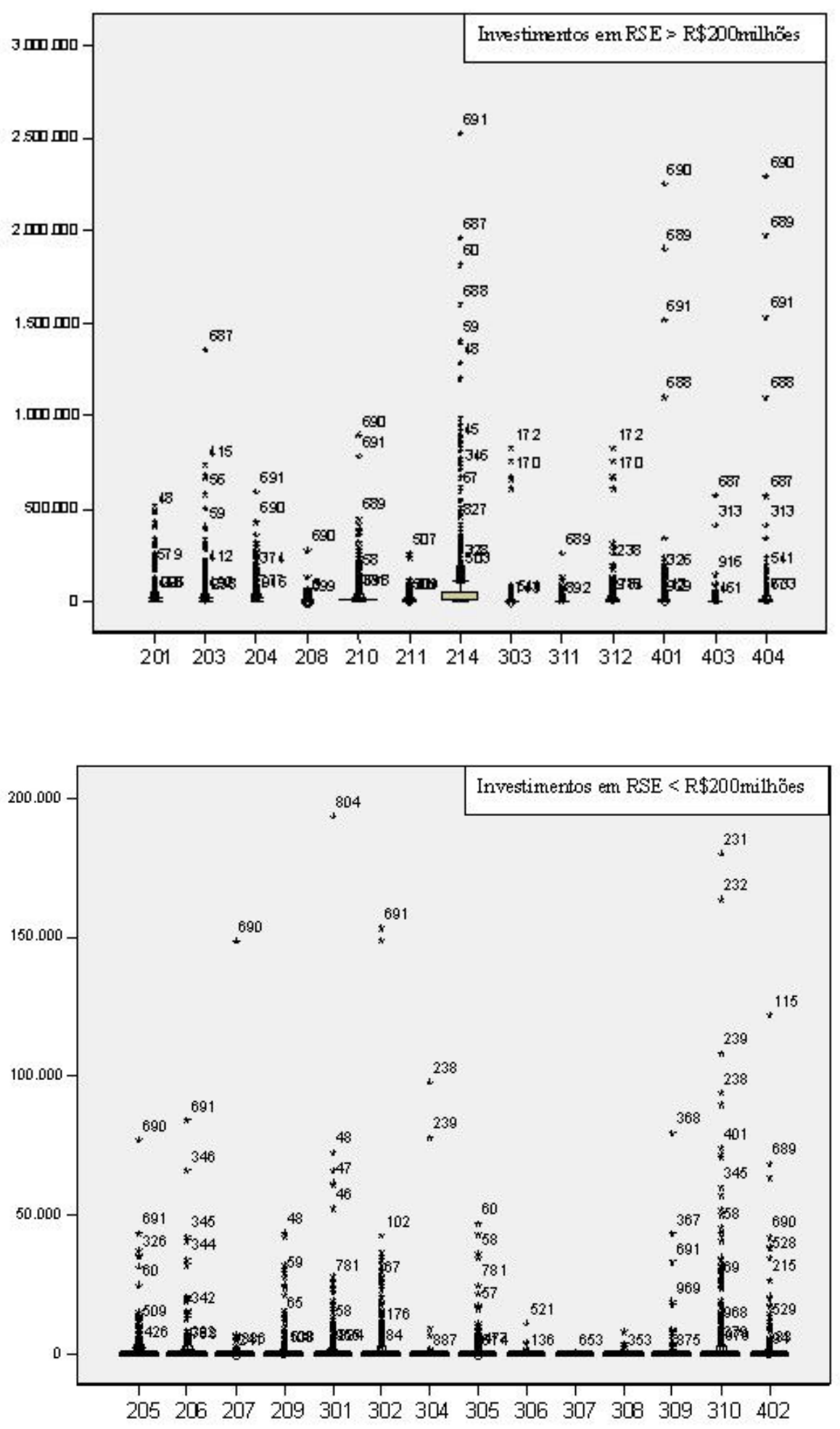

Figura 4 - Gráficos Boxplot das variáveis dependentes e independentes originais 
Uma outra característica desejável é a homocedasticidade, que é a suposição de que o nível de variância das variáveis dependentes exibe valores iguais ao longo do domínio das variáveis preditoras (independentes). O seu oposto é a heterocedasticidade, que significa a falta de homocedasticidade. Para o caso de análise univariada o teste mais comum e que é utilizado no presente trabalho é o de Levene. Apesar de ser um requisito desejável para a análise de modelos lineares, violações modestas podem ser acomodadas, desde que as diferenças sejam decorrentes de assimetrias e não de observações atípicas (HAIR, 2005, p. 287).

A característica de linearidade é desejável ao se utilizar técnicas correlacionais como, por exemplo, regressões, análise fatorial e modelagem de equações estruturais, já que tais técnicas respondem adequadamente quando a relação entre as variáveis dependente e independente é proporcional.

\subsubsection{Transformação logarítmica das variáveis}

A análise da distribuição das variáveis de estudo indicou forte assimetria positiva ("skewness") e comportamento exponencial, duas características que Hair $(2005$, p. 81) diagnostica como decisoras à adoção de transformação logarítmica para melhoria da simetria e linearização das variáveis do estudo.

A Figura 5 apresenta, como caso característico, o resultado da transformação da variável V201 da sub-amostra das empresas com RO positivo no seu valor correspondente ao logaritmo natural ou neperiano. Graficamente se percebe a melhoria na normalidade, seja pelo histograma da distribuição com formato simétrico ou pelo gráfico Normal Q-Q, no qual a normalidade é tanto mais significativa quanto mais a distribuição está aderente à reta de referência de $45 \%$ de inclinação. Matematicamente, no caso exemplificado, o resultado do teste de normalidade de KolmogorovSmirnov da variável original obteve um Sig igual a $0,0 \%$ e o da variável transformada resultou em Sig igual a 1,2\%, uma melhora, entretanto, abaixo do mínimo desejável de 5,0\% para ser considerada uma Distribuição Normal ao nível da significância estatística adotada nesse trabalho.

Freqüentemente, os grupos de medidas que têm valores originais maiores costumam ter uma variabilidade maior e, nesse caso, essa transformação reduz essa variabilidade fazendo com que a 
variância ao longo dos grupos seja também reduzida, melhorando o nível de homocedasticidade e a resposta do modelo estatístico ao fenômeno estudado.
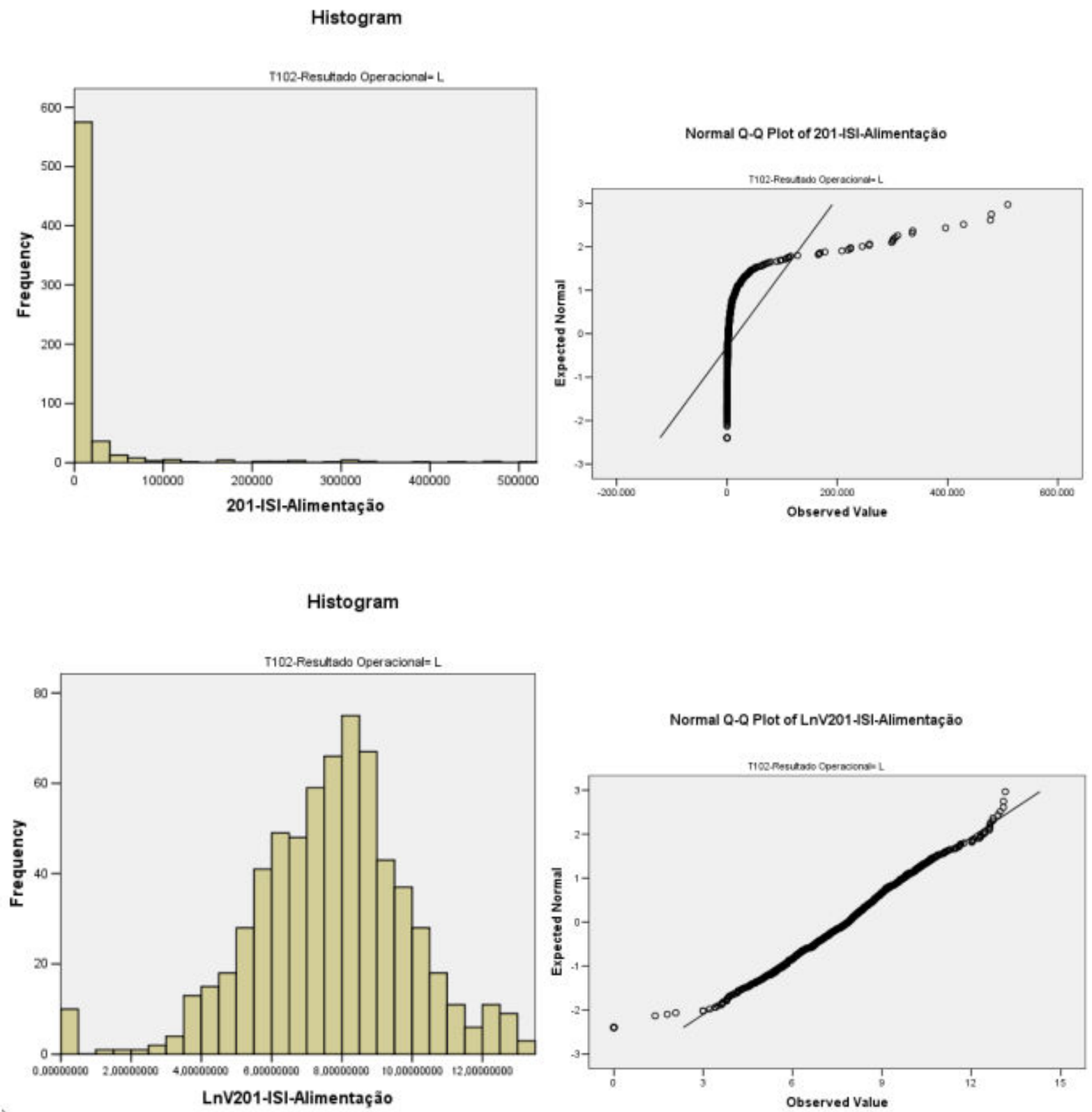

Figura 5 - Exemplo do resultado da transformação logarítmica da variável V201 (antes/ depois)

A transformação logarítmica é aplicável somente onde os valores assumidos pelas variáveis sejam maiores que zero. No caso do presente estudo algumas variáveis assumiram valores zero e também 
negativos. Para que a transformação pudesse ser efetivada, algumas aproximações práticas foram utilizadas:

Aproximação 1: Valores zero para as variáveis do presente estudo ocorreram principalmente nos investimentos em RSE quando algumas ações sociais não foram desenvolvidas. Nesses casos, o autor atribuíu um investimento de valor unitário. Essa aproximação não cria grande distorção, pois a amostra demonstra que as empresas que efetivamente investiram o fizeram com valores acima desse limite prático. Não foram encontrados casos onde o RO tenha sido zero e, portanto, essa aproximação não precisou ser adotada, ainda que o mesmo critério dos investimentos em RSE pudesse ter sido utilizado nesse caso.

Aproximação 2: No caso de RO negativo, quando a empresa teve prejuízo na sua operação, não é possível a aplicação direta do logaritmo, já que essa função matemática não está definida para valores negativos. Nesse caso, o autor definiu como regra dessa transformação, que o valor do logaritmo se refere ao módulo do valor da variável V102, que representa o RO. Dessa forma, os valores obtidos da transformação passaram a representar um comportamento linear em toda a faixa de valores possíveis para essas variáveis, sejam em situação de prejuízo ou de lucro.

Em resumo, as equações de transformação utilizadas foram:

\section{LnVnnn $=\ln ($ Vnnn $)$ para valores positivos de Vnnn}

\section{LnVnnn $=0$ para valor de $\operatorname{Vnnn}=0$}

\section{LnVnnn = -In(-Vnnn) para valores negativos de Vnnn}

Onde Vnnn é a variável original do BS padrão IBASE e também se aplicam às variáveis adicionais e transformadas mencionadas nas Tabelas 1 a 4 e 11.

A Tabela 13 resume a denominação codificada de todas as variáveis transformadas log natural do estudo. 
Tabela 13 - Variáveis transformadas log natural

\begin{tabular}{l|c}
\hline \multicolumn{1}{c|}{ Justificativa } & Código da variável \\
\hline Ln (Vnnn) & LnVnnn \\
\hline Ln (RLVnnn) & LnRLVnnn \\
\hline Ln (RSE_Total) & LnRSE_Total \\
\hline Ln (RSE_Voluntario) & LnRSE_Voluntario \\
\hline Ln (R_RSE_Total) & LnR_RSE_Total \\
\hline Ln (R_RSE_Voluntario) & LnR_RSE_Voluntario \\
\hline
\end{tabular}

A transformação log natural melhorou a simetria das variáveis escala da razão dos modelos, ainda que os testes de normalidade Kolmogorov-Smirnov e Shapiro-Wilk tenham identificado poucas variáveis com Distribuição Normal no nível de significância de 5,0\%. O Anexo 7.3 (Teste de normalidade das variáveis escala razão) apresenta os resultados do teste de normalidade das variáveis escala razão utilizadas nos modelos. Na análise gráfica utilizando as representações Normal Q-Q se observa um comportamento qualitativamente mais normal comparativamente às variáveis originais do BS, como exemplificado na Figura 5.

\subsubsection{Análise dos "dados perdidos" (missings)}

A análise dos "dados perdidos", mais conhecidos pelo termo técnico missings e como tal referenciados daqui em diante, são informações não disponíveis, normalmente não fornecidas pelos respondentes, ou dados considerados inválidos como, por exemplo, valores negativos para variáveis que devem ser somente positivas ou uma opção de resposta inexistente dentro da amostra.

O problema da existência dos missings é que, em análises multivariadas, a presença de um deles na lista das variáveis de análise pode eliminar aquela observação como um todo, podendo prejudicar as análises pela pequena quantidade de casos válidos remanescentes na amostra. Nesse caso, Hair (2005, p. 61) sugere vários procedimentos e alternativas para minimizar ou contornar essa situação indesejável. A decisão se baseia na análise dos ganhos e perdas em se eliminar a variável que tenha um comportamento dos missings considerado crítico ou substituí-los por valores atribuídos segundo critérios estatísticos. A quantidade de casos válidos dentro da amostra da pesquisa sugere a não utilização de técnicas de atribuição de valor para os missings. 
As quantidades de casos presentes no estudo refletem também o trabalho de validação das informações dos BSs padrão IBASE publicados e disponíveis nos sites da Internet do IBASE e das próprias empresas. $\mathrm{O}$ autor cruzou informações do BS e encontrou algumas com erros evidentes. Aquelas que não puderam ser recuperadas com o uso de informações adicionais obtidas em contatos com as próprias empresas, foram consideradas como missings e retiradas da amostra final.

A Tabela 14 apresenta o sumário da quantidade de casos do banco de dados das variáveis selecionadas para os modelos da pesquisa.

Tabela 14 - Sumário dos casos para variáveis dependentes e independentes do modelo (2000-2004)

\begin{tabular}{|c|c|c|c|c|}
\hline \multirow{2}{*}{$\begin{array}{l}\text { Variáveis Dependentes e Independentes do } \\
\text { modelo da pesquisa }\end{array}$} & \multicolumn{2}{|c|}{ Casos Válidos } & \multicolumn{2}{|c|}{ Missing } \\
\hline & $\mathbf{N}$ & $\%$ & $\mathbf{N}$ & $\%$ \\
\hline Ano & 897 & $100,0 \%$ & 0 & $0,0 \%$ \\
\hline Cod.Setor & 891 & $99,3 \%$ & 6 & $0,7 \%$ \\
\hline 101-Receita Líquida & 879 & $98,0 \%$ & 18 & $2,0 \%$ \\
\hline 102-Resultado Operacional & 842 & $93,9 \%$ & 55 & $6,1 \%$ \\
\hline 103-Folha de Pagamento Bruta & 882 & $98,3 \%$ & 15 & $1,7 \%$ \\
\hline 201-ISI-Alimentação & 894 & $99,7 \%$ & 3 & $0,3 \%$ \\
\hline 202-ISI-Encargos sociais compulsórios & 894 & $99,7 \%$ & 3 & $0,3 \%$ \\
\hline 203-ISI-Previdência privada & 894 & $99,7 \%$ & 3 & $0,3 \%$ \\
\hline 204-ISI-Saúde & 894 & $99,7 \%$ & 3 & $0,3 \%$ \\
\hline 205-ISI-Segurança e medicina trabalho & 894 & $99,7 \%$ & 3 & $0,3 \%$ \\
\hline 206-ISI-Educação & 894 & $99,7 \%$ & 3 & $0,3 \%$ \\
\hline 207-ISI-Cultura & 894 & $99,7 \%$ & 3 & $0,3 \%$ \\
\hline 208-ISI-Capacitação e desenv. profiss. & 894 & $99,7 \%$ & 3 & $0,3 \%$ \\
\hline 209-ISI-Creches ou auxílio-creche & 894 & $99,7 \%$ & 3 & $0,3 \%$ \\
\hline 210-ISI-Participação lucros/resultados & 894 & $99,7 \%$ & 3 & $0,3 \%$ \\
\hline 211-ISI-Outros & 894 & $99,7 \%$ & 3 & $0,3 \%$ \\
\hline 213-ISI-Total com compulsório & 894 & $99,7 \%$ & 3 & $0,3 \%$ \\
\hline 214-ISI-Total sem compulsorio & 894 & $99,7 \%$ & 3 & $0,3 \%$ \\
\hline 301-ISE-Educação & 852 & $95,0 \%$ & 45 & $5,0 \%$ \\
\hline 302-ISE-Cultura & 852 & $95,0 \%$ & 45 & $5,0 \%$ \\
\hline 303-ISE-Saúde e saneamento & 852 & $95,0 \%$ & 45 & $5,0 \%$ \\
\hline 304-ISE-Habitação & 852 & $95,0 \%$ & 45 & $5,0 \%$ \\
\hline 305-ISE-Esporte & 852 & $95,0 \%$ & 45 & $5,0 \%$ \\
\hline 306-ISE-Lazer e diversão & 852 & $95,0 \%$ & 45 & $5,0 \%$ \\
\hline 307-ISE-Creches & 852 & $95,0 \%$ & 45 & $5,0 \%$ \\
\hline 308-ISE-Alimentação & 852 & $95,0 \%$ & 45 & $5,0 \%$ \\
\hline 309-ISE-Combate fome... & 852 & $95,0 \%$ & 45 & $5,0 \%$ \\
\hline 310-ISE-Outros & 854 & $95,2 \%$ & 43 & $4,8 \%$ \\
\hline 311-ISE-Agregados & 855 & $95,3 \%$ & 42 & $4,7 \%$ \\
\hline 312-ISE-Total sem compulsório & 855 & $95,3 \%$ & 42 & $4,7 \%$ \\
\hline 313-Tributos (excluídos encargos sociais) & 854 & $95,2 \%$ & 43 & $4,8 \%$ \\
\hline 314-ISE-Total com compulsório & 854 & $95,2 \%$ & 43 & $4,8 \%$ \\
\hline 401-IA-Invest relacionados prod/operação & 809 & $90,2 \%$ & 88 & $9,8 \%$ \\
\hline 402-IA-Invest programas \& proj. externos & 809 & $90,2 \%$ & 88 & $9,8 \%$ \\
\hline 403-IA-Agregado & 810 & $90,3 \%$ & 87 & $9,7 \%$ \\
\hline 404-IA-Total & 809 & $90,2 \%$ & 88 & $9,8 \%$ \\
\hline
\end{tabular}


A Tabela 15 apresenta a quantidade de casos referentes às variáveis das séries 500 e 600 , respectivamente "Indicadores do Corpo Funcional" e "Exercício da Cidadania Empresarial", que foram desconsideradas nesse trabalho que ficou focado nos valores financeiros do BS. Como resultado dessa estratégia, maximizou-se a quantidade de casos úteis da amostra, pois essas séries têm elevada quantidade de missings e também se delineou um modelo mais parcimonioso em termos de quantidade das variáveis presentes.

Tabela 15 - Sumário dos casos para variáveis que não foram selecionadas para o modelo (2000-2004)

\begin{tabular}{|c|c|c|c|c|}
\hline \multirow{3}{*}{$\begin{array}{l}\text { Variáveis que não foram selecionadas para } \\
\text { compor o modelo da pesquisa }\end{array}$} & \multicolumn{4}{|c|}{ Casos } \\
\hline & \multicolumn{2}{|c|}{ Válidos } & \multicolumn{2}{|c|}{ Missing } \\
\hline & $\mathbf{N}$ & $\%$ & $\mathbf{N}$ & $\%$ \\
\hline 501-N $\mathrm{N}^{\mathrm{o}}$ de empregados em dezembro & 845 & $94,2 \%$ & 52 & $5,8 \%$ \\
\hline 502- $\mathrm{N}^{\mathrm{o}}$ admissões no período & 793 & $88,4 \%$ & 104 & $11,6 \%$ \\
\hline 503-No empregados terceirizados & 614 & $68,5 \%$ & 283 & $31,5 \%$ \\
\hline 504-N ${ }^{\circ}$ estagiários & 520 & $58,0 \%$ & 377 & $42,0 \%$ \\
\hline $505-\mathrm{N}^{\circ}$ empregados acima 45 anos & 697 & $77,7 \%$ & 200 & $22,3 \%$ \\
\hline $506-\mathrm{N}^{\mathrm{o}}$ mulheres na empresa & 751 & $83,7 \%$ & 146 & $16,3 \%$ \\
\hline $507-\%$ cargos chefia por mulheres & 672 & $74,9 \%$ & 225 & $25,1 \%$ \\
\hline $508-\mathrm{N}^{\circ}$ negros na empresa & 493 & $55,0 \%$ & 404 & $45,0 \%$ \\
\hline $509-\%$ cargos chefia por negros & 367 & $40,9 \%$ & 530 & $59,1 \%$ \\
\hline $510-\mathrm{N}^{\circ}$ portadores deficiência & 603 & $67,2 \%$ & 294 & $32,8 \%$ \\
\hline 601-Relação maior e menor remuneração & 453 & $50,5 \%$ & 444 & $49,5 \%$ \\
\hline 602-Total acidentes de trabalho & 456 & $50,8 \%$ & 441 & $49,2 \%$ \\
\hline 603-Projetos sociais ambientais definidos por & 511 & $57,0 \%$ & 386 & $43,0 \%$ \\
\hline 604-Padrões de segurança definidos por & 508 & $56,6 \%$ & 389 & $43,4 \%$ \\
\hline 605-Liberdade sindical, negociação coletiva & 335 & $37,3 \%$ & 562 & $62,7 \%$ \\
\hline 606-Previdência privada contempla & 325 & $36,2 \%$ & 572 & $63,8 \%$ \\
\hline 607-Participação lucros/ resultados & 445 & $49,6 \%$ & 452 & $50,4 \%$ \\
\hline 608-Seleção fornecedores padrões éticos e RS & 509 & $56,7 \%$ & 388 & $43,3 \%$ \\
\hline 609-Participação empregados trabalho voluntário & 523 & $58,3 \%$ & 374 & $41,7 \%$ \\
\hline $610-\mathrm{N}^{\circ}$ reclamações consumidores na empresa & 204 & $22,7 \%$ & 693 & $77,3 \%$ \\
\hline 611-Nº reclamações consumidores no Procon & 138 & $15,4 \%$ & 759 & $84,6 \%$ \\
\hline $612-\mathrm{N}^{\circ}$ reclamações consumidores na Justiça & 147 & $16,4 \%$ & 750 & $83,6 \%$ \\
\hline 613-\% de reclamações solucionadas na empresa & 212 & $23,6 \%$ & 685 & $76,4 \%$ \\
\hline 614-\% reclamações solucionadas Procon & 131 & $14,6 \%$ & 766 & $85,4 \%$ \\
\hline 615-\% reclamações solucionadas Justiça & 128 & $14,3 \%$ & 769 & $85,7 \%$ \\
\hline 616-DVA & 409 & $45,6 \%$ & 488 & $54,4 \%$ \\
\hline 617-DVA \% governo & 291 & $32,4 \%$ & 606 & $67,6 \%$ \\
\hline 618-DVA \% colaboradores & 291 & $32,4 \%$ & 606 & $67,6 \%$ \\
\hline 619-DVA \% acionistas & 291 & $32,4 \%$ & 606 & $67,6 \%$ \\
\hline 620 -DVA $\%$ terceiros & 291 & $32,4 \%$ & 606 & $67,6 \%$ \\
\hline $621-\mathrm{DVA} \%$ retido & 289 & $32,2 \%$ & 608 & $67,8 \%$ \\
\hline
\end{tabular}




\subsubsection{Deteção dos outliers}

A seguir são analisados os "dados com valores atípicos", mais conhecidos pelo termo técnico outliers e como tal referenciados daqui em diante. Outliers são observações notadamente diferentes das outras observações e podem ser categorizadas em duas classes: benéficas e problemáticas. Os outliers categorizados como benéficos são valores atípicos, porém indicativos de características da população e que não seriam descobertas no curso normal da análise. Os outliers categorizados como problemáticos não são representativos da população, são contrários aos objetivos da análise e podem distorcer os testes estatísticos.

A detecção dos outliers no presente estudo utilizou duas das metodologias citadas por Hair (2005, p. 72) e aplicáveis sobre varíaveis em escala razão: Multivariada e Univariada. O objetivo foi identificar os casos da amostra que poderiam ter distorcido um comportamento característico da população analisada. Essa condição se faz ainda mais relevante ao utilizar-se modelos lineares, pois nesse caso os outliers causam grande impacto na qualidade do resultado final.

Para permitir uma análise comparativa entre todos os modelos propostos no item 3.3.1 (Construção dos modelos estatísticos), os casos válidos da amostra considerados no processamento estatístico foram aqueles que satisfizeram as condições de aceitabilidade por todos os modelos, simultaneamente. Isso é, no curso da análise dos outliers que impactaram negativamente cada um dos modelos, os casos identificados como tal foram removidos da amostra.

\subsubsection{Deteção multivariada dos outliers}

A detecção multivariada de outlier utilizou a medida " $\mathrm{D}^{2}$ de Mahalanobis", também conhecida como "Distância de Mahalanobis". Ela é usada para medir as distâncias em um espaço multidimensional das observações a um ponto de referência, levando em consideração a correlação entre as variáveis e não somente a contribuição de cada variável de forma isolada, procedimento utilizado quando se considera o cálculo da distância euclidiana entre as observações (TAGUCHI e JUGULUM, 2002, p. 6). Adicionalmente, ela possui propriedades estatísticas que viabilizam testes de significância para estabelecimento do critério de corte para qualificação da observação como outlier. Hair (2005, p. 72 e 192) sugere que os testes estatísticos para significância da identificação 
de outliers devam ser bastante conservadores, não excedendo $0,1 \%$ para designação de um outlier. $\mathrm{O}$ teste de significância se baseia no valor $\mathrm{T}$ de Student calculado como $\mathrm{D}^{2} / \mathrm{df}$, onde $\mathrm{D}^{2}$ é a Distância de Mahalanobis de cada observação da amostra e df é o grau de liberdade que corresponde à quantidade de variáveis consideradas no cálculo de $\mathrm{D}^{2}$ e que deve ser comparado com o valor T de Student crítico.

Os modelos multivariados das séries B e C apresentados na Tabela 12 ensejaram a avaliação de outliers dentro dos critérios mencionados acima. Esses modelos tiveram 3, 24 ou 26 variáveis independentes e os respectivos valores $\mathrm{T}$ de Student críticos para decisão do enquadramento dos casos amostrais na categoria de outliers foram: 12,924, 3,745 e 3,707.

O Anexo 7.2 apresenta os valores de Distância de Mahalanobis e os correspondentes valores de T de Student calculados para cada um dos modelos das séries B e C da Tabela 12. A Tabela 16 apresenta os 26 casos considerados outliers por essa metodologia. Como esse método somente apresenta um índice agregado, que é a distância de Mahalanobis, não é possível identificar quais são as variáveis que contribuíram para sua definição como outlier; então, o autor cruzou os valores das distâncias de Mahalanobis com os de ZScore ${ }^{13}$, obtidos no método univariado, para identificar quais foram as variáveis individuais do modelo que mais estariam influenciando o valor de $\mathrm{D}^{2}$. Nesse caso, foram considerados somente os valores de ZScore superiores a 3,5. Esse é um critério aproximado, pois ele não considera a correlação entre as variáveis, que é um efeito tratado na Distância de Mahalanobis; entretanto, como estão consideradas as variáveis com ZScore detentoras de valores elevados, é correto supor, no mínimo, que elas são relevantes para o distanciamento calculado. A conveniência do uso do método multivariado associado ao univariado é o de identificar as variáveis que mais influenciaram a distância de Malahanobis e, portanto, poder classificar o outlier em benéfico ou problemático. Nenhum dos casos de outliers identificados foram classificados como problemático, pois eles se referiram somente a ações sociais que foram prestigiadas com investimentos mais elevados, denotando um comportamento diferenciado das demais empresas e caracterizando uma estratégia particularizada quanto aos investimentos em RSE e, portanto, um comportamento que pode ser analisado em estudos de casos, mas pouco adequado na análise selecionada nesse estudo.

\footnotetext{
${ }^{13}$ ZScore: veja a definição desse conceito no item 3.4.4.2 (Deteção univariada dos outliers).
} 
Notar que as variáveis que mais contribuíram para os casos outliers apresentados na Tabela 16 se referem à série 300 (54 das 71 variáveis identificadas), que são os Indicadores Sociais Externos. Também, nota-se uma maior incidência de variáveis dessensibilizadas do porte das empresas, identificadas como LnRLVnnn (52 casos), como possíveis causadoras da condição de outlier em relação às variáveis originais (19 casos), isso é, as variáveis dessensibilizadas apresentaram maior variabilidade que as variáveis originais.

Tabela 16 - Outliers pela deteção multivariada da Distância de Mahalanobis

\begin{tabular}{|c|c|c|c|}
\hline Caso & Razão Social & Ano & $\begin{array}{l}\text { Variáveis que podem ter influenciado a } \\
\text { distância de Mahalanobis }\end{array}$ \\
\hline 19 & AES Sul Dist Gaúcha de Energia & 2001 & LnRLV306, LnRLV308 \\
\hline 66 & Banco Itaú & 2001 & $\begin{array}{l}\text { LnRLV305, LnRLV306, LnRLV307, } \\
\text { LnRLV308 }\end{array}$ \\
\hline 67 & Banco Itaú & 2002 & LnRLV207, LnRLV308 \\
\hline 69 & Banco Itaú & 2004 & LnRLV306, LnRLV307 \\
\hline 79 & Bandeirante Energia & 2003 & LnRLV305, LnRLV308, LnRLV402 \\
\hline 93 & Belgo Mineira (Empresas Belgo Mineira) & 2000 & $\begin{array}{l}\text { LnRLV304, LnRLV306, LnRLV307, } \\
\text { LnRLV308 }\end{array}$ \\
\hline 94 & Belgo Mineira (Empresas Belgo Mineira) & 2001 & $\begin{array}{l}\text { LnRLV304, LnRLV306, LnRLV307, } \\
\text { LnRLV308 }\end{array}$ \\
\hline 139 & Camargo Corrêa & 2002 & LnV307 \\
\hline 141 & Camargo Corrêa & 2004 & LnRLV307, LnRLV308 \\
\hline 238 & CHESF - Cia Hidro Elétrica do SFrancisco & 2002 & LnV304, LnRLV206, LnRLV305 \\
\hline 239 & CHESF - Cia Hidro Elétrica do SFrancisco & 2003 & LnV304, LnRLV206, LnRLV304 \\
\hline 280 & Coelba & 2001 & LnRLV306, LnRLV307, LnRLV308 \\
\hline 296 & Copel - Cia Paranaense de Energia Elétrica & 2000 & LnV304 \\
\hline 297 & Copel - Cia Paranaense de Energia Elétrica & 2001 & LnV306 \\
\hline 298 & Copel - Cia Paranaense de Energia Elétrica & 2002 & LnV207, LnV304 \\
\hline 362 & DuPont & 2003 & $\begin{array}{l}\text { LnRLV202, LnRLV203, LnRLV204, } \\
\text { LnRLV205, LnRLV206, LnRLV210, } \\
\text { LnRLV213, LnRLV214, LnRLV301, } \\
\text { LnRLV313, LnRLV314, LnRLV402 }\end{array}$ \\
\hline 372 & ECT Nacional & 2000 & LnV207, LnV308 \\
\hline 415 & $\begin{array}{l}\text { Eletropaulo Metropolitana Eletricidade São } \\
\text { Paulo }\end{array}$ & 2003 & LnV307, LnV308 \\
\hline 430 & Embraer & 2004 & LnRLV304 \\
\hline 521 & Grupo Pão de Açúcar & 2000 & LnV306, LnV307, LnV308 \\
\hline 581 & Itausa & 2004 & LnRLV306, LnRLV307, LnRLV308 \\
\hline 676 & Perdigão & 2000 & LnV204 \\
\hline 677 & Perdigão & 2001 & LnV204 \\
\hline 826 & Unibanco & 2001 & LnV306, LnV307, LnV308 \\
\hline 881 & Votorantim Celulose e Papel & 2000 & LnRLV304, LnRLV307, LnRLV308 \\
\hline 882 & Votorantim Celulose e Papel & 2001 & LnRLV302, LnRLV307, LnRLV308 \\
\hline
\end{tabular}

\subsubsection{Deteção univariada dos outliers}

A detecção univariada de outliers utilizou os valores dos dados de cada variável individualmente convertidos em escores padronizados, denominado como ZScore : 


\section{Zscore $=($ Valor da variável - Média $) /$ Desvio Padrão}

As propriedades do ZScore são ter média de valor zero e desvio padrão de valor 1. Hair (2005, p. 72) indica que, para amostras de tamanho pequeno ( 80 observações ou menos) as diretrizes sugerem identificar os casos com Zscore acima de 2,5 como outliers. No caso de grandes amostras, no qual se enquadra a amostra sob estudo, as diretrizes sugerem o valor de corte de Zscore entre 3 e 4 . O autor optou por considerar outlier os casos nos quais o ZScore é maior que 4, pois acredita que não devam ser retiradas todas as condições desfavoráveis ao extremo sob pena de permanecer na amostra uma condição muito particularizada que irá resultar em um modelo super-ajustado, o que contradiz o comportamento no ambiente real.

Esse método de deteção foi utilizado para a variável dependente e as independentes escala razão dos modelos univariados correspondentes à série $\mathrm{A}$ apresentadas na Tabela 12, a saber: LnV102, LnRLV102, LnRSE_Voluntario, LnRSE_Total, LnR_RSE_Voluntario e LnR_RSE_Total.

A Tabela 17 apresenta as duas únicas observações consideradas outlier univariado e as variáveis causadoras dessa condição.

Tabela 17 - Outliers pela deteção univariada

\begin{tabular}{c|l|c|l}
\hline Caso & \multicolumn{1}{|c|}{ Razão Social } & Ano & Variáveis que podem ter influenciado o valor do ZScore \\
\hline 362 & DuPont & 2003 & LnR_RSE_Voluntario, LnR_RSE_Total \\
\hline 541 & Hospital Mater Dei & 2003 & LnR_RSE_Voluntario \\
\hline
\end{tabular}

\subsubsection{Deteção dos outliers "comportamentais"}

Além dos processos de identificação dos outliers baseado na Distância de Mahalanobis e ZScore, o autor analisou o comportamento dos grupos de empresas e identificou que, no setor financeiro, o Banco do Nordeste do Brasil foi a única empresa que relatou RO negativo em seu BS de 2003. Esse comportamento singular dentro do setor sugere a sua remoção da amostra para evitar que esse caso venha a constituir um agrupamento com um único elemento. $\mathrm{O}$ autor decidiu remover também o BS referente ao ano 2002 por considerar que a empresa poderia estar sujeita a algum comportamento característico da situação de 2003, podendo representar um viés no comportamento do modelo. 
Durante a análise dos modelos representando as empresas com RO positivo foi detetada heterocedasticidade em alguns modelos. $\mathrm{O}$ item 4.1.7 (Análise dos modelos referentes às empresas que operaram com lucro) detalha a análise e identifica os cinco casos que estavam acarretando tal comportamento e justificativas de sua remoção da amostra.

A Tabela 18 resume os outliers "comportamentais" que foram identificados e retirados da amostra.

Tabela 18 - Casos de outliers "comportamentais" retirados da amostra

\begin{tabular}{c|l|c}
\hline Amostra & \multicolumn{1}{|c|}{ Razão Social } & Ano \\
\hline 42 & Bahia Sul Celulose & 2000 \\
\hline 56 & Banco do Brasil & 2000 \\
\hline 61 & Banco do Nordeste do Brasil & 2002 \\
\hline 62 & Banco do Nordeste do Brasil & 2003 \\
\hline 142 & Cambará Produtos Florestais & 2000 \\
\hline 263 & Suzano de Papel e Celulose & 2000 \\
\hline 660 & Orsa Celulose, Papel e Embalagens & 2000 \\
\hline
\end{tabular}

No total foram identificados e removidos 35 casos da amostra.

\subsection{Estratégia de seleção das ferramentas estatísticas}

O autor elegeu a técnica de modelos lineares de análise de variância, opção denominada GLM -

General Linear Model na ferramenta SPSS $^{14}$, pela conveniência dela tratar simultaneamente as análises de variância (ANOVA) e co-variância (ANCOVA), posto que existe uma única variável dependente, escala razão, que é o desempenho financeiro da empresa e variáveis independentes em escala razão e categóricas.

Buscou-se identificar quais variáveis representando as diversas ações em RSE, traduzidas em investimentos, conseguiam explicar a variação do desempenho financeiro e, concomitantemente, investigar a existência da influência dos fatores como o porte das empresas, a conjuntura ecnômica

\footnotetext{
${ }^{14}$ A técnica de Regressão Logística Binária seria a escolha natural por ser uma técnica menos exigente em termos de normalidade, visto que as variáveis não apresentaram Sig superior a 5,0\% nos testes de normalidade, entretanto, os resultados obtidos foram pouco relevantes para os objetivos do estudo porque o percentual de acerto do modelo em identificar a relação entre desempenho financeiro e investimentos em RSE foi muito baixo e essa técnica foi abandonada em favor do modelo linear que teve melhor resultado.
} 
e social que pudesse ser captada na variável "Ano" em que foi publicado o BS e o Setor de atuação da empresa. A conveniência do tratamento selecionado permitiu a utilização dos investimentos ao longo de um período de tempo sem a necessidade de aplicação de fatores de correção monetária (deflatores) nas variáveis financeiras do modelo ${ }^{15}$.

\subsection{Limitações da Pesquisa}

Esse estudo, como qualquer outro de investigação científica, carrega algumas limitações. É importante que elas sejam destacadas para que a análise dos dados e as suas conclusões sejam feitas diante do devido contexto.

As limitações da pesquisa estão apresentadas nesse ponto do estudo, pois, em vista dos resultados bastante significativos obtidos na análise matemática, o autor deseja enfatizar os aspectos tratados na construção do modelo e as implicações sociais que normalmente permeiam os trabalhos analisados na revisão bibliográfica.

O construto utilizado não permite avaliar os elementos internos da RSE preconizados por Carrol (1991, p. 39) quanto às responsabilidades econômica, legal, ética e filantrópica, pois foca unicamente a materialização da estratégia empresarial refletida nos investimentos em RSE, sejam esses voluntários ou compulsórios. Dessa feita, não se busca avaliar os benefícios sociais resultantes dos investimentos declarados pelas empresas em seus BSs e seus reflexos no desempenho financeiro das mesmas. A pesquisa também não considerou os efeitos dos investimentos em projetos sociais sobre as comunidades beneficiárias dos mesmos, isso é, não foi considerado o valor agregado aos stakeholders decorrente dos investimentos financeiros de RSE.

\footnotetext{
15 Durante a fase de análise preliminar dos dados, o autor efetuou estudos considerando os valores financeiros da amostra deflacionados de acordo com os índices de correção monetária IGP-DI, IGP-M e IPCA e considerou os resultados insatisfatórios para responder as perguntas da pesquisa. Outra abordagem também explorada foi o estudo da evolução dos investimentos ao longo dos anos buscando encontrar algum comportamento que pudesse captar um índice que refletisse um possível fator de correção monetária vinculado às verbas de RSE. Entretanto, os resultados não tiveram significância estatística e tampouco refletiram valores que tivessem alguma possível explicação comportamental generalizado por parte das empresas participantes da amostra. $\mathrm{O}$ autor acredita que a estratégia analítica selecionada para o presente estudo prescinde da necessidade de correção monetária, pois a variável Ano, presente no modelo, já é suficiente para isso.
} 
O modelo utilizado, ao confrontar desempenho financeiro somente com os investimentos em RSE, deixou de considerar os demais aspectos que também têm forte influência tais como processos operacionais, estratégia comercial, política de recursos humanos e estratégia de relacionamento com os clientes, para citar alguns deles.

Foram consideradas somente empresas que produzem bens ou serviços e, portanto, não se incluem as organizações do Terceiro Setor diretamente, ainda que se saiba que algumas das empresas focalizadas na pesquisa possam ter atuado em parceria com aquelas.

A pesquisa não considerou a conseqüência, entendida como inevitável, da ampliação do poder das empresas ao assumirem causas sociais, decorrentes das dificuldades do Estado como mantenedor das necessidades básicas do cidadão. Essa situação faz com que as empresas deixem de ser apenas produtoras de bens e serviços e passem a influenciar e participar diretamente em outras dimensões sociais, eventualmente transformando-se em instituições com grande influência política e social, conforme foi abordado por Schroeder e Schroeder (2004, p. 5). Não foi considerado qualquer limite sobre o nível de responsabilidade ou grau de influência das empresas sobre a sociedade.

A amostra contém somente as empresas que de certa forma já consideram a RSE como um fator de destaque em sua estratégia empresarial e social e, apesar de conter empresas lucrativas e não lucrativas, não é possível aquilatar se o desempenho financeiro é afetado pela estratégia de RSE, isso é, o autor não identifica a possibilidade de criação de um grupo de controle composto por empresas que não tenham qualquer preocupação com a RSE que possa servir de referência a essa comparação.

A amostra foi coletada de maneira intencional por meio da análise dos BSs publicados no período do estudo e a quantidade de empresas é um percentual bastante reduzido em relação à totalidade nacional. Por este motivo não se pode generalizar os resultados para o universo das empresas brasileiras socialmente engajadas. Todavia, há de se considerar que muitas delas são reconhecidas pela sociedade como relevantes do ponto de vista empresarial e também social e, portanto, a amostra tem potencial para estudos futuros com circunscrições temáticas mais focalizadas.

A decisão por limitar as variáveis independentes àquelas representativas de investimentos financeiros se deve ao fato de existirem muitas variáveis dentro do BS que não preencheram as 
condições técnicas para a aplicação das ferramentas estatísticas selecionadas, isso é, algumas variáveis foram excluídas, por exemplo, em função da existência de missings excessivos que comprometem a quantidade de casos úteis da amostra. Tal premissa, eventualmente, pode ter expurgado importantes variáveis explicativas do fenômeno.

Finalmente, se reforça o escopo da pesquisa que é a determinação das variáveis significativas em explicar a variância do desempenho financeiro nos vários aspectos propostos e não se a forma de dependência dessa relação é positiva ou negativa ou a determinação de um modelo explicativo para o fenômeno. É importante destacar que, além da análise do nível de significância, o estudo destaca também o nível de relevância das variáveis, no qual relevância significa o poder explicativo da variável independente à variância do resultado financeiro ${ }^{16}$.

${ }^{16}$ Significância versus Relevância: uma variável significativa representa que ela tem comportamento adequado à resposta do modelo ao nível de significância estatística estabelecido. Entretanto, esse efeito pode ser de pequena ou grande monta e aí o fator relevância irá indicar se é uma variável que tem forte poder explicativo ou não, e nesse caso, sua influência é tênue e eventualmente de pouca utilidade prática. De forma oposta, uma variável pode não ser significativa, pois tem comportamento que não pode ser representado no modelo como, por exemplo, um comportamento aleatório, mas pode ser de grande relevância e ter grande peso no fenômeno. A presente investigação procurou incluir comentários sobre a relevância do poder explicativo somente nos casos de existência de significância estatística. 


\section{APRESENTAÇÃO DOS RESULTADOS}

Ultrapassada a etapa de exame e preparação dos dados do item 3.4 (Exame dos Dados Coletados), este item analisará os dados utilizando os modelos matemáticos definidos e, ao final, responderá as questões da pesquisa apresentadas no item 1.4 (Questões da pesquisa).

A análise exploratória deste estudo se baseou em uma conduta sistematizada e abrangente fundamentada na segmentação em quatro cenários distintos obtidos da combinação do fator Porte da empresa e natureza voluntária ou compulsória dos investimentos em RSE, conforme já detalhado no item 3.3.2 (As variáveis do modelo da pesquisa).

Para cada cenário foram analisados: i) os modelos agregados que contêm os investimentos em RSE em um único valor total. $\mathrm{O}$ objetivo foi verificar a existência de correlação significativa entre o investimento total em RSE e o Resultado Operacional (RO); ii) os modelos que consideraram os investimentos em RSE segmentados e totalizados por natureza dos investimentos, isso é, foram considerados os totais referentes aos investimentos em Indicadores Sociais Internos (ISI), focados nos recursos humanos da empresa e seus dependentes, aos Indicadores Sociais Externos (ISE) focados nas ações sociais à comunidade e aos Indicadores Ambientais (IA), focados nos investimentos em meio ambiente e sustentabilidade tanto internos quanto externos à empresa como, por exemplo, programas de melhoria da produção com redução de uso de insumos, redução de poluição, educação voltada à sustentabilidade ou em programas semelhantes na comunidade; iii) os modelos detalhados que identificaram as ações correspondentes a cada um dos programas em RSE preconizados pelo BS padrão IBASE e que estão detalhados no item 1.5.2 (O Balanço Social padrão IBASE); iv) a última segmentação se refere ao RO, na qual o estudo separa as empresas em dois grupos, o das empresas que apresentaram RO negativo e o das empresas com RO positivo no ano de publicação de seu BS.

Não foi possível a definição de um único modelo matemático aplicável para todos os valores de RO, visto que a análise gráfica efetuada no item 3.4 (Exame dos Dados Coletados) demonstrou que a função não é contínua e tem comportamento diferente nas regiões de lucro e prejuízo. Isso já era esperado, pois não existem valores de investimento negativo para que matematicamente a função pudesse ter uma solução única. Ademais, por entender que empresas que operam na região de RO positivo tendem a ter estratégias empresariais diferentes daquelas que operam com RO negativo, o 
autor estabeleceu na sua linha de investigação que cada um desses dois grupos de empresas seria tratado individualmente.

A Figura 6 esquematiza as 24 visões propostas. A última coluna à direita na figura contém o nomecódigo do modelo correspondente a cada uma delas e que será utilizado como referência no trabalho.

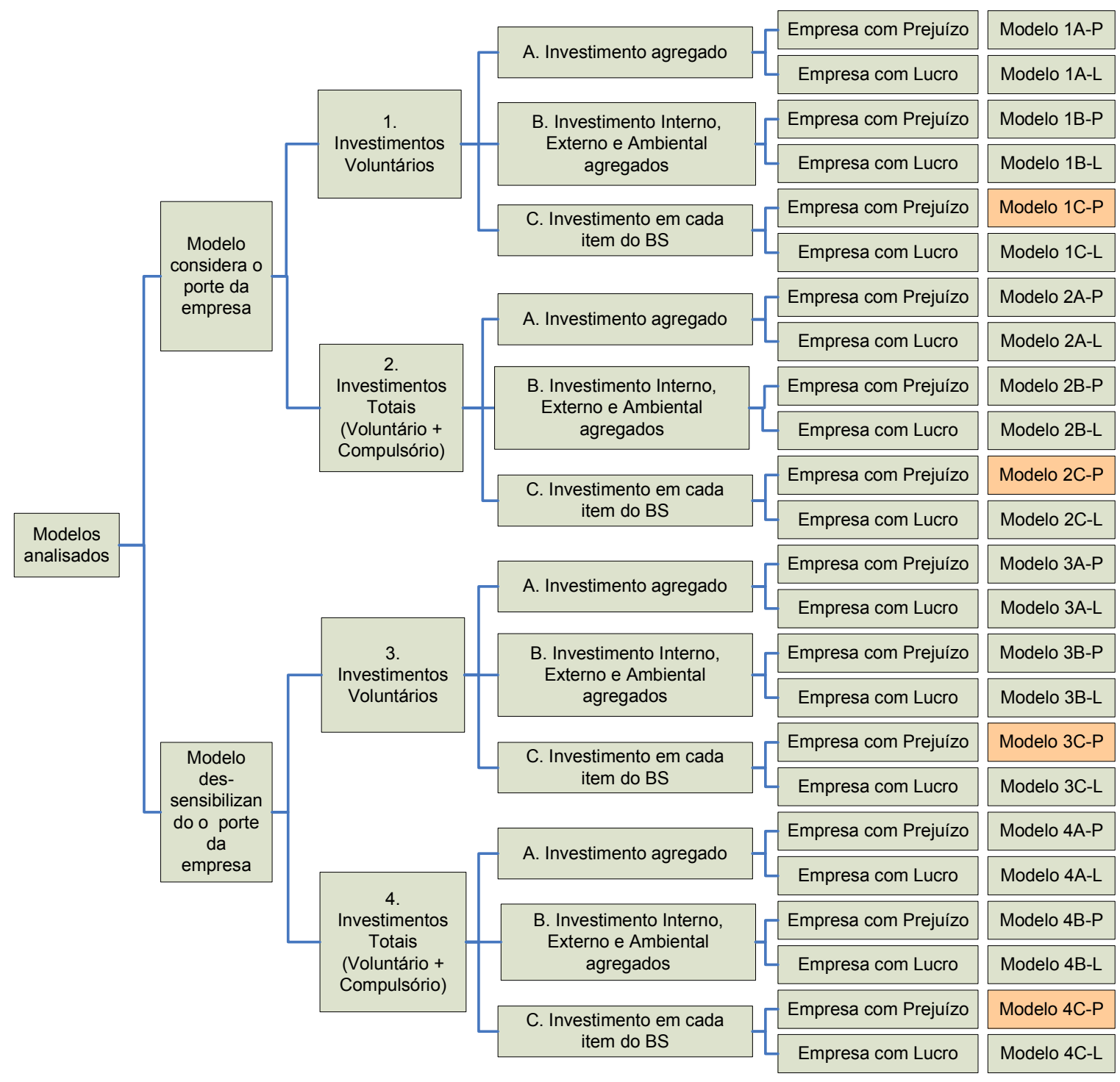

Figura 6 - Modelos GLM propostos

Hair (2005, p. 286) faz referência à quantidade de covariáveis a serem acrescentadas no modelo estatístico, recomendando uma norma prática que a limita ao valor de [(0,10 x tamanho da amostra) 
- (número de grupos - 1)], pois um número grande de variáveis reduz a eficiência estatística dos procedimentos. A análise da sub-amostra das empresas lucrativas, com 25 agrupamentos (5 setores nos 5 anos do estudo) e 691 casos amostrais, atende o limite sugerido; entretanto, a sub-amostra das empresas com prejuízo, com 20 agrupamentos (4 setores, pois o setor bancário não se fez presente nos 5 anos do estudo) e 147 casos na amostra, não é suficiente para atender o modelo detalhado que considera as 26 variáveis do BS padrão IBASE. Por conta disso, dos 24 modelos propostos inicialmente, os modelos 1C-P, 2C-P, 3C-P e 4C-P não foram considerados no presente estudo, mas ficaram aqui registrados para uso futuro, quando a quantidade de casos vier a atender o requisito técnico mencionado. Os modelos 1B-P, 2B-P, 3B-P e 4B-P serão avaliados condicionalmente, pois, apesar de não atenderem integralmente o requisito, que nesse caso demandaria ao menos 220 casos amostrais, essa etapa do estudo ainda tem caráter exploratório e não se pretende obter modelos explicativos. Assim, tal limite mínimo pode ser flexibilizado.

\subsection{Operacionalização da análise GLM}

A análise GLM dos 24 modelos foi dividida em 4 segmentos numerados de 1 a 4 , cada um pertencente a um ramo da Figura 6. Cada ramo foi analisado em três etapas identificadas com A, B e C, começando da análise do investimento em RSE agregado em uma única variável de investimento (letra A). Na sequência, a análise considerou os valores agregados por natureza do investimento em RSE e referentes aos Indicadores Sociais Internos, Externos e Ambientais (letra B). Na última etapa, a análise considerou cada investimento em RSE de acordo com as variáveis do BS padrão IBASE (letra C). O objetivo foi partir do geral ao detalhado em termos de investimentos em RSE e, dessa feita, procurar perceber o comportamento empresarial referente ao processo decisório sobre os investimentos em RSE.

O nível de significância utilizado nas análises estatísticas foi definido pelo autor em 5,0\%.

Primeiramente foi analisada a sub-amostra referente às empresas com RO negativo em cada um dos modelos previstos e finalizada com um item de conclusão detalhado. A seguir, foi explorada a subamostra das empresas com RO positivo com seu correspondente item de conclusão detalhado. O item 4 (Apresentação dos Resultados) foi encerrado com as respostas às questões da pesquisa, 
sendo que cada uma das questões foi analisada à luz dos resultados obtidos na análise de cada uma das sub-amostras.

Como os modelos utilizados são semelhantes, diferindo somente na composição das variáveis independentes, a descrição da análise do primeiro modelo foi detalhada, incluindo as definições e justificativas teóricas das técnicas estatísticas utilizadas. A partir daí, as descrições foram focalizadas na análise dos resultados de cada modelo, sem a repetição dos aspectos teóricos, caso já tenham sido abordados. E também, somente as variáveis que se mostraram estatisticamente significativas na análise estão apresentadas nas tabelas analisadas. O Anexo 7.6 (Resultados

completos da análise GLM referente às empresas que operaram com RO negativo) apresenta a versão integral das tabelas de todos os modelos utilizados.

\subsection{Análise dos modelos referentes às empresas que operaram com RO negativo}

A sub-amostra das empresas que apresentaram RO negativo num total de 147 casos foi analisada utilizando oito modelos: 1A-P, 1B-P, 2A-P, 2B-P, 3A-P, 3B-P, 4A-P e 4B-P, descritos nos próximos itens e seguido por uma conclusão do comportamento dos mesmos.

\subsubsection{Análise dos modelos 1A-P e 1B-P}

Os modelos 1A-P e 1B-P consideraram as empresas com RO negativo ou "Prejuízo" e analisaram essa condição com os investimento voluntários em RSE, considerando o porte das empresas.

O Modelo 1A-P correspondente à Tabela 19, analisou a relação entre o RO negativo com os investimentos voluntários totais em RSE. 
Tabela 19 - Modelo 1A-P considera o porte das empresas, investimentos voluntários em RSE e operação com prejuízo

\begin{tabular}{l|c|c|c}
\hline \multicolumn{1}{c|}{ Modelo 1A-P } & Sig & Eta Quadrado Parcial & Poder Observado \\
\hline Teste de Levene & $\mathbf{0 , 1 4 2}$ & & \\
\hline Assertividade do modelo (R-Sqr) & $\mathbf{0 , 0 0 0}$ & 0,566 & 1,000 \\
\hline LnRSE_Voluntario & $\mathbf{0 , 0 0 0}$ & 0,407 & 1,000 \\
\hline Ano & $\mathbf{0 , 0 4 6}$ & 0,086 & 0,695 \\
\hline Setor & $\mathbf{0 , 0 1 7}$ & 0,091 & 0,773 \\
\hline Ano * Setor & 0,835 & 0,064 & 0,327 \\
\hline
\end{tabular}

O primeiro teste de validação do modelo foi o Teste de Levene da homogeneidade dos resíduos. Resíduo ou erro é a diferença entre o valor da variável dependente calculada pelo modelo e o valor correspondente presente na amostra. Para que o modelo seja válido, espera-se que o valor do resíduo seja pequeno e que sua variância tenha um comportamento aleatório ao longo dos agrupamentos definidos pelos fatores, que no caso do estudo são o ano de publicação do BS e o setor econômico de atuação da empresa, isso é, que tenha um comportamento de acordo com a Distribuição Normal com média zero e desvio-padrão constante ao longo dos agrupamentos. Nessas condições, a validação do modelo ocorre quando a hipótese H0 não é rejeitada, ou seja, se a significância resultante do teste resultar em um valor maior que 5,0\%.

No caso da Tabela 19, o Teste de Levene apresentou o valor de Sig igual a 14,2\% que está acima de $5,0 \%$, indicando que não se pode negar que a variância do erro foi igual ao longo dos grupos e que as diferenças foram devidas a variações aleatórias. Nesse caso, diz-se que existe homocedasticidade e pode ser efetuado o segundo teste de validação.

O segundo teste foi o de avaliação da representatividade dos fatores do modelo e teve por objetivo analisar a significância das variáveis independentes do modelo para explicar as variações da variável dependente que é o RO. Ele utilizou o Teste F de Snedecor de igualdade das médias dos grupos. O mecanismo utilizado pelo Teste $\mathrm{F}$ de Snedecor é a avaliação da significância da relação entre a variância entre os grupos e a variância dentro dos grupos. Se o resultado for inferior a 5,0\% rejeita-se a hipótese $\mathrm{H} 0$ e considera-se que aquele fator contribuiu para explicar as variações da variável dependente e deve ser considerado no modelo explicativo. A coluna "Sig" da tabela contém o resultado desse teste.

No primeiro aspecto da análise da representatividade deseja-se saber se o modelo escolhido pode representar o fenômeno em estudo e para tal avalia-se o seu nível de assertividade. A métrica escolhida é o valor de $\mathrm{R}^{2}$ ou R-Sqr, conhecido como Coeficiente de Determinação ou Correlação de 
Pearson e que, no estudo, está presente na tabela com a denominação "Assertividade do modelo (RSqr)". Ele avalia a proporção da variância da variável dependente que pode ser predita a partir das variáveis independentes e é uma medida generalizada da força de associação das variáveis, mas não reflete a extensão com que qualquer variável independente está associada à dependente. No caso do Modelo 1A-P, a assertividade foi significativa porque teve valor igual a $0,0 \%$, menor que o limite de 5,0\% adotado no estudo. É importante destacar que o estudo buscou identificar a existência de relações significativas e não o valor dessa correlação.

No segundo aspecto da análise da representatividade são analisados os efeitos entre os grupos. Nesse teste, cuja hipótese H0 é que as médias dos grupos são iguais, o objetivo é constatar se a variável dependente (RO negativo) responde às variações das variáveis independentes, isso é, se as variáveis independentes contribuem para a explicação do modelo escolhido. A Tabela 19 que apresenta os resultados do modelo 1A-P e indicou que as variáveis LnRSE_Voluntario (total dos investimentos voluntários em RSE), Ano e Setor foram significativas, estavam relacionadas ao RO negativo e deviam ser incluídas no modelo, pois apresentaram Sig iguais a 0,0\%, 4,6\% e 1,7\% respectivamente, todas inferiores a 5,0\%. O efeito cruzado das variáveis Ano e Setor (Ano * Setor) não se mostrou significativo para explicar a variância do RO negativo, pois o valor de Sig, 83,5\%, foi superior a 5,0\%, isso é, a inexistência de interação entre esses fatores indica que ao longo dos anos do estudo, a variância do RO negativo referente aos diversos setores não foram significativamente alterados entre si. Esse comportamento se repetiu com essa mesma forma nos modelos 1B-P, 2A-P, 2B-P, 3A-P, 3B-P, 4A-P e 4B-P.

Aliado ao teste de representatividade, a coluna "Eta Quadrado Parcial" - EQP (Partial Eta Square no SPSS) da tabela indica o poder explicativo com que cada um dos fatores independentes da equação de regressão linear influenciou a variação da variável dependente ou, em outras palavras, descreve a proporção da variabilidade total da variável dependente atribuída ao fator correspondente. O valor de Eta Quadrado Parcial é obtido a partir da divisão do valor da soma dos quadrados das diferenças atribuídas ao fator pela soma dos quadrados das diferenças atribuída ao fator e também do erro, que nesse último caso são as diferenças entre o valor do modelo e o valor da amostra. Na Tabela 19 observou-se que a assertividade do modelo foi de 56,6\%, um valor relevante e a variável que mais contribuíu foi a LnRSE_Voluntario com 40,7\% da variação do RO negativo. O valor Eta Quadrado Parcial não deve ser interpretado no caso dos fatores não relevantes, isso é, os que tiveram o valor de Sig superior a 5,0\%. 
A coluna "Poder Observado" indica o poder do teste de inferência estatística (HAIR, 2005, p. 30), que é a probabilidade de rejeitar corretamente a hipótese nula quando essa deve ser rejeitada. Isso é, o nível de certeza da influência do fator calculado ao nível de significância de $5,0 \%$, que foi estabelecido para o presente estudo. Valores elevados do "Poder Observado" atribuem maior poder explicativo ao fator, o que significa maior segurança de que a decisão de aceitação do fator como significativo para o modelo está correta.

Apesar de representarem conceitos e terem comportamentos por vezes semelhantes, Eta Quadrado Parcial e Poder Observado têm significados e interpretações próprios. O primeiro define o percentual de explicação da variável e o segundo, a probabilidade de que essa hipótese esteja correta.

Em resumo, a Tabela 19 pode ser interpretada da seguinte forma: O Modelo 1A-P atendeu o requisito de homogeneidade de erro, pois o Teste de Levene teve Sig igual a 14,2\%, superior ao valor de corte de 5,0\%. Ele se mostrou relevante, pois o Poder Observado teve probabilidade próxima de $100 \%{ }^{17}$, ao nível de significância de $5,0 \%$, isso quer dizer que essa conclusão foi correta e as variáveis independentes conseguiram explicar $56,6 \%$ da variabilidade do RO negativo, cabendo a diferença a fatores externos ao modelo. As variáveis independentes LnRSE_Voluntario (total dos investimentos voluntários em RSE), Ano e Setor, com Sig entre 0,0\% e 4,6\% foram consideradas significativas porque os valores foram inferiores ao valor de corte de 5,0\% e, portanto, estavam relacionadas ao RO negativo. As variáveis relevantes foram o LnRSE_Voluntario, que explicou $40,7 \%$ da variabilidade da variável dependente, com praticamente $100 \%$ de certeza de que essa decisão estava correta, seguidas pelo Setor e Ano, respectivamente com Poder Observado de 77,3\% e $69,5 \%$ e capacidade explicativa de $9,1 \%$ e $8,6 \%$.

Em uma análise qualitativa e utilizando outra terminologia poder-se-ia descrever o resultado como: Considerando o efeito do porte das empresas analisadas que operaram com RO negativo, existe uma

${ }^{17}$ Apesar do valor apresentado na tabela ser igual a $100 \%$, isso se deve ao arredondamento de três casas decimais utilizado. Na prática não se pode considerar o valor absoluto de $100 \%$, pois significaria uma certeza absoluta, uma condição não aplicável aos fenômenos estudados. Na situação oposta, de valor igual a 0,0\%, a mesma justificativa prática é aplicável. 
correlação estatisticamente significativa entre o RO negativo e os investimentos voluntários totais em RSE, sendo que, a conjuntura econômica e social refletida no ano de publicação do BS e o setor de atuação, tiveram influência significativa, ainda que não muito relevante, no estabelecimento desses investimentos.

O Modelo 1B-P, correspondente à Tabela 20, analisou a relação entre o RO negativo e os investimentos voluntários em RSE segmentados por natureza do investimento social, isso é, os investimentos em Indicadores Sociais Internos, Externos e Ambientais. Ele indicou homocedasticidade, já que o Teste de Levene teve Sig igual a 42,2\%, acima de 5,0\%, mostrando que o modelo foi estatisticamente significativo e conseguiu explicar $65,4 \%$ da variância do RO negativo. As variáveis independentes LnV214 (Indicadores Sociais Internos - Investimentos Sociais Internos Totais), Ano e Setor, com Sig entre $0,0 \%$ e 2,6\% foram significativas porque foram valores inferiores ao valor de corte de $5,0 \%$ e portanto se considerou que estavam relacionadas ao RO negativo. A variável LnV214 explicou 48,2\% do RO negativo e o Setor e Ano, embora ambos sejam significativos $(0,3 \%$ e 2,6\%), comparativamente à LnV214, tiveram menor influência sobre o modelo $(12,5 \%$ e $10,0 \%)$.

Tabela 20 - Modelo 1B-P considera o porte das empresas, investimentos voluntários segmentados por natureza de RSE e operação com prejuízo

\begin{tabular}{l|c|c|c}
\hline \multicolumn{1}{c|}{ Modelo 1B-P } & Sig & Eta Quadrado Parcial & Poder Observado \\
\hline Teste de Levene & $\mathbf{0 , 4 2 2}$ & & \\
\hline Assertividade do modelo (R Sqr) & $\mathbf{0 , 0 0 0}$ & 0,654 & 1,000 \\
\hline LnV214 & $\mathbf{0 , 0 0 0}$ & 0,482 & 1,000 \\
\hline Ano & $\mathbf{0 , 0 2 6}$ & 0,100 & 0,762 \\
\hline Setor & $\mathbf{0 , 0 0 3}$ & 0,125 & 0,903 \\
\hline
\end{tabular}

Em uma análise qualitativa e utilizando outra terminologia, poder-se-ia descrever o resultado como: Considerando o efeito do porte das empresas analisadas que operaram com RO negativo, existe uma correlação estatisticamente significativa entre o RO negativo e os investimentos voluntários em RSE concentrados nos Indicadores Sociais Internos, sendo que a conjuntura econômica e social e o setor de atuação se mostraram estatisticamente significativas, ainda que pouco relevantes na diferenciação das estratégias de investimento em RSE dessas empresas.

Como já mencionado, esses resultados do modelo 1B-P devem ser considerados com ressalva, pois a quantidade de casos não atingiu a quantidade sugerida para a análise; entretanto, em vista dos valores bastante relevantes obtidos, o autor considera que não existem evidências para não aceitar 
as conclusões formuladas, principalmente no tocante à assertividade do modelo e à variável representando o investimento em RSE.

\subsubsection{Análise dos modelos 2A-P e 2B-P}

Os modelos 2A-P e 2B-P consideraram as empresas com RO negativo, o porte das mesmas e se diferenciam dos modelos anteriores por trabalhar com a soma dos investimentos voluntários e os compulsórios em RSE, de acordo com a definição do padrão IBASE.

O Modelo 2A-P correspondente à Tabela 21 analisou a relação entre o RO negativo e o investimento agregado total. O modelo foi homocedástico com Sig igual a 25,3\%. A variável independente LnRSE_Total (total dos investimentos voluntários e compulsórios em RSE), com Sig igual a $0,0 \%$, foi significativa porque seu valor foi inferior ao valor de corte de 5,0\% e, portanto, se considera que está relacionada ao RO negativo. Ela conseguiu explicar 39,0\% da variação do RO negativo. Diferentemente do modelo 1A-P, no qual a influência da conjuntura econômica e social e setor se manisfestaram de forma significativa, ainda que com pequena relevância, o modelo 2A-P não foi influenciado por esses fatores.

Tabela 21 - Modelo 2A-P considera o porte das empresas, investimentos totais de RSE e operação com prejuízo

\begin{tabular}{l|c|c|c}
\hline \multicolumn{1}{c|}{ Modelo 2A-P } & Sig & Eta Quadrado Parcial & Poder Observado \\
\hline Teste de Levene & $\mathbf{0 , 2 5 3}$ & & \\
\hline Assertividade do modelo (R-Sqr) & $\mathbf{0 , 0 0 0}$ & 0,553 & 1,000 \\
\hline LnRSE_Total & $\mathbf{0 , 0 0 0}$ & 0,390 & 1,000 \\
\hline
\end{tabular}

Em uma análise qualitativa e utilizando outra terminologia poder-se-ía descrever o resultado como: Considerando o efeito do porte das empresas analisadas que operaram com RO negativo, existe uma correlação estatisticamente significativa entre o RO negativo e os investimentos totais em RSE sem contudo existir uma influência comportamental significativa decorrente da conjuntura econômica e social ou do setor de atuação. O modelo 2A-P teve o mesmo comportamento qualitativo do modelo 1A-P, exceto que esse se mostrou também sensível ao ano de publicação do BS e setor de atuação.

O Modelo 2B-P correspondente à Tabela 22 analisou a relação entre o RO negativo e os investimentos totais segmentados por natureza do investimento social, isso é, os investimentos em 
Indicadores Sociais Internos, Externos e Ambientais. Possui homocedasticidade, pois o Teste de Levene apresentou Sig igual a 18,63\%, superior a 5,0\%. O modelo foi estatisticamente significativo, pois o Sig da assertividade do modelo foi igual a $0,0 \%$, inferior a 5,0\% e ele conseguiu explicar $61,3 \%$ da variância do RO negativo, um valor bastante relevante. As variáveis LnV213 (Investimentos Sociais Internos Voluntários) e Setor foram significativas, pois tiveram Sig respectivamente iguais a $0,0 \%$ e $0,2 \%$; portanto, se considera que estejam relacionadas ao RO negativo. Elas conseguiram explicar respectivamente 38,7\% e 13,2\% da variância do RO negativo. O modelo teve muita relevância e evidenciou que o foco dos investimentos em RSE esteve nas ações ditadas pelos Indicadores Sociais Internos. Esse modelo não foi influenciado pelo ano de publicação do BS.

Tabela 22 - Modelo 2B-P considera o porte das empresas, investimentos totais segmentados por natureza de RSE e operação com prejuízo

\begin{tabular}{l|c|c|c}
\hline \multicolumn{1}{c|}{ Modelo 2B-P } & Sig & Eta Quadrado Parcial & Poder Observado \\
\hline Teste de Levene & $\mathbf{0 , 1 8 6}$ & & \\
\hline Assertividade do modelo (R Sqr) & $\mathbf{0 , 0 0 0}$ & 0,613 & 1,000 \\
\hline LnV213 & $\mathbf{0 , 0 0 0}$ & 0,387 & 1,000 \\
\hline Setor & $\mathbf{0 , 0 0 2}$ & 0,132 & 0,921 \\
\hline
\end{tabular}

Em uma análise qualitativa e utilizando outra terminologia, poder-se-ia descrever o resultado como: Considerando o efeito do porte das empresas analisadas que operaram com RO negativo, existe uma correlação estatisticamente significativa entre o RO negativo e os investimentos totais em RSE concentrados nos Indicadores Sociais Internos, sendo que o setor de atuação se mostrou estatisticamente significativo, ainda que pouco relevante na diferenciação das estratégias de investimento em RSE dessas empresas. O modelo 2B-P teve o mesmo comportamento qualitativo do modelo 1B-P, exceto que esse se mostrou sensível ao ano de publicação do BS.

\subsubsection{Análise dos modelos 3A-P e 3B-P}

Os modelos 3A-P e 3B-P foram elaborados visando analisar as estratégias das empresas onde o porte foi retirado da percepção do modelo. Dessa forma, o trabalho buscou identificar o impacto que essa situação possa ter influenciado nas decisões dos investimentos voluntários em RSE e sua relação com o RO negativo. 
O Modelo 3A-P correspondente à Tabela 23 analisou a relação entre o RO negativo e os investimentos voluntários totais em RSE, sem considerar o porte da empresa. O modelo foi homocedástico com Sig igual a 96,1\% e conseguiu explicar $14,3 \%$ da variação do RO. A variável independente LnR_RSE_Voluntario (total dos investimentos voluntários em RSE, dessensibilizado do porte da empresa) não foi significativa para o modelo, pois teve Sig igual a $11,5 \%$, superior a 5,0\%. As variáveis independentes Ano e Setor, respectivamente com Sig iguais a 3,0\% e 4,2\%

foram significativas porque tiveram valores inferiores ao valor de corte de 5,0\%. Conseqüentemente, se concluiu que o modelo foi válido, mas com pequena relevância prática e os investimentos voluntários não tiveram correlação com o RO negativo. Ano e Setor tiveram poder explicativo sobre a variância do RO negativo, respectivamente 7,6\% e 5,9\%, influências pouco relevantes.

Tabela 23 - Modelo 3A-P considera investimentos voluntários de RSE, operação com prejuízo e dessensibiliza o porte das empresas

\begin{tabular}{l|c|c|c}
\hline \multicolumn{1}{c|}{ Modelo 3A-P } & Sig & Eta Quadrado Parcial & Poder Observado \\
\hline Teste de Levene & $\mathbf{0 , 9 6 1}$ & & \\
\hline Assertividade do modelo (R-Sqr) & $\mathbf{0 , 0 0 7}$ & 0,143 & 0,932 \\
\hline LnR_RSE_Voluntario & 0,115 & 0,018 & 0,350 \\
\hline Ano & $\mathbf{0 , 0 3 0}$ & 0,076 & 0,747 \\
\hline Setor & $\mathbf{0 , 0 4 2}$ & 0,059 & 0,665 \\
\hline
\end{tabular}

Em uma análise qualitativa e utilizando outra terminologia poder-se-ía descrever o resultado como: Dessensibilizado o efeito do porte das empresas que operaram com RO negativo, não foi observada uma correlação estatisticamente significativa entre o RO negativo e os investimentos voluntários agregados em RSE. O modelo 3A-P teve um comportamento qualitativo diferente dos modelos 1A$\mathrm{P}$ e 2A-P, que consideravam o porte das empresas, pois nesses foram identificados relacionamentos entre o RO negativo e os investimentos em RSE.

O Modelo 3B-P correspondente à Tabela 24 analisou a relação entre o RO negativo e os investimentos voluntários totais segmentados por natureza dos investimentos, isso é, os investimentos em Indicadores Sociais Internos, Externos e Ambientais e onde a influência do porte das empresas foi retirada do modelo. Possui homocedasticidade, pois o Teste de Levene apresentou Sig igual a 52,2\%, superior a 5,0\%. O modelo foi estatisticamente significativo e conseguiu explicar 29,4\% da variância do RO negativo, um valor bastante baixo e de pouca relevância prática. As variáveis independentes LnRLV214 (Investimentos Sociais Internos Totais dessensibilizados do porte das empresas), Ano e Setor, com Sig entre 0,1\% e 4,0\% foram significativas porque foram 
valores inferiores ao valor de corte de $5,0 \%$ e portanto se pode afirmar que estão relacionadas ao RO negativo. A variável LnRLV214 explicou 10,8\% da variância do RO negativo e o Setor e Ano explicaram respectivamente $9,4 \%$ e $9,2 \%$, valores pouco relevantes.

Tabela 24 - Modelo 3B-P considera investimentos voluntários segmentados por programas de RSE, operação com prejuízo e dessensibiliza o porte das empresas

\begin{tabular}{l|c|c|c}
\hline \multicolumn{1}{c|}{ Modelo 3B-P } & Sig & Eta Quadrado Parcial & Poder Observado \\
\hline Teste de Levene & $\mathbf{0 , 5 2 2}$ & & \\
\hline Assertividade do modelo (R Sqr) & $\mathbf{0 , 0 1 3}$ & 0,294 & 0,978 \\
\hline LnRLV214 & $\mathbf{0 , 0 0 1}$ & 0,108 & 0,938 \\
\hline Ano & $\mathbf{0 , 0 4 0}$ & 0,092 & 0,714 \\
\hline Setor & $\mathbf{0 , 0 1 7}$ & 0,094 & 0,775 \\
\hline
\end{tabular}

Em uma análise qualitativa e utilizando outra terminologia poder-se-ía descrever o resultado como: Dessensibilizado o efeito do porte das empresas analisadas que operaram com RO negativo, foi observada uma correlação estatisticamente significativa entre o RO negativo e os investimentos voluntários totais direcionados aos Indicadores Sociais Internos em RSE, com influência discriminadora da conjuntura econômica e social e do setor de atuação sobre as decisões de investimentos em RSE. Entretanto, do ponto de vista prático que possa ser utilizado na determinação de um modelo explicativo, os níveis de relevância dessas relações não se mostraram suficientes, apesar de apresentarem indícios comportamentais semelhantes aos dos modelos anteriores (1B-P e 2B-P) no que se referiam principalmente aos investimentos em RSE, porém em níveis bastante tênues. O comportamento diferenciado entre os modelos 3A-P e 3B-P poderia ser explicado pelo baixo nível de assertividade do investimento voluntário total, que agregou outras verbas além dos Indicadores Sociais Internos, as quais não aparentaram ter uma relação entre o RO negativo e os investimentos em RSE.

\subsubsection{Análise dos modelos 4A-P e 4B-P}

Os modelos 4A-P e 4B-P foram elaborados visando analisar as estratégias das empresas e nos quais o porte das mesmas foi retirado da percepção do modelo. Dessa forma, o trabalho buscou identificar o impacto que essa situação interferiu nos investimentos totais, voluntários e compulsórios, em RSE e sua relação com o RO negativo. 
O Modelo 4A-P correspondente à Tabela 25 analisou a relação entre o RO negativo e os investimentos totais em RSE, sem considerar o porte da empresa. O modelo foi homocedástico com Sig igual a $96,1 \%$ e conseguiu explicar $13,2 \%$ da variação do RO negativo. Além da menor capacidade explicativa desse modelo comparativamente aos modelos $1 \mathrm{~A}-\mathrm{P}$ e $2 \mathrm{~A}-\mathrm{P}$ que consideravam o porte da empresa nos modelos, não existiu significância estatística entre os investimentos em RSE e o RO negativo, já que o Sig obtido foi 38,0\%, superior a 5,0\% estabelecido como limite.

Tabela 25 - Modelo 4A-P considera os investimentos totais de RSE, operação com prejuízo e dessensibiliza o porte das empresas

\begin{tabular}{l|c|c|c}
\hline \multicolumn{1}{c|}{ Modelo 4A-P } & Sig & Eta Quadrado Parcial & Poder Observado \\
\hline Teste de Levene & $\mathbf{0 , 9 6 1}$ & & \\
\hline Assertividade do modelo (R-Sqr) & $\mathbf{0 , 0 1 3}$ & 0,132 & 0,903 \\
\hline Intercepto & $\mathbf{0 , 0 0 0}$ & 0,169 & 0,999 \\
\hline LnR_RSE_Total & 0,380 & 0,006 & 0,141 \\
\hline Ano & $\mathbf{0 , 0 3 6}$ & 0,073 & 0,727 \\
\hline
\end{tabular}

Em uma análise qualitativa e utilizando outra terminologia poder-se-ía descrever o resultado como: Dessensibilizado o efeito do porte das empresas analisadas que operaram com RO negativo, não foi observado um relacionamento estatisticamente significativo entre ele e os investimentos totais em RSE. O modelo 4A-P teve comportamento semelhante ao 3A-P.

O Modelo 4B-P correspondente à Tabela 26 analisou a relação entre o RO negativo e os investimentos totais segmentados por natureza dos investimentos, isso é, os investimentos em Indicadores Sociais Internos, Externos e Ambientais e onde a influência do porte das empresas foi retirada do modelo. Possui homocedasticidade, pois o Teste de Levene apresentou Sig igual a $50,0 \%$, acima de $5,0 \%$. O modelo foi estatisticamente significativo mas conseguiu explicar somente 18,5\% da variância do RO negativo, um nível de pouca relevância. As variáveis independentes LnRLV213 (Investimentos Sociais Internos Voluntários dessensibilizados do porte das empresas) e Setor, com Sig respectivamente iguais a $3,0 \%$ e $0,8 \%$ foram significativas porque foram valores inferiores ao valor de corte de 5,0\% e se considerou que estavam relacionadas ao RO negativo, entretanto, a variável LnRLV213 explicou somente 4,0\% do RO negativo e o Setor, 9,6\%, valores pouco relevantes. 
Tabela 26 - Modelo 4B-P considera investimentos totais segmentados por programas de RSE, operação com prejuízo e dessensibiliza o porte das empresas

\begin{tabular}{l|c|c|c}
\hline \multicolumn{1}{c|}{ Modelo 4B-P } & Sig & Eta Quadrado Parcial & Poder Observado \\
\hline Teste de Levene & $\mathbf{0 , 5 0 0}$ & & \\
\hline Assertividade do modelo (R Sqr) & $\mathbf{0 , 0 0 7}$ & 0,185 & 0,948 \\
\hline LnRLV213 & $\mathbf{0 , 0 3 0}$ & 0,040 & 0,588 \\
\hline Setor & $\mathbf{0 , 0 0 8}$ & 0,096 & 0,835 \\
\hline
\end{tabular}

Em uma análise qualitativa e utilizando outra terminologia poder-se-ía descrever o resultado como: Dessensibilizado o efeito do porte das empresas que operaram com RO negativo, foi observada uma correlação estatisticamente significativa entre o RO negativo e os investimentos totais direcionados aos Indicadores Sociais Internos em RSE, com influência discriminadora do setor de atuação. Entretanto, do ponto de vista prático que possa ser utilizado na determinação de um modelo explicativo, os níveis de relevância dessas relações não se mostraram suficientes, apesar de apresentarem indícios comportamentais semelhantes aos dos modelos anteriores (1B-P e 2B-P) no que se referia principalmente aos investimentos em RSE, porém em níveis bastante tênues. $\mathrm{O}$ modelo 4B-P teve comportamento semelhante ao 3B-P. O comportamento diferenciado entre os modelos 4A-P e 4B-P poderia ser explicado pelo baixo nível de assertividade do investimento voluntário total, que agregou outras verbas além dos Indicadores Sociais Internos, as quais não aparentaram ter uma relação entre o RO negativo e os investimentos em RSE.

\subsubsection{Conclusão sobre os modelos das empresas que operaram com RO negativo}

Após as transformações logarítmicas naturais das variáveis do estudo e remoção dos outliers, todos os modelos estudados pertencentes ao gupo das empresas com RO negativo apresentaram homocedasticidade e permitem apresentar as conclusões que seguem.

Dos oito modelos estudados, o 1A-P, 1B-P, 2A-P, 2B-P, 3B-P e 4B-P apresentaram assertividade significativa e também relacionamento entre o RO negativo e os investimentos em RSE, sejam voluntários ou totais (voluntários + compulsórios). O modelo, 4A-P, apresentou assertividade, mas não encontrou uma relação significativa entre RO negativo e investimento em RSE e finalmente, o modelo 3A-P não apresentou assertividade e, portanto, nada se pode afirmar sobre a relação entre o RO negativo e os investimentos em RSE. 
Os modelos 1A-P, 1B-P, 2A-P e 2B-P que consideraram o porte das empresas apresentaram relevância muito maior tanto na assertividade do modelo quanto no relacionamento entre o desempenho financeiro e os investimentos em RSE em relação aos demais: 3B-P e 4B-P. Isso sugere considerar que o porte da empresa foi um fator relevante para a explicação das ações em RSE das empresas analisadas que tiveram RO negativo. Tal comportamento já se pronunciava durante a análise de outliers, onde a Tabela 16 apresentava uma maior incidência de variáveis dessensibilizadas como possíveis causadoras da condição de outlier (52 casos) em relação às variáveis originais (19 casos), isso é, as variáveis dessensibilizadas apresentaram maior variabilidade que as variáveis originais.

Os modelos 1A-P, 1B-P e 3B-P apresentaram influência do setor de atuação e da conjuntura econômica e social do período refletida no ano de publicação do BS. Os modelos 2B-P e 4B-P foram influenciados somente pelo setor.

Os modelos 1A-P e 2A-P, que consideraram o investimento total, não discricionário por natureza de ação em RSE, indicaram que o RO negativo está correlacionado ao investimento em RSE, já os modelos 1B-P e 2B-P, que discriminaram a natureza do investimento em Indicadores Sociais Internos, Externos e Ambientais, indicaram clara predominância para os investimentos em Indicadores Sociais Internos. Os demais indicadores, Sociais Externos e Ambientais, não apresentaram significância. A ser confirmado em investigações futuras, o autor supõe que os níveis de assertividade dos modelos 1B-P e 2B-P são melhores que os correspondentes $1 \mathrm{~A}-\mathrm{P}$ e $2 \mathrm{~A}-\mathrm{P}$, pois os investimentos dos segmentos de Indicadores Sociais Externos e Ambientais estariam sendo definidos por estratégias pouco relacionadas ao RO negativo.

A ser confirmado em investigações futuras, o autor supõe que os programas em RSE referentes aos Indicadores Sociais Internos se transformam em benefícios trabalhistas e, portanto, tendem a acompanhar o RO (como estratégias empresariais de definição de contingente de funcionários, nível de especialização e outros aspectos que estão alinhados ao RO presente e futuro). O mesmo não aconteceria em relação aos Indicadores Sociais Externos e mesmo aos Ambientais, onde os investimentos de alto valor são devidos a projetos específicos (como alteração de processo produtivo para redução de poluição) que estariam associados a ações pontuais e não a projetos de longa duração (como, por exemplo, educação sobre sustentabilidade) que são mais longos e se supõe que tenham menor investimento, o que não seria percebido pelo modelo de regressão linear. 
Nenhum dos modelos que analisaram a variância do RO negativo perante a interação dos fatores Ano e Setor (Ano * Setor) encontraram indícios significativos dessa existência, o que significa que, ao longo dos anos do estudo, não ocorreu mudanças relevantes na variância de RO negativo que refletisse uma alteração do comportamento dos diversos setores.

\subsection{Análise dos modelos referentes às empresas que operaram com RO positivo}

Os mesmos modelos matemáticos adotados para analisar as empresas com RO negativo descritos no item 4.2 (Análise dos modelos referentes às empresas que operaram com RO negativo), foram utilizados na análise das empresas com RO positivo; entretanto, todos os 12 casos apresentaram heterocedasticidade ao se efetuar o Teste de Levene; portanto, na forma adotada, se mostraram inadequados para demonstrar corretamente as relações entre as variáveis. O Anexo 7.7 (Resultados completos da análise GLM referente às empresas que operaram com RO positivo) apresenta os resultados da análise das empresas que operaram com lucro, utilizando a abordagem semelhante à das empresas com prejuízo, evidenciando a heterocedasticidade presente na linha Teste de Levene, com Sig inferior a 5,0\% e invalidando essa forma de análise.

O problema da heterocedasticidade pode ser contornado pela aplicação de diversas técnicas que busquem tornar o modelo homocedástico e, então, possibilitar a análise matemática do fenômeno, isso é, o fato de existir heterocedasticidade não significa a não existência de relacionamento entre as variáveis, mas somente que essa relação pode não ter sido perceptível pelo modelo adotado. As transformações já efetuadas nas variáveis dos modelos quando foram aplicadas as transformações logarítmicas descritas no item 3.4.2. (Transformação logarítmica das variáveis) foram suficientes para garantir a análise da sub-amostra das empresas com RO negativo, mas não para garantir o atendimento pleno a esse requisito técnico no tocante à sub-amostra das empresas com RO positivo. É importante destacar que as transformações podem conduzir a uma melhoria no nível de homocedasticidade, mas obviamente, caso não exista qualquer relação entre as variáveis, nenhuma técnica irá criá-la, isso é, a matemática auxilia na procura de relações atávicas existentes na amostra analisada. 
Neter (1990, p. 400) sugere como medida para remediar a desigualdade das variâncias dos erros, a técnica dos Mínimos Quadrados Ponderados (Weighted Least Squares) ${ }^{18}$. Entretanto, o autor considera que a alteração dos valores das variáveis com o uso de um fator de ponderação visando melhorar a homocedasticidade, como sugerido por Neter, atende os objetivos do estudo que é identificar as variáveis significativas para explicar a relação entre o desempenho financeiro e as ações em RSE refletidas nos investimentos efetuados, mas dificulta a análise do modelo final em uma fase descritiva do fenômeno, devido à ponderação individual dos fatores. A solução adotada pelo autor foi alterar a maneira como as varíaveis foram analisadas e os resultados obtidos foram bastante favoráveis e serão descritos nos próximos itens.

Para buscar a obtenção de homocedasticidade e considerando os resultados de alguns tratamentos matemáticos experimentados, o autor optou por usar o processo de segmentação por setor de atuação, mantendo os demais critérios de cálculo inalterados, isso é, alterando a maneira como foi processado o modelo para que fosse considerado apenas o fator Ano e a partir daí, os modelos foram analisados com referência a cada setor individualmente. Dessa maneira, os 12 modelos iniciais previstos foram desdobrados para cada um dos 5 setores, resultando em 60 modelos, onde somente oito deles ainda permaneceram heterocedásticos, demonstrando o acerto da estratégia selecionada. O benefício para a análise nessa abordagem foi a possibilidade de percepção das estratégias em RSE com uma visão setorial ao longo do período de estudo, mantendo uma lógica comparável àquela utilizada na análise efetuada com o grupo de empresas com RO negativo.

Os oito modelos heterocedásticos foram reanalisados individualmente buscando identificar as razões dessa condição. Foi investigado o comportamento de cada modelo para cada ano do período de estudo buscando identificar comportamentos diferenciados que pudessem explicar a heterocedasticidade.

\footnotetext{
${ }^{18}$ Procedimento de ajuste pelos Mínimos Quadrados Ponderados: i) Ajustar o modelo de regressão pelos mínimos quadrados não ponderados e analisar os resíduos; ii) Estimar a função de variância (ou função desvio padrão) pela regressão (ou pela análise dos quadrados dos resíduos ou resíduos absolutos) no(s) preditor(es) apropriados; iii) Usar os valores ajustados da variância estimada ou função do desvio padrão para obter os pesos Wi de cada fator; e iv) Estimar os coeficientes da regressão usando esses pesos.

Se os coeficientes estimados diferirem substancialmente dos coeficientes de regressão estimados pelos mínimos quadrados ordinários, é aconselhável fazer iteração do processo dos mínimos quadrados ponderados usando os resíduos dos mínimos quadrados ponderados para reestimar a variância ou a função do desvio padrão e, então, obter os pesos revistos. Uma ou duas iterações são suficientes para estabilizar os coeficientes de regressão estimados. Esse processo é freqüentemente chamado mínimos quadrados ponderados iterativamente.
} 
A investigação da causa-raiz da heterocedasticidade dos modelos: 1A-L, 1B-L, 2B-L, 3B-L, 4A-L, 4B-L e 4C-L acabou sendo localizada no setor AGI, no qual foi descoberta a existência de quatro casos amostrais no ano 2000 que estão apresentados na Tabela 27. O comportamento de um ou mais desses quatro casos causou a heterocedasticidade. A partir daí, seria possível identificar esse(s) caso(s) e retirá-lo(s) da amostra. Entretanto, três ou menos casos são insuficientes para representar adequadamente o fenômeno; portanto, o autor decidiu simplesmente removê-los todos para não comprometer a generalidade do modelo.

Tabela 27 - Empresas retiradas da amostra para ajuste de homocedasticidade referente ao setor AGI

\begin{tabular}{c|l|c}
\hline Amostra & \multicolumn{1}{|c|}{ Razão Social } & Ano \\
\hline 42 & Bahia Sul Celulose & 2000 \\
\hline 142 & Cambará Produtos Florestais & 2000 \\
\hline 263 & Suzano de Papel e Celulose & 2000 \\
\hline 660 & Orsa Celulose, Papel e Embalagens & 2000 \\
\hline
\end{tabular}

A investigação da causa-raiz da heterocedasticidade do modelo 2B-L acabou sendo localizada no setor FIN, no qual foram localizados sete casos amostrais referente ao ano 2000. O modelo de regressão linear calculado considerando esses casos apresentou assertividade do modelo não significativa, já que o valor de Sig resultou em 19,1\%, superior ao limite de 5,0\%, confirmando o comportamento distintivo. Uma investigação mais apurada localizou um comportamento diferenciado no caso 56, referente ao BS do Banco do Brasil/2000, que foi caracterizado como outlier e retirado da amostra.

O reprocessamento após a retirada desses cinco casos da amostra reclassificou os oito modelos como homocedásticos e os resultados foram considerados nas análises a seguir. Uma análise comparativa entre os resultados antes e após a retirada dos cinco casos mencionados, exceto nos modelos referentes aos setores AGI e FIN que se tornaram homocedásticos, não encontrou diferenças qualitativas nos resultados para os modelos já homocedásticos, tendo sido observado somente uma melhoria na qualidade das variáveis já significativas (Sig com menor valor, Eta com maior valor e PO com maior valor).

Os próximos itens apresentam os resultados dessa nova abordagem analítica. Os critérios de aceitabilidade das hipóteses estatísticas são os mesmos até agora descritos e somente as variáveis estatisticamente significativas foram apresentadas nas tabelas. As tabelas completas com todas as 
variáveis e os valores correspondentes estão apresentadas no Anexo 7.8 (Resultados completos da análise GLM referente às empresas que operaram com RO positivo).

O setor de atuação da empresa aparentou ter influência nos modelos utilizados pela sub-amostra das empresas com RO positivo, pois antes da segmentação dos modelos em setores individualizados, os modelos não eram homocedástivos e passaram a sê-lo após a segmentação; entretanto, a presente análise não permite quantificar esse impacto.

\subsubsection{Análise dos modelos 1A-L}

Os modelos setoriais 1A-L consideraram o porte das empresas com RO positivo e analisaram os investimentos voluntários totais em RSE para cada setor de atuação.

A Tabela 28 apresenta os modelos setoriais e se constata que os mesmos foram homocedásticos por apresentarem Sig do Teste de Levene entre 15,0\% e 74,9\%, superiores ao limite de 5,0\%. As assertividades dos modelos foram significativas, pois tiveram Sig igual a $0,0 \%$ (menor que 5,0\%) e conseguiram explicar entre $60,2 \%$ e $82,5 \%$ da variância do RO positivo (coluna EQP = Eta Quadrado Parcial), valores bastante relevantes. Os investimentos voluntários em RSE representados pela variável LnRSE_Voluntario (total dos investimentos voluntários em RSE) foram significativos porque seu Sig foi igual a $0,0 \%$; portanto, se considera que eles estejam relacionados ao RO positivo e explicaram entre $56,1 \%$ e $81,5 \%$ da variância do RO positivo, valores bastante relevantes. A conjuntura econômica e social refletida no ano de publicação do BS teve influência significativa somente no comportamento do modelo referente ao setor AGI, no qual Sig foi igual a 1,7\%, menor que $5,0 \%$, com capacidade explicativa de $11,9 \%$, um valor pouco relevante. 
Tabela 28 - Modelo 1A-L considera o porte das empresas, investimentos voluntários em RSE e operação com lucro

\begin{tabular}{|c|c|c|c|c|c|c|c|c|c|c|c|c|c|c|c|}
\hline \multirow{2}{*}{ Modelo 1A-L } & \multicolumn{3}{|c|}{ IND } & \multicolumn{3}{|c|}{ SRV } & \multicolumn{3}{|c|}{ ELE } & \multicolumn{3}{|c|}{ AGI } & \multicolumn{3}{|c|}{ FIN } \\
\hline & Sig & EQP & PO & Sig & EQP & PO & Sig & EQP & PO & Sig & EQP & PO & Sig & EQP & PO \\
\hline $\begin{array}{l}\text { Teste de } \\
\text { Levene }\end{array}$ & 0,692 & & & 0,717 & & & 0,749 & & & 0,300 & & & 0,150 & & \\
\hline $\begin{array}{l}\text { Assertividade } \\
\text { do modelo } \\
\text { (R-Sqr) }\end{array}$ & 0,000 & 0,792 & 1,000 & 0,000 & 0,695 & 1,000 & 0,000 & 0,602 & 1,000 & 0,000 & 0,735 & 1,000 & 0,000 & 0,825 & 1,000 \\
\hline $\begin{array}{l}\text { LnRSE_- } \\
\text { Voluntario }\end{array}$ & 0,000 & 0,789 & 1,000 & 0,000 & 0,683 & 1,000 & 0,000 & 0,561 & 1,000 & 0,000 & 0,728 & 1,000 & 0,000 & 0,815 & 1,000 \\
\hline Ano & 0,607 & 0,013 & 0,218 & 0,439 & 0,028 & 0,294 & 0,187 & 0,053 & 0,472 & 0,017 & 0,119 & 0,776 & 0,234 & 0,135 & 0,355 \\
\hline
\end{tabular}

Em uma análise qualitativa e utilizando outra terminologia poder-se-ía descrever o resultado como: Considerando o efeito do porte das empresas analisadas que operaram com RO positivo, existiu uma correlação estatisticamente significativa entre ele e os investimentos voluntários totais em RSE, sendo que, a conjuntura econômica e social refletida no ano de publicação do BS foi um fator que determinou um comportamento diferenciador significativo somente no setor AGI, ainda que de pequena relevância.

Contrastando o modelo 1A-L com o seu correspondente 1A-P que analisou as empresas com RO negativo, observou-se que os resultados dos testes referentes às empresas com RO positivo apresentaram significância e relevância explicativa muito superiores, indicando uma maior homogeneidade no processo decisório dessas empresas sobre o montante alocado para os investimentos voluntários totais em RSE. Ademais, à exceção do setor AGI, os demais setores se mostraram insensíveis aos efeitos da conjuntura econômica e social ao longo do período do estudo.

\subsubsection{Análise dos modelos 1B-L}

Os modelos setoriais 1B-L consideraram o porte das empresas com RO positivo e analisaram os investimentos voluntários em RSE segmentados por natureza dos investimentos com os Indicadores Sociais Internos, Externos e Ambientais.

A Tabela 29 apresenta os modelos setoriais e se constata que os mesmos foram homocedástico por apresentarem Sig do Teste de Levene entre $25,0 \%$ e $92,5 \%$, superiores ao limite de 5,0\%. As assertividades dos modelos foram significativas, pois tiveram Sig igual a $0,0 \%$ (menor que 5,0\%) e 
conseguiram explicar entre $67,7 \%$ e $81,5 \%$ da variância do RO positivo, valores bastante relevantes. Os investimentos voluntários em RSE referentes aos Indicadores Sociais Internos (LnV214) se mostraram relacionados ao RO positivo das empresas porque seu Sig foi igual a $0,0 \%$, menor que $5,0 \%$, e explicaram entre $28,8 \%$ e $57,2 \%$ da variância do RO. Os setores SRV e ELE apresentaram significância respectiva de $0,3 \%$ e $0,9 \%$ nos investimentos em Indicadores Sociais Externos (LnV312), indicando relacionamento com o RO positivo e explicaram, respectivamente, 6,4\% e $6,0 \%$ da variância do RO positivo, valores inexpressivos, mas indicando uma característica diferenciadora significativa em relação aos demais setores. A conjuntura econômica e social refletida no ano de publicação do BS tiveram influência significativa somente para o setor AGI, porém a capacidade de explicação da variância do RO positivo foi de apenas $13,5 \%$, mas que representa uma sinalização de comportamento diferenciado em relação aos demais setores, ainda que de pequena monta.

Tabela 29 - Modelo 1B-L considera o porte das empresas, investimentos voluntários segmentados por natureza de RSE e operação com lucro

\begin{tabular}{|c|c|c|c|c|c|c|c|c|c|c|c|c|c|c|c|}
\hline \multirow{2}{*}{ Modelo 1B-L } & \multicolumn{3}{|c|}{ IND } & \multicolumn{3}{|c|}{ SRV } & \multicolumn{3}{|c|}{ ELE } & \multicolumn{3}{|c|}{ AGI } & \multicolumn{3}{|c|}{ FIN } \\
\hline & Sig & EQP & PO & Sig & EQP & PO & Sig & EQP & PO & Sig & EQP & PO & Sig & EQP & PO \\
\hline $\begin{array}{l}\text { Teste de } \\
\text { Levene }\end{array}$ & 0,925 & & & 0,713 & & & 0,620 & & & 0,460 & & & 0,250 & & \\
\hline $\begin{array}{l}\text { Assertividade } \\
\text { do modelo } \\
\text { (R Sqr) } \\
\end{array}$ & 0,000 & 0,810 & 1,000 & 0,000 & 0,711 & 1,000 & 0,000 & 0,677 & 1,000 & 0,000 & 0,753 & 1,000 & 0,000 & 0,815 & 1,000 \\
\hline LnV214 & 0,000 & 0,500 & 1,000 & 0,000 & 0,423 & 1,000 & 0,000 & 0,288 & 1,000 & 0,000 & 0,449 & 1,000 & 0,000 & 0,572 & 1,000 \\
\hline LnV312 & 0,301 & 0,005 & 0,178 & 0,003 & 0,064 & 0,845 & 0,009 & 0,060 & 0,751 & 0,208 & 0,020 & 0,241 & 0,319 & 0,037 & 0,165 \\
\hline Ano & 0,622 & 0,013 & 0,212 & 0,485 & 0,026 & 0,270 & 0,288 & 0,044 & 0,385 & 0,010 & 0,135 & 0,824 & 0,272 & 0,132 & 0,323 \\
\hline
\end{tabular}

Em uma análise qualitativa e utilizando outra terminologia poder-se-ía descrever o resultado como: Considerando o efeito do porte das empresas analisadas que operaram com RO positivo, existiu uma correlação estatisticamente significativa entre ele e os investimentos voluntários totais em RSE referente aos Indicadores Sociais Internos. As evidências de que os setores SRV e ELE também investiram em Indicadores Sociais Externos de forma correlacionada ao seu RO positivo é significativa, porém pouco relevante. A conjuntura econômica e social refletida no ano de publicação do BS foi um fator que determinou um comportamento diferenciado somente no setor AGI, ainda que de pouca relevância.

Contrastando o modelo 1B-L com seu correspondente 1B-P que analisou as empresas com RO negativo, observou-se que os resultados dos testes referentes às empresas com RO positivo apresentaram significância e relevância muito superiores, indicando uma maior homogeneidade no 
comportamento estratégico em RSE nessas empresas. Ademais, à exceção do setor AGI, os demais setores se mostraram insensíveis aos efeitos da conjuntura econômica e social ao longo do período do estudo.

\subsubsection{Análise dos modelos 1C-L}

Os modelos setoriais $1 \mathrm{C}$-L consideraram o porte das empresas com RO positivo e analisaram os investimentos voluntários em RSE discriminados em cada ação preconizada pelo BS padrão IBASE.

A Tabela 30 apresenta os modelos setoriais e se constata que os mesmos foram homocedásticos por apresentarem Sig do Teste de Levene entre 23,8\% e 94,2\%, superiores ao limite de 5,0\%. As assertividades dos modelos foram significativas, pois tiveram Sig igual a 0,0\% (menor que 5,0\%) e conseguiram explicar entre $74,5 \%$ e $97,2 \%$ da variância do RO positivo. Nos cinco setores foram identificados 32 investimentos voluntários em RSE significativos e que, portanto, tiveram relacionamento com o RO positivo e eles conseguiram explicar entre $0,7 \%$ e $39,5 \%$ dessa variância. Desses, 10 explicaram acima de 10,0\% da variância do RO positivo, o que pode significar um comportamento característico dos setores constituintes desse grupo. Dos investimentos em RSE preconizados no BS padrão IBASE e considerados nesse modelo, o setor IND teve 13 deles correlacionados com seu RO e foi o que teve maior quantidade, seguido por SRV com 10, AGI com 4, ELE com 3 e FIN com 2. Por outro lado, analisando o poder explicativo dos investimentos significativos notou-se clara diferenciação entre os setores IND e SRV, em contraposição aos setores AGI e FIN. Estes apresentaram menor diversificação de investimentos significativos, mas tiveram um poder explicativo substancialmente maior que os daqueles. Como o setor ELE não apresentou comportamento semelhante ao AGI e FIN, mesmo tendo poucos investimentos significativos, conclui-se que esses comportamentos têm grande potencial para serem foco de estudos mais específicos que investiguem essas características. A conjuntura econômica e social refletida no ano de publicação do BS se mostrou significativa somente nos setores SRV e AGI aos níveis de 2,9\% e 15,7\% respectivamente. Para o setor SRV o valor é inexpressivo para uso prático que possa ser utilizado na determinação de um modelo explicativo. 
Tabela 30 - Modelo 1C-L considera o porte das empresas, investimentos voluntários individualizados por ação em RSE do BS padrão IBASE e operação com lucro

\begin{tabular}{|c|c|c|c|c|c|c|c|c|c|c|c|c|c|c|c|}
\hline \multirow{2}{*}{ Modelo 1C-L } & \multicolumn{3}{|c|}{ IND } & \multicolumn{3}{|c|}{ SRV } & \multicolumn{3}{|c|}{ ELE } & \multicolumn{3}{|c|}{ AGI } & \multicolumn{3}{|c|}{ FIN } \\
\hline & Sig & EQP & PO & Sig & EQP & PO & Sig & EQP & PO & Sig & EQP & PO & Sig & EQP & PO \\
\hline Levene & 365 & & & 910 & & & 0,238 & & & 358 & & & 942 & & \\
\hline $\begin{array}{l}\text { Assertividade } \\
\text { do modelo } \\
\text { (R-Sqr) }\end{array}$ & 00 & 0,828 & 000 & 0,000 & 08 & 1,000 & 0,000 & 0,745 & 00 & 0,000 & 0,868 & 0 & 0,000 & 0,972 & 1,000 \\
\hline $\mathrm{Lr}$ & 38 & 23 & 0,546 & +30 & 001 & 0,124 & 0,625 & 0,003 & 0,077 & 0,550 & 0,006 & 0,091 & 038 & 0,395 & 0,580 \\
\hline $\mathrm{Ln}$ & 000 & 0,104 & 0,995 & 0,000 & 0,038 & 0,996 & 0,001 & 0,121 & 0,933 & 0,000 & 0,220 & 0,980 & 0,546 & 0,042 & 0,087 \\
\hline & 221 & 0,008 & 0,231 & 0,000 & 0,080 & 1,000 & 0,156 & 0,023 & 0,294 & 0,370 & 0,014 & 0,144 & 0,064 & 0,332 & 0,471 \\
\hline LnV205 & 694 & 0,001 & 0,068 & 0,000 & 0,034 & 0,992 & 0,993 & 0,000 & 0,050 & 0,869 & 0,000 & 0,053 & 0,085 & 0,294 & 0,408 \\
\hline & 0,033 & 0,025 & 0,571 & 0,098 & 0,005 & 0,380 & 0,917 & 0,000 & 0,051 & 0,815 & 0,001 & 0,056 & 0,614 & 0,030 & 0,076 \\
\hline & & 0,007 & 0,205 & & 0,009 & 0,590 & 0,902 & 0,000 & 52 & 0,051 & 0,063 & 0,499 & 0,600 & 0,032 & 0,078 \\
\hline & 034 & 0,024 & 0,565 & 0,631 & 0,000 & 0,077 & 0,061 & 0,039 & 0,466 & 0,006 & 0,121 & 0,801 & 0,328 & 0,106 & 0,153 \\
\hline & & 52 & 1,000 & & 5 & 0,2 & 38 & 47 & 0,548 & 0,000 & 0,208 & 0,972 & 73 & 0,131 & 0,182 \\
\hline & 0,032 & 0,025 & 0,573 & 0,000 & 0,114 & 1,000 & 0,261 & 0,014 & 0,201 & 0,441 & 0,010 & 0,119 & 0,860 & 0,004 & 0,053 \\
\hline & 0,043 & 0,022 & 0,528 & 0,580 & 0,001 & 0,086 & 0,969 & 0,000 & 0,050 & 0,917 & 0,000 & 0,051 & 0,836 & 0,005 & 0,054 \\
\hline & 0,020 & 0,029 & 0,644 & 0,020 & 0,010 & 0,642 & 0,240 & 0,016 & 0,216 & 0,851 & 0,001 & 0,054 & 0,362 & 0,093 & 0,138 \\
\hline & 0,222 & 0,008 & 0,230 & 0,000 & 0,035 & 0,993 & 0,397 & 0,008 & 0,134 & 0,652 & 0,003 & 0,073 & 0,876 & 0,003 & 0,052 \\
\hline & 0,003 & 0,046 & 0,840 & 0,992 & 0,000 & 0,050 & & 0,000 & & & 0,000 & & & 0,000 & \\
\hline & 0,961 & 0,000 & 0,050 & 0,387 & 0,001 & 0,139 & 0,119 & 0,027 & 0,344 & 0,117 & 0,041 & 0,347 & 0,040 & 0,390 & 0,572 \\
\hline $\mathrm{Ln}$ & 0,137 & 0,012 & 0,318 & 0,050 & 0,007 & 0,499 & 0,176 & 0,021 & 0,271 & 0,133 & 0,038 & 0,322 & 0,440 & 0,068 & 0,112 \\
\hline & 0,000 & 0,111 & 0,997 & 0,024 & 0,009 & 0,618 & $\mathbf{0 , 0 2 9}$ & 0,053 & 0,595 & 0,709 & 0,002 & 0,066 & & 0,000 & \\
\hline 01 & 0,050 & 0,021 & 0,500 & 0,000 & 0,073 & 1,000 & 0,221 & 0,017 & 0,230 & 0,001 & 0,167 & 0,923 & 0,692 & 0,018 & 0,066 \\
\hline & 0,002 & 0,050 & 0,866 & 0,229 & 0,003 & 0,225 & 0,501 & 0,005 & 0,103 & 0,595 & 0,005 & 0,082 & 0,371 & 0,090 & 0,135 \\
\hline LnV403 & 0,002 & 0,049 & 0,863 & 0,750 & 0,000 & 0,062 & 0,195 & 0,019 & 0,252 & 0,843 & 0,001 & 0,054 & 0,692 & 0,018 & 0,066 \\
\hline Ano & 0,903 & 0,006 & 0,106 & 0,000 & 0,029 & 0,981 & 0,255 & 0,057 & 0,407 & 0,017 & 0,157 & 0,774 & 0,477 & 0,231 & 0,177 \\
\hline
\end{tabular}

Em uma análise qualitativa e utilizando outra terminologia poder-se-ía descrever o resultado como: Considerando o efeito do porte das empresas analisadas que operaram com RO positivo, existiu uma correlação estatisticamente significativa entre ele e alguns dos investimentos voluntários em RSE preconizados no BS padrão IBASE. Os setores que tiveram maior quantidade de investimentos em RSE foram IND e SRV, respectivamente com 13 e 10 programas dentro dos investimentos em RSE do BS padrão IBASE, seguidos por AGI com 4, ELE com 3 e FIN com 2, denotando que o setor foi um fator relevante na discriminação das estratégias de investimento em RSE. A conjuntura econômica e social refletida no ano de publicação do BS foi um fator que determinou um comportamento diferenciador significativo nos setores SRV e AGI, porém, relevante somente no setor AGI. Os setores IND e SRV aparentaram desenvolver suas estratégias de investimentos em RSE mais atreladas ao desempenho financeiro, já que apresentaram maior quantidade de ações correlacionadas ao RO positivo. As estratégias dos demais setores aparentaram a existência de outros direcionadores decisórios para a determinação dos investimentos em RSE. Não existe 
referência comparativa desses modelos com os das empresas com RO negativo pelo fato deles não terem sido considerados por falta de quantidade suficiente de casos na amostra.

\subsubsection{Análise dos modelos 2A-L}

Os modelos setoriais 2A-L consideraram o porte das empresas com RO positivo e analisaram os investimentos totais que compreenderam os voluntários e os compulsórios em RSE.

A Tabela 31 apresenta os modelos setoriais e se constata que os mesmos foram homocedásticos por apresentarem Sig do Teste de Levene entre 26,7\% e 99,0\%, superiores ao limite de 5,0\%. As assertividades dos modelos foram significativas, pois tiveram Sig igual a $0,0 \%$ (menor que 5,0\%) e conseguiram explicar entre $56,7 \%$ e $82,5 \%$ da variância do RO positivo, valores muito relevantes. Os investimentos voluntários em RSE totalizados na variável LnRSE_Total (total dos investimentos voluntários e compulsórios em RSE) se mostraram relacionados ao RO positivo da empresa porque seu Sig foi igual a $0,0 \%$, menor que $5,0 \%$, e seus valores explicaram entre $52,4 \%$ e $81,4 \%$ dessa variância, um valor muito relevante. A conjuntura econômica e social refletida no ano de publicação do BS e o setor não tiveram influência explicativa significativa em nenhum dos setores do estudo.

Tabela 31 - Modelo 2A-L considera o porte das empresas, investimentos totais em RSE e operação com lucro

\begin{tabular}{l|l|l|l|l|l|l|l|l|l|l|l|l|l|l|l}
\hline \multirow{2}{*}{\begin{tabular}{l} 
Modelo 2A-L \\
\cline { 2 - 12 }
\end{tabular}} & Sig & EQP & PO & Sig & EQP & PO & Sig & EQP & PO & Sig & EQP & PO & Sig & EQP & PO \\
\hline $\begin{array}{l}\text { Teste de } \\
\text { Levene }\end{array}$ & $\mathbf{0 , 6 3 3}$ & & & $\mathbf{0 , 2 6 7}$ & & & $\mathbf{0 , 9 9 0}$ & & & $\mathbf{0 , 7 4 3}$ & & & $\mathbf{0 , 2 8 1}$ & & \\
\hline $\begin{array}{l}\text { Assertividade } \\
\text { do modelo } \\
\text { (R-Sqr) }\end{array}$ & $\mathbf{0 , 0 0 0}$ & 0,760 & 1,000 & $\mathbf{0 , 0 0 0}$ & 0,725 & 1,000 & $\mathbf{0 , 0 0 0}$ & 0,567 & 1,000 & $\mathbf{0 , 0 0 0}$ & 0,686 & 1,000 & $\mathbf{0 , 0 0 0}$ & 0,825 & 1,000 \\
\hline $\begin{array}{l}\text { LnRSE_Total } \\
\mathbf{0 , 0 0 0}\end{array}$ & 0,755 & 1,000 & 0,000 & 0,715 & 1,000 & $\mathbf{0 , 0 0 0}$ & 0,524 & 1,000 & $\mathbf{0 , 0 0 0}$ & 0,677 & 1,000 & $\mathbf{0 , 0 0 0}$ & 0,814 & 1,000 \\
\hline
\end{tabular}

Em uma análise qualitativa e utilizando outra terminologia poder-se-ía descrever o resultado como: Considerando o efeito do porte das empresas analisadas que operaram com RO positivo, existiu uma correlação estatisticamente significativa entre ele e os seus investimentos em RSE totais, voluntários e compulsórios, sendo que a conjuntura econômica e social refletida no ano de publicação do BS e o setor não foram fatores diferenciadores das decisões de investimento em RSE nessas empresas. 
Contrastando o modelo 2A-L com seu correspondente 1A-L que se diferenciam respectivamente em investimentos voluntários e totais em RSE, observa-se um comportamento semelhante em todos os setores, a menos do setor AGI que no modelo 2A-L deixa de ser influenciado significativamente pela conjuntura econômica e social refletida no ano de publicação do BS. Os modelos correspondentes 2A-L e 2A-P, diferenciados da condição respectiva de lucro e prejuízo apresentaram comportamentos significativamente iguais, porém o poder de explicação do modelo 2A-L é muito superior ao 2A-P.

\subsubsection{Análise dos modelos 2B-L}

Os modelos setoriais 2B-L consideraram o porte das empresas com RO positivo e analisaram os investimentos totais que compreendem os valores voluntários e compulsórios em RSE, segmentados por natureza dos investimentos com os Indicadores Sociais Internos, Externos e Ambientais.

A Tabela 32 apresenta os modelos setoriais e se constata que os mesmos foram homocedástico por apresentarem Sig do Teste de Levene entre 35,5\% e 99,3\%, superiores ao limite de 5,0\%. As assertividades dos modelos foram significativas, pois tiveram Sig igual a $0,0 \%$ (menor que 5,0\%) e conseguiram explicar entre $65,9 \%$ e $83,0 \%$ da variância do RO positivo, valores bastante relevantes. Os investimentos totais em RSE, referentes aos Indicadores Sociais Internos (V213), se mostraram relacionados ao RO positivo das empresas porque seu Sig foi igual a $0,0 \%$, menor que $5,0 \%$, e seus valores explicaram entre $27,2 \%$ e $63,6 \%$ da variância do RO positivo. O setor SRV foi significativo com Sig igual a $0,0 \%$ no que se refere aos investimentos em Indicadores Sociais Externos (V314) e apresentou tênue relevância, explicando $5,0 \%$ da variância do RO positivo, um valor inexpressivo para uso em modelos explicativos, mas indicando uma característica diferenciadora significativa em relação aos demais setores. O setor AGI foi significativo com Sig igual a $0,0 \%$ no que se refere aos investimentos em Indicadores Ambientais (V404), explicando 7,7\% da variância do RO, indicando uma característica diferenciadora significativa dos demais setores, embora de tênue relevância. A conjuntura econômica e social refletida no ano de publicação do BS teve influência significativa somente para o setor AGI, porém a capacidade de explicação da variância do RO foi de apenas $14,2 \%$, mas que sinalizou um comportamento diferenciado relevante em relação aos demais setores. 
Tabela 32 - Modelo 2B-L considera o porte das empresas, investimentos totais segmentados por natureza de RSE e operação com lucro

\begin{tabular}{l|c|c|c|c|c|c|c|c|c|c|c|c|c|c|c}
\hline \multirow{2}{*}{\begin{tabular}{l} 
Modelo 2B-L \\
\cline { 2 - 13 }
\end{tabular}} & $\mathbf{3 i g}$ & EQP & PO & Sig & EQP & PO & Sig & EQP & PO & Sig & EQP & PO & Sig & EQP & PO \\
\hline $\begin{array}{l}\text { Teste de } \\
\text { Levene }\end{array}$ & $\mathbf{0 , 9 9 3}$ & & & $\mathbf{0 , 6 4 4}$ & & & $\mathbf{0 , 6 8 0}$ & & & $\mathbf{0 , 7 5 4}$ & & & $\mathbf{0 , 1 0 1}$ & & \\
\hline $\begin{array}{l}\text { Assertividade } \\
\text { do modelo } \\
\text { (R Sqr) }\end{array}$ & $\mathbf{0 , 0 0 0}$ & 0,795 & 1,000 & $\mathbf{0 , 0 0 0}$ & 0,670 & 1,000 & $\mathbf{0 , 0 0 0}$ & 0,659 & 1,000 & $\mathbf{0 , 0 0 0}$ & 0,713 & 1,000 & $\mathbf{0 , 0 0 0}$ & 0,824 & 1,000 \\
\hline LnV213 & $\mathbf{0 , 0 0 0}$ & 0,444 & 1,000 & $\mathbf{0 , 0 0 0}$ & 0,272 & 1,000 & $\mathbf{0 , 0 0 0}$ & 0,327 & 1,000 & $\mathbf{0 , 0 0 0}$ & 0,445 & 1,000 & $\mathbf{0 , 0 0 0}$ & 0,661 & 1,000 \\
\hline LnV314 & 0,110 & 0,013 & 0,358 & $\mathbf{0 , 0 1 0}$ & 0,050 & 0,738 & 0,244 & 0,012 & 0,213 & 0,847 & 0,000 & 0,054 & 0,518 & 0,014 & 0,097 \\
\hline LnV404 & 0,132 & 0,011 & 0,324 & 0,798 & 0,000 & 0,057 & 0,994 & 0,000 & 0,050 & $\mathbf{0 , 0 1 3}$ & 0,077 & 0,714 & 0,393 & 0,024 & 0,134 \\
\hline Ano & 0,877 & 0,006 & 0,117 & 0,719 & 0,016 & 0,173 & 0,196 & 0,053 & 0,463 & $\mathbf{0 , 0 0 7}$ & 0,142 & 0,848 & 0,348 & 0,134 & 0,319 \\
\hline
\end{tabular}

Em uma análise qualitativa e utilizando outra terminologia poder-se-ía descrever o resultado como: Considerando o efeito do porte das empresas analisadas que operaram com RO positivo, existiu uma correlação estatisticamente significativa entre ele e os investimentos totais em RSE referente aos Indicadores Sociais Internos. Existiu tênue evidência de que as empresas do setor SRV também investiram em Indicadores Sociais Externos de forma relacionada ao seu RO positivo e da mesma forma, o setor AGI relativamente aos Indicadores Ambientais. A conjuntura econômica e social refletida no ano de publicação do BS foi um fator que determinou um comportamento diferenciador somente no setor AGI, ainda que de pouca relevância.

Contrastando o modelo 2B-L com seu correspondente 1B-L que se diferenciaram respectivamente em investimentos voluntários e totais em RSE, observou-se um comportamento semelhante em todos os setores, a menos do setor ELE que no modelo 2B-L deixou de ter influência significativa nos investimentos em Indicadores Sociais Externos e o setor AGI, que percebeu uma influência significativa nos investimentos em Indicadores Ambientais. Portanto, essa diferenciação comportamental pode ser devida ao fator voluntário e compulsório da natureza dos investimentos em RSE. Os modelos correspondentes 2B-L e 2B-P, diferenciados da condição respectiva de lucro e prejuízo, apresentaram significâncias semelhantes no que se refere aos investimentos em Indicadores Sociais Internos. 


\subsubsection{Análise dos modelos 2C-L}

Os modelos setoriais $2 \mathrm{C}$-L consideraram o porte das empresas com RO positivo e analisaram os investimentos totais, voluntários e compulsórios, em RSE e discriminados em cada ação preconizada pelo BS padrão IBASE.

A Tabela 33 apresenta os modelos setoriais e se constata que os mesmos foram homocedásticos por apresentarem Sig do Teste de Levene entre 20,9\% e 87,1\%, superiores ao limite de 5,0\%. As assertividades dos modelos foram significativas, pois tiveram Sig igual a $0,0 \%$ (menor que 5,0\%) e conseguiram explicar entre $74,8 \%$ e $98,5 \%$ da variância do RO positivo, valores bastante relevantes. Nos cinco setores foram identificados 24 investimentos voluntários em RSE significativos com Sig entre $0,0 \%$ e $4,8 \%$ e eles conseguiram explicar entre $2,9 \%$ e $53,8 \%$ da variância do RO positivo. Desses, 10 explicaram acima de 10,0\% da variância do RO positivo, o que pode significar um comportamento característico dos setores constituintes desse grupo. Dos investimentos em RSE preconizados no BS padrão IBASE e considerados nesse modelo, o setor IND teve 8 , SRV teve 7 e AGI teve 5 deles correlacionados com seu RO positivo e foram os que tiveram maior quantidade, seguidos por ELE com 3 e FIN com 1. Por outro lado, analisando o poder explicativo dos investimentos significativos, notou-se clara diferenciação entre os setores IND e SRV em contraposição aos setores AGI e FIN. Esses apresentaram menor diversificação de investimentos significativos, mas tiveram um poder explicativo substancialmente maior que os daqueles. A conjuntura econômica e social refletida no ano de publicação do BS se mostrou significativa com Sig igual a $3,3 \%$, menor que $5,0 \%$, somente no setor AGI ao poder explicativo de $14,1 \%$, indicando que, nesse caso, ela afetou as decisões dos investimentos em RSE, ainda que a um nível pouco relevante. 
Tabela 33 - Modelo 2C-L considera o porte das empresas, investimentos totais individualizados por ação em RSE do BS padrão IBASE e operação com lucro

\begin{tabular}{|c|c|c|c|c|c|c|c|c|c|c|c|c|c|c|c|}
\hline \multirow{2}{*}{ Modelo 2C-L } & \multicolumn{3}{|c|}{ IND } & \multicolumn{3}{|c|}{ SRV } & \multicolumn{3}{|c|}{ ELE } & \multicolumn{3}{|c|}{ AGI } & \multicolumn{3}{|c|}{ FIN } \\
\hline & \begin{tabular}{|l|} 
Sig \\
\end{tabular} & EQP & PO & Sig & EQP & PO & Sig & EQP & PO & Sig & EQP & PO & Sig & EQP & PO \\
\hline $\begin{array}{l}\text { Teste de } \\
\text { Levene }\end{array}$ & 0,295 & & & 0,871 & & & 0,222 & & & 0,209 & & & 0,601 & & \\
\hline $\begin{array}{l}\text { Assertividade } \\
\text { do modelo } \\
\text { (R-Sqr) }\end{array}$ & 0,000 & 0,854 & 1,000 & 0,000 & 0,838 & 1,000 & 0,000 & 0,748 & 1,000 & {$[0,000$} & 0,875 & 1,000 & 0,000 & 0,985 & 1,000 \\
\hline LnV202 & 0,000 & 0,141 & 1,000 & 0,316 & 0,009 & 0,170 & 0,301 & 0,012 & 0,177 & 0,079 & 0,053 & 0,420 & 0,147 & 0,276 & 0,292 \\
\hline LnV203 & 0,000 & 0,102 & 0,994 & 0,076 & 0,029 & 0,427 & 0,012 & 0,071 & 0,720 & 0,000 & 0,213 & 0,972 & 0,291 & 0,157 & 0,168 \\
\hline LnV204 & 0,314 & 0,006 & 0,171 & 0,000 & 0,116 & 0,963 & 0,120 & 0,028 & 0,342 & 0,183 & 0,031 & 0,263 & 0,845 & 0,006 & 0,054 \\
\hline LnV205 & 0,992 & 0,000 & 0,050 & 0,967 & 0,000 & 0,050 & 0,902 & 0,000 & 0,052 & 0,864 & 0,001 & 0,053 & 0,024 & 0,538 & 0,690 \\
\hline LnV207 & 0,463 & 0,003 & 0,113 & 0,024 & 0,046 & 0,624 & 0,970 & 0,000 & 0,050 & 0,048 & 0,067 & 0,510 & 0,597 & 0,042 & 0,077 \\
\hline LnV209 & 0,001 & 0,062 & 0,928 & 0,796 & 0,001 & 0,058 & 0,070 & 0,037 & 0,443 & 0,008 & 0,117 & 0,769 & 0,303 & 0,150 & 0,162 \\
\hline LnV210 & 0,000 & 0,122 & 0,999 & 0,031 & 0,042 & 0,581 & 0,032 & 0,052 & 0,577 & 0,000 & 0,218 & 0,975 & 0,383 & 0,110 & 0,128 \\
\hline LnV302 & 0,020 & 0,029 & 0,643 & 0,002 & 0,084 & 0,880 & 0,196 & 0,019 & 0,252 & 0,569 & 0,006 & 0,087 & 0,990 & 0,000 & 0,050 \\
\hline LnV304 & 0,005 & 0,042 & 0,799 & & 0,000 & & & 0,000 & & & 0,000 & & & 0,000 & \\
\hline LnV305 & 0,924 & 0,000 & 0,051 & 0,006 & 0,068 & 0,797 & 0,859 & 0,000 & 0,054 & 0,697 & 0,003 & 0,067 & 0,751 & 0,015 & 5,060 \\
\hline LnV311 & 0,000 & 0,089 & 0,987 & 0,000 & 0,121 & 0,970 & 0,025 & 0,057 & 0,617 & 0,686 & 0,003 & 0,068 & & 0,000 & \\
\hline LnV401 & 0,368 & 0,004 & 0,146 & 0,726 & 0,001 & 0,064 & 0,140 & 0,025 & 0,313 & 0,001 & 0,179 & 0,934 & 0,743 & 0,016 & 50,060 \\
\hline LnV402 & 0,003 & 0,049 & 0,854 & 0,316 & 0,009 & 0,169 & 0,531 & 0,005 & 0,095 & 0,854 & 0,001 & 0,054 & 0,830 & 0,007 & 70,054 \\
\hline LnV403 & 0,060 & 0,020 & 0,470 & 0,043 & 0,037 & 0,530 & 0,145 & 0,024 & 0,306 & 0,812 & 0,001 & 0,056 & 0,422 & 0,094 & $+0,115$ \\
\hline Ano & 0,878 & 0,007 & 0,116 & 0,592 & 0,025 & 0,221 & 0,286 & 0,055 & 0,384 & 0,033 & 0,141 & 0,697 & 0,722 & 0,163 & 0,104 \\
\hline
\end{tabular}

Em uma análise qualitativa e utilizando outra terminologia poder-se-ía descrever o resultado como:

Considerando o efeito do porte das empresas analisadas que operaram com RO positivo, existiu uma correlação estatisticamente significativa entre ele e alguns dos investimentos voluntários em RSE preconizados no BS padrão IBASE. Dentro dos investimentos em RSE do BS padrão IBASE, o setor que teve maior quantidade de investimentos de RSE foi IND com 8 programas, seguidos por SRV com 7, AGI com 5, ELE com 3 e FIN com 1, denotando que o setor foi um fator relevante na discriminação das estratégias de investimento em RSE. A conjuntura econômica e social refletida no ano de publicação do BS foi um fator que determinou um comportamento diferenciador significativo somente no setor AGI.

Contrastando o modelo 2C-L com o correspondente 1C-L que analisou respectivamente os investimentos voluntários e totais em RSE das empresas com RO positivo, observou-se que os modelos tiveram nível de assertividade próximos. A quantidade de programas preconizados pelo BS padrão IBASE que estavam correlacionados com o RO positivo do modelo $1 \mathrm{C}$-L foi de 32, inferior aos 24 presentes no modelo 2C-L e 21 deles estavam presentes simultaneamente nos dois modelos, confirmando a relativa semelhança entre os modelos. Não existe referência comparativa desses modelos com os das empresas com RO negativo pelo fato desses não terem sido considerados por falta de quantidade suficiente de casos na amostra. 


\subsubsection{Análise dos modelos 3A-L}

Os modelos setoriais 3A-L foram elaborados visando analisar as estratégias das empresas onde o porte das mesmas foi retirado da percepção do modelo. Dessa forma, o trabalho buscou identificar o impacto que essa situação pudesse ter interferido nos investimentos voluntários totais em RSE e sua relação com o RO positivo.

A Tabela 34 apresenta os modelos setoriais e se constata que os mesmos foram homocedásticos por apresentarem Sig do Teste de Levene entre $18,0 \%$ e 95,5\%, superiores ao limite de 5,0\%. Os modelos referentes aos setores IND, SRV e ELE não foram válidos, por apresentarem as assertividades dos modelos com Sig entre $8,5 \%$ e $41,9 \%$, superiores a 5,0\%, o que permitiu concluir que, nesses casos, não existiu correlação entre os investimentos voluntários totais e o RO positivo. As assertividades dos modelos referentes aos setores AGI e FIN foram significativas, pois tiveram Sig respectivos iguais a $0,6 \%$ e $0,0 \%$ (menor que 5,0\%) e conseguiram explicar respectivamente $14,7 \%$ e $75,3 \%$ da variância do RO positivo e as variáveis LnR_RSE_Voluntario (investimentos voluntários totais em RSE) foram significativas porque seus Sigs foram iguais respectivamente a $0,3 \%$ e $0,0 \%$; portanto, considerou-se que elas estavam relacionadas ao ROs positivos e explicaram respectivamente $9,5 \%$ e $75,0 \%$ da variância dos mesmos. A conjuntura econômica e social refletida no ano de publicação do BS teve poder explicativo significativo somente no setor AGI, com Sig igual a $4,3 \%$, menor que $5,0 \%$, e poder explicativo de $8,6 \%$ da variação do RO positivo, um valor pouco relevante.

Tabela 34 - Modelo 3A-L considera investimentos voluntários em RSE, operação com lucro e dessensibiliza o porte das empresas

\begin{tabular}{l|c|c|c|c|c|c|c|c|c|c|c|c|c|c|c}
\hline Modelo 3A-L & \multicolumn{3}{|c|}{ IND } & \multicolumn{3}{c|}{ SRV } & \multicolumn{3}{c|}{ ELE } & \multicolumn{3}{c|}{ AGI } & \multicolumn{3}{c}{ FIN } \\
\cline { 2 - 13 } & Sig & EQP & PO & Sig & EQP & PO & Sig & EQP & PO & Sig & EQP & PO & Sig & EQP & PO \\
\hline $\begin{array}{l}\text { Teste de } \\
\text { Levene }\end{array}$ & $\mathbf{0 , 7 5 3}$ & & & $\mathbf{0 , 1 8 0}$ & & & $\mathbf{0 , 7 7 2}$ & & & $\mathbf{0 , 9 5 5}$ & & & $\mathbf{0 , 2 6 7}$ & \\
\hline $\begin{array}{l}\text { Assertividade } \\
\text { do modelo } \\
\text { (R-Sqr) }\end{array}$ & 0,085 & 0,043 & 0,656 & 0,100 & 0,057 & 0,629 & 0,419 & 0,037 & 0,349 & $\mathbf{0 , 0 0 6}$ & 0,147 & 0,885 & $\mathbf{0 , 0 0 0}$ & 0,753 & 1,000 \\
\hline $\begin{array}{l}\text { LnR_RSE_ } \\
\text { Voluntario }\end{array}$ & 0,089 & 0,013 & 0,397 & 0,183 & 0,011 & 0,265 & 0,898 & 0,000 & 0,052 & $\mathbf{0 , 0 0 3}$ & 0,095 & 0,859 & $\mathbf{0 , 0 0 0}$ & 0,750 & 1,000 \\
\hline Ano & 0,137 & 0,031 & 0,534 & 0,110 & 0,047 & 0,570 & 0,297 & 0,036 & 0,380 & $\mathbf{0 , 0 4 3}$ & 0,086 & 0,661 & 0,310 & 0,108 & 0,300 \\
\hline
\end{tabular}


Em uma análise qualitativa e utilizando outra terminologia poder-se-ía descrever o resultado como: Dessensibilizado o efeito do porte das empresas que operaram com RO positivo, existe uma correlação estatisticamente significativa entre o RO positivo e os investimentos voluntários totais em RSE somente nos setores AGI e FIN, sendo que, a conjuntura econômica e social refletida no ano de publicação do BS foi um fator que determinou um comportamento diferenciador significativo somente no setor AGI, ainda que de pequena relevância. A decisão de investimento voluntário total em RSE não foi diferenciada pelo setor de atuação das empresas analisadas, pois todas tiveram um comportamento qualitativamente semelhante. Os investimentos voluntários totais em RSE referentes aos setores IND, SRV e ELE não apresentaram qualquer correlação com o RO positivo.

Contrastando o modelo 3A-L com os modelos correspondentes 1A-L e 2A-L que percebiam o porte das empresas, observou-se que o setor AGI apresentou correlação com o RO positivo; entretanto, ao não considerar o porte das empresas, no caso dos modelos 3A-L, observou-se que esse relacionamento, ainda que apresentasse significância, seu poder explicativo foi bastante reduzido. No caso do setor FIN, o porte não fez diferença no comportamento dos modelos, isso é, os investimentos voluntários totais em RSE apresentaram correlação com o RO positivo com valores basatante relevantes em ambas condições.

\subsubsection{Análise dos modelos 3B-L}

Os modelos setoriais 3B-L foram elaborados visando analisar as estratégias das empresas onde o porte das mesmas foi retirado da percepção do modelo. Dessa forma, o trabalho buscou identificar o impacto que essa situação possa ter interferido nos investimentos voluntários em RSE segmentados por natureza dos investimentos com os Indicadores Sociais Internos, Externos e Ambientais e sua relação com o RO positivo.

A Tabela 35 apresenta os modelos setoriais e se constatou que os mesmos foram homocedásticos por apresentarem Sig do Teste de Levene entre 26,7\% e 90,6\%, superiores ao limite de 5,0\%. Os modelos referentes aos setores IND, SRV e ELE não foram válidos, por apresentarem as assertividades dos modelos com Sig entre 33,6\% e 42,6\%, superiores a 5,0\%, o que permitiu 
concluir que, nesses casos, não existiu correlação entre os investimentos voluntários totais segmentados nos Indicadores Sociais Internos, Externos e Ambientais e o RO positivo. As assertividades dos modelos referentes aos setores AGI e FIN foram significativas, pois tiveram Sig respectivos iguais a $1,3 \%$ e $0,0 \%$ (menor que $5,0 \%$ ) e conseguiram explicar respectivamente, $18,4 \%$ e 73,2\% da variância do RO positivo. Os investimentos voluntários em RSE, referentes aos Indicadores Sociais Internos (LnRLV214) do setor FIN, se mostraram relacionados ao RO positivo das empresas porque seu Sig foi igual a 0,0\%, menor que 5,0\%, e explicou 67,6\% da variância do RO positivo, bastante relevante. O modelo referente ao setor AGI não apresentou investimentos em RSE relacionados ao RO positivo, pois nenhum dos segmentos de investimento teve significância, tendo apresentado uma reduzida relevância da influência da conjuntura econômica e social $(10,8 \%)$ sobre o RO positivo.

Tabela 35 - Modelo 3B-L considera investimentos voluntários segmentados por programas de RSE, operação com lucro e dessensibiliza o porte das empresas

\begin{tabular}{l|l|l|l|l|l|l|l|l|l|l|l|l|l|l|l|l}
\hline \multirow{2}{*}{\begin{tabular}{l} 
Modelo 3B-L \\
\cline { 2 - 12 }
\end{tabular}} & Sig & EQP & PO & Sig & EQP & PO & Sig & EQP & PO & Sig & EQP & PO & Sig & EQP & PO \\
\hline $\begin{array}{l}\text { Teste de } \\
\text { Levene }\end{array}$ & $\mathbf{0 , 9 0 6}$ & & & $\mathbf{0 , 2 6 7}$ & & & $\mathbf{0 , 8 9 7}$ & & & $\mathbf{0 , 3 7 8}$ & & & $\mathbf{0 , 3 9 5}$ & & \\
\hline $\begin{array}{l}\text { Assertividade } \\
\text { do modelo } \\
\text { (R Sqr) }\end{array}$ & 0,341 & 0,038 & 0,484 & 0,336 & 0,058 & 0,480 & 0,426 & 0,061 & 0,420 & $\mathbf{0 , 0 1 3}$ & 0,184 & 0,874 & $\mathbf{0 , 0 0 0}$ & 0,732 & 1,000 \\
\hline LnRLV214 & 0,063 & 0,017 & 0,460 & 0,603 & 0,002 & 0,081 & 0,293 & 0,010 & 0,182 & 0,716 & 0,002 & 0,065 & $\mathbf{0 , 0 0 0}$ & 0,676 & 1,000 \\
\hline Ano & 0,461 & 0,018 & 0,285 & 0,406 & 0,030 & 0,312 & 0,455 & 0,032 & 0,284 & $\mathbf{0 , 0 2 9}$ & 0,108 & 0,712 & 0,370 & 0,108 & 0,261 \\
\hline
\end{tabular}

Em uma análise qualitativa e utilizando outra terminologia poder-se-ía descrever o resultado como: Dessensibilizado o efeito do porte das empresas que operaram com RO positivo, foi observada uma correlação estatisticamente significativa entre o RO positivo e seus investimentos voluntários totais em RSE referente aos Indicadores Sociais Internos somente nas empresas do setor FIN que foram analisadas. O setor AGI não evidenciou uma relação entre os investimentos sociais e o RO positivo, mas apontou uma tênue relevância da conjuntura econômica e social na explicação da variação do RO positivo. Os setores IND, SRV e ELE não apresentaram qualquer relação dos investimentos em RSE com o RO positivo.

Contrastando o modelo 3B-L com o modelo correspondente 1B-L observou-se que o porte da empresa é um fator diferenciador da capacidade explicativa do modelo em relação ao RO positivo nos setores IND, SRV, ELE e AGI, pois o claro relacionamento entre o RO positivo em relação aos investimentos em RSE identificado nos modelos 1B-L não estão presentes nos mesmos modelos 
setoriais 3B-L. Somente os modelos referentes ao setor FIN apresentaram relacionamento entre RO positivo e investimentos em RSE, independente de considerar ou não o porte no modelo das empresas analisadas.

\subsubsection{Análise dos modelos 3C-L}

Os modelos setoriais 3C-L foram elaborados visando analisar as estratégias das empresas onde o porte das mesmas foi retirado da percepção do modelo. Dessa forma, o trabalho buscou identificar o impacto que essa situação pudesse ter interferido nos investimentos voluntários em RSE e discriminados em cada ação preconizada pelo BS padrão IBASE.

A Tabela 36 apresenta os modelos setoriais e se constata que os mesmos foram homocedásticos por apresentarem Sig do Teste de Levene entre 36,0\% e 87,2\%, superiores ao limite de 5,0\%. As assertividades dos modelos foram significativas, pois tiveram Sig entre $0,0 \%$ e $0,8 \%$ (menor que $5,0 \%$ e conseguiram explicar entre $32,3 \%$ e $93,4 \%$ da variância do RO positivo, valores bastante relevantes no caso do setor FIN. O modelo do setor ELE não foi considerado válido, pois o nível de assertividade foi igual a $37,3 \%$, superior a $5,0 \%$ e nesse setor não se pode dizer que existiu correlação entre os investimentos voluntários em RSE e o RO positivo.

Nos quatro setores, IND, SRV, AGI e FIN foram identificados 20 investimentos voluntários em RSE significativos com Sig entre $0,0 \%$ e $4,2 \%$ e eles conseguiram explicar entre $2,8 \%$ e $53,5 \%$ da variância do RO positivo. Desses, 8 explicaram acima de 10,0\% da variância do RO positivo, o que pode significar um comportamento característico dos setores constituintes desse grupo. Dos investimentos em RSE preconizados no BS padrão IBASE e considerados nesse modelo, o setor IND teve 8, SRV e AGI tiveram 5 e FIN teve 2 deles correlacionados com seu RO positivo. Por outro lado, analisando o poder explicativo dos investimentos significativos notou-se elevado poder explicativo pelo setor FIN, comparativamente aos dos demais setores. A conjuntura econômica e social refletida no ano de publicação do BS se mostrou significativa com Sig igual a 3,3\%, menor que $5,0 \%$, somente no setor AGI, ao poder explicativo de $14,1 \%$, indicando que, nesse caso, ela afetou as decisões dos investimentos em RSE, ainda que a um nível pouco relevante. 
Tabela 36 - Modelo 3C-L considera os investimentos totais individualizados por ação em RSE do BS padrão IBASE, operação com lucro e dessensibiliza o porte das empresas

\begin{tabular}{|c|c|c|c|c|c|c|c|c|c|c|c|c|c|c|c|}
\hline \multirow{2}{*}{ Modelo 3C-L } & \multicolumn{3}{|c|}{ IND } & \multicolumn{3}{|c|}{ SRV } & \multicolumn{3}{|c|}{ ELE } & \multicolumn{3}{|c|}{ AGI } & \multicolumn{3}{|c|}{ FIN } \\
\hline & Sig & EQP & PO & Sig & EQP & PO & Sig & EQP & PO & Sig & EQP & PO & Sig & EQP & PO \\
\hline $\begin{array}{l}\text { Teste de } \\
\text { Levene }\end{array}$ & 0,620 & & & 0,360 & & & 0,872 & & & 0,609 & & & 0,415 & & \\
\hline $\begin{array}{l}\text { Assertividade } \\
\text { do modelo } \\
\text { (R-Sqr) }\end{array}$ & 0,000 & 0,466 & 1,000 & 0,008 & 0,323 & 0,991 & 0,373 & 0,241 & 0,800 & 0,003 & 0,504 & 0,993 & 0,007 & 0,934 & 0,967 \\
\hline LnRLV203 & 0,000 & 0,109 & 0,997 & 0,033 & 0,041 & 0,574 & 0,036 & 0,049 & 0,560 & 0,001 & 0,160 & 0,910 & 0,326 & 0,107 & 0,154 \\
\hline LnRLV206 & 0,000 & 0,067 & 0,950 & 0,831 & 0,000 & 0,055 & 0,861 & 0,000 & 0,053 & 0,604 & 0,005 & 0,081 & 0,624 & 0,028 & 0,074 \\
\hline LnRLV207 & 0,476 & 0,003 & 0,109 & 0,041 & 0,037 & 0,534 & 0,386 & 0,008 & 0,138 & 0,214 & 0,026 & 0,235 & 0,737 & 0,013 & 0,061 \\
\hline LnRLV208 & 0,372 & 0,004 & 0,145 & 0,837 & 0,000 & 0,055 & 0,541 & 0,004 & 0,093 & 0,361 & 0,014 & 0,148 & 0,031 & 0,421 & 0,627 \\
\hline LnRLV209 & 0,000 & 0,078 & 0,974 & 0,290 & 0,010 & 0,184 & 0,078 & 0,035 & 0,423 & 0,006 & 0,123 & 0,807 & 0,763 & 0,011 & 0,059 \\
\hline LnRLV210 & 0,001 & 0,054 & 0,894 & 0,827 & 0,000 & 0,055 & 0,559 & 0,004 & 0,089 & 0,008 & 0,113 & 0,769 & 0,756 & 0,011 & 0,060 \\
\hline LnRLV302 & 0,635 & 0,001 & 0,076 & 0,002 & 0,086 & 0,892 & 0,175 & 0,021 & 0,272 & 0,584 & 0,005 & 0,084 & 0,679 & 0,020 & 0,067 \\
\hline LnRLV304 & 0,000 & 0,120 & 0,999 & & 0,000 & 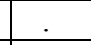 & & 0,000 & & 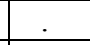 & 0,000 & &. & 0,000 & 1 \\
\hline LnRLV305 & 0,545 & 0,002 & 0,093 & 0,004 & 0,071 & 0,825 & 0,874 & 0,000 & 0,053 & 0,516 & 0,007 & 0,098 & 0,562 & 0,039 & 0,084 \\
\hline LnRLV306 & 0,018 & 0,030 & 0,658 & 0,067 & 0,030 & 0,450 & 0,744 & 0,001 & 0,062 & & 0,000 & & 0,791 & 0,008 & 0,057 \\
\hline LnRLV308 & 0,266 & 0,007 & 0,199 & 0,134 & 0,020 & 0,322 & 0,020 & 0,059 & 0,647 & 0,042 & 0,068 & 0,534 & 0,365 & 0,092 & 0,137 \\
\hline LnRLV311 & 0,000 & 0,092 & 0,990 & 0,004 & 0,071 & 0,820 & 0,734 & 0,001 & 0,063 & 0,964 & 0,000 & 0,050 &. & 0,000 & - \\
\hline LnRLV401 & 0,715 & 0,001 & 0,065 & 0,180 & 0,016 & 0,267 & 0,091 & 0,032 & 0,393 & 0,000 & 0,210 & 0,974 & 0,655 & 0,023 & 0,070 \\
\hline LnRLV402 & 0,023 & 0,028 & 0,628 & 0,151 & 0,019 & 0,300 & 0,837 & 0,000 & 0,055 & 0,425 & 0,011 & 0,124 & 0,686 & 0,019 & 0,066 \\
\hline LnRLV403 & 0,672 & 0,001 & 0,071 & 0,776 & 0,001 & 0,059 & 0,125 & 0,026 & 0,335 & 0,990 & 0,000 & 0,050 & 0,011 & 0,535 & 0,816 \\
\hline Ano & 0,527 & 0,017 & 0,253 & 0,278 & 0,044 & 0,392 & 0,343 & 0,049 & 0,345 & 0,040 & 0,130 & 0,671 & 0,684 & 0,146 & 0,118 \\
\hline
\end{tabular}

Em uma análise qualitativa e utilizando outra terminologia poder-se-ía descrever o resultado como:

Dessensibilizado o efeito do porte das empresas analisadas que operaram com RO positivo, existe uma correlação estatisticamente significativa entre o RO positivo e alguns dos investimentos voluntários em RSE preconizados no BS padrão IBASE. O setor que teve maior quantidade de investimentos de RSE relacionados com o RO positivo foi o IND com 8 programas, seguidos por SRV e AGI com 5 cada um e FIN com 2, denotando que o setor foi um fator relevante na discriminação das estratégias de investimento em RSE. A conjuntura econômica e social refletida no ano de publicação do BS foi um fator que determinou um comportamento diferenciador significativo somente no setor AGI. O setor ELE não apresentou relacionamento entre o RO positivo e os investimentos em RSE preconizados no BS padrão IBASE.

Contrastando o modelo 3C-L com o correspondente 1C-L que analisou os investimentos voluntários das empresas com RO positivo sob o ponto de vista respectivo de não considerar o porte e considerar o porte das empresas analisadas, observou-se que, excetuando o setor ELE, os modelos tiveram nível de assertividade próximos. A quantidade de programas preconizados pelo BS padrão IBASE que estavam correlacionados com o RO positivo do modelo $1 \mathrm{C}-\mathrm{L}$ foi de 32, inferior aos 20 presentes no modelo 3C-L e 15 deles estavam presentes simultaneamente nos dois modelos, 
confirmando a relativa semelhança entre os modelos. Não existe referência comparativa desses modelos com os das empresas com RO negativo pelo fato desses não terem sido considerados por falta de quantidade suficiente de casos na amostra.

\subsubsection{Análise dos modelos 4A-L}

Os modelos setoriais 4A-L foram elaborados visando analisar as estratégias das empresas onde o porte das mesmas foi retirado da percepção do modelo. Dessa forma, o trabalho buscou identificar o impacto que essa situação pudesse ter interferido nos investimentos totais em RSE e sua relação com o RO positivo.

A Tabela 37 apresenta os modelos setoriais e se constata que os mesmos foram homocedásticos por apresentarem Sig do Teste de Levene entre 24,6\% e 90,3\%, superiores ao limite de 5,0\%. Os modelos referentes aos setores IND, SRV, ELE e AGI não foram válidos, por apresentarem Sig da assertividade do modelo entre $10,8 \%$ e $33,4 \%$, superiores a $5,0 \%$, o que permitiu concluir que, nesses casos, não se pode dizer que existiu correlação entre os investimentos voluntários totais e o RO positivo. A assertividade do modelo do setor FIN foi significativa, pois teve Sig iguail a $0,0 \%$ (menor que 5,0\%) e conseguiu explicar $70,9 \%$ da variância do RO positivo. Os investimentos totais em RSE representados pela variável LnR_RSE_Voluntario foram significativos porque seu Sig foi igual $0,0 \%$, portanto, considerou-se que eles estavam relacionados ao RO positivo e explicaram $70,5 \%$ da variância do mesmo. A conjuntura econômica e social refletida no ano de publicação do BS não teve poder explicativo significativo.

Tabela 37 - Modelo 4A-L considera os investimentos totais de RSE, operação com prejuízo e dessensibiliza o porte das empresas

\begin{tabular}{l|l|l|l|l|l|l|l|l|l|l|l|l|l|l|l|l}
\hline \multirow{2}{*}{\begin{tabular}{l} 
Modelo 4A-L \\
\cline { 2 - 11 }
\end{tabular}} & Sig & EQP & PO & Sig & EQP & PO & Sig & EQP & PO & Sig & EQP & PO & Sig & EQP & PO \\
\hline $\begin{array}{l}\text { Teste de } \\
\text { Levene }\end{array}$ & $\mathbf{0 , 7 9 1}$ & & & $\mathbf{0 , 2 4 6}$ & & & $\mathbf{0 , 7 8 7}$ & & & $\mathbf{0 , 9 0 3}$ & & & $\mathbf{0 , 3 9 6}$ & & \\
\hline $\begin{array}{l}\text { Assertividade } \\
\text { do modelo } \\
\text { (R-Sqr) }\end{array}$ & 0,108 & 0,040 & 0,619 & 0,172 & 0,048 & 0,538 & 0,334 & 0,042 & 0,401 & 0,167 & 0,069 & 0,491 & $\mathbf{0 , 0 0 0}$ & 0,709 & 1,000 \\
\hline $\begin{array}{l}\text { LnR_RSE_ } \\
\text { Total }\end{array}$ & 0,134 & 0,010 & 0,322 & 0,598 & 0,002 & 0,082 & 0,385 & 0,006 & 0,139 & 0,312 & 0,011 & 0,172 & $\mathbf{0 , 0 0 0}$ & 0,705 & 1,000 \\
\hline
\end{tabular}


Em uma análise qualitativa e utilizando outra terminologia poder-se-ía descrever o resultado como: Dessensibilizado o efeito do porte das empresas que operaram com RO positivo, foi observada uma correlação estatisticamente significativa entre o RO positivo e os investimentos voluntários totais em RSE somente no setor FIN, sendo que, a conjuntura econômica e social refletida no ano de publicação do BS não foi um fator que determinou um comportamento diferenciador significativo. Os demais modelos setoriais (IND, SRV, ELE e AGI) não foram adequados para representar o fenômeno sob estudo e nenhum deles apresentou uma assertividade significativa, o que permite concluir que esses setores, caso não se considere o porte das empresas analisadas, não é possível estabelecer uma relação significativa entre o RO positivo e os investimentos em RSE.

Contrastando o modelo 4A-L com o modelo 3A-L que correspondiam respectivamente às condições de investimentos voluntários e totais em RSE, observou-se um comportamento semelhante referente ao setor FIN no qual o RO positivo estava correlacionado aos investimentos em RSE. Os setores IND, SRV e ELE nos modelos 3A-L e 4A-L não apresentaram qualquer relacionamento entre os investimentos em RSE e o RO positivo. Existe uma tênue diferença referente ao setor AGI dos modelos citados. No caso do modelo 4A-L o setor AGI não se mostrou significativo, mas no modelo 3A-L ele era significativo, ainda que de baixa relevância do poder explicativo.

\subsubsection{Análise dos modelos 4B-L}

Os modelos setoriais 4B-L foram elaborados visando analisar as estratégias das empresas nos quais o porte das mesmas foi retirado da percepção do modelo. Dessa forma, o trabalho buscou identificar o impacto que essa situação possa ter interferido nos investimentos totais em RSE segmentados por natureza dos investimentos com os Indicadores Sociais Internos, Externos e Ambientais e sua relação com o RO positivo.

A Tabela 38 apresenta os modelos setoriais e se constatou que os mesmos foram homocedásticos por apresentarem Sig do Teste de Levene entre 25,3\% e 97,8\%, superiores ao limite de 5,0\%. Os modelos referentes aos setores IND, SRV e ELE não foram válidos por que apresentaram Sig entre $18,0 \%$ e 38,0\%, superiores a 5,0\%, o que permitiu concluir que, nesses casos, não existiu relacionamento entre os investimentos totais e o RO positivo. As assertividades dos modelos 
referentes aos setores AGI e FIN foram significativas, pois tiveram Sig respectivos iguais a 2,5\% e $0,0 \%$, menor que 5,0\%, e conseguiram explicar respectivamente, $16,5 \%$ e $72,4 \%$ da variância do RO positivo. Os investimentos voluntários em RSE, referentes aos Indicadores Sociais Internos (LnV213) do setor FIN, se mostraram relacionados ao RO positivo das empresas porque seu Sig foi igual a $0,0 \%$, menor que $5,0 \%$, e explicou $72,4 \%$ da variância do $\mathrm{RO}$ positivo, um valor muito relevante. Por sua vez, o modelo referente ao setor AGI apresentou investimentos voluntários em RSE referentes aos Indicadores Ambientais (LNV404), relacionados ao RO positivo porque seu Sig foi igual a $0,5 \%$, menor que $5,0 \%$, e explicou $9,5 \%$ da variância do RO positivo, um valor pouco relevante, mas que denota uma característica que também esteve associada ao setor AGI, nesse e no modelo 2B-L. A influência da conjuntura econômica e social refletida no ano de publicação do BS foi significativa (Sig igual a 4,8\%, inferior a 5,0\%), mas com pouca relevância $(9,6 \%$ ).

Tabela 38 - Modelo 4B-L considera investimentos totais segmentados por programas de RSE, operação com lucro e dessensibiliza o porte das empresas

\begin{tabular}{l|c|c|c|c|c|c|c|c|c|c|c|c|c|c|c}
\hline \multirow{2}{*}{\begin{tabular}{l} 
Modelo 4B-L \\
\cline { 2 - 14 }
\end{tabular}} & Sig & EQP & PO & Sig & EQP & PO & Sig & EQP & PO & Sig & EQP & PO & Sig & EQP & PO \\
\hline $\begin{array}{l}\text { Teste de } \\
\text { Levene }\end{array}$ & $\mathbf{0 , 9 1 4}$ & & & $\mathbf{0 , 2 5 3}$ & & & $\mathbf{0 , 9 7 8}$ & & & $\mathbf{0 , 6 1 8}$ & & & $\mathbf{0 , 8 9 5}$ & & \\
\hline $\begin{array}{l}\text { Assertividade } \\
\text { do modelo } \\
\text { R Sqr) }\end{array}$ & 0,380 & 0,036 & 0,458 & 0,180 & 0,073 & 0,604 & 0,369 & 0,065 & 0,455 & $\mathbf{0 , 0 2 5}$ & 0,165 & 0,821 & $\mathbf{0 , 0 0 0}$ & 0,724 & 1,000 \\
\hline LnV213 & 0,892 & 0,000 & 0,052 & 0,089 & 0,022 & 0,397 & 0,153 & 0,018 & 0,297 & 0,812 & 0,001 & 0,056 & $\mathbf{0 , 0 0 0}$ & 0,686 & 1,000 \\
\hline LnV404 & 0,527 & 0,002 & 0,097 & 0,065 & 0,026 & 0,455 & 0,641 & 0,002 & 0,075 & $\mathbf{0 , 0 0 5}$ & 0,095 & 0,808 & 0,337 & 0,034 & 0,156 \\
\hline Ano & 0,599 & 0,013 & 0,222 & 0,398 & 0,030 & 0,316 & 0,403 & 0,036 & 0,312 & $\mathbf{0 , 0 4 8}$ & 0,096 & 0,646 & 0,466 & 0,089 & 0,215 \\
\hline
\end{tabular}

Em uma análise qualitativa e utilizando outra terminologia poder-se-ía descrever o resultado como: Dessensibilizado o efeito do porte das empresas que operaram com RO positivo, foi observada uma correlação estatisticamente significativa entre o RO positivo e os investimentos totais em RSE somente nos setores AGI e FIN, sendo que, a conjuntura econômica e social refletida no ano de publicação do BS foi um fator que determinou um comportamento diferenciador significativo somente no setor AGI. Os demais modelos setoriais (IND, SRV e ELE) não foram adequados para representar o fenômeno sob estudo e nenhum deles apresentou uma assertividade significativa, o que permite concluir que esses setores, caso não se considere o porte das empresas analisadas, não é possível estabelecer uma relação significativa entre o RO positivo e os investimentos em RSE.

Contrastando o modelo 4B-L com o modelo 3B-L que correspondem respectivamente às condições de investimentos totais e voluntários em RSE, observa-se um comportamento semelhante onde os modelos referentes aos setores AGI e FIN são significativos e os demais não são significativos. O 
que permite concluir que, no caso dos setores AGI e FIN, a natureza voluntária ou total dos investimentos em RSE possuem significância no relacionamento com o RO positivo. Contrastando o modelo 4B-L com o seu correspondente 4B-P que correspondem respectivamente à condição de lucro e prejuízo, observa-se que o RO negativo das empresas analisadas tinham relacionamento com os investimentos em Indicadores Sociais Internos em RSE e eram diferenciados pelo setor de atuação. No caso daquelas com RO positivo, somente o setor FIN e AGI mantiveram relacionamento entre ele e os investimentos sociais; os modelos dos demais setores não se mostraram assertivos, significando a inexistência de qualquer relacionamento.

\subsubsection{Análise dos modelos 4C-L}

Os modelos setoriais 4C-L foram elaborados visando analisar as estratégias das empresas onde o porte das mesmas foi retirado da percepção do modelo. Dessa forma, o trabalho buscou identificar o impacto que essa situação pudesse ter interferido nos investimentos totais em RSE e discriminados em cada ação preconizada pelo BS padrão IBASE.

A Tabela 39 apresenta os modelos setoriais e se constata que os mesmos foram homocedásticos por apresentarem Sig do Teste de Levene entre 34,4\% e 73,4\%, superiores ao limite de 5,0\%. As assertividades dos modelos foram significativas, pois tiveram Sig entre $0,0 \%$ e $0,3 \%$ (menor que $5,0 \%$ ) e conseguiram explicar entre $33,3 \%$ e 97,2\% da variância do RO positivo, valores bastante relevantes no caso do setor FIN. O setor ELE não apresenta relacionamento significativo entre o RO positivo e os investimentos em RSE, pois o nível de assertividade foi igual a 37,3\%, superior a $5,0 \%$, e se pode concluir que o modelo não é válido.

Nos demais quatro setores, IND, SRV, AGI e FIN foram identificados 19 investimentos voluntários em RSE significativos com Sig entre $0,0 \%$ e 5,0\% e eles conseguiram explicar entre 3,3\% e 57,9\% da variância do RO positivo. Desses, 8 explicaram acima de 10,0\% da variância do RO positivo, o que pode significar um comportamento característico dos setores constituintes desse grupo. Dos investimentos em RSE preconizados no BS padrão IBASE e considerados nesse modelo, o setor IND teve 9, AGI teve 5, SRV teve 3 e FIN teve 2 deles correlacionados com seu RO positivo. Por outro lado, analisando o poder explicativo dos investimentos significativos notou-se elevado poder 
explicativo pelo setor FIN, comparativamente aos dos demais setores. O setor ELE não foi considerado um modelo válido. A conjuntura econômica e social refletida no ano de publicação do BS não se mostrou significativa para nenhum dos modelos.

\begin{tabular}{|c|c|c|c|c|c|c|c|c|c|c|c|c|c|c|c|}
\hline \multirow{2}{*}{ Modelo 4C-L } & \multicolumn{3}{|c|}{ IND } & \multicolumn{3}{|c|}{ SRV } & \multicolumn{3}{|c|}{ ELE } & \multicolumn{3}{|c|}{ AGI } & \multicolumn{3}{|c|}{ FIN } \\
\hline & Sig & EQP & PO & Sig & EQP & PO & Sig & EQP & PO & Sig & EQP & PO & Sig & EQP & PO \\
\hline $\begin{array}{l}\text { Teste de } \\
\text { Levene }\end{array}$ & 0,724 & & & 0,471 & & & 0,628 & & & 0,734 & & & 0,344 & & \\
\hline $\begin{array}{l}\text { Assertividade } \\
\text { do modelo } \\
\text { (R-Sqr) }\end{array}$ & 0,000 & 0,490 & 1,000 & 0,011 & 0,333 & 0,990 & 0,137 & 0,306 & 0,916 & 0,002 & 0,540 & 0,996 & 0,003 & 0,972 & 0,995 \\
\hline LnV202 & 0,434 & 0,003 & 0,122 & 0,487 & 0,004 & 0,106 & 0,006 & 0,085 & 0,801 & 0,069 & 0,057 & 0,446 & 0,017 & 0,579 & 0,758 \\
\hline LnV203 & 0,000 & 0,119 & 0,998 & 0,053 & 0,034 & 0,492 & 0,283 & 0,013 & 0,187 & 0,001 & 0,171 & 0,921 & 0,262 & 0,175 & 0,185 \\
\hline LnV206 & 0,004 & 0,045 & 0,824 & 0,940 & 0,000 & 0,051 & 0,987 & 0,000 & 0,050 & 0,583 & 0,005 & 0,084 & 0,050 & 0,443 & 0,529 \\
\hline LnV207 & 0,580 & 0,002 & 0,085 & 0,038 & 0,039 & 0,547 & 0,379 & 0,009 & 0,141 & 0,264 & 0,022 & 0,199 & 0,523 & 0,061 & 0,090 \\
\hline LnV209 & 0,000 & 0,079 & 0,974 & 0,412 & 0,006 & 0,129 & 0,081 & 0,035 & 0,415 & 0,015 & 0,099 & 0,689 & 0,146 & 0,277 & 0,294 \\
\hline LnV210 & 0,001 & 0,057 & 0,908 & 0,939 & 0,000 & 0,051 & 0,269 & 0,014 & 0,196 & 0,008 & 0,118 & 0,773 & 0,648 & 0,031 & 0,070 \\
\hline LnV304 & 0,000 & 0,120 & 0,998 & . & 0,000 & $\dot{-}$ & +3 & 0,000 & . & & 0,000 & $f^{2}$ &. & 0,000 & \\
\hline LnV305 & 0,276 & 0,007 & 0,193 & 0,009 & 0,061 & 0,753 & 0,710 & 0,002 & 0,066 & 0,363 & 0,015 & 0,147 & 0,882 & 0,003 & 0,052 \\
\hline LnV306 & 0,010 & 0,037 & 0,741 & 0,102 & 0,024 & 0,372 & 0,845 & 0,000 & 0,054 & & 0,000 & - & 0,208 & 0,216 & 0,225 \\
\hline LnV308 & 0,357 & 0,005 & 0,151 & 0,108 & 0,024 & 0,363 & 0,006 & 0,083 & 0,794 & 0,012 & 0,106 & 0,724 & 0,813 & 0,009 & 0,055 \\
\hline LnV311 & 0,000 & 0,074 & 0,966 & 0,003 & 0,076 & 0,843 & 0,824 & 0,001 & 0,056 & 0,943 & 0,000 & 0,051 & . & 0,000 & . \\
\hline LnV313 & 0,014 & 0,033 & 0,695 & 0,413 & 0,006 & 0,129 & 0,761 & 0,001 & 0,060 & 0,316 & 0,018 & 0,169 & 0,888 & 0,003 & 0,052 \\
\hline LnV401 & 0,458 & 0,003 & 0,115 & 0,137 & 0,020 & 0,317 & 0,016 & 0,065 & 0,684 & 0,000 & 0,232 & 0,983 & 0,263 & 0,175 & 0,184 \\
\hline LnV402 & 0,011 & 0,035 & 0,722 & 0,158 & 0,018 & 0,291 & 0,993 & 0,000 & 0,050 & 0,184 & 0,031 & 0,262 & 0,930 & 0,001 & 0,051 \\
\hline
\end{tabular}

Em uma análise qualitativa e utilizando outra terminologia poder-se-ía descrever o resultado como:

Dessensibilizado o efeito do porte das empresas analisadas que operaram com RO positivo, foi observada uma correlação estatisticamente significativa entre o RO positivo e alguns dos investimentos totais em RSE preconizados no BS padrão IBASE. O setor que teve maior quantidade de investimentos de RSE relacionados com o RO positivo foi o IND com 9 programas, seguidos por AGI com 5, SRV com 3 e FIN com 2, denotando que o setor foi um fator relevante na discriminação das estratégias de investimento em RSE. A conjuntura econômica e social refletida no ano de publicação do BS não se mostrou significativa para explicar o relacionamento do RO positivo e os investimentos em RSE de acordo com os programas detalhados no BS padrão IBASE.

Contrastando o modelo 4C-L com o correspondente $2 \mathrm{C}$-L que analisaram os investimentos totais das empresas com RO positivo sob o ponto de vista respectivo de não considerar o porte e considerar o porte das empresas analisadas, observou-se que os modelos tiveram nível de assertividade próximos. A quantidade de programas preconizados pelo BS padrão IBASE que 
estavam correlacionados com o RO positivo do modelo $1 \mathrm{C}$-L foi de 25, inferior aos 19 presentes no modelo 4C-L e 13 deles estavam presentes simultaneamente nos dois modelos, confirmando a relativa semelhança entre os modelos. Não existe referência comparativa desses modelos com os das empresas com RO negativo pelo fato desses não terem sido considerados por falta de quantidade suficiente de casos na amostra.

\subsubsection{Conclusão sobre os modelos das empresas que operaram com RO positivo}

Após as transformações logarítmicas naturais das variáveis do estudo, remoção dos outliers e ao processo de segmentação dos modelos por setor de atuação, todos os modelos estudados e que pertenciam ao gupo das empresas que tiveram RO positivo apresentaram homocedasticidade.

Todos os modelos (1A-L, 1B-L, 1C-L, 2A-L, 2B-L e 2C-L) que consideraram o porte das empresas apresentaram alto poder explicativo da variância do RO positivo referente a assertividade do modelo, se comparados com seus equivalentes que dessensibilizaram o porte das empresas analisadas. A Tabela $\mathbf{4 0}$ apresenta os valores descritivos comparativos do poder de explicação dessas duas subamostras.

Tabela 40 - Comparativo do poder de explicação do modelo baseado no porte das empresas

\begin{tabular}{l|c|c}
\hline \multirow{2}{*}{$\begin{array}{c}\text { Variável } \\
\text { Descritiva }\end{array}$} & \multicolumn{2}{|c}{ Poder de explicação do modelo } \\
\cline { 2 - 3 } & Considerando o porte das empresas & Não considerando o porte das empresas \\
\hline Valor máximo & $99 \%(\mathrm{FIN})$ & $97 \%(\mathrm{FIN})$ \\
\hline Valor mínimo & $57 \%(\mathrm{ELE})$ & $15 \%(\mathrm{AGI})$ \\
\hline Média & $77 \%$ & $53 \%$ \\
\hline Desvio-padrão & $10 \%$ & $27 \%$ \\
\hline
\end{tabular}

Nota: Os setores que definiram os valores limites estão entre-parênteses

Ao considerar o porte das empresas na análise, foi constatado que os investimentos totais e os investimentos em Indicadores Sociais Internos foram as variáveis independentes que mais estiveram correlacionadas ao RO positivo. A Tabela 41 apresenta o poder explicativo médio da variância do RO positivo decorrente das variáveis independentes Investimentos Totais em RSE e Indicadores Sociais Internos, na qual o setor FIN apresentou o maior poder explicativo e o ELE com o menor, indicando uma ordenação pelo critério de homogeneidade dos decisores sobre os investimentos em RSE. O setor mais homogêneo foi o FIN e o menos, o ELE. Conforme já mencionado, a hipótese do 
autor para tal posicionamento do setor ELE se deve à diversidade dos negócios abraçados por ele (Geração, Transmissão e Distribuição de energia).

\section{Tabela 41 - Poder de explicação médio da variância do RO positivo pelos investimentos totais em RSE e Indicadores Sociais Internos, considerando o porte das empresas

\begin{tabular}{l|c|c|c|c|c}
\hline Setor & FIN & IND & AGI & SRV & ELE \\
\hline $\begin{array}{l}\text { Poder de explicação médio dos investimentos } \\
\text { totais em RSE e Indicadores Sociais Internos }\end{array}$ & $72 \%$ & $62 \%$ & $57 \%$ & $52 \%$ & $42 \%$ \\
\hline
\end{tabular}

Ao dessensibilizar o porte das empresas na análise, o setor FIN foi o que apresentou maior relacionamento entre o RO positivo e os investimentos em RSE. O poder de explicação do setor FIN nos modelos 3A-L, 3B-L, 4A-L e 4B-L variaram entre 68,0\% e 75,0\%, valores muito relevantes e adequados para o desenvolvimento de modelos explicativos. Mesmo os modelos 3C-L e 4C-L apresentaram apresentaram poder explicativo do setor FIN entre 42,0\% e 58,0\%, valores com boa relevância.

Ao considerarmos todos os demais setores (IND, SRV, ELE e AGI) referentes aos modelos válidos que dessensibilizaram o porte das empresas (3A-L, 3B-L, 3C-L, 4A-L, 4B-L e 4C-L), encontramos o poder de explicação da variância do RO positivo pelos investimentos em RSE variando entre $3,0 \%$ e $23 \%$, com valor médio de $9,0 \%$ e desvio-padrão de $5,0 \%$, níveis pouco relevantes para a construção de modelos explicativos, porém significativos o suficiente para amparar investigações sobre decisões estratégicas empresariais de investimentos em RSE, isso é, usar os comportamentos setoriais como indicativos para investigação sobre estratégias empresariais e não para a elaboração de modelos explicativos.

Tal comportamento dos modelos dessensibilizados do porte das empresas já se pronunciava durante a análise de outliers, pois a Tabela 16 apresentava uma maior incidência de variáveis dessensibilizadas como possíveis causadoras da condição de outlier (52 casos) em relação às variáveis originais (19 casos), isso é, as variáveis dessensibilizadas apresentaram maior variabilidade que as variáveis originais.

$\mathrm{O}$ ano de publicação do BS que refletiu a conjuntura econômica e social teve menor influência sobre o comportamento dos modelos referentes às empresas com RO positivo que as de RO negativo. Enquanto que quatro dos 8 modelos trabalhados sob RO negativo foram sensíveis ao ano, com poder explicativo entre $7,0 \%$ e $10,0 \%$, dos 60 modelos que utilizaram o RO positivo, somente 
dez foram influenciados pelo ano, com poder explicativo entre 3,0 e 16\%. Destes, nove referiram-se ao setor AGI e um ao setor SRV, isso é, praticamente nenhum setor foi influenciado pelo ano de publicação do BS, exceto o AGI.

\subsection{Respostas às perguntas da pesquisa referentes ao grupo de empresas com RO negativo}

Os resultados da análise do grupo de empresas que operaram com $\mathrm{RO}$ negativo indicaram um comportamento homocedástico em todos os modelos testados que já incorporavam as variáveis intervenientes. Isso permitiu elaborar as conclusões que seguem sem a necessidade de se destacar o comportamento setorial das empresas.

Outra consideração importante é que os modelos desenvolvidos não têm intenção de indicar uma relação causal entre o RO negativo e os investimentos em RSE, mas tão somente identificar a relação matemática que correlacionou essas variáveis buscando, nessa etapa da pesquisa, mapear aquelas que se mostraram significativas e que poderão evidenciar, em estudos futuros, a lógica da estratégia empresarial que foi adotada.

A análise da amostra do estudo indicou que as empresas investiram em RSE, em vários programas preconizados pelo BS padrão IBASE. Observou-se que alguns investimentos estavam relacionados com o RO negativo ao nível de significância de 5,0\% e encontram-se apresentados na Tabela 42, com o correspondente poder de explicação da relação entre o RO negativo e os investimentos em RSE. Outros investimentos não demonstraram tal relacionamento e, portanto, não atingiram o nível de significância de 5\% e não apareceram na tabela.

A Tabela 42 apresenta o poder de explicação das variáveis independentes significativas em relação ao RO negativo. As células vazias indicam que, nessas condições, as variáveis independentes não foram identificadas como significativas ao nível de 5,0\%. 
Tabela 42 - Quadro-resumo do poder de explicação das variáveis do RO negativo significativas dos modelos estudados

\begin{tabular}{|c|c|c|c|c|}
\hline Modelos considerando os valores totais de investimento em RSE & 1A-P & 2A-P & 3A-P & 4A-P \\
\hline Assertividade do modelo (R-Sqr) & $57 \%$ & $55 \%$ & & $13 \%$ \\
\hline Investimentos totais em RSE (valores Voluntários / Totais) & $41 \%$ & $39 \%$ & & \\
\hline Ano de publicação do BS & $9 \%$ & & & $7 \%$ \\
\hline Setor & $9 \%$ & & & \\
\hline $\begin{array}{c}\text { Modelos considerando os valores segmentados por natureza de } \\
\text { investimentos em RSE }\end{array}$ & $1 B-P$ & 2B-P & 3B-P & 4B-P \\
\hline Assertividade do modelo (R Sqr) & $65 \%$ & $61 \%$ & $29 \%$ & $18 \%$ \\
\hline V213 / V214 - Investimentos Sociais Internos (valores Voluntários / Totais) & $48 \%$ & $39 \%$ & $11 \%$ & $4 \%$ \\
\hline \multicolumn{5}{|l|}{ V312 - Total das contribuições para a sociedade } \\
\hline \multicolumn{5}{|l|}{ V404 - Total dos investimentos em meio ambiente } \\
\hline Ano de publicação do BS & $10 \%$ & & $9 \%$ & \\
\hline Setor & $12 \%$ & $13 \%$ & $9 \%$ & $10 \%$ \\
\hline
\end{tabular}

Os códigos dos modelos se referem às condições definidas pelo autor e presentes na Figura 6 do item 4.

Pergunta 1: Com base nas informações dos BSs padrão IBASE publicados pelas empresas, cuja estrutura está detalhada no item 1.5.2 (O Balanço Social padrão IBASE), existem evidências de que o desempenho financeiro refletido no Resultado Operacional esteja correlacionado às ações socialmente responsáveis das empresas que atuam no Brasil ?

Resposta 1: Sim, existe significância estatística que suporta a afirmação de que as empresas analisadas que operaram com RO negativo tiveram seu desempenho financeiro correlacionado com seus investimentos em RSE. Ao se considerar o porte das empresas (modelos 1A-P, 1B-P, 2A-P e 2B-P), foi observado que o nível de correlação é mais relevante que nos modelos nos quais não foi considerado o porte das empresas (modelos 3B-P, 4A-P e 4B-P). Dos oito modelos testados, somente dois deles, 3A-P e 4A-P, que não levam em consideração o porte das empresas, não apresentaram significância associada ao relacionamento entre o desempenho financeiro e os investimentos em RSE. Esses dois casos não desqualificam a conclusão, pois os modelos correspondentes, que levam em consideração o porte das empresas analisadas, foram significativos e confirmaram a declaração inicial da resposta à questão da pesquisa. 
Pergunta 2: No caso de existirem evidências neste sentido, quais foram os fatores que mais contribuíram para explicar essa relação?

Resposta 2: Os fatores que influenciaram a relação foram a natureza dos investimentos em RSE, o tipo de investimento em RSE (voluntário ou total), o porte da empresa, o ano de publicação do BS e o setor. O porte da empresa foi significativo e relevante para explicar a variância do RO negativo. Nos modelos 1A-P, 1B-P, 2A-P e 2B-P, nos quais o porte foi considerado, observou-se uma maior relevância na assertividade e na correlação entre o RO negativo e as variáveis independentes dos modelos em comparação com os modelos 3B-P, 4A-P e 4B-P. A conjuntura econômica e social percebida pela discriminação do ano de publicação do BS foi significativa nos modelos 1A-P, 1B-P e 3B-P que analisaram os investimentos voluntários, independente de se considerar ou não o porte das empresas, embora não tenha apresentado grande relevância para explicar a variância do RO negativo. No caso do modelo 2A-P, que analisou os investimentos totais em RSE, voluntários e compulsórios, a conjuntura econômica e social não foi significativa. O setor de atuação foi significativo nos modelos que analisaram os investimentos voluntários, independente de se considerar ou não o porte das empresas, apesar de não apresentarem grande relevância para explicar a variância do RO negativo. No caso dos modelos que analisaram os investimentos totais em RSE, voluntários e compulsórios, o setor não foi significativo para explicar a variância do RO negativo no modelo 2A-P que considera o valor agregado dos investimentos em RSE. Os modelos que separam a natureza dos investimentos em RSE em Indicadores Sociais Internos, Externos e Ambientais, identificaram que os investimentos nos Indicadores Sociais Internos foram significativos para explicar a variância do RO negativo, ainda que com pouca relevância e também tiveram esse mesmo comportamento em relação ao setor de atuação.

Pergunta 3: Existem variáveis que, agrupadas, podem identificar características singulares de um comportamento de gestão empresarial ?

Resposta 3: Os modelos utilizados pelo grupo de empresas que tiveram RO negativo não puderam aquilatar essa peculiaridade em relação às varáveis de ações em RSE do BS padrão IBASE por falta de uma quantidade significativa de casos da amostra utilizada; todavia, pode-se comentar que foi 
encontrado um significativo comportamento das empresas em relacionar seus investimentos em Indicadores Sociais Internos ao seu RO negativo (modelos 1B-P, 2B-P, 3B-P e 4B-P).

\subsection{Respostas às perguntas da pesquisa referentes ao grupo de empresas com RO positivo}

A análise do grupo de empresas que operaram com RO positivo indicou a necessidade técnica de se elaborar os modelos destacando individualmente o comportamento setorial das empresas. Essa solução foi a mais conveniente para a obtenção da característica de homocedasticidade desses modelos sem dificultar a análise dos mesmos.

A Tabela 43 apresenta, de forma compactada, o comportamento dos 30 modelos que trataram do comportamento das empresas quanto ao poder de explicação da variância do RO positivo pelas variáveis independentes, considerando o porte das empresas. O objetivo da tabela foi facilitar a visualização do comportamento dos modelos construídos para analisar o fenômeno sob estudo. Valores elevados significam que a relação não pode ser negada e permite ser transformada em um modelo matemático explicativo. Valores reduzidos indicam a existência de relacionamento significativo, porém com menor capacidade do modelo em traduzir o comportamento do mundo real, mas permitindo perceber comportamentos característicos. As células vazias indicam que nessas situações as variáveis independentes não foram identificadas como significativas ao nível de $5,0 \%$. Os modelos são referidos pelos seus códigos definidos pelo autor e presentes na Figura 6 do item 4.

Semelhantemente à Tabela 43, a Tabela 44 apresenta o comportamento dos restantes 30 modelos que trataram do comportamento das empresas e nos quais foi dessensibilizado o porte das mesmas. Notar que 15 dos modelos listados a seguir não apresentaram assertividade, indicando que, nesses casos, não existe relacionamento entre RO positivo e os investimentos em RSE estatisticamente significativos: modelos 3A-L, 3B-L e 4B-L e seus respectivos setores IND, SRV e ELE, modelo 4A-L e seus setores IND, SRV, ELE e AGI e modelos 3C-L e 4C-L no setor ELE. 
Tabela 43 - Poder de explicação da variância do RO positivo considerando o porte das empresas

\begin{tabular}{|c|c|c|c|c|c|c|c|c|c|c|}
\hline \multirow{2}{*}{ Investimentos em RSE totalizados } & \multicolumn{5}{|c|}{ Modelo 1A-L (Voluntário) } & \multicolumn{5}{|c|}{ Modelo 2A-L (Total) } \\
\hline & IND & SRV & ELE & AGI & FIN & IND & SRV & ELE & AGI & FIN \\
\hline Assertividade do modelo (R-Sqr) & $79 \%$ & $69 \%$ & $60 \%$ & $74 \%$ & $83 \%$ & $76 \%$ & $73 \%$ & $57 \%$ & $69 \%$ & $82 \%$ \\
\hline Investimento total em RSE (Voluntário / Total) & $79 \%$ & $68 \%$ & $56 \%$ & $73 \%$ & $81 \%$ & $76 \%$ & $72 \%$ & $52 \%$ & $68 \%$ & $81 \%$ \\
\hline Ano de publicação do BS (conjuntura) & & & & $12 \%$ & & & & & & \\
\hline \multirow{2}{*}{$\begin{array}{c}\text { Investimentos em RSE segmentados por } \\
\text { natureza: Indicadores Sociais Internos, Externos e } \\
\text { Ambientais } \\
\end{array}$} & \multicolumn{5}{|c|}{ Modelo 1B-L (Voluntário) } & \multicolumn{5}{|c|}{ Modelo 2B-L (Total) } \\
\hline & IND & SRV & ELE & AGI & FIN & IND & SRV & ELE & AGI & FIN \\
\hline Assertividade do modelo (R Sqr) & $81 \%$ & $71 \%$ & $68 \%$ & $75 \%$ & $82 \%$ & $80 \%$ & $67 \%$ & $66 \%$ & $71 \%$ & $82 \%$ \\
\hline $\begin{array}{l}\text { V213 / V214 - Investimentos Sociais Internos } \\
\text { Voluntários / Totais }\end{array}$ & $50 \%$ & $42 \%$ & $29 \%$ & $45 \%$ & $57 \%$ & $44 \%$ & $27 \%$ & $33 \%$ & $44 \%$ & $66 \%$ \\
\hline V312 - Total das contribuições para a sociedade & & $6 \%$ & $6 \%$ & & & & $5 \%$ & & & \\
\hline V404 - Total dos investimentos em meio ambiente & & & & & & & & & $8 \%$ & \\
\hline Ano de publicação do BS (conjuntura) & & & & $13 \%$ & & & & & $14 \%$ & \\
\hline \multirow{2}{*}{$\begin{array}{c}\text { Investimentos em RSE preconizados pelo BS } \\
\text { padrão IBASE }\end{array}$} & \multicolumn{5}{|c|}{ Modelo 1C-L (Voluntário) } & \multicolumn{5}{|c|}{ Modelo 2C-L (Total) } \\
\hline & IND & SRV & ELE & AGI & FIN & IND & SRV & ELE & AGI & FIN \\
\hline Assertividade do modelo (R-Sqr) & $83 \%$ & $81 \%$ & $74 \%$ & $87 \%$ & $97 \%$ & $85 \%$ & $84 \%$ & $75 \%$ & $87 \%$ & $99 \%$ \\
\hline V201 - Alimentação & $2 \%$ & & & & $39 \%$ & & & & & \\
\hline V202 - Encargos sociais compulsórios & & & & & & $14 \%$ & & & & \\
\hline V203 - Previdência privada & $10 \%$ & $4 \%$ & $12 \%$ & $22 \%$ & & $10 \%$ & $3 \%$ & $7 \%$ & $21 \%$ & \\
\hline V204-Saúde & & $8 \%$ & & & & & $12 \%$ & & & \\
\hline V205 - Segurança e medicina no trabalho & & $3 \%$ & & & & & & & & $54 \%$ \\
\hline V206 - Educação & $2 \%$ & & & & & & & & & \\
\hline V207 - Cultura & & $1 \%$ & & & & & $5 \%$ & & $7 \%$ & \\
\hline \multicolumn{11}{|l|}{ V208 - Capacitação e desenvolvimento profissional } \\
\hline V209-Creche ou auxílio-creche & $2 \%$ & & & $12 \%$ & & $6 \%$ & & & $12 \%$ & \\
\hline V210 - Participação nos lucros ou resultados & $15 \%$ & & $5 \%$ & $21 \%$ & & $12 \%$ & $4 \%$ & $5 \%$ & $22 \%$ & \\
\hline V211 - Outros benefícios & $2 \%$ & $11 \%$ & & & & & & & & \\
\hline V301 - Educação & $2 \%$ & & & & & & & & & \\
\hline V302-Cultura & $3 \%$ & $1 \%$ & & & & $3 \%$ & $8 \%$ & & & \\
\hline V303 - Saúde e saneamento & & $3 \%$ & & & & & & & & \\
\hline V304 - Habitação & $5 \%$ & & & & & $4 \%$ & & & & \\
\hline V305-Esporte & & & & & & & $7 \%$ & & & \\
\hline \multicolumn{11}{|l|}{ V306 - Lazer e diversão } \\
\hline \multicolumn{11}{|l|}{ V307 - Creches } \\
\hline V308 - Alimentação & & & & & $39 \%$ & & & & & \\
\hline \multicolumn{11}{|l|}{ V309 - Combate à fome e segurança alimentar } \\
\hline V310 - Outros programas & & $1 \%$ & & & & & & & & \\
\hline V311 - Indicadores Sociais Externos agregados & $11 \%$ & $1 \%$ & $5 \%$ & & & $9 \%$ & $12 \%$ & $6 \%$ & & \\
\hline \multicolumn{11}{|l|}{ V313 - Impostos excluídos encargos sociais } \\
\hline $\begin{array}{l}\text { V401 - Investimentos relacionados com a } \\
\text { produção/operação da empresa }\end{array}$ & $2 \%$ & $7 \%$ & & $17 \%$ & & & & & $18 \%$ & \\
\hline $\begin{array}{l}\text { V402 - Investimentos em programas/projetos } \\
\text { externos }\end{array}$ & $5 \%$ & & & & & $5 \%$ & & & & \\
\hline V403 - Indicadores Ambientais agregados & $5 \%$ & & & & & & $4 \%$ & & & \\
\hline Ano de publicação do BS (conjuntura) & & $3 \%$ & & $16 \%$ & & & & & $14 \%$ & \\
\hline
\end{tabular}


Tabela 44 - Poder de explicação da variância do RO positivo dessensibilizado do porte das empresas

\begin{tabular}{|c|c|c|c|c|c|c|c|c|c|c|}
\hline \multirow{2}{*}{ Investimentos em RSE totalizados } & \multicolumn{5}{|c|}{ Modelo 3A-L (Voluntário) } & \multicolumn{5}{|c|}{ Modelo 4A-L (Total) } \\
\hline & IND & SRV & ELE & AGI & FIN & IND & SRV & ELE & AGI & FIN \\
\hline Assertividade do modelo (R-Sqr) & & & & $15 \%$ & $75 \%$ & & & & & $71 \%$ \\
\hline Investimento total em RSE (Voluntário / Total) & & & & $9 \%$ & $75 \%$ & & & & & $70 \%$ \\
\hline Ano de publicação do BS (conjuntura) & & & & $9 \%$ & & & & & & \\
\hline \multirow{2}{*}{$\begin{array}{c}\text { Investimentos em RSE segmentados por } \\
\text { natureza: Indicadores Sociais Internos, Externos e } \\
\text { Ambientais }\end{array}$} & \multicolumn{5}{|c|}{ Modelo 3B-L (Voluntário) } & \multicolumn{5}{|c|}{ Modelo 4B-L (Total) } \\
\hline & IND & SRV & ELE & AGI & FIN & IND & SRV & ELE & AGI & FIN \\
\hline Assertividade do modelo (R Sqr) & & & & $18 \%$ & $73 \%$ & & & & $17 \%$ & $72 \%$ \\
\hline $\begin{array}{l}\text { V213 / V214 - Investimentos Sociais Internos } \\
\text { Voluntários / Totais }\end{array}$ & & & & & $68 \%$ & & & & & $69 \%$ \\
\hline V312 - Total das contribuições para a sociedade & & & & & & & & & & \\
\hline V404 - Total dos investimentos em meio ambiente & & & & & & & & & $10 \%$ & \\
\hline Ano de publicação do BS (conjuntura) & & & & $11 \%$ & & & & & $10 \%$ & \\
\hline \multirow{2}{*}{$\begin{array}{c}\text { Investimentos em RSE preconizados pelo BS } \\
\text { padrão IBASE }\end{array}$} & \multicolumn{5}{|c|}{ Modelo 3C-L (Voluntário) } & \multicolumn{5}{|c|}{ Modelo 4C-L (Total) } \\
\hline & IND & SRV & ELE & AGI & FIN & IND & SRV & ELE & AGI & FIN \\
\hline Assertividade do modelo (R-Sqr) & $47 \%$ & $32 \%$ & & $50 \%$ & $93 \%$ & $49 \%$ & $33 \%$ & & $54 \%$ & $97 \%$ \\
\hline \multicolumn{11}{|l|}{ V201 - Alimentação } \\
\hline V202 - Encargos sociais compulsories & & & & & & & & & & $\mathbf{5 8 \%}$ \\
\hline V203 - Previdência privada & $11 \%$ & $4 \%$ & & $16 \%$ & & $12 \%$ & & & $17 \%$ & \\
\hline \multicolumn{11}{|l|}{ V204 - Saúde } \\
\hline \multicolumn{11}{|l|}{ V205 - Segurança e medicina no trabalho } \\
\hline V206 - Educação & $7 \%$ & & & & & $4 \%$ & & & & $44 \%$ \\
\hline V207 - Cultura & & $4 \%$ & & & & & $4 \%$ & & & \\
\hline V208 - Capacitação e desenvolvimento profissional & & & & & $42 \%$ & & & & & \\
\hline V209 - Creche ou auxílio-creche & $8 \%$ & & & $12 \%$ & & $8 \%$ & & & $10 \%$ & \\
\hline V210 - Participação nos lucros ou resultados & $5 \%$ & & & $11 \%$ & & $6 \%$ & & & $12 \%$ & \\
\hline \multicolumn{11}{|l|}{ V211 - Outros benefícios } \\
\hline \multicolumn{11}{|l|}{ V301 - Educação } \\
\hline V302-Cultura & & $9 \%$ & & & & & & & & \\
\hline \multicolumn{11}{|l|}{ V303 - Saúde e saneamento } \\
\hline V304 - Habitação & $12 \%$ & & & & & $12 \%$ & & & & \\
\hline V305 - Esporte & & $7 \%$ & & & & & $6 \%$ & & & \\
\hline V306 - Lazer e diversão & $3 \%$ & & & & & $4 \%$ & & & & \\
\hline \multicolumn{11}{|l|}{ V307 - Creches } \\
\hline V308 - Alimentação & & & & $7 \%$ & & & & & $11 \%$ & \\
\hline \multicolumn{11}{|l|}{ V309 - Combate à fome e segurança alimentar } \\
\hline \multicolumn{11}{|l|}{ V310 - Outros programas } \\
\hline V311 - Indicadores Sociais Externos agregados & $9 \%$ & $7 \%$ & & & & $7 \%$ & $8 \%$ & & & \\
\hline V313 - Impostos excluídos encargos sociais & & & & & & $3 \%$ & & & & \\
\hline $\begin{array}{l}\text { V401 - Investimentos relacionados com a } \\
\text { produção/operação da empresa }\end{array}$ & & & & $21 \%$ & & & & & $23 \%$ & \\
\hline $\begin{array}{l}\text { V402 - Investimentos em programas/projetos } \\
\text { externos }\end{array}$ & $3 \%$ & & & & & $4 \%$ & & & & \\
\hline V403 - Indicadores Ambientais agregados & & & & & $53 \%$ & & & & & \\
\hline Ano de publicação do BS (conjuntura) & & & & $13 \%$ & & & & & & \\
\hline
\end{tabular}


A Tabela 45 apresenta a quantidade de ações em RSE preconizadas pelo BS padrão IBASE que se mostraram significativas no caso de empresas com RO positivo e tabuladas por setor e por natureza de investimento em RSE que são os Indicadores Sociais Internos (ISI) que possuem 11 programas diferentes, Indicadores Sociais Externos com 12 programas e os Indicadores Ambientais com três.

A variável tabular denominada "Índice" foi obtida da relação entre a quantidade de programas significativos identificados pelos modelos (Total) e a quantidade de programas existente em cada segmento de investimento em RSE (por exemplo, 52/11=4,7). Essa métrica foi definida pelo autor com o objetivo de ensejar a comparação entre segmentos de investimento com quantidades diferentes de programas em RSE.

Tabela 45 - Quantidade de ações em RSE preconizadas pelo BS padrão IBASE que se mostraram significativas no caso de empresas com RO positivo

\begin{tabular}{l|c|c|c|c|c|c|c}
\hline Segmento de investimento em RSE & IND & SRV & ELE & AGI & FIN & Total & Índice \\
\hline ISI (11 programas de RSE) & 18 & 12 & 4 & 13 & 5 & 52 & 4,7 \\
\hline ISE (12 programas de RSE) & 14 & 12 & 2 & 2 & 1 & 31 & 2,6 \\
\hline IA (3 programas de RSE) & 6 & 2 & 0 & 4 & 1 & 13 & 4,3 \\
\hline Total de casos significativos & 38 & 26 & 6 & 19 & 7 & 96 & \\
\hline
\end{tabular}

Observa-se que IND com 38 casos significativos é o setor com maior quantidade de programas em RSE correlacionados com o RO positivo, seguido por SRV, AGI, FIN e ELE. De modo semelhante, a variável Índice indicou que ISI e IA possuem pesos semelhantes em termos de quantidade de programas sociais correlacionados com RO positivo, isso é, os programas ISI e IA têm uma participação relativa semelhante na relação dos investimentos em RSE. A conclusão é que os setores com maior quantidade de ações em RSE significativas e os programas com maior valor do Índice indicam maior relacionamento entre o RO positivo e os investimentos em RSE. Portanto, do ponto de vista da quantidade de ações em RSE, os investimentos em Indicadores Sociais externos são menos relacionados ao valor do RO positivo. As análises levadas a cabo não têm condições de indicar os efeitos de valores efetivamente investidos, já que os modelos buscaram identificar as métricas significativas e não seus valores. Os modelos explicativos estão fora do escopo do estudo.

As respostas às questões da pesquisa aplicadas às empresas com RO positivo estão baseadas nas Tabelas 43 a 45. 
Pergunta 1: Com base nas informações dos BSs padrão IBASE publicados pelas empresas, cuja estrutura está detalhada no item 1.5.2 (O Balanço Social padrão IBASE), existem evidências de que o desempenho financeiro refletido no Resultado Operacional esteja correlacionado às ações socialmente responsáveis das empresas que atuam no Brasil ?

Resposta 1: Sim, existe significância estatística que sugere não rejeitar a hipótese de que as empresas analisadas que operaram com RO positivo tiveram seu desempenho financeiro correlacionado com seus investimentos em RSE. Ao se considerar o porte das empresas (Tabela 43), foi observado que o nível de correlação é mais relevante que nos modelos nos quais não se considerou o porte das mesmas (Tabela 44). Os 30 modelos que consideraram o porte das empresas apresentaram significância e também relevância no relacionamento entre RO positivo e investimentos em RSE. Dos 30 modelos que não consideraram o porte das empresas, 15 deles não apresentaram significância no relacionamento entre o RO positivo e os investimentos em RSE, o que permite supor que o porte das empresas é um fator determinante da estratégia de decisão sobre os investimentos em RSE. O setor FIN teve um comportamento destacado dos demais, pois foi o único a ter significância e relevância na relação entre RO positivo e investimentos em RSE tanto nos modelos que consideraram o porte das empresas quanto nos que não consideraram o porte e é um comportamento que merece uma investigação futura.

Pergunta 2: No caso de existirem evidências neste sentido, quais foram os fatores que mais contribuíram para explicar essa relação?

Resposta 2: Os fatores que influenciaram a relação foram a natureza dos investimentos em RSE, o tipo de investimento em RSE (voluntário ou total), o porte da empresa, o ano de publicação do BS, o setor. O porte da empresa foi significativo, pois afetou os resultados dos modelos, como se pode observar nas Tabelas 43 e 44. A conjuntura econômica e social percebida pela discriminação do ano de publicação do BS foi significativa apenas em alguns dos modelos do setor AGI e SRV, porém com pequena relevância. O setor de atuação foi significativo, pois somente após terem sido explicitados individualmente nos modelos, suas correlações entre o RO positivo e as variáveis independentes puderam ser percebidas matematicamente. Os modelos 1B-L, 2B-L, 3B-L e 4B-L que consideraram a natureza dos investimentos em RSE em Indicadores Sociais Internos, Externos 
e Ambientais identificaram que os investimentos nos Indicadores Sociais Internos foram significativos em todos eles, exceto para o setor AGI nos modelos 3B-L e 4B-L, nos quais não foi observada qualquer relação dos investimentos em RSE com o RO positivo. No caso dos investimentos em Indicadores Sociais Externos, somente os modelos 1B-L e 2B-L tiveram alguma contribuição explicativa. No caso dos investimentos em Indicadores Ambientais, somente os modelos 2B-L e 4B-L tiveram alguma contribuição significativa, ainda que de pouca relevância. As condições de investimentos voluntários e totais em RSE causaram algumas diferenças comportamentais visíveis nos modelos 1C-L, 2C-L, 3C-L e 4C-L.

Pergunta 3: Existem variáveis que, agrupadas, podem identificar características singulares de um comportamento de gestão empresarial ?

Resposta 3: Sim. A Tabela 45 apresenta o resumo dos agrupamentos das variáveis indicando que o setor IND foi o que teve maior diversidade de investimentos sociais relacionados ao RO positivo, seguido pelo SRV, AGI, FIN e ELE. Ainda, do ponto de vista da natureza dos investimentos, os Indicadores Sociais Internos e Indicadores Ambientais apresentaram praticamente uma mesma participação comparativa na quantidade dos programas sociais relacionados ao RO positivo, refletidos na variável Índice com os valores respectivos de 4,3 e 4,7. Os modelos 1C-L, 2C-L, 3C-L e 4C-L das Tabelas 43 e 44 permitem a visualização generalizada das decisões empresariais que apresentaram relacionamento entre o RO positivo e os investimentos em RSE.

O próximo item encerra o trabalho resumindo as conclusões mais gerais e elaborando recomendações sobre possíveis investigações nessa linha de pesquisa. 


\section{CONCLUSÕES E RECOMENDAÇÕES}

Este trabalho apresentou inicialmente os principais conceitos sobre responsabilidade social e o papel das empresas dentro desse contexto. $\mathrm{O}$ entendimento do papel das empresas perante a responsabilidade social tem sofrido alterações ao longo do tempo e ainda é motivo de controvérsias. O trabalho incluíu alguns posicionamentos de autores consagrados que se manifestaram sobre o tema e que são recorrentemente citados na bibliografia que aborda o papel das empresas e a responsabilidade social. Aparentemente é um assunto ainda em aberto e que oferta o desafio ao cientista de encontrar, nas investigações empíricas, a confirmação de uma teoria ainda não consolidada.

A disponibilidade de uma fonte secundária de informações sobre responsabilidade social empresarial com uma série histórica e estabilidade quanto à definição de seu conteúdo proporcionaram rara e preciosa oportunidade de rico estudo empírico. O volume de dados adequados às técnicas estatísticas utilizadas e a pequena quantidade de outliers identificados proporcionaram condições adequadas para considerar a validade dos resultados obtidos.

Um diferencial do presente estudo foi contar com informações quantitativas e objetivas baseadas em valores de investimento, não tendo sido necessária a inclusão de informações baseadas em variáveis de opinião que têm alta carga de subjetividade ou de influência de experiências pessoais diversas que nem sempre são captadas e que acabam por participar do processo como fontes de ruído, reduzindo a qualidade das análises. Dentro da investigação bibliográfica empreendida pelo autor, poucos estudos puderam contar com esse benefício e os que tiveram acesso a valores quantitativos utilizaram pesquisas limitadas a informações de grandes empresas como as 500 empresas da revista Fortune ou pequenas amostras, como citados no item 2.2 (RSE e o Desempenho Financeiro).

O período de estudo de 5 anos, entre 2000 e 2004, com 897 amostras cobrindo a contribuição de 298 empresas foi analisado por meio da aplicação de 68 modelos diferentes. A miríade de visões proporcionou o estabelecimento de um mapeamento que é uma contribuição ao estudo do tema. 
As perguntas da pesquisa puderam ser respondidas plenamente com os resultados obtidos das análises estatísticas com o nível de significância de 5,0\% previamente planejado e o detalhamento pode ser encontrado no item 4 (Apresentação dos Resultados).

De forma geral, baseado nos resultados obtidos, não se pode rejeitar a hipótese de que o desempenho financeiro e os investimentos em ações de responsabilidade estavam relacionados entre si, tanto para empresas que operaram com resultado operacional positivo quanto negativo. Foi observado que, ao considerarmos o porte das empresas nos modelos de estudo, o relacionamento entre o desempenho financeiro e as ações em responsabilidade social teve maior poder explicativo que no caso oposto, no qual o modelo foi construído para não perceber o porte da empresa. Nesse caso, em sua maioria, os resultados foram estatisticamente significativos, mas o relacionamento observado se mostrou tênue, indicando uma maior diversificação no comportamento decisório das empresas. Outra constatação generalizada é a influência discriminadora do ano de publicação do balanço social, que o autor considera que reflete, de certa forma, a conjuntura econômica e social vivenciada pela empresa e o setor no qual ela atua. Eles se fizeram sensíveis principalmente nas empresas que pertenciam ao grupo com resultado operacional negativo. Finalmente, observou-se que nas empresas que tiveram resultado operacional positivo, o setor de atuação teve alguma influência sobre alguns dos programas sociais preconizados no balanço social padrão IBASE. Essa análise não foi realizada no caso das empresas com resultado operacional negativo, pois foi prejudicada pela insuficiência de dados na amostra.

Do ponto de vista das técnicas estatísticas, as conclusões sobre o desempenho financeiro das empresas e o seu relacionamento com suas ações de responsabilidade social empresarial, resultantes do presente estudo empírico, são particulares ao grupo de empresas que participaram da amostra e não podem ser generalizadas para representar o comportamento da população das empresas que atuaram no Brasil. A primeira restrição para a generalização dos resultados ocorreu pelo fato da amostragem ter sido intencional, entretanto, como a amostra conta com uma quantidade de casos adequados a análises estatísticas de boa qualidade técnica, com diversidade de portes, setores e situação de desempenho financeiro das empresas, garantindo uma participação dessa variedade como a existente na população, o autor supõe que os resultados obtidos possam ser utilizados condicionalmente como representantes da população. A segunda restrição foi o comportamento das variáveis da amostra que não apresentaram aderência à Distribuição Normal dentro do nível de significância estabelecida no estudo; entretanto, o tratamento matemático aplicado aos dados 
coletados melhorou o perfil da distribuição estatística das variáveis da amostra, ainda que não tenham atingido o limite de 5,0\% definido no planejamento da pesquisa, as análises gráficas indicam que as variáveis estão próximas do comportamento da distribuição normal. Esse tratamento matemático foi complementado com a análise de outliers e da homocedasticidade, resultando em condições bastante favoráveis para validação dos modelos e seus resultados. Portanto, representam uma contribuição relevante para o avanço das investigações sobre o tema e oferta um mapeamento de oportunidades de investigações explicativas.

Sugere-se a aplicação de modelos explicativos confirmatórios nos anos que antecederam e sucederam o período de estudo de 2000 a 2004, visando confirmar ou identificar os desvios da amostra em relação a esses modelos, isso é, se as decisões empresariais permaneceram as mesmas como observado no período do estudo e identificar as razões de possíveis desvios que vierem a ser identificados.

Os resultados do presente estudo podem servir de base para a elaboração de questionários de pesquisa que ajudem a identificar o processo decisório utilizado na definição das ações e investimentos em responsabilidade social, focalizando principalmente as situações de maior relevância já identificadas.

Finalmente, apoiado pelo mapeamento resultante do presente estudo, uma abordagem complementar seria a identificação das razões pelas quais as variáveis não significativas se manifestaram como tal, isso é, os investimentos em programas de responsabilidade social que não representaram um comportamento característicos dos setores estudados poderiam estar enquadrados como investimentos estratégicos alinhados com uma lógica não percebida pelos modelos ou são realmente investimentos desprovidos de uma racionalidade que possa ser modelada matematicamente. 


\section{REFERÊNCIAS}

AAKER, David A. et al. Marketing Research. Estados Unidos da América: John Wiley \& Sons, Inc., 5th ed., 1995.

BALANÇO SOCIAL IBASE - Instituto Brasileiro de Análises Sociais e Econômicas. Disponível em: <www.balancosocial.org.br>. Balanços Sociais coletados nos períodos 29 nov. 2004 a 03 dez. 2004 e 01 nov. 2005 a 29 jan. 2006.

BATEMAN, Thomas S.; SNELL, Scott A.. Administração: Construindo Vantagem Competitiva. São Paulo: Ed. Atlas, 1. ed., 1998.

BESANKO, David et al. Economics of Strategy. United State of America, John Wiley \& Sons, Inc., 2nd ed., 2000.

CARROLL, Archie B. The Pyramid of Corporate Social Responsibility: Toward the Moral Management of Organizational Stakeholders. Business Horizons. Greenwich: Vol.

34, Iss. 4; pg. 39, 10 pgs, jul./aug. 1991 set. 1999.

. Corporate social responsibility. Business and Society. Chicago: Vol. 38, Iss. 3, p. 268,

COELHO, Philip R. P. et al. The social responsibility of corporate management: A classical critique. Mid - American Journal of Business. Muncie: Vol. 18, Iss. 1, p. 15, spring 2003.

DALMÁCIO, Flávia Zóboli. Indicadores para Análise da Demonstração do Valor Adicionado. Revista Brasileira de Contabilidade. São Paulo: $n^{0}$ 149, p. 89-97, set./out. 2004. Disponível em: < http://www.balancosocial.org.br/media/Analise\%20do\%20DVA.zip> . Acesso em: 20 mar. 2006.

DENTCHEV, Nikolay. Corporate Social Performance as a Business Strategy. Journal of Business Ethics. The Netherlands: Kluver Academic Publishers, 55, p. 397-412, 2004.

DOW JONES SUSTAINABILITY INDEXES. Disponível em: $<$ http://www.sustainabilityindex.com/htmle/djsi_world/members.html $>$. Acesso em: 10 out. 10/2004.

DRUCKER, Peter F. As novas realidades: no governo e na política, na economia e nas empresas, na sociedade e na visão do mundo. São Paulo: Livraria Pioneira Editora, 2. ed., 1991.

ETHOS - Instituto ETHOS. Disponível em: <www.ethos.org.br>. Acesso em 10 out. 2004.

FREEMAN, R. Edward. The Stakeholder Approach Revisited. Zeitschrift für Wirtschafts- und Unternehmensethik. Mering: Vol. 5, Iss. 3, pg. 228, 14 pgs, 2004.

FRIEDMAN, Milton. Capitalism and Freedom. Chicago: The University of Chicago Press, 1975.

GONÇALVES, Ernesto Lima (Org.). Balanço Social da Empresa na América Latina. São Paulo: Livraria Pioneira Editora, 1980. 
GRIFFIN, Jennifer J.; MAHON, John F. The corporate social performance and corporate financial performance debate: Twenty-five years of incomparable research. Business and Society. Chicago: Vol. 36, Iss. 1, pg. 5, mar. 1997.

HAIR Jr, Joseph F. Análise Multivariada de Dados. São Paulo, Bookman, 5. ed., 2005.

HILLMAN, Amy J.; KEIM, Gerald D. Shareholder value, stakeholder management, and social issues: What's the bottom line? Strategic Management Journal. Chichester:

Vol.22, Iss. 2, pg. 125, fev. 2001.

IBASE - Instituto Brasileiro de Análises Sociais e Econômicas. Disponível em: $<$ http://www.ibase.org.br>. Acesso em: 10 out. 2004.

KERLINGER, F.N. Metodologia da pesquisa em Ciências Sociais. São Paulo: Editora Pedagógica e Universitária, 1979.

LAKATOS, Eva Maria; MARCONI, Marina de Andrade. Fundamentos de Metodologia

Científica. São Paulo: 5. ed., Editora Atlas, 2003.

LEENSON, Eric, Entrevista: Para empresário americano, investimento ético é o futuro do mercado financeiro. INSTITUTO ETHOS: CONFERÊNCIA NACIONAL 2004. São Paulo. Disponível em: $<$ http://www.ethos.org.br/CN_2004/cobertura/noticia_interna.asp? codNoticia=62>. Acesso em: 10 out. 2004.

MATTAR, F.N. Pesquisa de Marketing: Metodologia, Planejamento, Execução. Análise. Vol. 1. São Paulo: Atlas, 1994.

MOHR, Louis A. et al. Do consumers expect companies to be socially responsible? The impact of corporate social responsibility on buying behaviour. The Journal of Consumer Affairs. Vol. 35, number 1, summer 2001.

MOIR, Lance. What do we mean by corporate social responsibility? Corporate

Governance. Bradford: Vol. 1, Iss. 2, p. 16, 2001.

NETER, John et. al. Applied Linear Regression Models. USA, Irwin, 1990.

ORLITZKY, Marc. Does firm size confound the relationship between corporate social performance and firm financial performance? Journal of Business Ethics. Dordrecht: Vol.33, Iss. 2, pg. 167, 14 pgs, sep. 2001.

PINDYCK, Robert S. e RUBINFELD, Daniel L. Microeconomia, São Paulo, Pearson Prentice Hall, 5. ed., 2004.

POST, Frederick R. A response to "the social responsibility of corporate management: A classical critique". Mid - American Journal of Business. Muncie: Vol. 18, Iss. 1, p. 25, spring 2003.

PRÊMIO BALANÇO SOCIAL - ABERJE APIMEC ETHOS FIDES IBASE. Disponível em: $<$ www.premiobalancosocial.org.br>. Acesso em: 24 mar. 2006. 
PRESTON, Lee E; O'BANNON, Douglas P. The Corporate Social-financial performance relationship. Business and Society. Chicago: Vol. 36, Iss. 4, pg. 419, dez. 1997.

REAL ETHICAL: Fundos Ethical Banco Real. Disponível em http://www.fundoethical.com.br. Acesso em 25 mar 2006.

ROMAN, Ronald M. et al. The relationship between social and financial performance. Business and Society. Chicago: Vol. 38, Iss. 1, pg. 109, mar. 1999.

SAM - Sustainable Asset Management. Disponível em: <www.sam-group.com>. Acesso em 10 out. 2004.

SCHROEDER, Jocimar Três; SCHROEDER, Ivanir - Responsabilidade Social Corporativa: Limites e Possibilidades. RAE-eletrônica. São Paulo: RAE Eletrônica FGV-EAESP, v. 3, n. 1, Art. 1, jan./jun. 2004. Disponível em:

$<$ www.rae.com.br/eletronica/index.cfm? FuseAction=Artigo\&ID $=1573 \&$ Secao $=$ COMPTO\&Volum $\mathrm{e}=3 \&$ Numero $=1 \& \mathrm{Ano}=2004>$. Acesso em: 10 out. 2004.

SHAYON, Diana Russel. A Terceira Onda. Revista RI - Relações com Investidores. Rio de Janeiro: $n^{\text {o }}$ 63, p. 14-15, mai. 2003.

STOXX LTD. Disponível em: <www.stoxx.com/index.html>. Acesso em 10 out. 2004.

STANWICK, Peter A.; STANWICK, Sarah D. The determinants of corporate social performance: An empirical examination. American Business Review. West Haven: Vol. 16, Iss. 1, p. 86, jan. 1998a.

. The relationship between corporate social performance and organizational size, financial performance, and environmental performance: An empirical examination. Journal of Business Ethics. Dordrecht: Vol.17, Iss. 2, pg. 195, 10 pgs, jan. 1998b.

TAGUCHI, Genichi e JUGULUM Rajesh, The Mahalanobis-Taguchi Strategy: A Pattern Technology System. ISBN: 0-471-02333-7, Wiley, may 2002. Disponível em: < www.wiley.com/WileyCDA/WileyTitle/productCd-0471023337,descCd-tableOfContents.html>. Acesso em 06 nov. 2006.

ULLMANN, Arieh A. Data in search of a theory: A critical examination of the relationships among social performance, social disclosure, and economic performance of US firms. Academy of Management. The Academy of Management Review (pre-1986). Briarcliff Manor: Vol. 10, Iss. 000003; p. 540, 18 pags, jul. 1985.

WOOD, Donna J. Corporate Social Performance Revisited. Academy of Management. The Academy of Management Review. Briarcliff Manor: Vol. 16, nº 4, p. 691-718, 1991.

. The Fortune database as a CSP measure. Business and Society. Chicago: Vol. 34, Iss. 2, p. 197, 2 pgs., ago. 1995.

WU, Meng-Ling. Corporate Social Performance, Corporate Financial Performance, and Firm Size: A Meta-Analysis. Journal of American Academy of Business. Cambridge. Hollywood: Vol. 8, Iss. 1, p. 163, mar. 2006. 
YIN, Robert K. Case Study Research: Design and Methods. California, Sage Publications, Inc., Revised Ed., 1989. 


\section{ANEXOS}

\subsection{Balanço Social - Modelo Empresas - IBASE}

\begin{tabular}{|c|c|c|c|c|c|c|}
\hline$\frac{\text { Balanço Social Anual / } 2005}{\text { Enprest }}$ & & & & & & 1Base \\
\hline 1 - Base de Cálculo & & 2005 Valor (Mil re & reais) & & 004 Valor (Mil re & ais) \\
\hline Receita liquida $(R L)$ & & & & & & \\
\hline Resultado operacional (RO) & & & & & & \\
\hline Folha de pagamento bruta (FPB) & & & & & & \\
\hline 2 - Indicadores Sociais Internos & Valor (mil) & $\%$ sobre FPB & $\%$ sobre RL & Valor (mil) & $\%$ sobre FPB & $\%$ sobre RL \\
\hline Alimentação & & & & & & \\
\hline Encargos sociais compulsórios & & & & & & \\
\hline Previdência privada & & & & & & \\
\hline Saúde & & & & & & \\
\hline Segurança e saúde no trabalho & & & & & & \\
\hline Educação & & & & & & \\
\hline Cultura & & & & & & \\
\hline Capacitação e desenvolvimento profissional & & & & & & \\
\hline Creches ou auxilio-creche & & & & & & \\
\hline Participação nos lucros ou resultados & & & & & & \\
\hline Outros & & & & & & \\
\hline Total - Indicadores sociais internos & & & & & & \\
\hline 3 - Indicadores Sociais Externos & Valor (mil) & \% sobre RO & $\%$ sobre RL & Valor (mil) & \% sobre RO & \% sobre RL \\
\hline Educação & & & & & & \\
\hline Cultura & & & & & & \\
\hline Saúde e saneamento & & & & & & \\
\hline Esporte & & & & & & \\
\hline Combate à fome e segurança alimentar & & & & & & \\
\hline$\overline{\text { Outros }}$ & & & & & & \\
\hline Total das contribuições para a sociedade & & & & & & \\
\hline Tributos (excluidos encargos sociais) & & & & & & \\
\hline $\begin{array}{l}\text { Total - Indicadores sociais externos } \\
\end{array}$ & & & & & & \\
\hline 4 - Indicadores Ambientais & Valor (mil) & \% sobre RO & \% sobre RL & Valor (mil) & \% sobre RO & $\%$ sobre RL \\
\hline Investimentos relacionados com a produção/ operação & resa & & & & & \\
\hline Investimentos em programas e/ou projetos externos & & & & & & \\
\hline Total dos investimentos em meio ambiente & & & & & & \\
\hline $\begin{array}{l}\text { Quanto ao estabelecimento de "metas anuais" para minimizar } \\
\text { residuos, o consumo em geral na produção/ operação e } \\
\text { aumentar a eficácia na utilização de recursos naturais, a }\end{array}$ & $\begin{array}{l}\text { ( ) não possui n } \\
\text { ( ) cumpre de } 0\end{array}$ & $\begin{array}{l}\text { metas () cumpre } \\
0 \text { a } 50 \% \text { () cumpr }\end{array}$ & $\begin{array}{l}\text { e de } 51 \text { a } 75 \% \\
\text { ore de } 76 \text { a } 100 \%\end{array}$ & $\begin{array}{l}\text { ( ) não possui n } \\
\text { ( ) cumpre de } 0\end{array}$ & $\begin{array}{l}\text { metas ( ) cump } \\
\text { b a } 50 \% \text { ( ) cum }\end{array}$ & $\begin{array}{l}\text { de } 51 \text { a } 75 \% \\
\text { de } 76 \text { a } 100 \%\end{array}$ \\
\hline 5 - Indicadores do Corpo Funcional & & 2005 & & & 2004 & \\
\hline$N^{\circ}$ de empregados(as) ao final do período & & & & & & \\
\hline № de admissões durante o periodo & & & & & & \\
\hline $\mathrm{N}^{\circ}$ de empregados(as) terceirizados(as) & & & & & & \\
\hline $\mathrm{N}^{\circ}$ de estagiários(as) & & & & & & \\
\hline $\mathrm{N}^{\circ}$ de empregados(as) acima de 45 anos & & & & & & \\
\hline $\mathrm{N}^{\circ}$ de mulheres que trabalham na empresa & & & & & & \\
\hline$\%$ de cargos de chefia ocupados por mulheres & & & & & & \\
\hline $\mathrm{N}^{\circ}$ de negros(as) que trabalham na empresa & & & & & & \\
\hline$\%$ de cargos de chefia ocupados por negros(as) & & & & & & \\
\hline $\mathrm{N}^{\circ}$ de portadores(as) de deficiência ou necessidades especiais & & & & & & \\
\hline $\begin{array}{l}6 \text { - Informaçōes relevantes quanto ao exercício da } \\
\text { cidadania empresarial }\end{array}$ & & 2005 & & & Metas 2006 & \\
\hline Relação entre a maior e a menor remuneração na empresa & & & & & & \\
\hline Número total de acidentes de trabalho & & & & & & \\
\hline $\begin{array}{l}\text { Os projetos sociais e ambientais desenvolvidos pela empresa } \\
\text { foram definidos por: }\end{array}$ & ( ) direção & $\begin{array}{l}\text { ( ) direção e } \\
\text { gerências }\end{array}$ & \begin{tabular}{|c|} 
( ) todos(as) \\
empregados(as)
\end{tabular} & () direção & $\begin{array}{l}\text { (x) direção e } \\
\text { gerências }\end{array}$ & \begin{tabular}{|l} 
( ) todos(as) \\
empregados(as)
\end{tabular} \\
\hline $\begin{array}{l}\text { Os pradrões de segurança e salubridade no ambiente de } \\
\text { trabalho foram definidos por: }\end{array}$ & \begin{tabular}{l|} 
( ) direção e \\
gerências
\end{tabular} & \begin{tabular}{c|} 
( ) todos(as) \\
empregados(as)
\end{tabular} & $\begin{array}{c}\text { ( ) todos(as)+ } \\
\text { Cipa }\end{array}$ & \begin{tabular}{|c|} 
( ) direção e \\
gerências
\end{tabular} & \begin{tabular}{|c|} 
( ) todos(as) \\
empregados(as)
\end{tabular} & $\begin{array}{c}(\mathrm{x}) \text { todos(as) + } \\
\text { Cipa }\end{array}$ \\
\hline $\begin{array}{l}\text { Quanto à liberdade sindical, ao direito de negociação coletiva e } \\
\text { à representação interna dos(as) trabalhadores(as), a empresa: }\end{array}$ & $\begin{array}{l}\text { ( ) não se } \\
\text { envolve }\end{array}$ & \begin{tabular}{c|} 
( ) segue as \\
normas da OIT
\end{tabular} & $\begin{array}{l}\text { ( ) incentiva e } \\
\text { segue a OIT }\end{array}$ & $\begin{array}{l}\text { ( ) não se } \\
\text { envolverá }\end{array}$ & \begin{tabular}{|l|} 
() seguirá as \\
normas da OIT \\
\end{tabular} & $\begin{array}{l}\text { (x) incentivará e } \\
\text { seguirá a OIT }\end{array}$ \\
\hline A previdência privada contempla: & () direção & $\begin{array}{l}\text { () direção e } \\
\text { gerências }\end{array}$ & \begin{tabular}{|c|} 
( ) todos(as) \\
empregados(as) \\
\end{tabular} & () direção & $\begin{array}{l}\text { () direção e } \\
\text { gerências }\end{array}$ & $\begin{array}{c}\text { (x) todos(as) } \\
\text { empregados(as) } \\
\end{array}$ \\
\hline A participação dos lucros ou resultados contempla: & () direção & () direção e & $\begin{array}{l}\text { () todos(as) } \\
\text { empregaros(as) }\end{array}$ & () direção & $\begin{array}{l}\text { () direção } \mathrm{e} \\
\text { gerencias }\end{array}$ & $\begin{array}{l}\text { (x) }(x) \text { todos(as) } \\
\text { empreados(as) }\end{array}$ \\
\hline $\begin{array}{l}\text { Na seleção dos fornecedores, os mesmos padröes éticos e de } \\
\text { responsabilidade social e ambiental adotados pela empresa: }\end{array}$ & \begin{tabular}{c|} 
( ) não são \\
considerados
\end{tabular} & ( ) sãenclas sugeridos & \begin{tabular}{|l|l|} 
empregaaossas \\
( ) são exigidos
\end{tabular} & \begin{tabular}{|l|} 
( ) não serão \\
considerados
\end{tabular} & $\begin{array}{l}\text { gerenclas } \\
(x) \text { serão } \\
\text { sugeridos }\end{array}$ & $\begin{array}{l}\text { ( )mpregaaos las) } \\
\text { ( ) serão exigidos }\end{array}$ \\
\hline $\begin{array}{l}\text { Quanto à participação de empregados(as) em programas de } \\
\text { trabalho voluntário, a empresa: }\end{array}$ & $\begin{array}{l}\text { () não se } \\
\text { envolve }\end{array}$ & () apóia & $\begin{array}{l}\text { () organiza e } \\
\text { incentiva }\end{array}$ & $\begin{array}{l}\text { () não se } \\
\text { envolverá }\end{array}$ & () apoiará & $\begin{array}{l}\text { (x) organizará e } \\
\text { incentivará }\end{array}$ \\
\hline Número total de reclamações e críticas de consumidores(as): & na empresa & no Procon & na Justiça & \begin{tabular}{|l|} 
na empresa \\
\end{tabular} & no Procon & na Justiça \\
\hline \% de reclamações e críticas atendidas ou solucionadas: & \begin{tabular}{r|r} 
na empresa \\
$\%$ \\
\end{tabular} & $\begin{array}{r}\text { no Procon } \\
\% \\
\end{array}$ & $\begin{array}{r}\text { na Justiça } \\
\% \\
\end{array}$ & \begin{tabular}{|r|} 
na empresa \\
$\%$
\end{tabular} & $\begin{array}{r}\text { no Procon } \\
\% \\
\end{array}$ & $\begin{array}{r}\text { na Justiça } \\
\% \\
\end{array}$ \\
\hline Valor adicionado total a distribuir (em mil $\mathrm{R} \$):$ & Em 2005: & & & Em 2004: & & \\
\hline Distribuição do Valor Adicionado (DVA): & $\begin{array}{l}\text { - \% governo } \\
\text { \% acionista: }\end{array}$ & $\begin{array}{r}\% \text { colabo } \\
\text { \% terceiros }\end{array}$ & $\begin{array}{l}\text { oradores(as) } \\
\% \text { \% retido }\end{array}$ & $\begin{array}{l}\% \text { \% governo } \\
\text { \% acionistas }\end{array}$ & $\%$ cola & $\begin{array}{l}\text { adores(as) } \\
\text { \% retido }\end{array}$ \\
\hline 8 & & & & & & \\
\hline
\end{tabular}




\begin{tabular}{|c|c|c|c|c|c|c|c|c|c|c|}
\hline & $\stackrel{\not}{\sim}$ & $\frac{5}{7}$ & $\left|\begin{array}{l}3 \\
\vdots \\
⿱ 亠 䒑\end{array}\right|$ & & $\stackrel{\leftrightarrow}{\dot{i}}$ & $\stackrel{8}{3}$ & 5 & & & $\bar{F}$ \\
\hline & \begin{tabular}{|l|l}
7 \\
0 \\
0
\end{tabular} & 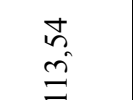 & 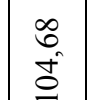 & 范 & 资 & \begin{tabular}{l}
7 \\
\multirow{2}{\infty}{} \\
$\infty$
\end{tabular} & 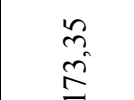 & & & 焉 \\
\hline & \begin{tabular}{|l|}
$\frac{\alpha}{v}$ \\
\end{tabular} & $\frac{8}{9}$ & 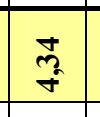 & $\frac{7 y}{7}$ & $\frac{9}{7}$ & $:$ & 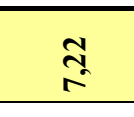 & 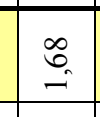 & & $\frac{10}{40}$ \\
\hline & 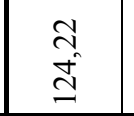 & 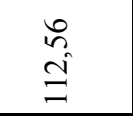 & 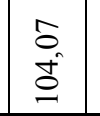 & 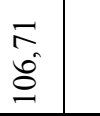 & $\overline{\underline{g}}$ & 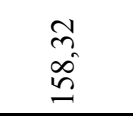 & 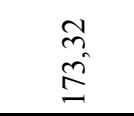 & & 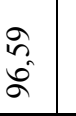 & $\overline{\widetilde{a}}$ \\
\hline & \begin{tabular}{|l|} 
\pm \\
\end{tabular} & $\overline{\mathrm{s}}$ & \begin{tabular}{|l|l}
0 \\
$\vdots$ \\
0
\end{tabular} & : & 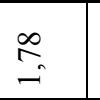 & $\overrightarrow{0}$ & $\stackrel{9}{0}$ & & त्: & $\vec{a}$ \\
\hline & \begin{tabular}{|l|l}
$\infty$ \\
0 \\
0
\end{tabular} & 素 & $\mid$ & $\overrightarrow{\mathcal{N}^{2}}$ & 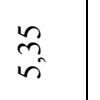 & $\overrightarrow{\bar{c}_{3}}$ & $\frac{n}{3}$ & & & $\overline{\vec{s}}$ \\
\hline & $\Xi$ & : & 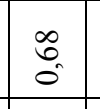 & 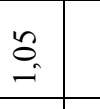 & F & $\stackrel{8}{0}$ & $\stackrel{8}{0}$ & $\overline{0}$ & 管: & $\frac{m}{i}$ \\
\hline & $\exists$ & Fe & $\mid \begin{array}{c}0 \\
\tilde{i}\end{array}$ & \pm & $\overline{7}$ & $\frac{\infty}{0}$ & $\frac{\infty}{\partial}$ & శి & & $\frac{\infty}{0}$ \\
\hline & 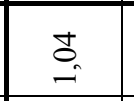 & $\stackrel{8}{-g}$ & $\stackrel{9}{9}$ & $\frac{1}{d}$ & 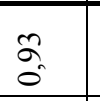 & $\underline{n}$ & g్d & 7 & & $\frac{8}{80}$ \\
\hline & 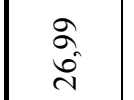 & $\overline{\vec{\gamma}}$ & 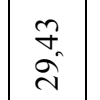 & 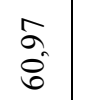 & $\begin{array}{l}8 \\
\dot{y} \\
\dot{y}\end{array}$ & 可 & 孛 & $\mid$ & $\frac{\pi}{\pi}$ & 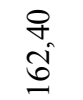 \\
\hline & $\Xi$ & $\stackrel{n}{2}$ & $\nexists$ & $\overline{\bar{a}}$ & : & $\stackrel{8}{-}$ & $\stackrel{t}{ \pm}$ & $\frac{\infty}{7}$ & & $E_{0}^{5}$ \\
\hline & 萦 & 孛 & \begin{tabular}{|l|l}
0 \\
$\frac{0}{2}$
\end{tabular} & d. & 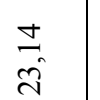 & 。 & $\underset{F}{F}$ & $\mid \begin{array}{l}\bar{a} \\
\underline{\underline{a}}\end{array}$ & 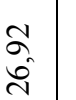 & 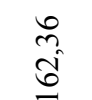 \\
\hline & \begin{tabular}{|l|}
$t$ \\
\end{tabular} & $\underbrace{+}_{3}$ & 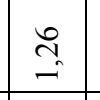 & \pm & 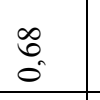 & $\frac{t}{0}$ & $\stackrel{t}{0}$ & f & 管 & : \\
\hline & $\bar{\Phi}$ & $\stackrel{g}{+}$ & $\%$ & $\frac{7}{7}$ & 总 & $\bar{\Xi}$ & $\underline{\underline{s}}$ & 里 & & 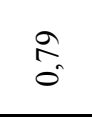 \\
\hline & \begin{tabular}{|l|}
$\frac{\infty}{0}$ \\
\end{tabular} & $\underline{I}$ & $\stackrel{\infty}{=}$ & 8 & 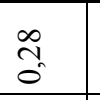 & à & 号: & 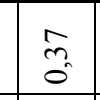 & 8 & 3 \\
\hline & \begin{tabular}{|l|}
$\mathbf{3}$ \\
0
\end{tabular} & $\stackrel{\infty}{\infty}$ & 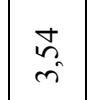 & $\stackrel{0}{f}$ & : & $\alpha_{0}^{\infty}$ & $\stackrel{\infty}{=}$ & $\cong$ & & $\stackrel{\wp}{q}$ \\
\hline & 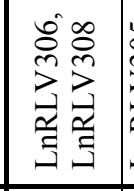 & & & & & & & & & \\
\hline & \begin{tabular}{|l|}
$\overline{\mathrm{g}}$ \\
\end{tabular} & $\begin{array}{l}\overline{\mathrm{g}} \\
\end{array}$ & 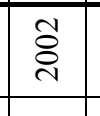 & $\bar{z}$ & 恶 & हू & $\overline{\bar{\delta}}$ & 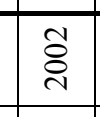 & & 害 \\
\hline & 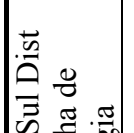 & 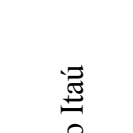 & & & & & & & & \\
\hline & 㩊意 & 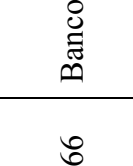 & 16 & & $\begin{array}{l} \\
\end{array}$ & 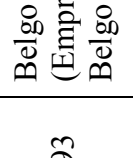 & 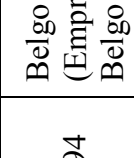 & & & \\
\hline & & $\stackrel{8}{8}$ & & & & 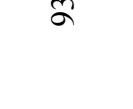 & & & & \\
\hline
\end{tabular}




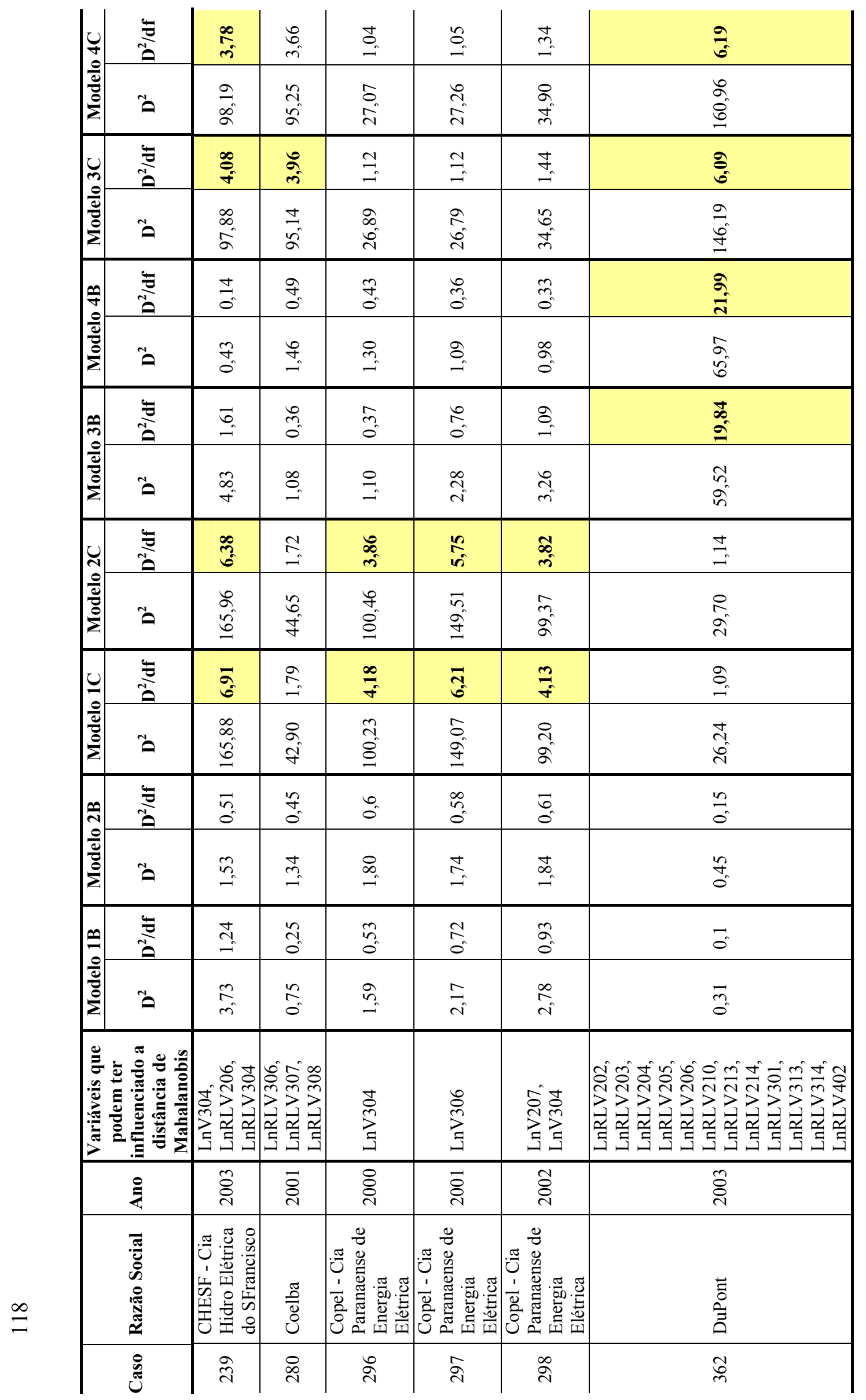




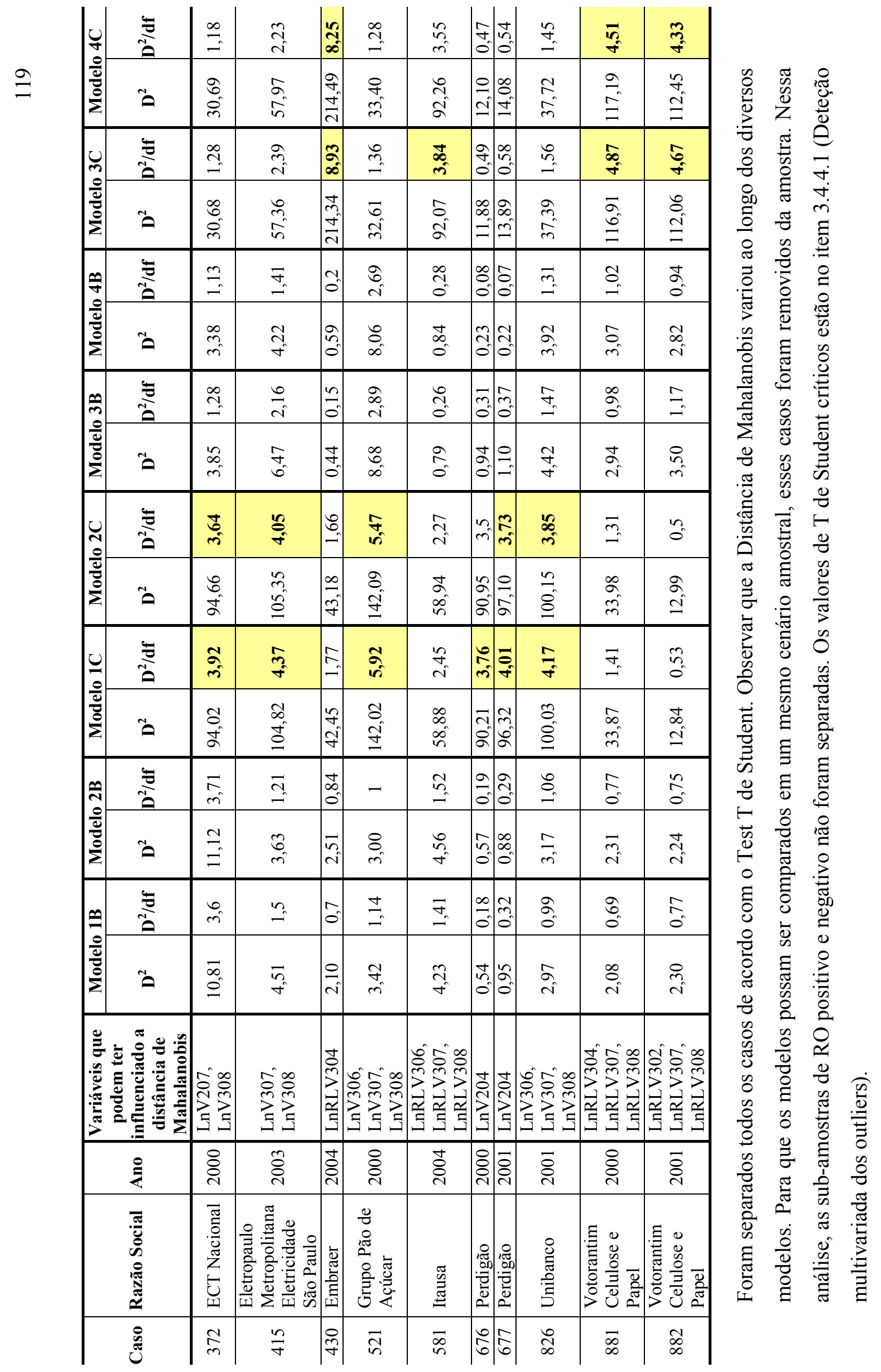




\subsection{Teste de normalidade das variáveis escala razão}

Seguem os resultados do teste de normalidade das variáveis utilizadas. Foram consideradas com distribuições normais as variáveis nas quais o valor de Sig foi superior a 5,0\%. Foram testadas separadamente as sub-amostras de RO negativo e positivo.

Os resultados mostraram que poucas variáveis tiveram distribuição normal ao nível de 5,0\%. Os gráficos Q-Q do item 7.4 permitiram avaliar aquelas que estão próximas de um comportamento segundo a distribuição normal e quais aquelas que se distanciaram mais desse critério.

Variáveis transformadas considerando o porte das empresas que operaram com prejuízo

\begin{tabular}{|c|c|c|c|c|c|c|}
\hline \multirow{2}{*}{ Resultado Operacional negativo $=$ Prejuízo } & \multicolumn{3}{|c|}{ Kolmogorov-Smirnov } & \multicolumn{3}{|c|}{ Shapiro-Wilk } \\
\hline & Statistic & df & Sig. & Statistic & df & Sig. \\
\hline LnV102-Resultado Operacional & ,093 & 144 & 004 & ,930 & 144 &, 000 \\
\hline LnV201-ISI-Alimentação &, 111 & 144 &, 000 & ,892 & 144 &, 000 \\
\hline LnV202-ISI-Encargos sociais compulsórios &, 125 & 144 & 000 & ,821 & 144 &, 000 \\
\hline LnV203-ISI-Previdência privada & ,269 & 144 &, 000 & ,821 & 144 &, 000 \\
\hline LnV204-ISI-Saúde &, 110 & 144 & 000 & ,941 & 144 &, 000 \\
\hline LnV205-ISI-Segurança e medicina trabalho & 192 & 144 &, 000 &, 873 & 144 &, 000 \\
\hline LnV206-ISI-Educação &, 128 & 144 &, 000 & ,932 & 144 &, 000 \\
\hline LnV207-ISI-Cultura & , 478 & 144 &, 000 & ,471 & 144 &, 000 \\
\hline LnV208-ISI-Capacitação e desenv. profiss. &, 165 & 144 &, 000 & ,912 & 144 &, 000 \\
\hline LnV209-ISI-Creches ou auxílio-creche & ,285 & 144 & 000 &, 820 & 144 &, 000 \\
\hline LnV210-ISI-Participação lucros/resultados & ,371 & 144 & 000 &, 733 & 144 &, 000 \\
\hline LnV211-ISI-Outros &, 171 & 144 &, 000 & ,868 & 144 &, 000 \\
\hline LnV213-ISI-Total com compulsório &, 085 & 144 &, 012 & ,959 & 144 &, 000 \\
\hline LnV214-ISI-Total sem compulsorio & 087 & 144 & 009 & 967 & 144 &, 002 \\
\hline LnV301-ISE-Educação & ,299 & 135 &, 000 &, 810 & 135 &, 000 \\
\hline LnV302-ISE-Cultura &, 355 & 135 &, 000 & ,723 & 135 &, 000 \\
\hline LnV303-ISE-Saúde e saneamento & ,395 & 135 &, 000 & ,551 & 135 &, 000 \\
\hline LnV304-ISE-Habitação &, 537 & 135 & 000 &, 133 & 135 &, 000 \\
\hline LnV305-ISE-Esporte & , 432 & 135 &, 000 &, 590 & 135 &, 000 \\
\hline LnV306-ISE-Lazer e diversão &, 535 & 135 &, 000 & 156 & 135 &, 000 \\
\hline LnV307-ISE-Creches &, 534 & 135 &, 000 &, 126 & 135 &, 000 \\
\hline LnV308-ISE-Alimentação & ,539 & 135 & 000 &, 187 & 135 &, 000 \\
\hline LnV309-ISE-Combate fome... & , 487 & 135 &, 000 &, 350 & 135 &, 000 \\
\hline LnV310-ISE-Outros & 235 & 136 &, 000 &, 881 & 136 &, 000 \\
\hline LnV311-ISE-Agregados &, 535 & 136 &, 000 & ,272 & 136 &, 000 \\
\hline LnV312-ISE-Total & 083 & 136 &, 022 & ,966 & 136 &, 002 \\
\hline LnV313-Tributos (excluídos encargos sociais) & 167 & 136 & 000 & ,826 & 136 &, 000 \\
\hline LnV314-ISE-Total+compulsório & 101 & 136 &, 002 & ,944 & 136 &, 000 \\
\hline LnV401-IA-Invest relacionados prod/operação & 230 & 131 & 000 & 875 & 131 &, 000 \\
\hline LnV402-IA-Invest programas \& proj. externos &, 422 & 131 &, 000 & ,638 & 131 &, 000 \\
\hline LnV403-IA-Agregado &, 500 & 131 &, 000 &, 455 & 131 &, 000 \\
\hline LnV404-IA-Total &, 114 & 131 &, 000 & ,934 & 131 & 000 \\
\hline
\end{tabular}


Variáveis transformadas dessensibilizadas do porte das empresas que operaram com prejuízo

\begin{tabular}{|c|c|c|c|c|c|c|}
\hline \multirow{2}{*}{ Resultado Operacional negativo $=$ Prejuízo } & \multicolumn{3}{|c|}{ Kolmogorov-Smirnov } & \multicolumn{3}{|c|}{ Shapiro-Wilk } \\
\hline & Statistic & df & Sig. & Statistic & df & Sig. \\
\hline LnRLV102-Resultado Operacional &, 084 & 143 &, 016 & ,945 & 143 &, 000 \\
\hline LnRLV201-ISI-Alimentação & 148 & 143 &, 000 & ,747 & 143 &, 000 \\
\hline LnRLV202-ISI-Encargos sociais compulsórios & 223 & 143 &, 000 & ,607 & 143 &, 000 \\
\hline LnRLV203-ISI-Previdência privada & 279 & 144 &, 000 & ,776 & 144 &, 000 \\
\hline LnRLV204-ISI-Saúde & 153 & 143 &, 000 & ,780 & 143 &, 000 \\
\hline LnRLV205-ISI-Segurança e medicina trabalho & ,212 & 143 & ,000 & ,812 & 143 &, 000 \\
\hline LnRLV206-ISI-Educação & , 165 & 143 & ,000 & ,882 & 143 & ,000 \\
\hline LnRLV207-ISI-Cultura & 485 & 144 & ,000 & ,492 & 144 &, 000 \\
\hline LnRLV208-ISI-Capacitação e desenv. profiss. & , 193 & 143 & ,000 & ,811 & 143 & ,000 \\
\hline LnRLV209-ISI-Creches ou auxílio-creche & ,266 & 143 &, 000 & ,847 & 143 &, 000 \\
\hline LnRLV210-ISI-Participação lucros/resultados & 377 & 144 &, 000 & ,696 & 144 &, 000 \\
\hline LnRLV211-ISI-Outros & 181 & 143 &, 000 & ,786 & 143 &, 000 \\
\hline LnRLV213-ISI-Total com compulsório & ,054 & 143 & ,200 & 991 & 143 &, 493 \\
\hline LnRLV214-ISI-Total sem compulsorio &, 045 & 143 & ,200 & ,982 & 143 &, 062 \\
\hline LnRLV301-ISE-Educação & ,296 & 134 &, 000 & ,821 & 134 &, 000 \\
\hline LnRLV302-ISE-Cultura & ,362 & 134 &, 000 & ,749 & 134 &, 000 \\
\hline LnRLV303-ISE-Saúde e saneamento & 397 & 134 &, 000 & 601 & 134 &, 000 \\
\hline LnRLV304-ISE-Habitação & ,537 & 135 &, 000 & ,133 & 135 &, 000 \\
\hline LnRLV305-ISE-Esporte & ,433 & 134 &, 000 & ,616 & 134 &, 000 \\
\hline LnRLV306-ISE-Lazer e diversão & ,540 & 135 &, 000 & ,211 & 135 &, 000 \\
\hline LnRLV307-ISE-Creches &, 537 & 135 &, 000 & 157 & 135 &, 000 \\
\hline LnRLV308-ISE-Alimentação & ,539 & 135 &, 000 &, 186 & 135 &, 000 \\
\hline LnRLV309-ISE-Combate fome... & , 479 & 134 &, 000 & ,428 & 134 &, 000 \\
\hline LnRLV310-ISE-Outros & 240 & 135 &, 000 & ,865 & 135 &, 000 \\
\hline LnRLV311-ISE-Agregados &, 536 & 136 &, 000 & 275 & 136 &, 000 \\
\hline LnRLV312-ISE-Total sem compulsório & 147 & 135 &, 000 & ,909 & 135 &, 000 \\
\hline LnRLV313-Tributos (excluídos encargos sociais) & 302 & 135 &, 000 & 629 & 135 &, 000 \\
\hline LnRLV314-ISE-Total com compulsório & 221 & 135 &, 000 & ,754 & 135 &, 000 \\
\hline LnRLV401-IA-Invest relacionados prod/operação & 243 & 130 &, 000 & ,852 & 130 &, 000 \\
\hline LnRLV402-IA-Invest programas \& proj. externos & 422 & 130 &, 000 & 645 & 130 &, 000 \\
\hline LnRLV403-IA-Agregado & ,504 & 131 &, 000 & ,465 & 131 &, 000 \\
\hline LnRLV404-IA-Total & , 169 & 130 &, 000 & ,883 & 130 &, 000 \\
\hline
\end{tabular}

Variáveis transformadas do Total dos investimentos em RSE (considera o porte das empresas)

\begin{tabular}{l|c|c|c|c|c|c}
\hline \multirow{2}{*}{ Resultado Operacional negativo = Prejuízo } & \multicolumn{2}{|c|}{ Kolmogorov-Smirnov } & \multicolumn{3}{c}{ Shapiro-Wilk } \\
\cline { 2 - 7 } & Statistic & $\mathbf{d f}$ & Sig. & Statistic & df & Sig. \\
\hline LnRSE_Voluntario &, 065 & 127 & $\mathbf{2 0 0}$ &, 980 & 127 & $\mathbf{0 6 4}$ \\
\hline LnRSE_Total &, 049 & 127 & $\mathbf{2 0 0}$ &, 984 & 127 & $\mathbf{1 3 9}$ \\
\hline
\end{tabular}

Variáveis transformadas do Total dos investimentos em RSE (dessensibilizadas do porte das empresas)

\begin{tabular}{l|c|c|c|c|c|c}
\hline \multirow{2}{*}{ Resultado Operacional negativo = Prejuízo } & \multicolumn{2}{|c|}{ Kolmogorov-Smirnov } & \multicolumn{3}{|c}{ Shapiro-Wilk } \\
\cline { 2 - 7 } & Statistic & $\mathbf{d f}$ & Sig. & Statistic & df & Sig. \\
\hline LnR_RSE_Voluntario &, 071 & 143 & $\mathbf{, 0 7 6}$ &, 969 & 143 &, 003 \\
\hline LnR_RSE_Total &, 126 & 143 &, 000 &, 914 & 143 &, 000 \\
\hline
\end{tabular}


Variáveis transformadas considerando o porte das empresas que operaram com lucro

\begin{tabular}{|c|c|c|c|c|c|c|}
\hline \multirow{2}{*}{ Resultado Operacional positivo $=$ Lucro } & \multicolumn{3}{|c|}{ Kolmogorov-Smirnov } & \multicolumn{3}{|c|}{ Shapiro-Wilk } \\
\hline & Statistic & df & Sig. & Statistic & df & Sig. \\
\hline LnV102-Resultado Operacional & 039 & 664 &, 020 & ,995 & 664 &, 024 \\
\hline LnV201-ISI-Alimentação &, 040 & 664 &, 012 & ,977 & 664 &, 000 \\
\hline LnV202-ISI-Encargos sociais compulsórios & 071 & 664 &, 000 & ,906 & 664 &, 000 \\
\hline LnV203-ISI-Previdência privada & ,256 & 664 &, 000 & ,845 & 664 &, 000 \\
\hline LnV204-ISI-Saúde & 057 & 664 &, 000 & ,976 & 664 &, 000 \\
\hline LnV205-ISI-Segurança e medicina trabalho & ,169 & 664 &, 000 & ,905 & 664 &, 000 \\
\hline LnV206-ISI-Educação & ,145 & 664 & ,000 & ,929 & 664 &, 000 \\
\hline LnV207-ISI-Cultura & ,427 & 664 & ,000 & ,617 & 664 &, 000 \\
\hline LnV208-ISI-Capacitação e desenv. profiss. & ,139 & 664 & , 000 & ,934 & 664 & ,000 \\
\hline LnV209-ISI-Creches ou auxílio-creche & ,264 & 664 &, 000 & ,847 & 664 &, 000 \\
\hline LnV210-ISI-Participação lucros/resultados & , 165 & 664 &, 000 & 880 & 664 &, 000 \\
\hline LnV211-ISI-Outros & ,106 & 664 &, 000 & ,927 & 664 &, 000 \\
\hline LnV213-ISI-Total com compulsório &, 050 & 664 & ,000 & ,995 & 664 & ,026 \\
\hline LnV214-ISI-Total sem compulsorio &, 042 & 664 &, 006 & ,991 & 664 &, 001 \\
\hline LnV301-ISE-Educação & 257 & 643 & ,000 & ,854 & 643 &, 000 \\
\hline LnV302-ISE-Cultura &, 252 & 644 &, 000 & 847 & 644 &, 000 \\
\hline LnV303-ISE-Saúde e saneamento & ,358 & 644 &, 000 & ,713 & 644 &, 000 \\
\hline LnV304-ISE-Habitação &, 523 & 644 &, 000 & 047 & 644 &, 000 \\
\hline LnV305-ISE-Esporte & ,351 & 644 & ,000 & ,717 & 644 &, 000 \\
\hline LnV306-ISE-Lazer e diversão & ,521 & 644 &, 000 & 263 & 644 &, 000 \\
\hline LnV307-ISE-Creches &, 533 & 644 &, 000 & 157 & 644 &, 000 \\
\hline LnV308-ISE-Alimentação &, 527 & 644 &, 000 &, 184 & 644 &, 000 \\
\hline LnV309-ISE-Combate fome... & ,449 & 644 &, 000 &, 501 & 644 &, 000 \\
\hline LnV310-ISE-Outros &, 180 & 645 &, 000 & ,910 & 645 &, 000 \\
\hline LnV311-ISE-Agregados &, 525 & 646 &, 000 & ,351 & 646 &, 000 \\
\hline LnV312-ISE-Total &, 059 & 646 &, 000 & ,966 & 646 &, 000 \\
\hline LnV313-Tributos (excluídos encargos sociais) & 135 & 646 &, 000 & ,867 & 646 &, 000 \\
\hline LnV314-ISE-Total+compulsório &, 042 & 646 &, 009 & ,973 & 646 &, 000 \\
\hline LnV401-IA-Invest relacionados prod/operação & 235 & 607 &, 000 & ,876 & 607 &, 000 \\
\hline LnV402-IA-Invest programas \& proj. externos & ,354 & 607 &, 000 & ,739 & 607 &, 000 \\
\hline LnV403-IA-Agregado & ,509 & 608 &, 000 & 423 & 608 &, 000 \\
\hline LnV404-IA-Total & ,116 & 607 & ,000 & ,942 & 607 &, 000 \\
\hline
\end{tabular}


Variáveis transformadas dessensibilizadas do porte das empresas que operaram com lucro

\begin{tabular}{|c|c|c|c|c|c|c|}
\hline \multirow{2}{*}{ Resultado Operacional positivo $=$ Lucro } & \multicolumn{3}{|c|}{ Kolmogorov-Smirnov } & \multicolumn{3}{|c|}{ Shapiro-Wilk } \\
\hline & Statistic & df & Sig. & Statistic & df & Sig. \\
\hline LnRLV102-Resultado Operacional & 076 & 663 &, 000 & ,966 & 663 &, 000 \\
\hline LnRLV201-ISI-Alimentação &, 124 & 663 &, 000 & ,773 & 663 &, 000 \\
\hline LnRLV202-ISI-Encargos sociais compulsórios & 257 & 663 &, 000 & ,559 & 663 &, 000 \\
\hline LnRLV203-ISI-Previdência privada & ,269 & 663 &, 000 & ,793 & 663 &, 000 \\
\hline LnRLV204-ISI-Saúde & ,141 & 663 &, 000 & ,731 & 663 &, 000 \\
\hline LnRLV205-ISI-Segurança e medicina trabalho & ,186 & 664 & ,000 & 823 & 664 & ,000 \\
\hline LnRLV206-ISI-Educação & ,171 & 663 & ,000 & 842 & 663 &, 000 \\
\hline LnRLV207-ISI-Cultura & ,433 & 664 & ,000 & ,631 & 664 &, 000 \\
\hline LnRLV208-ISI-Capacitação e desenv. profiss. & ,217 & 664 & ,000 & ,787 & 664 & ,000 \\
\hline LnRLV209-ISI-Creches ou auxílio-creche &, 270 & 664 &, 000 &, 851 & 664 &, 000 \\
\hline LnRLV210-ISI-Participação lucros/resultados & ,277 & 663 &, 000 &, 710 & 663 &, 000 \\
\hline LnRLV211-ISI-Outros & 189 & 663 &, 000 & ,789 & 663 &, 000 \\
\hline LnRLV213-ISI-Total com compulsório & ,048 & 663 & ,001 & ,980 & 663 & ,000 \\
\hline LnRLV214-ISI-Total sem compulsorio & ,083 & 663 & ,000 & 810 & 663 &, 000 \\
\hline LnRLV301-ISE-Educação & 274 & 644 & ,000 & ,833 & 644 &, 000 \\
\hline LnRLV302-ISE-Cultura & ,271 & 644 &, 000 &, 820 & 644 &, 000 \\
\hline LnRLV303-ISE-Saúde e saneamento & ,368 & 644 &, 000 & , 740 & 644 &, 000 \\
\hline LnRLV304-ISE-Habitação & ,526 & 644 &, 000 & 058 & 644 &, 000 \\
\hline LnRLV305-ISE-Esporte & ,364 & 644 &, 000 & ,745 & 644 &, 000 \\
\hline LnRLV306-ISE-Lazer e diversão &, 527 & 644 &, 000 & 291 & 644 &, 000 \\
\hline LnRLV307-ISE-Creches &, 534 & 644 &, 000 & 184 & 644 &, 000 \\
\hline LnRLV308-ISE-Alimentação &, 535 & 644 &, 000 & ,219 & 644 &, 000 \\
\hline LnRLV309-ISE-Combate fome... & ,462 & 644 &, 000 &, 543 & 644 &, 000 \\
\hline LnRLV310-ISE-Outros & 204 & 645 &, 000 & ,889 & 645 &, 000 \\
\hline LnRLV311-ISE-Agregados & ,530 & 645 &, 000 & ,349 & 645 &, 000 \\
\hline LnRLV312-ISE-Total sem compulsório & 166 & 645 &, 000 & ,838 & 645 &, 000 \\
\hline LnRLV313-Tributos (excluídos encargos sociais) & 336 & 645 &, 000 &, 579 & 645 &, 000 \\
\hline LnRLV314-ISE-Total com compulsório & ,217 & 645 &, 000 & ,746 & 645 &, 000 \\
\hline LnRLV401-IA-Invest relacionados prod/operação & 249 & 607 &, 000 & 837 & 607 &, 000 \\
\hline LnRLV402-IA-Invest programas \& proj. externos & ,358 & 607 &, 000 & ,754 & 607 &, 000 \\
\hline LnRLV403-IA-Agregado & ,512 & 607 &, 000 & ,426 & 607 &, 000 \\
\hline LnRLV404-IA-Total &, 152 & 606 & ,000 & ,875 & 606 & ,000 \\
\hline
\end{tabular}

\begin{tabular}{l|c|c|c|c|c|c}
\multicolumn{6}{c}{ Variáveis transformadas do Total dos investimentos em RSE (considera o porte das empresas) } \\
\hline \multirow{2}{*}{ Resultado Operacional positivo = Lucro } & \multicolumn{1}{|c|}{ Kolmogorov-Smirnov } & \multicolumn{3}{c}{ Shapiro-Wilk } \\
\cline { 2 - 7 } & Statistic & $\mathbf{d f}$ & Sig. & Statistic & df & Sig. \\
\hline LnRSE_Voluntario &, 055 & 596 &, 000 &, 992 & 596 &, 003 \\
\hline LnRSE_Total &, 035 & 596 & $\mathbf{, 0 8 7}$ &, 993 & 596 &, 005 \\
\hline
\end{tabular}

Variáveis transformadas do Total dos investimentos em RSE (dessensibilizadas do porte)

\begin{tabular}{l|c|c|c|c|c|c}
\hline \multicolumn{2}{c}{ Resultado Operacional positivo $=$ Lucro } & \multicolumn{3}{|c}{ Kolmogorov-Smirnov } & \multicolumn{3}{c}{ Shapiro-Wilk } \\
\cline { 2 - 7 } & Statistic & df & Sig. & Statistic & df & Sig. \\
\hline LnR_RSE_Voluntario &, 043 & 663 &, 005 &, 989 & 663 &, 000 \\
\hline LnR_RSE_Total &, 085 & 663 &, 000 &, 939 & 663 &, 000 \\
\hline
\end{tabular}




\subsection{Gráficos Normal Q-Q}

O gráfico Normal Q-Q permite visualizar a aderência à distribuição normal de maneira mais objetiva que aquela, também gráfica, que avalia a conformação do histograma no formato de um sino, como exemplificado pela variável LnV201-ISI-Alimentação na Figura 5.

No gráfico normal Q-Q, a aderência à distribuição normal se verifica quanto melhor é a proximidade da resposta à reta inclinada. Seguem as variáveis do estudo, separadas lado-a-lado nos grupos de RO negativo (Prejuízo - P) e positivo (Lucro - L). Um teste de normalidade qualitativo.

Os gráficos Normal Q-Q que seguem apresentam todas as variáveis transformadas pelo logaritmo natural que foram utilizadas no estudo. Notar que a distribuição das sub-amostras das empresas com RO positivo e negativo guardam certa semelhança entre si. Essa característica poderá apoiar os estudos dos modelos explicativos. Considerando que algumas das distribuições foram fortemente não normais, essas necessitam de um maior cuidado na análise de sua influência sobre os modelos de estudo.

\subsubsection{Variável Resultado Operacional considerando o porte das empresas}
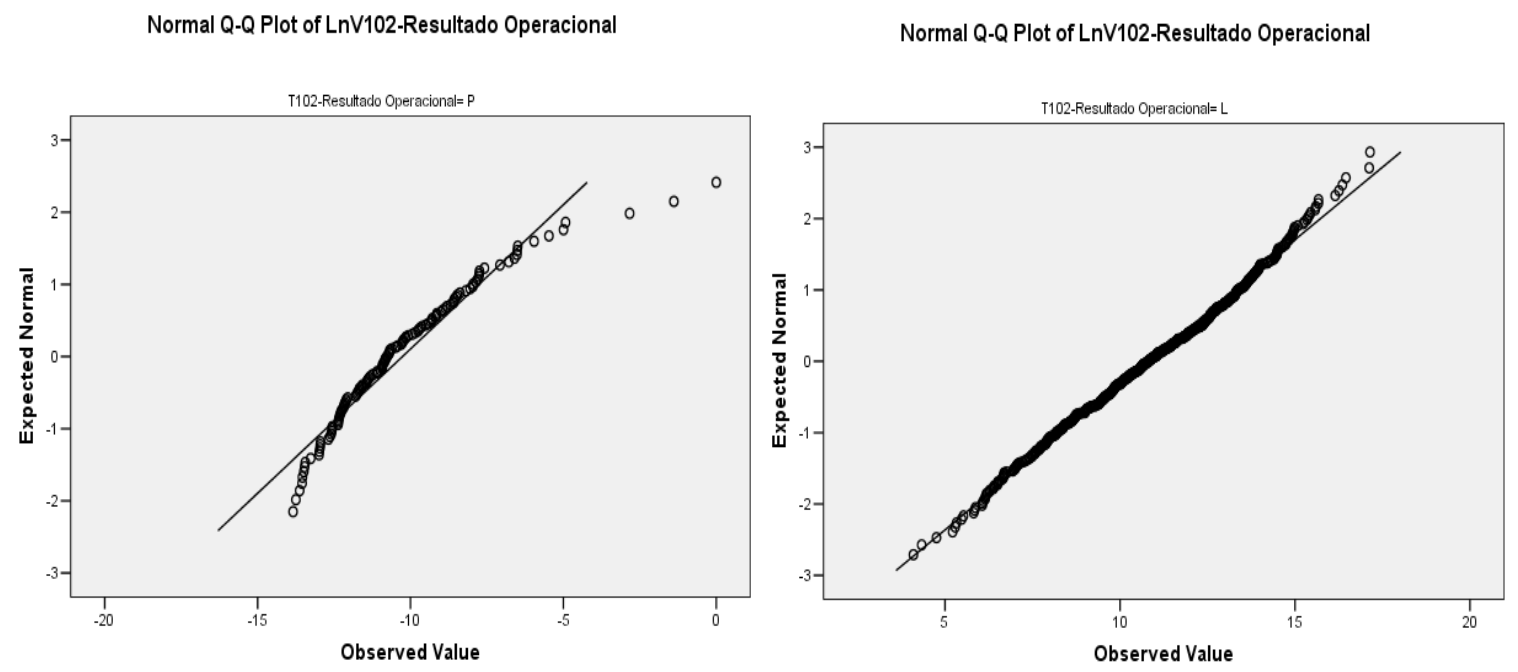


\subsubsection{Variáveis Indicadores Sociais Internos considerando o porte das empresas}

Normal Q-Q Plot of LnV201-ISI-Alimentação

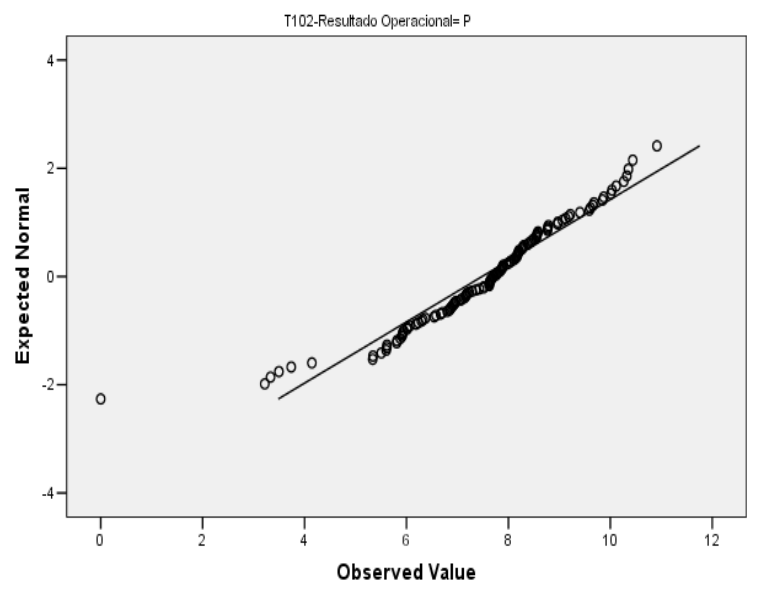

Normal Q-Q Plot of LnV202-ISI-Encargos sociais compulsórios

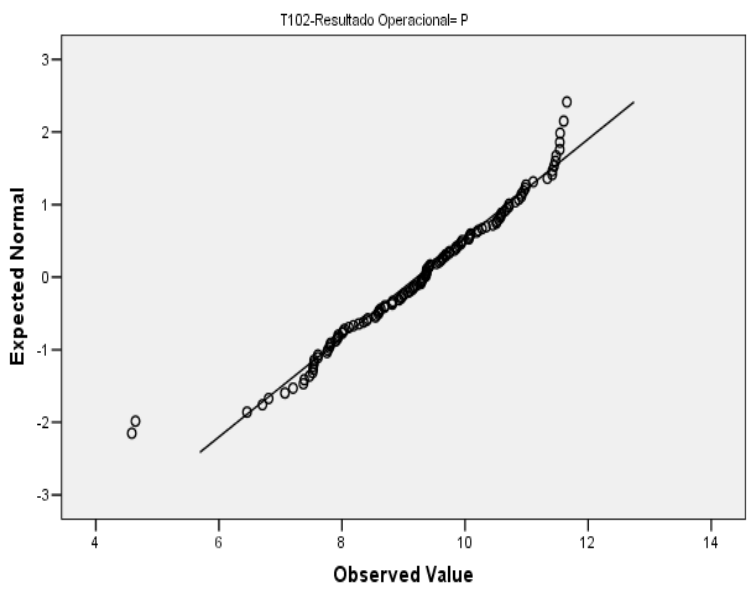

Normal Q-Q Plot of LnV201-ISI-Alimentação

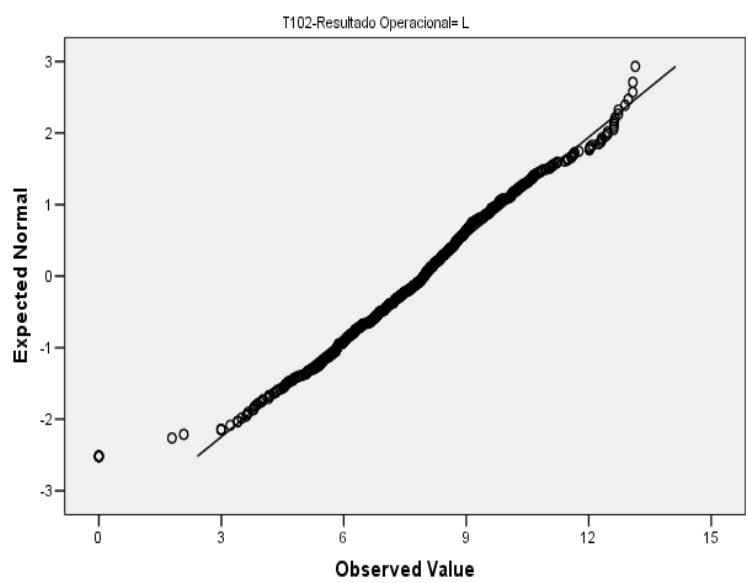

Normal Q-Q Plot of LnV202-ISI-Encargos sociais compulsórios

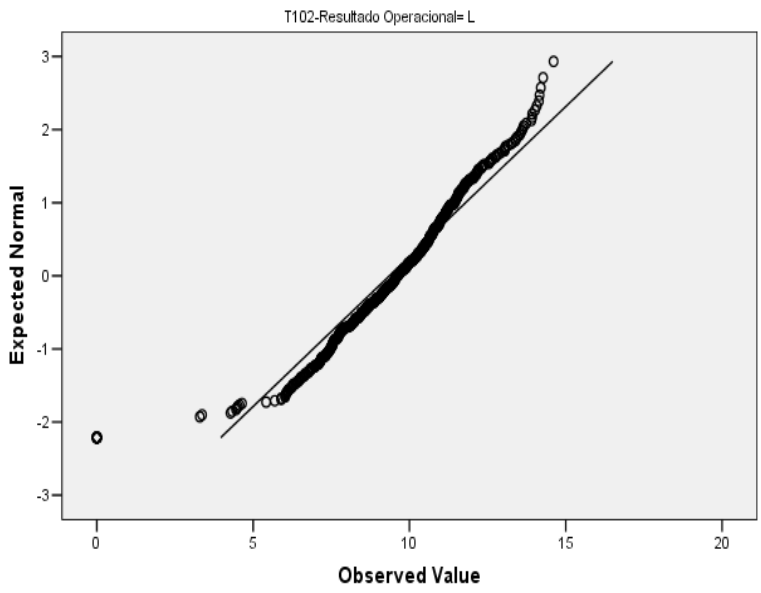


Normal Q-Q Plot of LnV203-ISI-Previdência privada

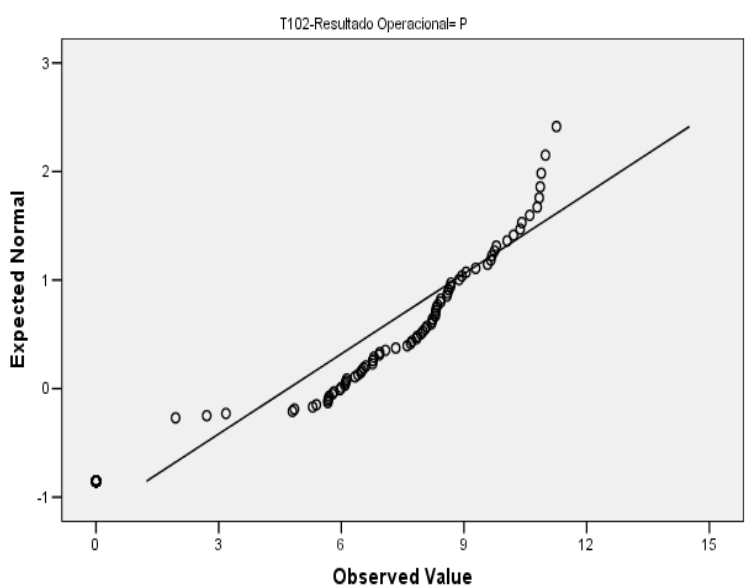

Normal Q-Q Plot of LnV204-ISI-Saúde

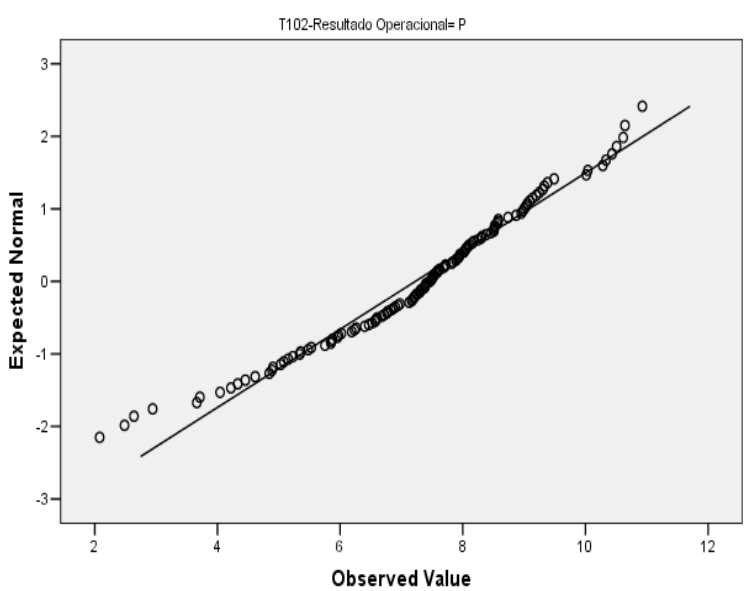

Normal Q-Q Plot of LnV205-ISI-Segurança e medicina trabalho

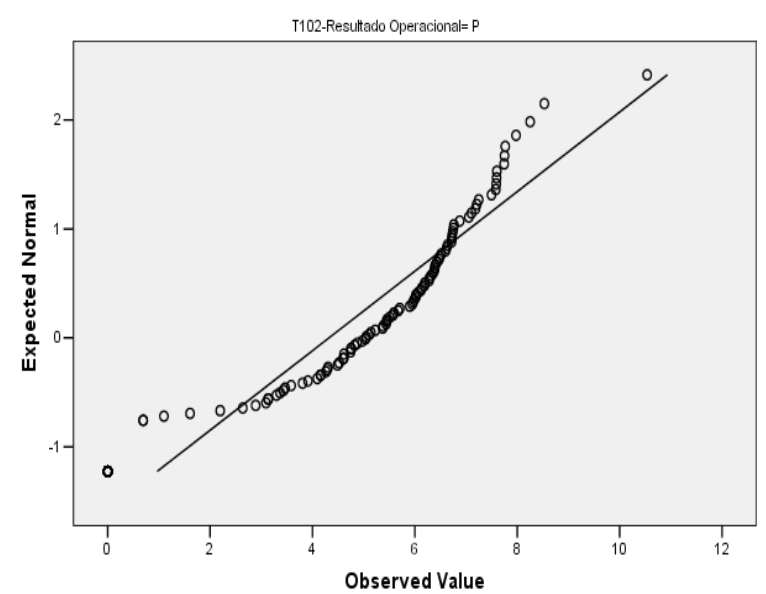

Normal Q-Q Plot of LnV203-ISI-Previdência privada

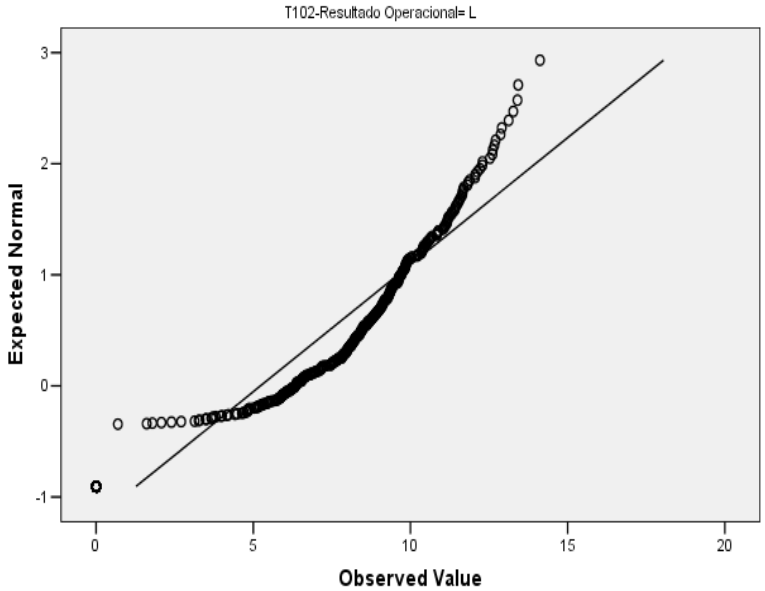

Normal Q-Q Plot of LnV204-ISI-Saúde

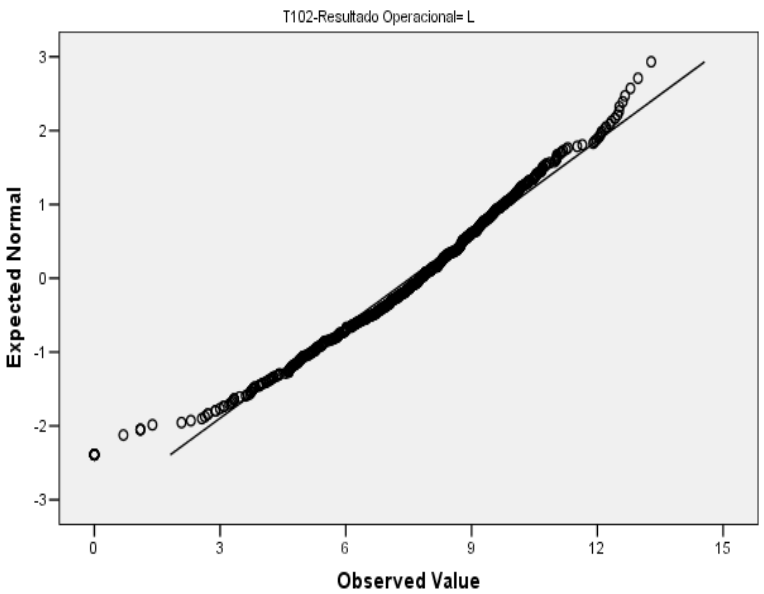

Normal Q-Q Plot of LnV205-ISI-Segurança e medicina trabalho

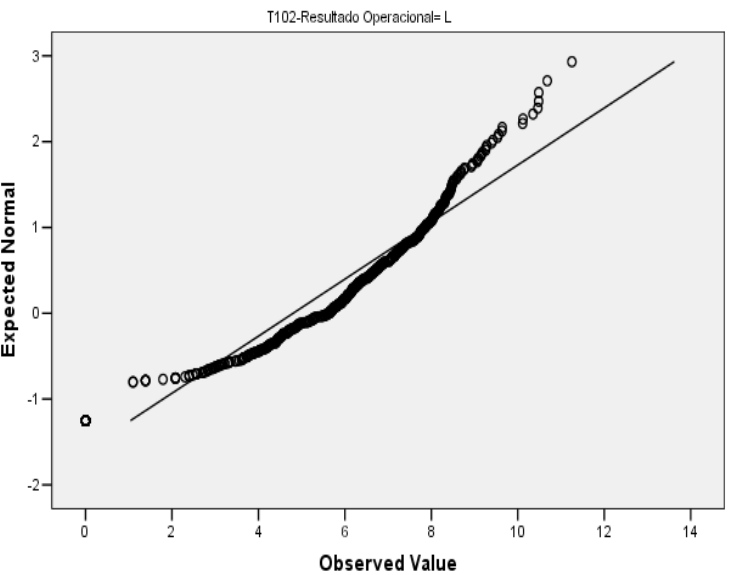


Normal Q-Q Plot of LnV206-ISI-Educação

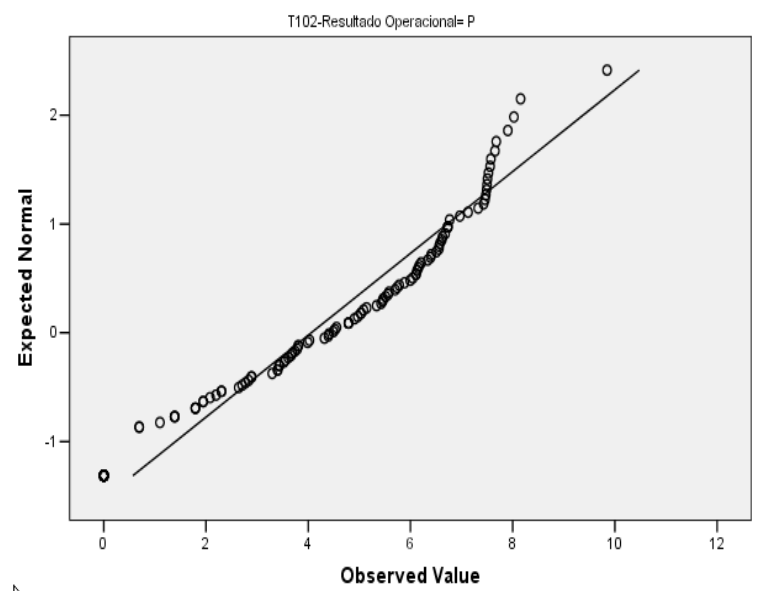

Normal Q-Q Plot of LnV207-ISI-Cultura

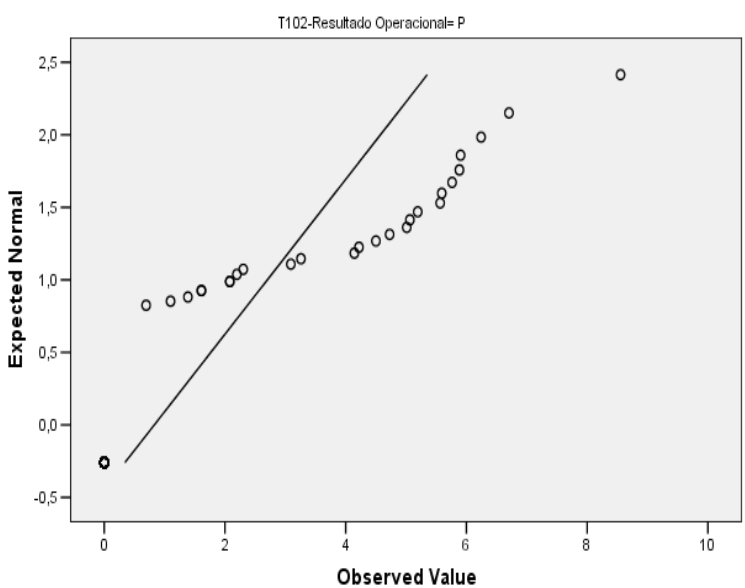

Normal Q-Q Plot of LnV208-ISI-Capacitação e desenv. profiss.

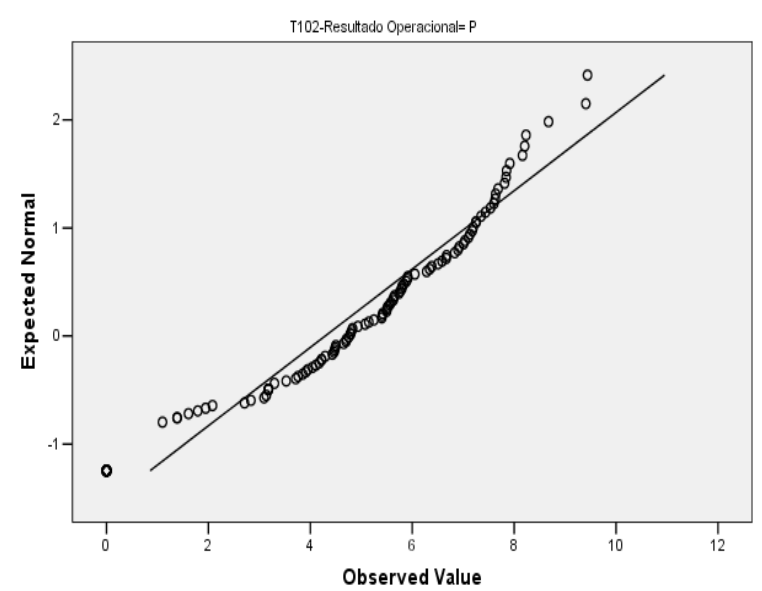

Normal Q-Q Plot of LnV206-ISI-Educação

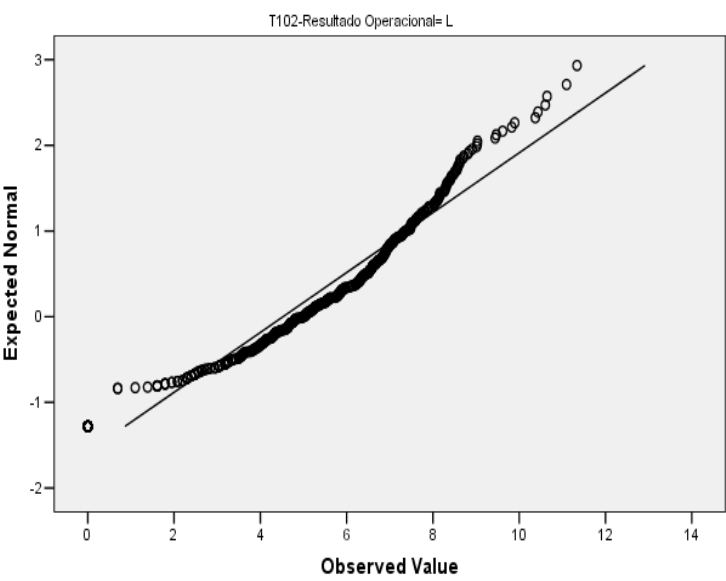

Normal Q-Q Plot of LnV207-ISI-Cultura

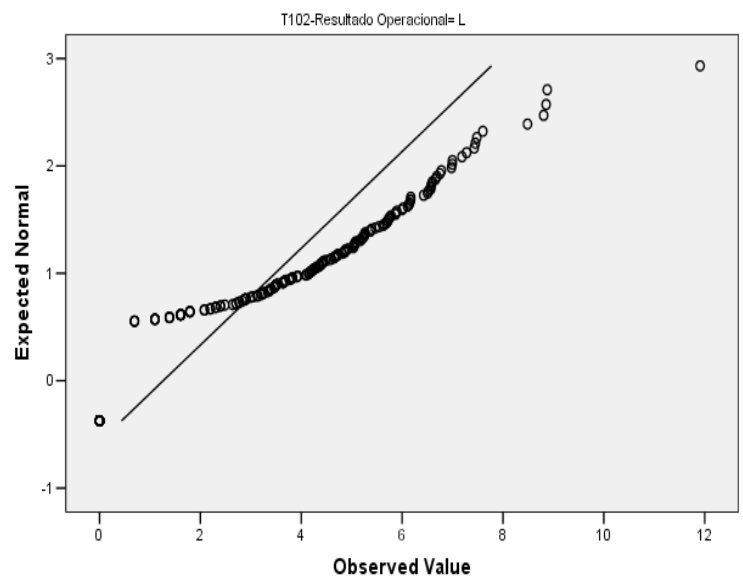

Normal Q-Q Plot of LnV208-ISI-Capacitação e desenv. profiss.

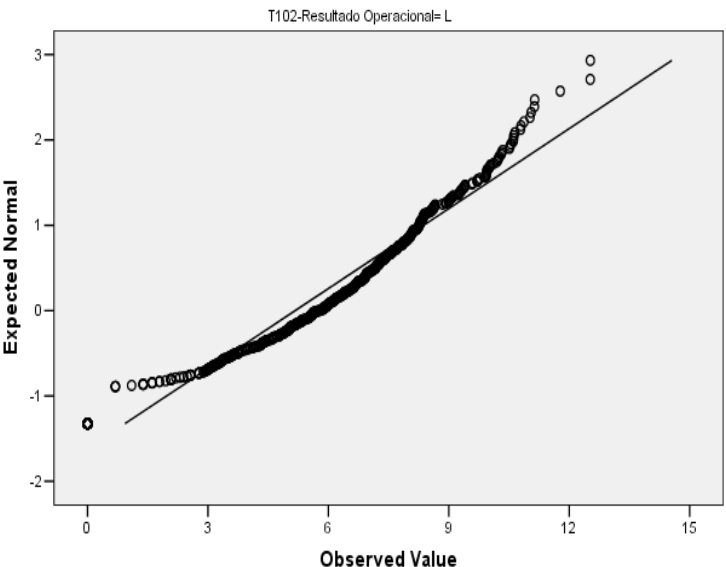


Normal Q-Q Plot of LnV209-ISI-Creches ou auxilio-creche

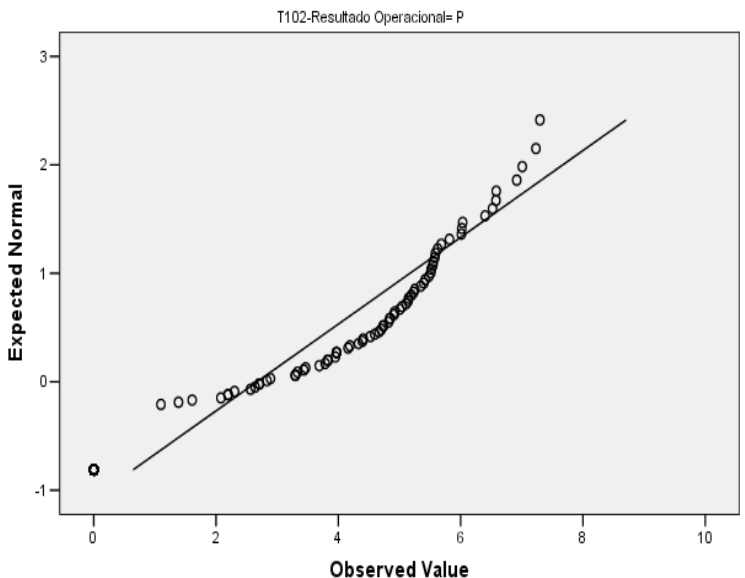

Normal Q-Q Plot of LnV210-ISI-Participação lucros/resultados

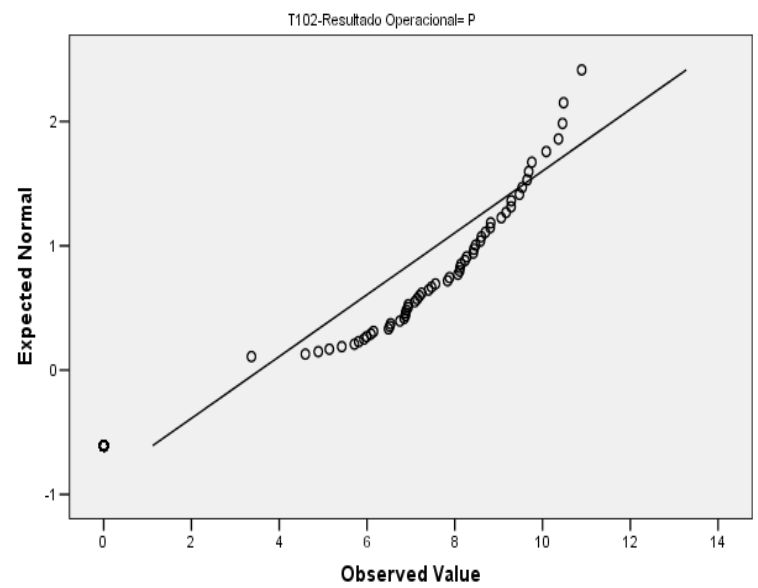

Normal Q-Q Plot of LnV211-ISI-Outros

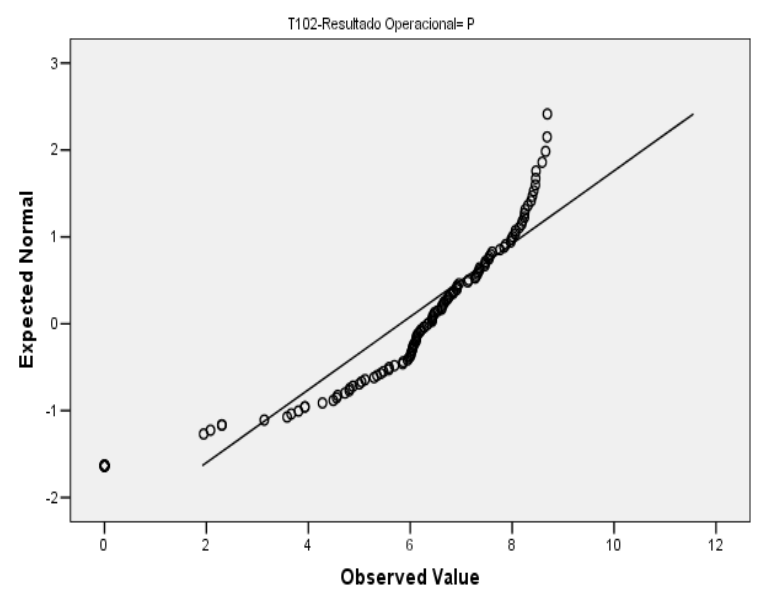

Normal Q-Q Plot of LnV209-ISI-Creches ou auxilio-creche

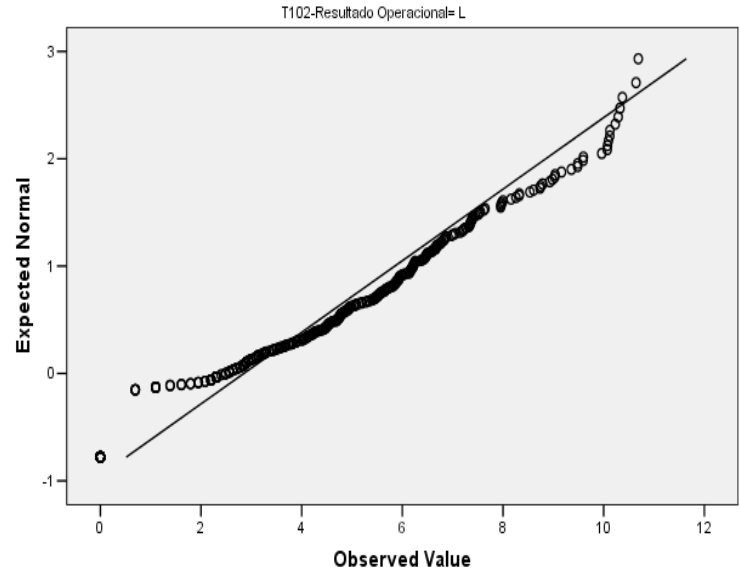

Normal Q-Q Plot of LnV210-ISI-Participação lucros/resultados

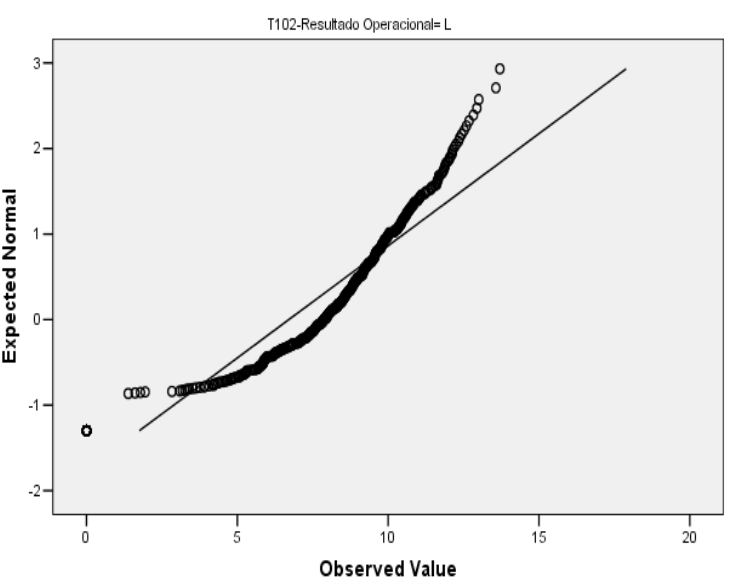

Normal Q-Q Plot of LnV211-ISI-Outros

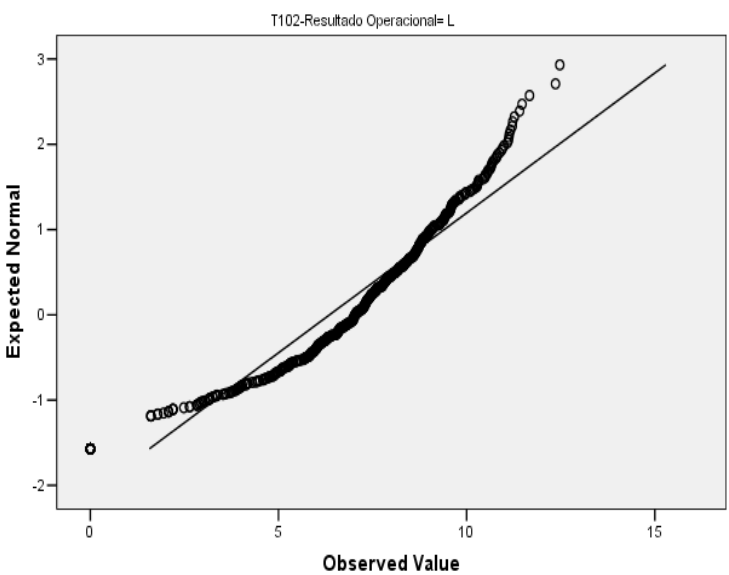


Normal Q-Q Plot of LnV213-ISI-Total com compulsório

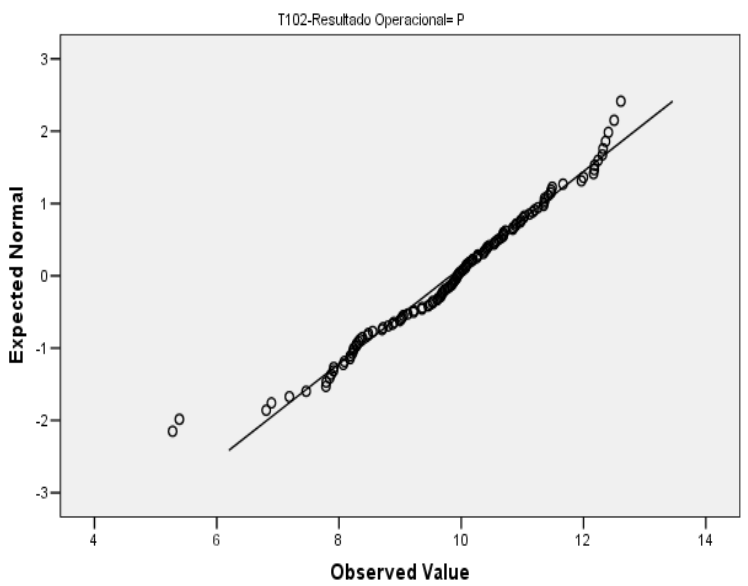

Normal Q-Q Plot of LnV214-ISI-Total sem compulsorio

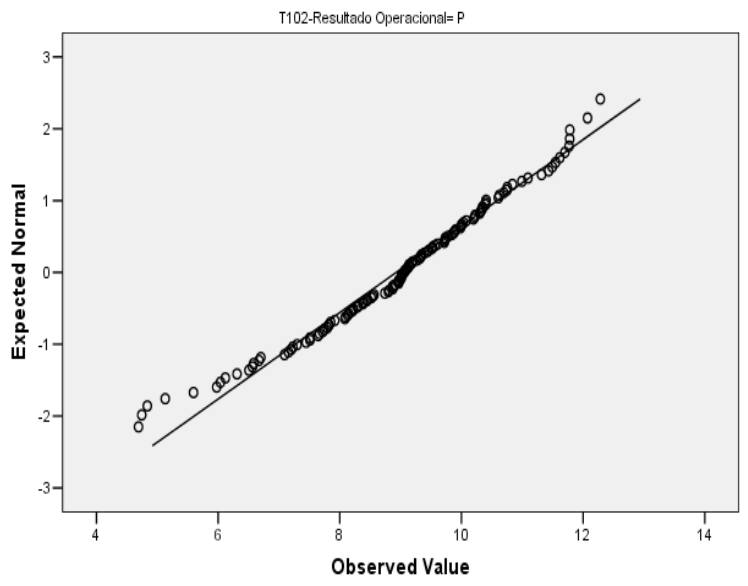

Normal Q-Q Plot of LnV213-ISI-Total com compulsório

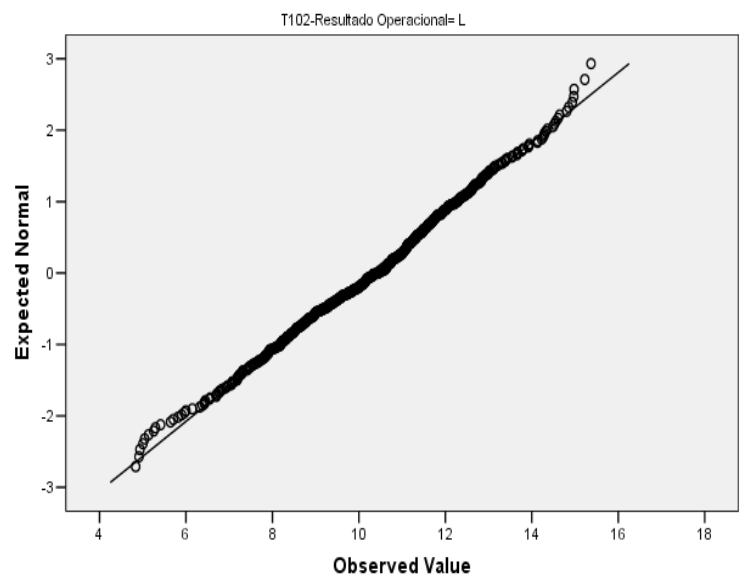

Normal Q-Q Plot of LnV214-ISI-Total sem compulsorio

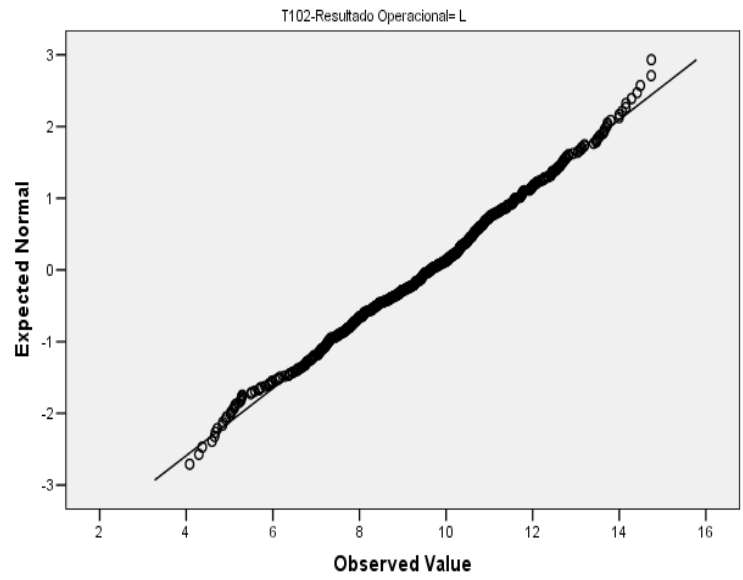




\subsubsection{Variáveis Indicadores Sociais Externos considerando o porte das empresas}
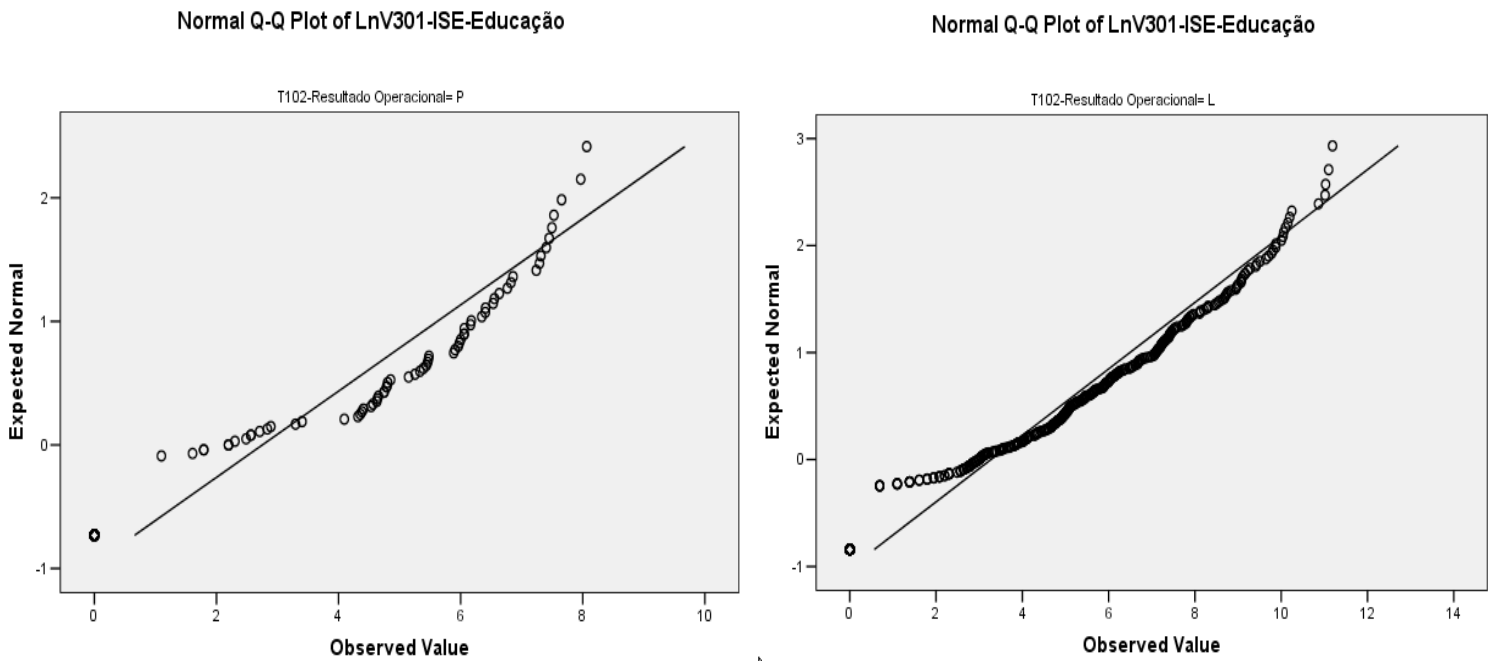

Normal Q-Q Plot of LnV302-ISE-Cultura
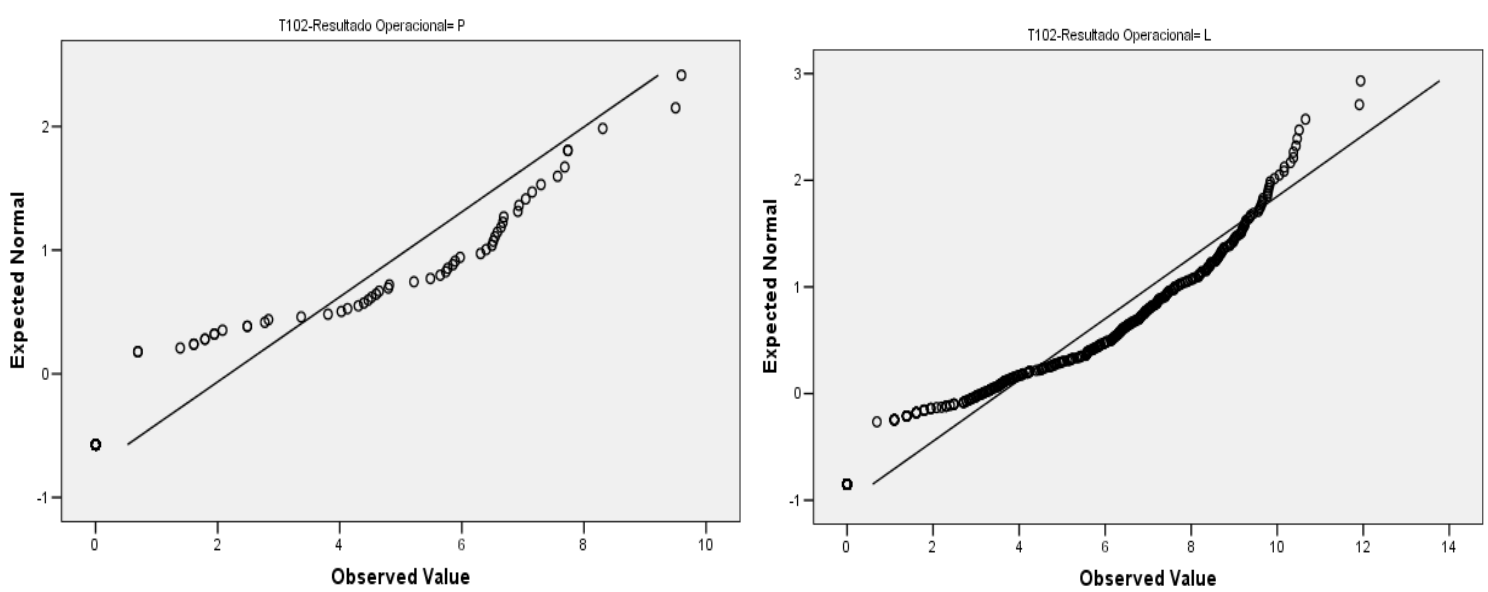
Normal Q-Q Plot of LnV303-ISE-Saúde e saneamento

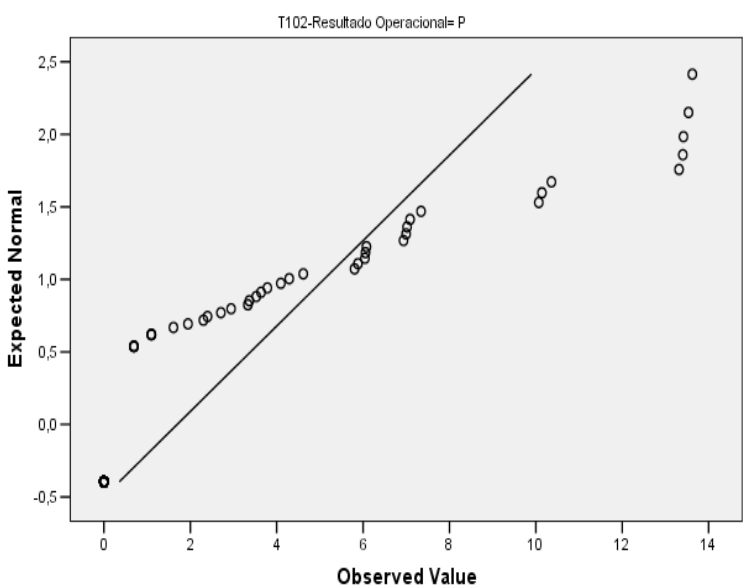

Normal Q-Q Plot of LnV304-ISE-Habitação

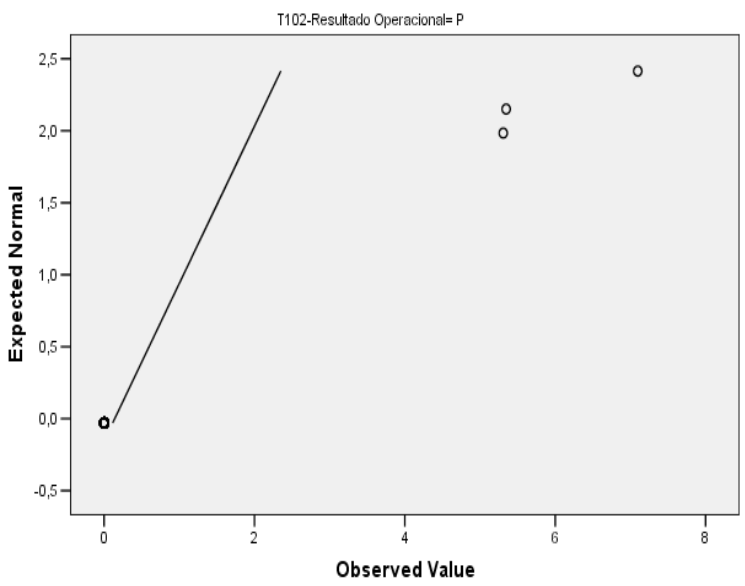

Normal Q-Q Plot of LnV305-ISE-Esporte

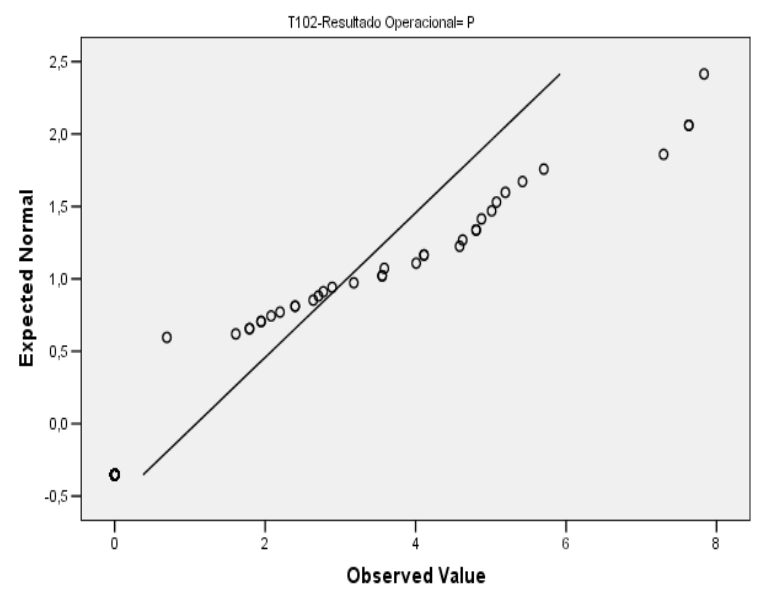

Normal Q-Q Plot of LnV303-ISE-Saúde e saneamento

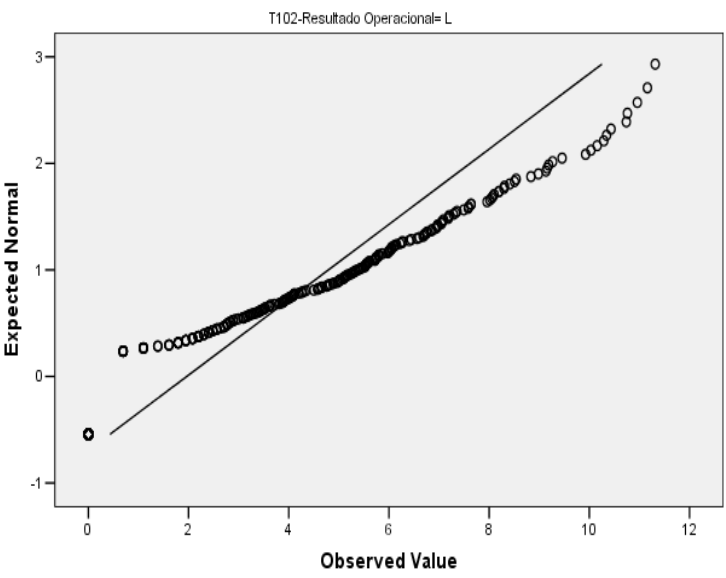

Normal Q-Q Plot of LnV304-ISE-Habitação

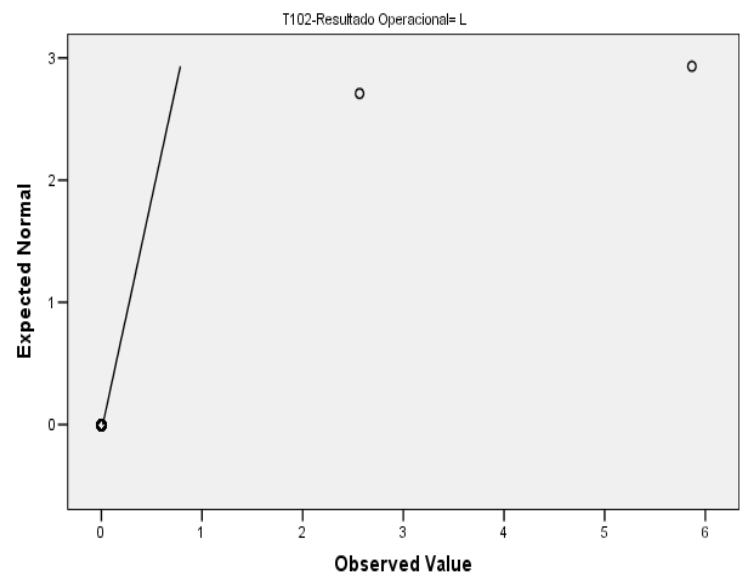

Normal Q-Q Plot of LnV305-ISE-Esporte

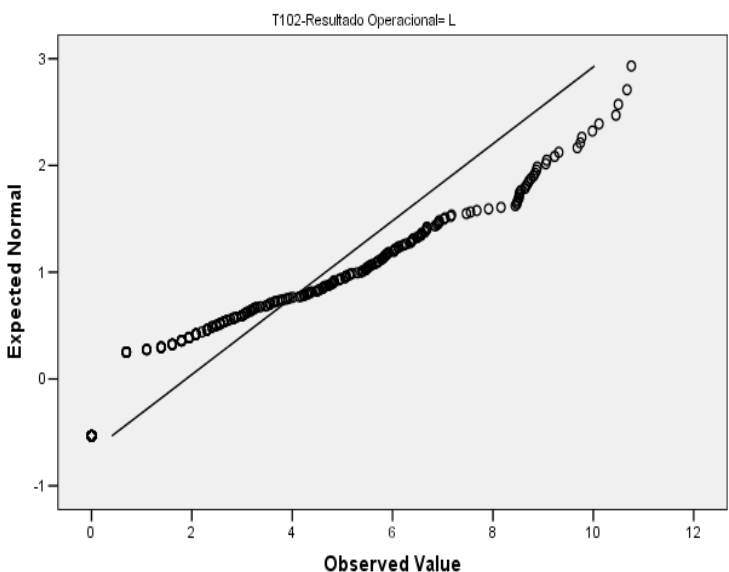


Normal Q-Q Plot of LnV306-ISE-Lazer e diversão

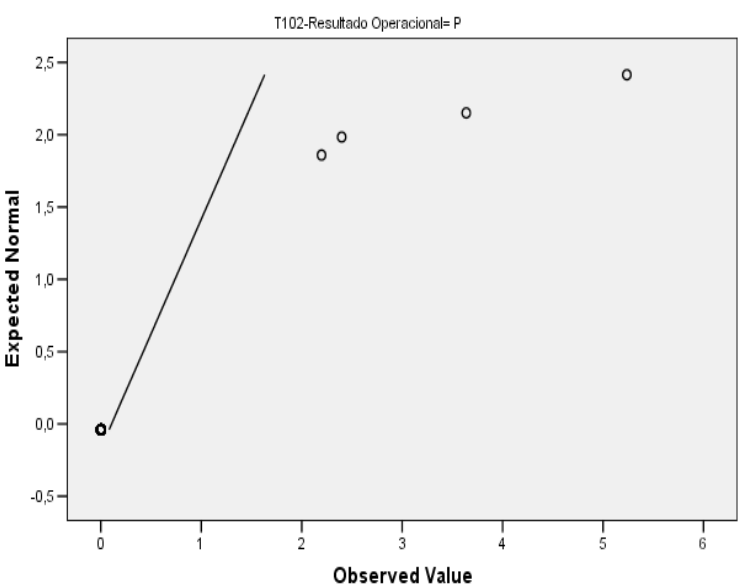

Normal Q-Q Plot of LnV307-ISE-Creches

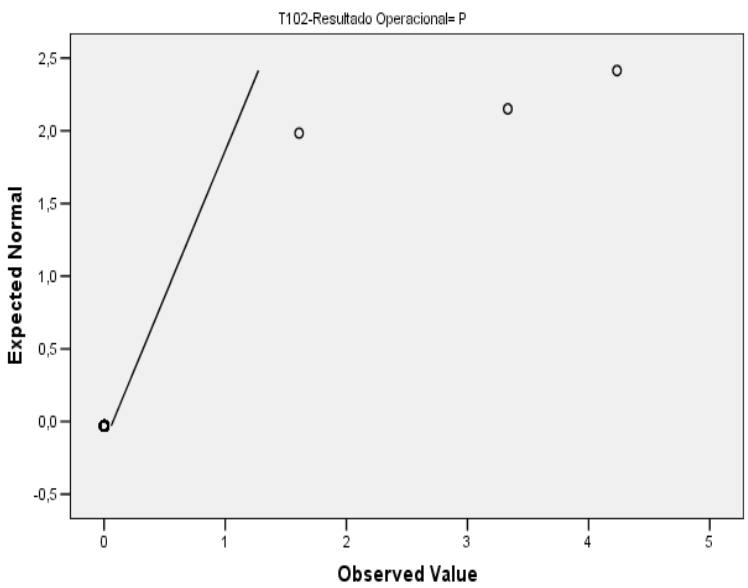

Normal Q-Q Plot of LnV308-ISE-Alimentação

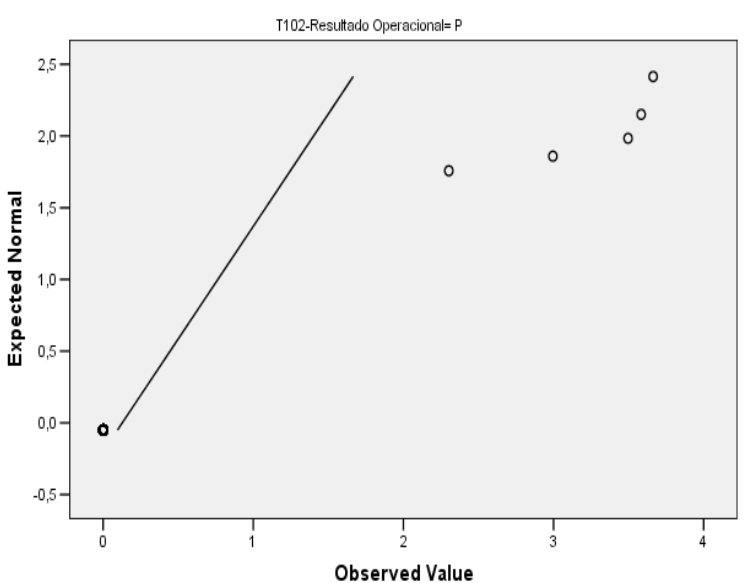

Normal Q-Q Plot of LnV306-ISE-Lazer e diversão

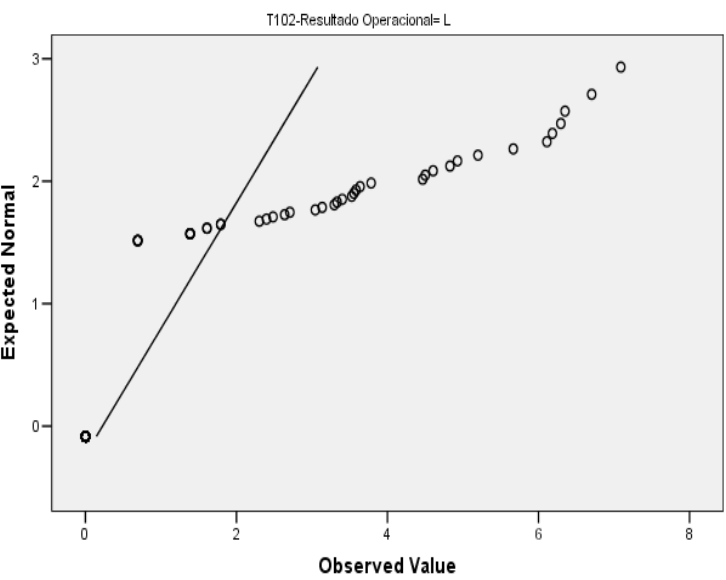

Normal Q-Q Plot of LnV307-ISE-Creches

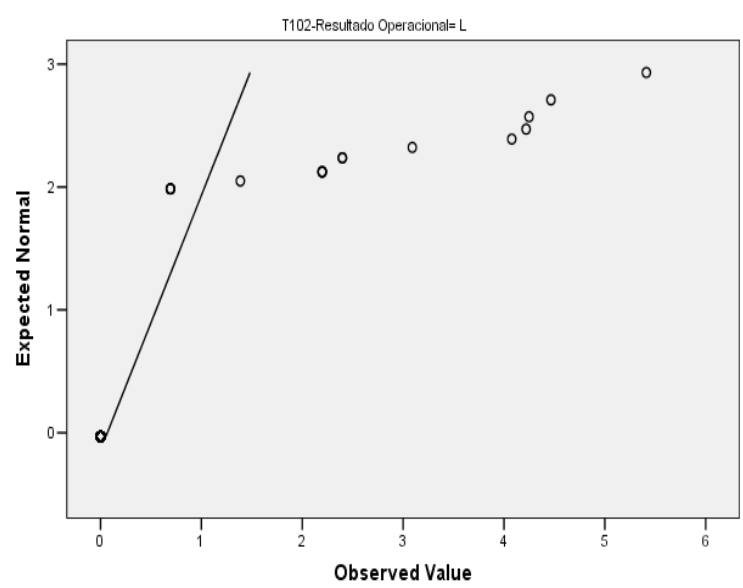

Normal Q-Q Plot of LnV308-ISE-Alimentação

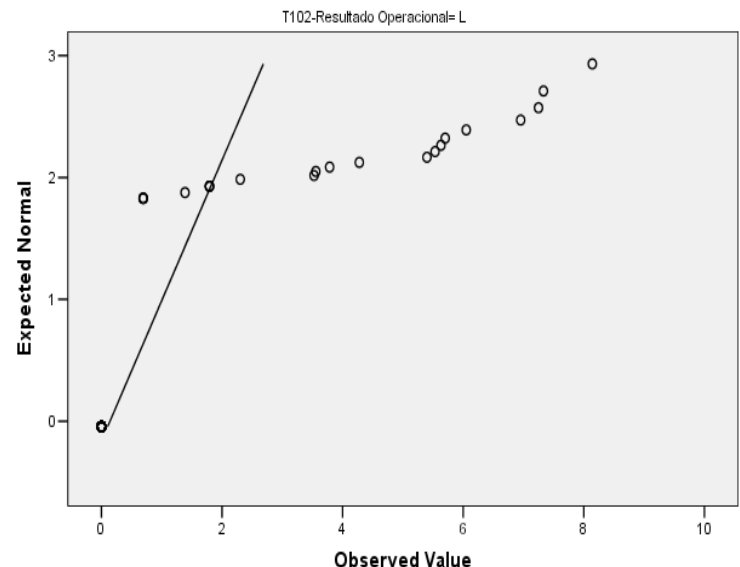


Normal Q-Q Plot of LnV309-ISE-Combate fome.

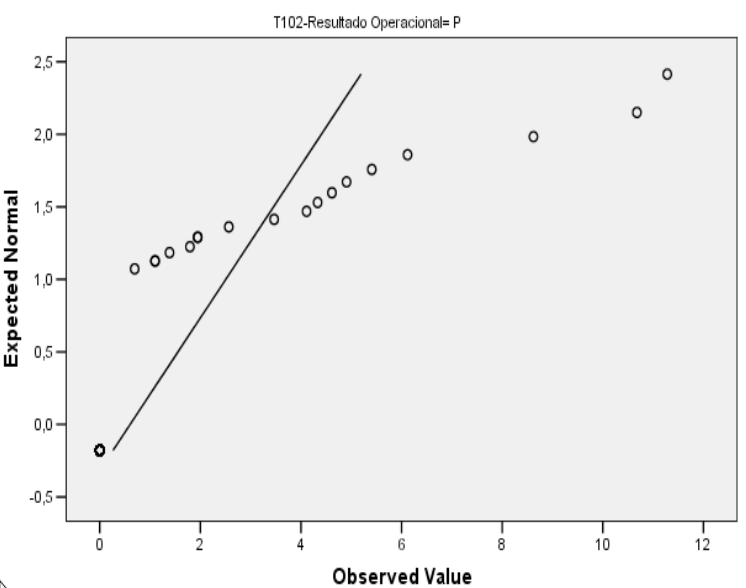

Normal Q-Q Plot of LnV310-ISE-Outros

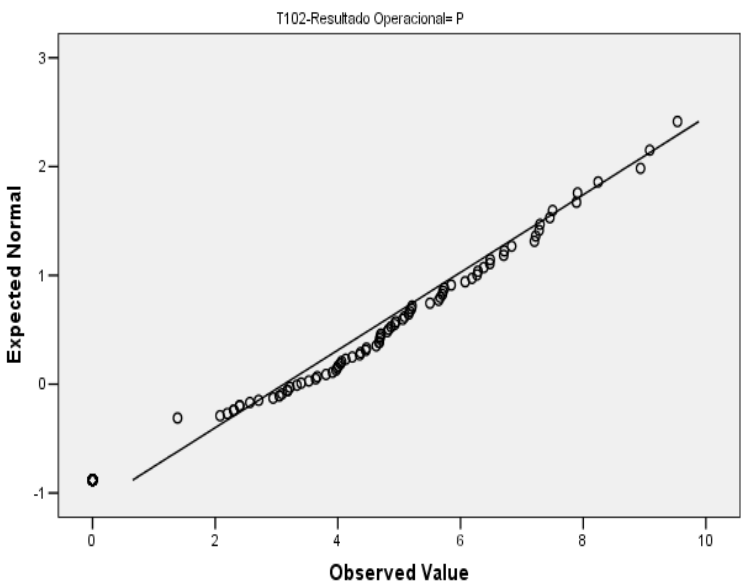

Normal Q-Q Plot of LnV311-ISE-Agregados

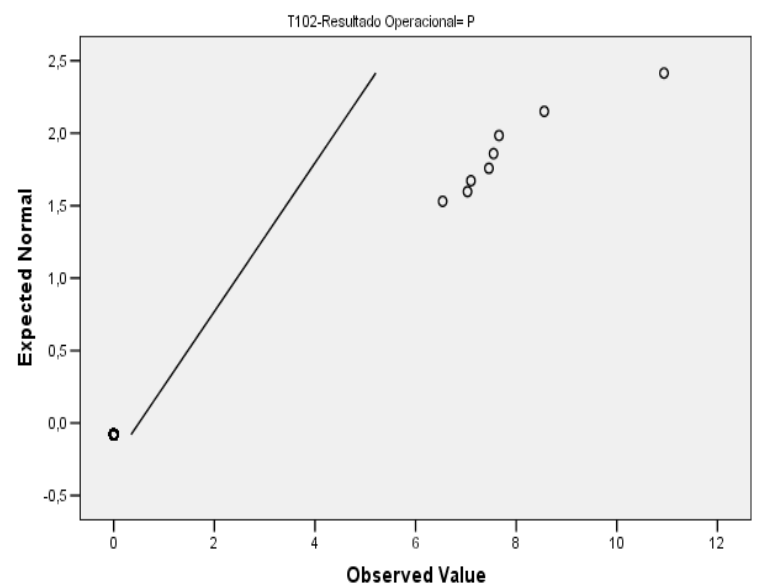

Normal Q-Q Plot of LnV309-ISE-Combate fome..

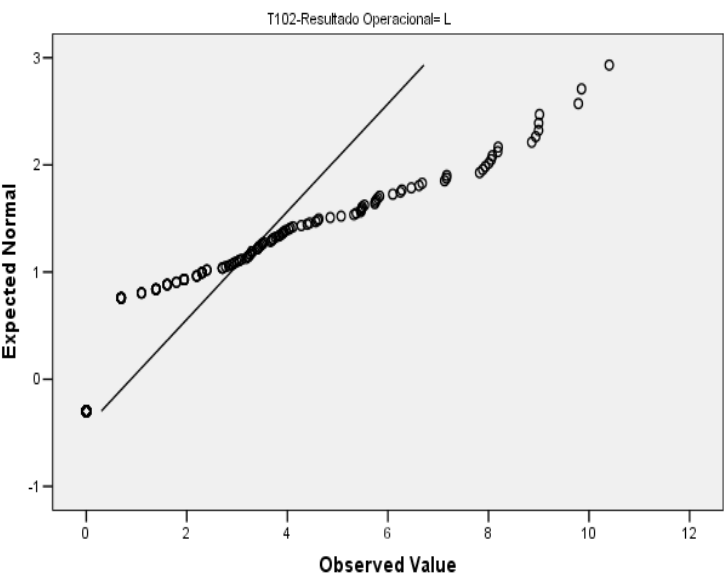

Normal Q-Q Plot of LnV310-ISE-Outros

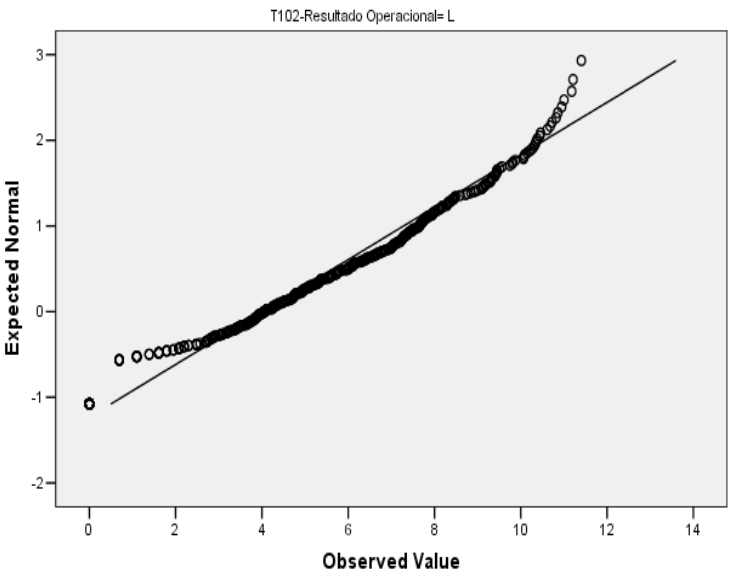

Normal Q-Q Plot of LnV311-ISE-Agregados

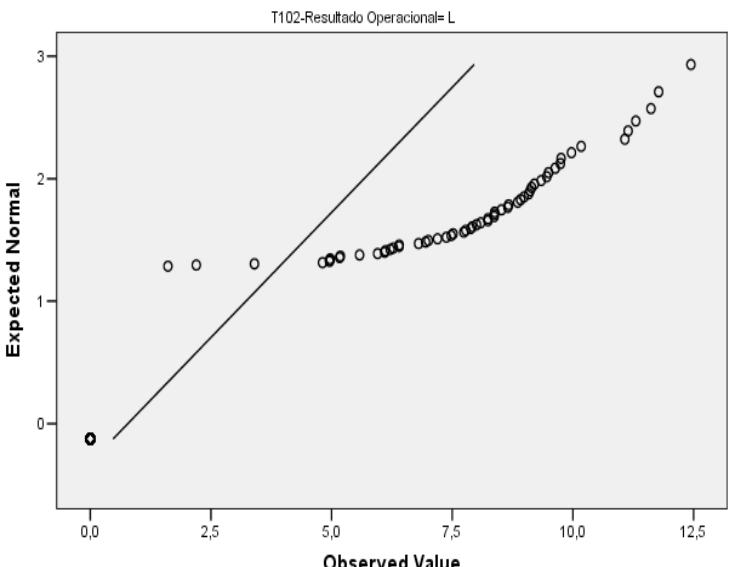


Normal Q-Q Plot of LnV312-ISE-Total

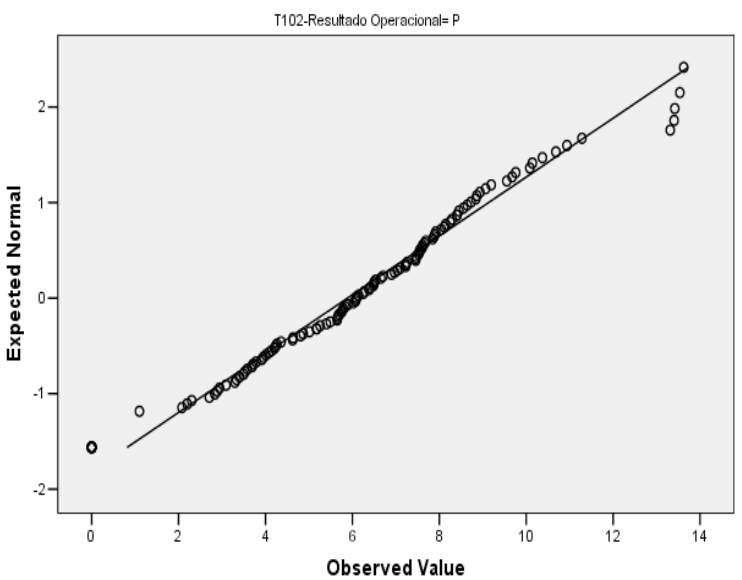

Normal Q-Q Plot of LnV313-Tributos (excluidos encargos sociais)

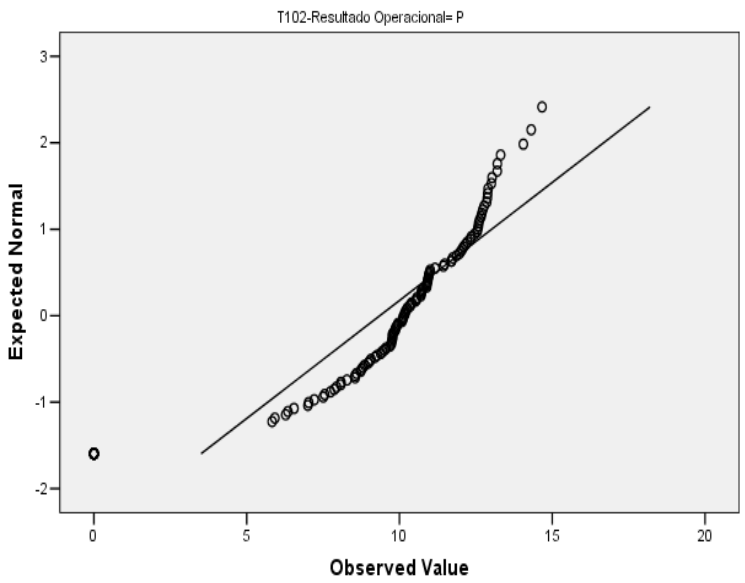

Normal Q-Q Plot of LnV314-ISE-Total+compulsório

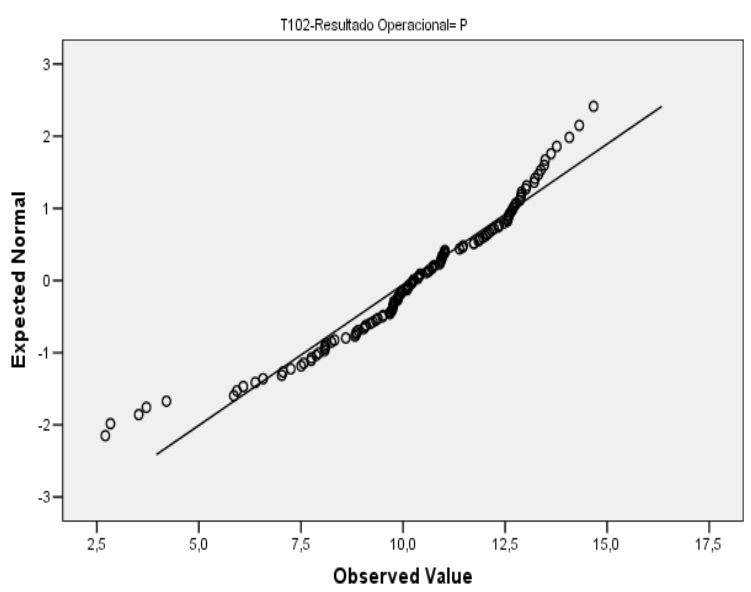

Normal Q-Q Plot of LnV312-ISE-Total

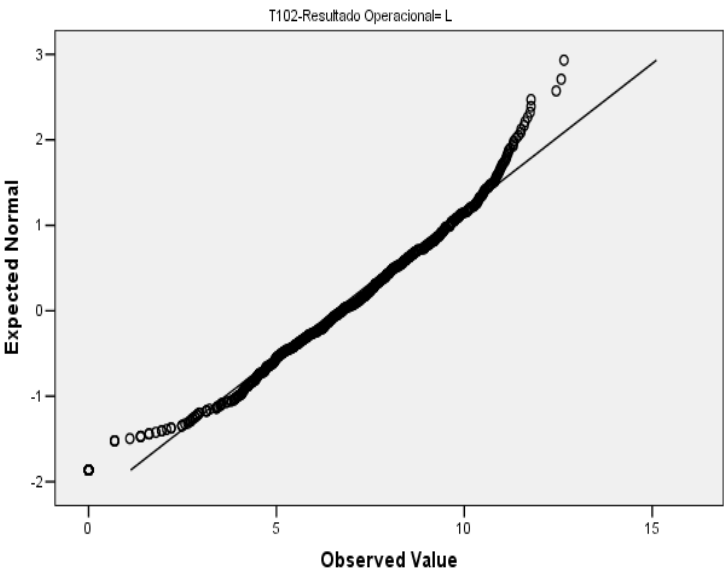

Normal Q-Q Plot of LnV313-Tributos (excluidos encargos sociais)

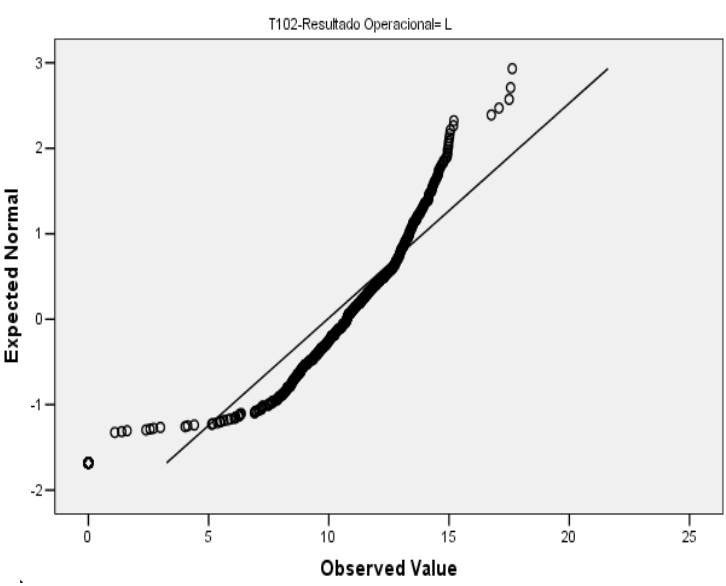

Normal Q-Q Plot of LnV314-ISE-Total+compulsório

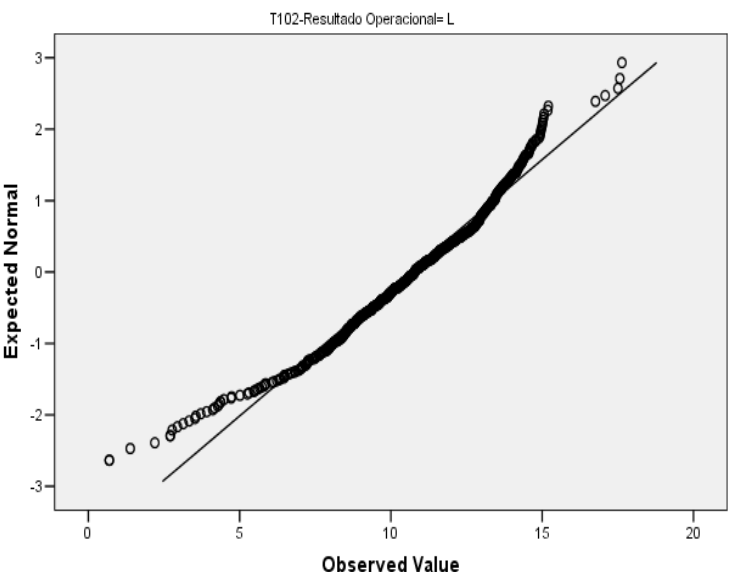




\subsubsection{Variáveis Indicadores Ambientais considerando o porte das empresas}

Normal Q-Q Plot of LnV401-IA-Invest relacionados prod/operação

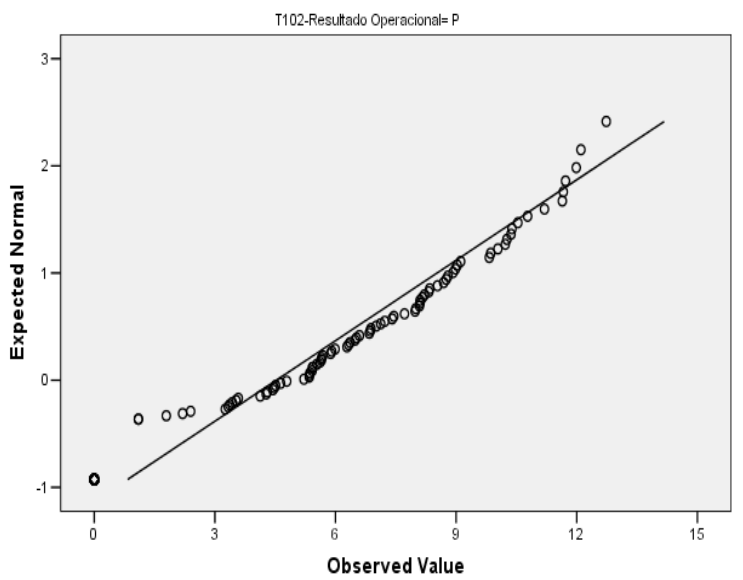

Normal Q-Q Plot of LnV402-IA-Invest programas \& proj. externos

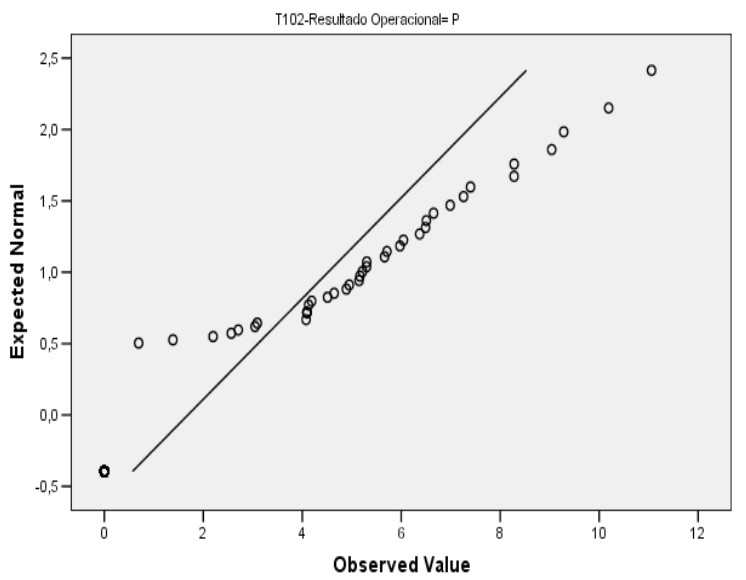

Normal Q-Q Plot of LnV401-IA-Invest relacionados prod/operação

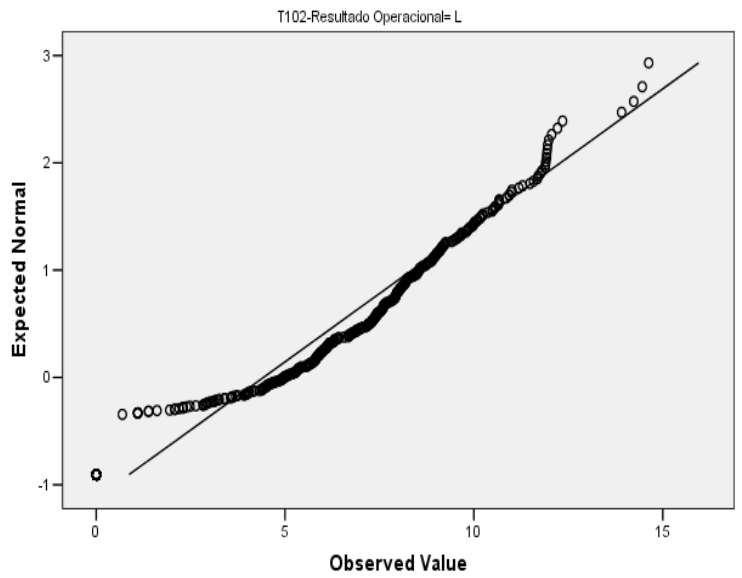

Normal Q-Q Plot of LnV402-IA-Invest programas \& proj. externos

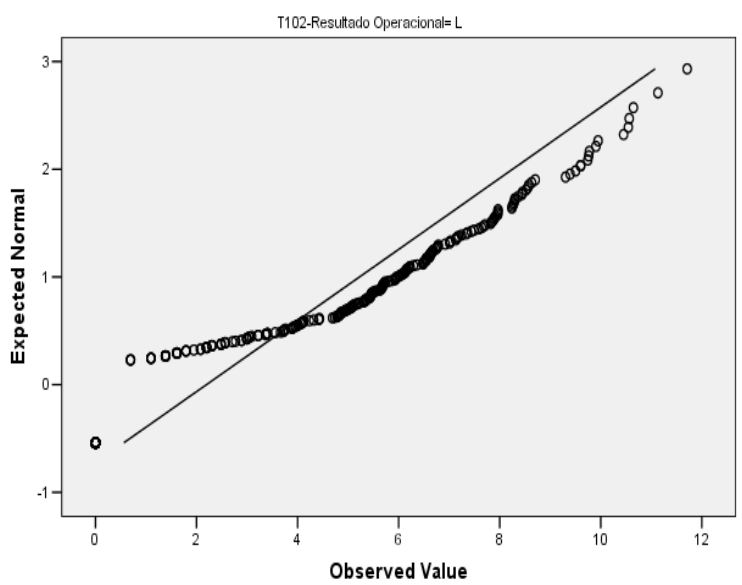


Normal Q-Q Plot of LnV403-IA-Agregado

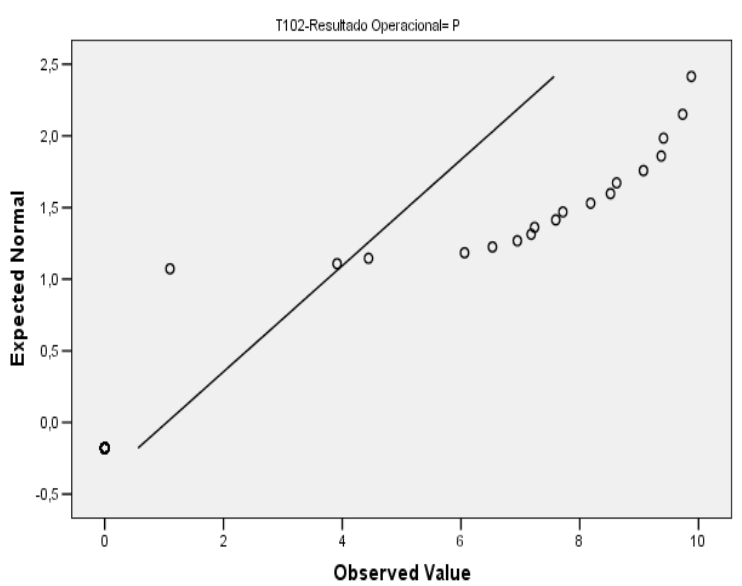

Normal Q-Q Plot of LnV404-IA-Total

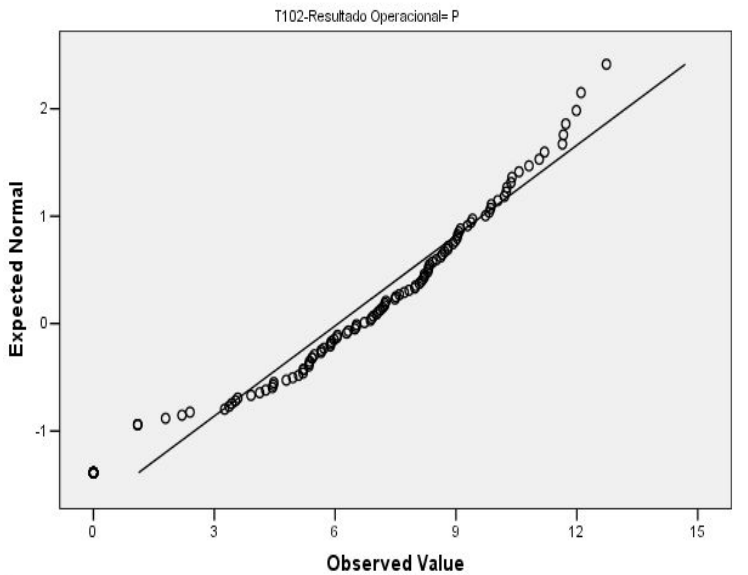

Normal Q-Q Plot of LnV403-IA-Agregado

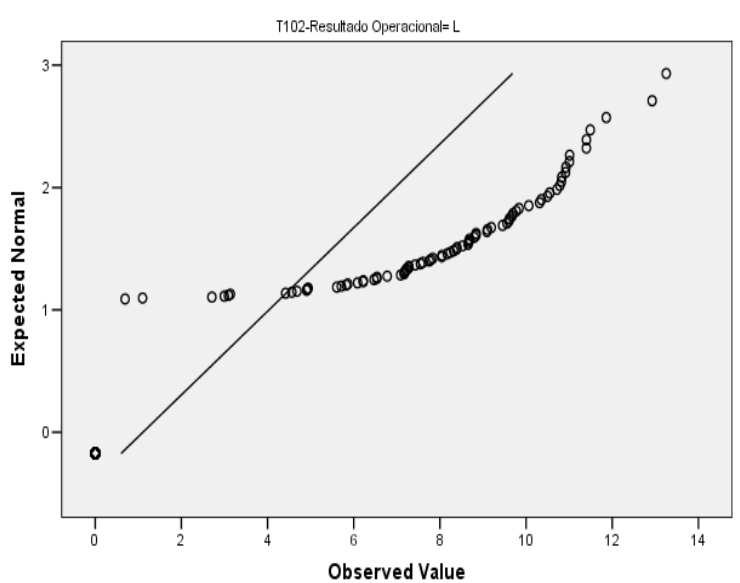

Normal Q-Q Plot of LnV404-IA-Total

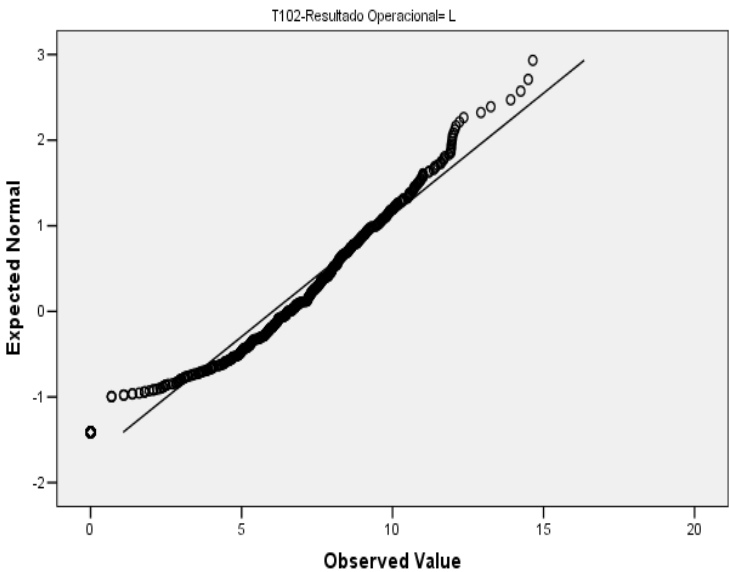




\subsubsection{Variáveis Investimentos Totais considerando o porte das empresas}

Normal Q-Q Plot of LnRSE_Voluntario

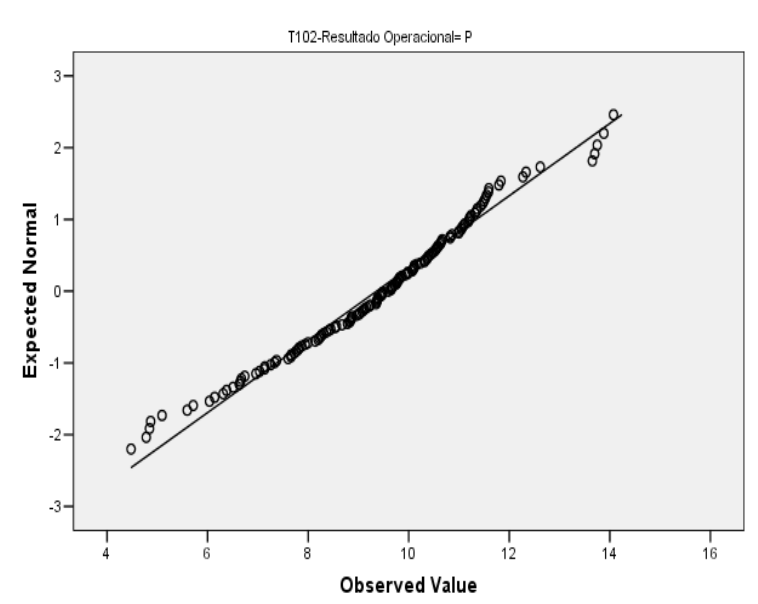

Normal Q-Q Plot of LnRSE_Total

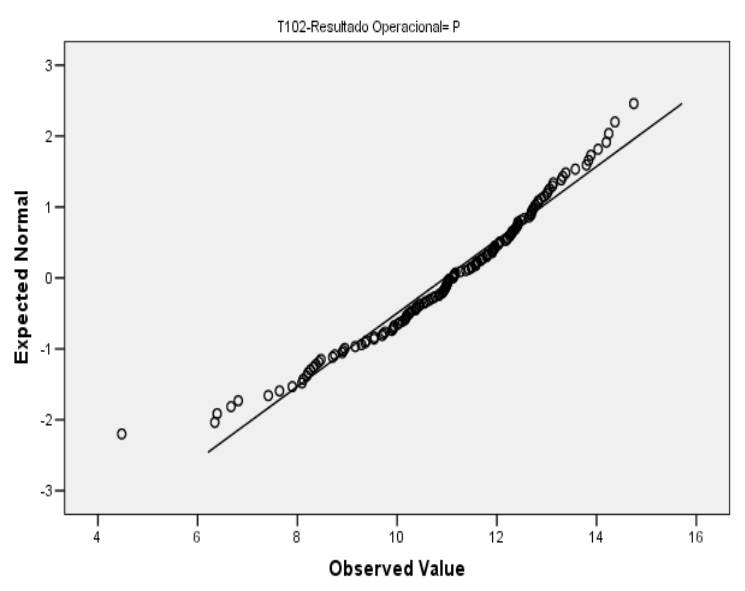

Normal Q-Q Plot of LnRSE_Voluntario

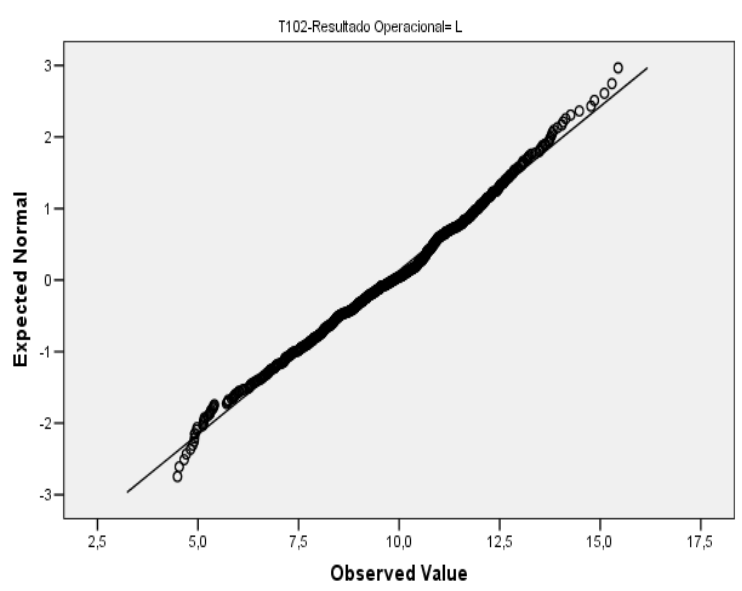

Normal Q-Q Plot of LnRSE_Total

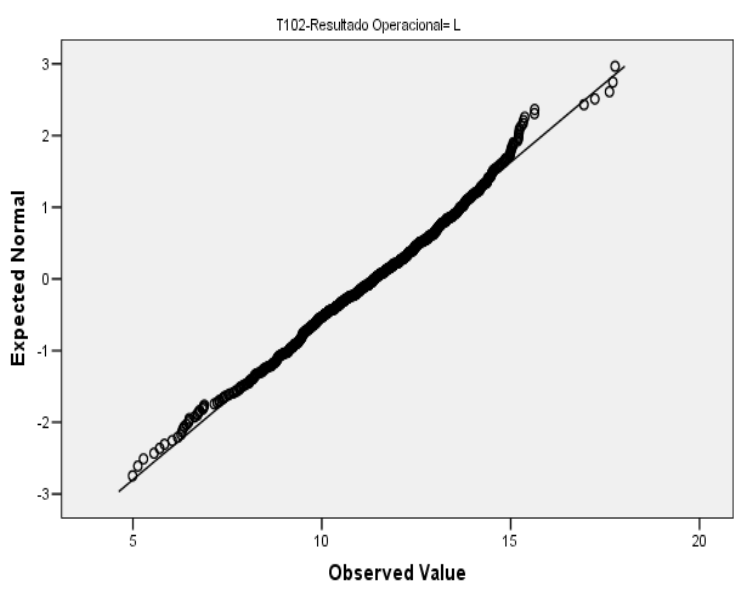




\subsubsection{Variável Resultado Operacional dessensibilizada do porte das empresas}

Normal Q-Q Plot of LnRLV102-Resultado Operacional

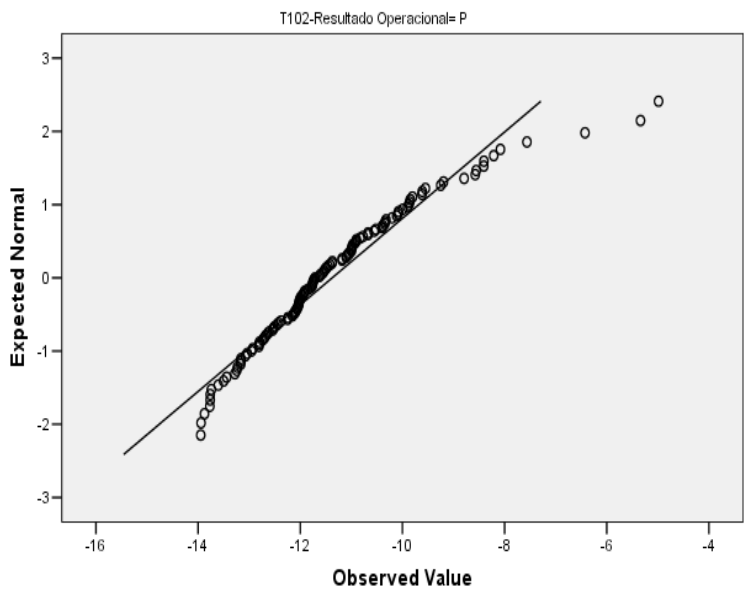

Normal Q-Q Plot of LnRLV102-Resultado Operacional

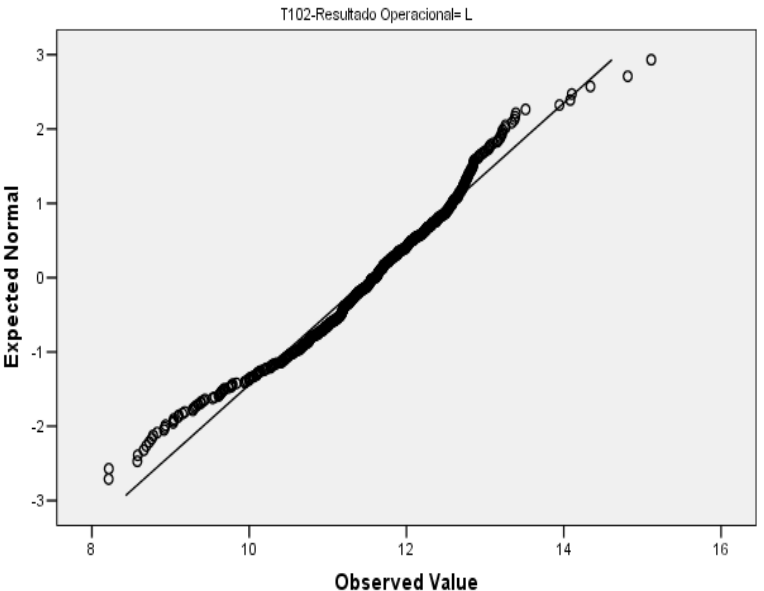

\subsubsection{Variáveis Indicadores Sociais Internos dessensibilizadas do porte das empresas}

Normal Q-Q Plot of LnRLV201-ISI-Alimentação

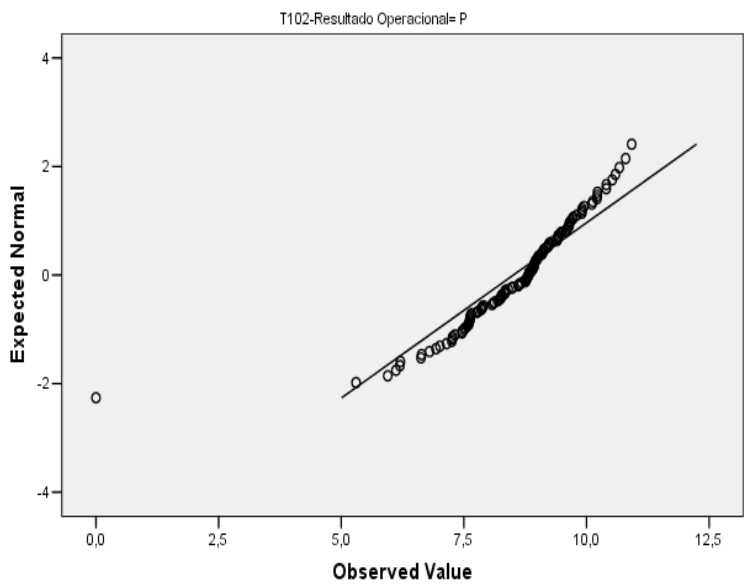

Normal Q-Q Plot of LnRLV201-ISI-Alimentação

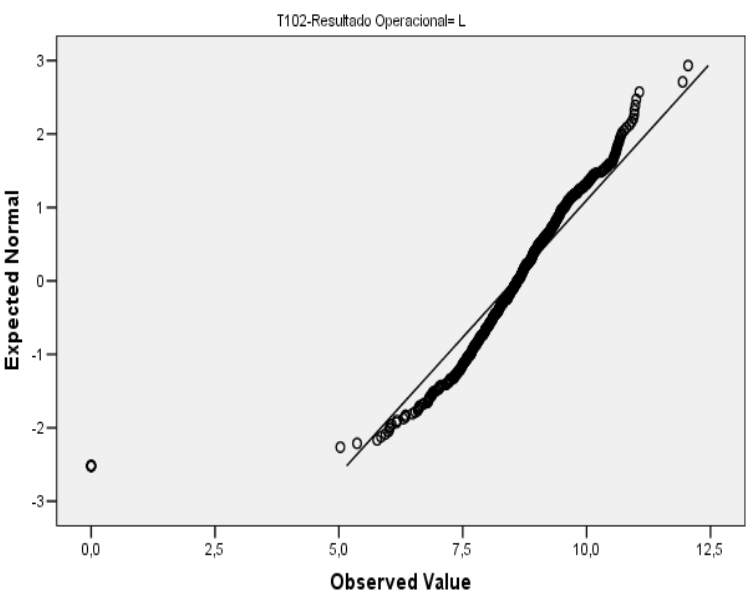


Normal Q-Q Plot of LnRLV202-ISI-Encargos sociais compulsórios

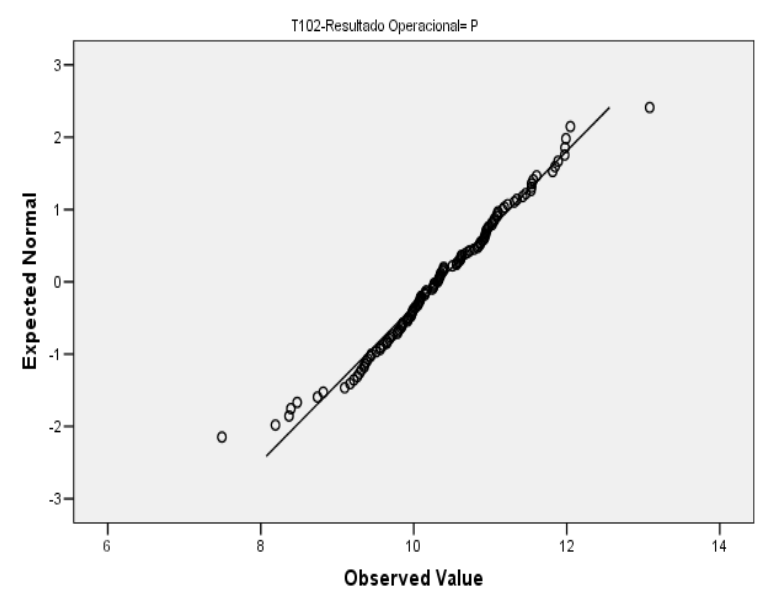

Normal Q-Q Plot of LnRLV203-ISI-Previdência privada

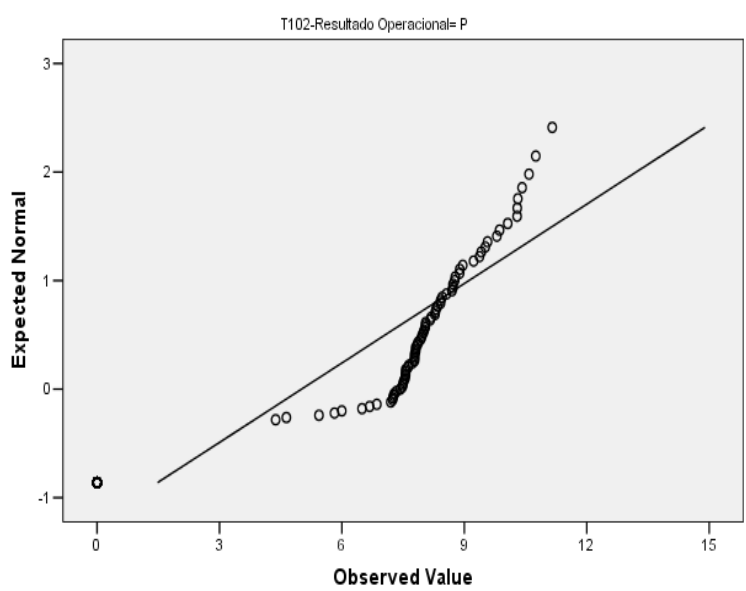

Normal Q-Q Plot of LnRLV204-ISI-Saúde

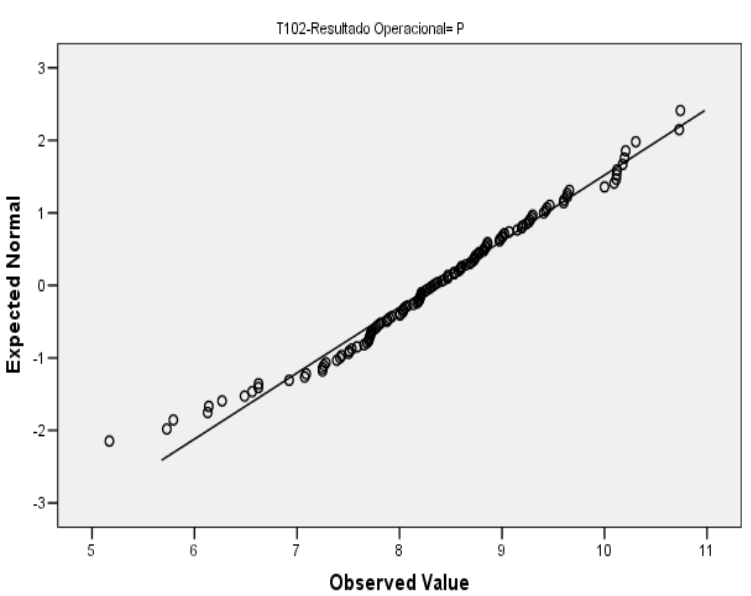

Normal Q-Q Plot of LnRLV202-ISI-Encargos sociais compulsórios

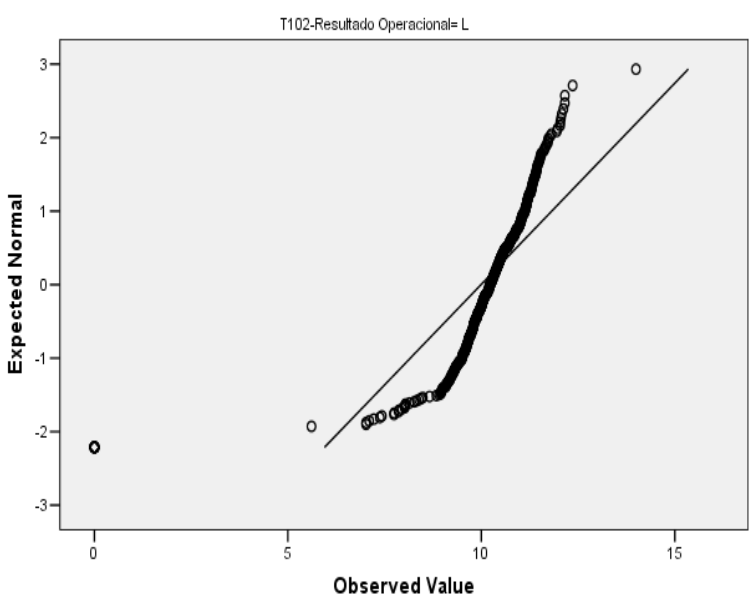

Normal Q-Q Plot of LnRLV203-ISI-Previdência privada

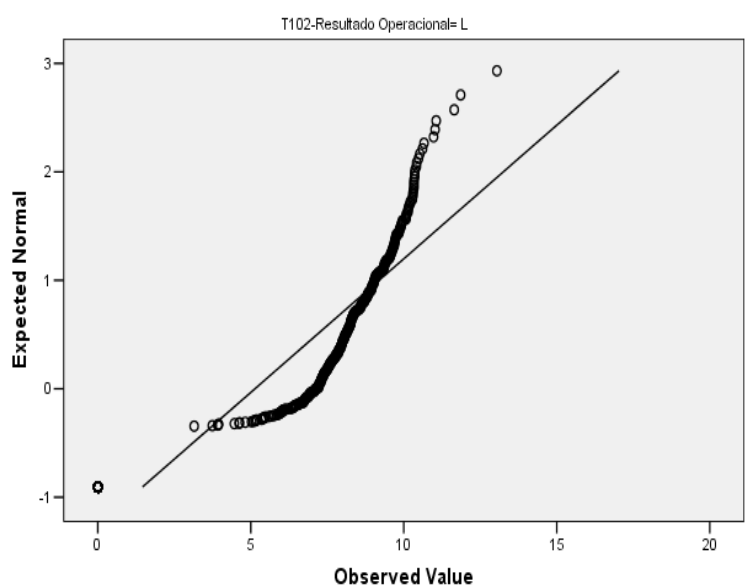

Normal Q-Q Plot of LnRLV204-ISI-Saúde

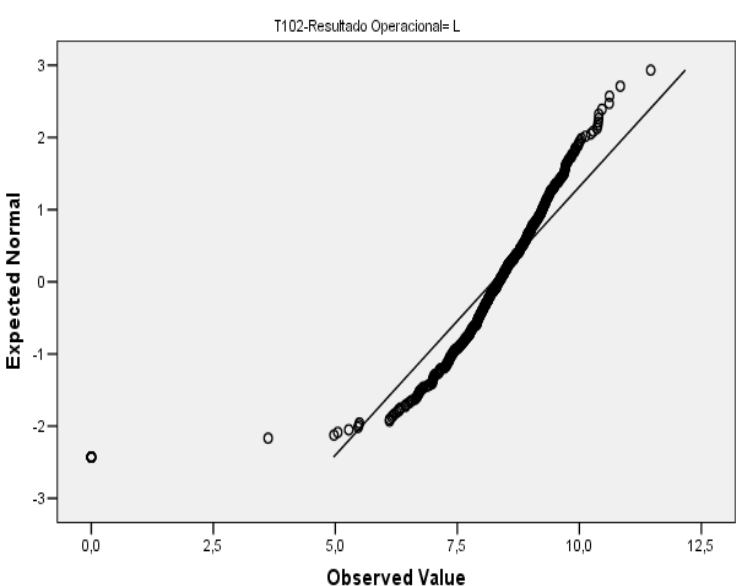


Normal Q-Q Plot of LnRLV205-ISI-Segurança e medicina trabalho

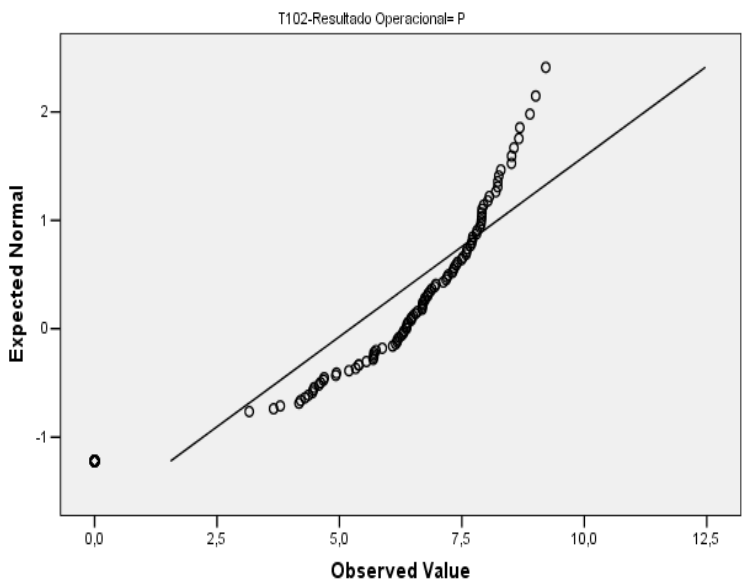

Normal Q-Q Plot of LnRLV206-ISI-Educação

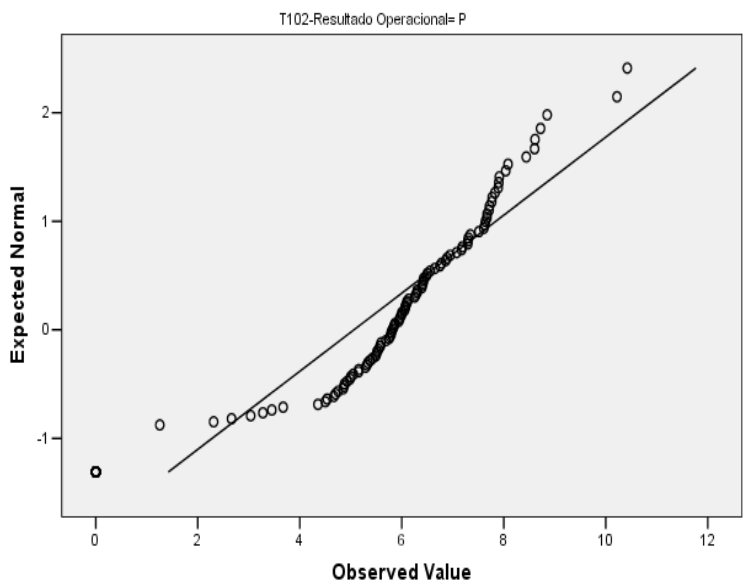

Normal Q-Q Plot of LnRLV207-ISI-Cultura

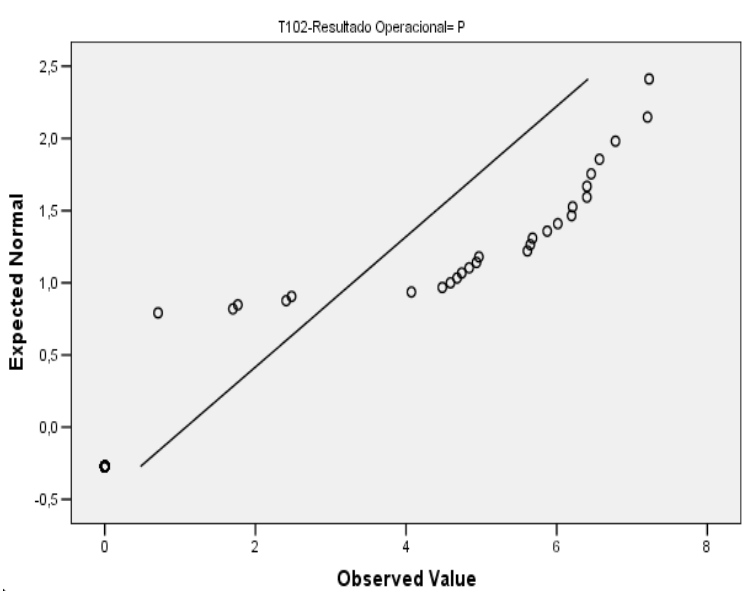

Normal Q-Q Plot of LnRLV205-ISI-Segurança e medicina trabalho

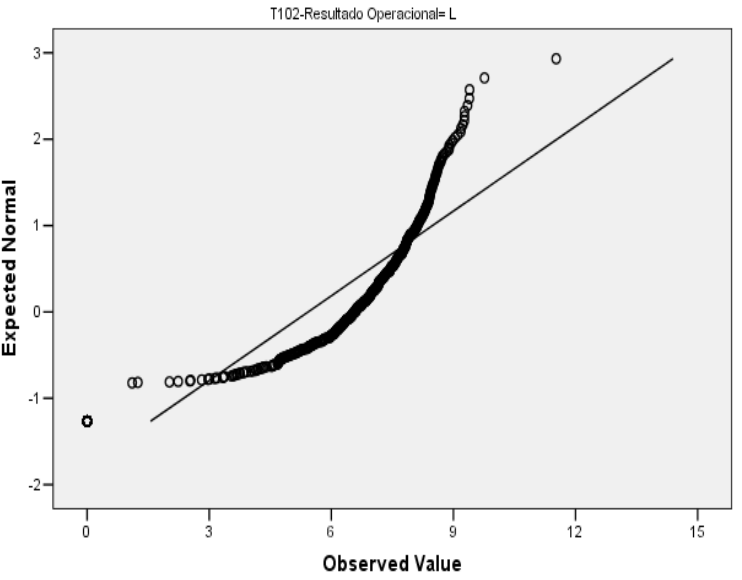

Normal Q-Q Plot of LnRLV206-ISI-Educação

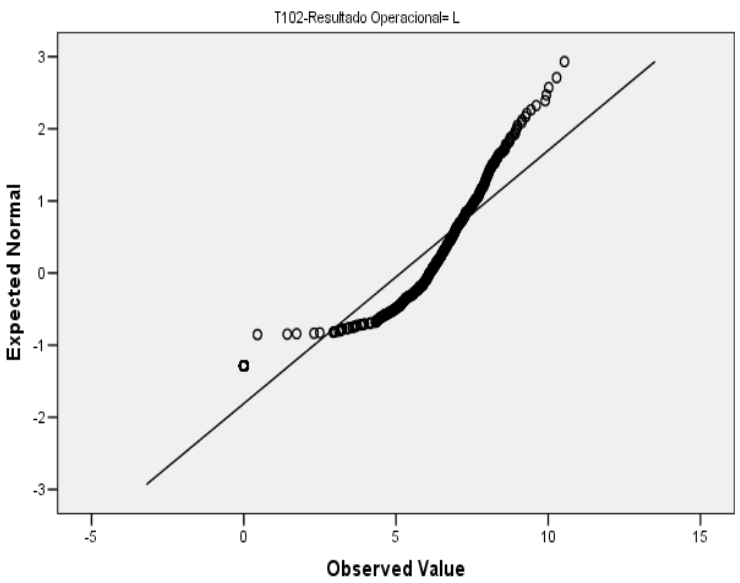

Normal Q-Q Plot of LnRLV207-ISI-Cultura

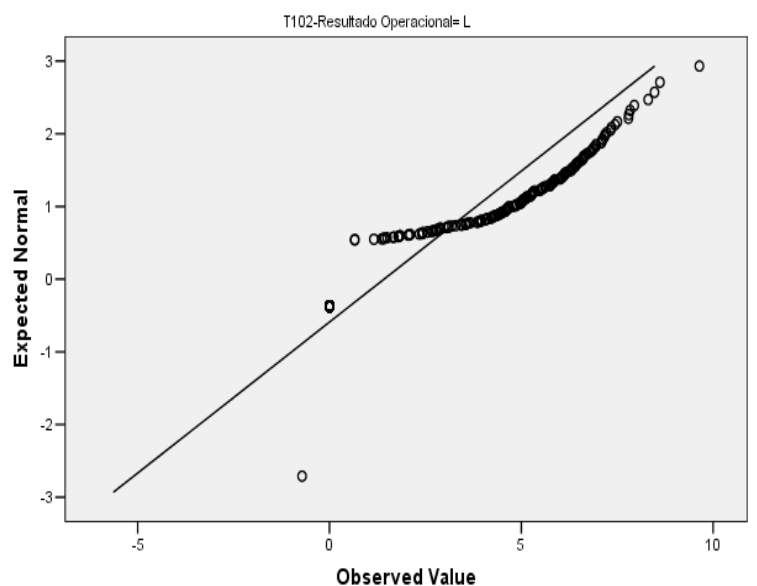


Normal Q-Q Plot of LnRLV208-ISI-Capacitação e desenv. profiss.

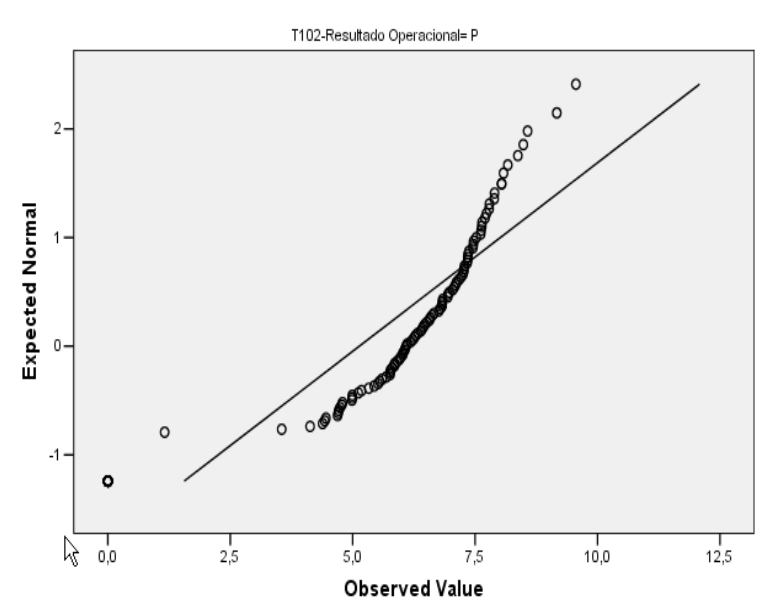

Normal Q-Q Plot of LnRLV209-ISI-Creches ou auxilio-creche

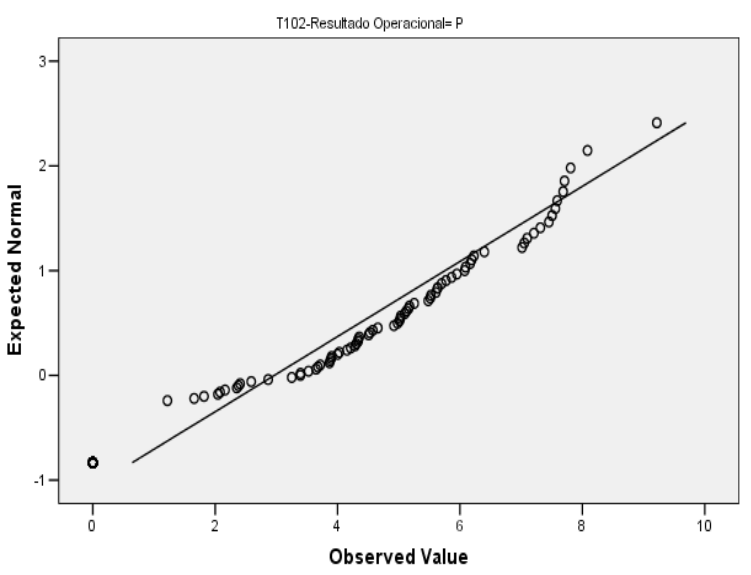

Normal Q-Q Plot of LnRLV210-ISI-Participação lucros/resultados

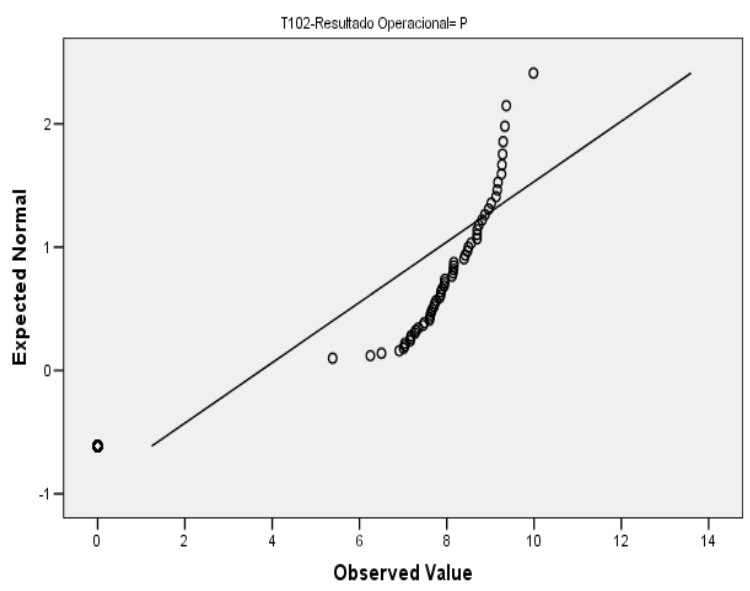

Normal Q-Q Plot of LnRLV208-ISI-Capacitação e desenv. profiss.

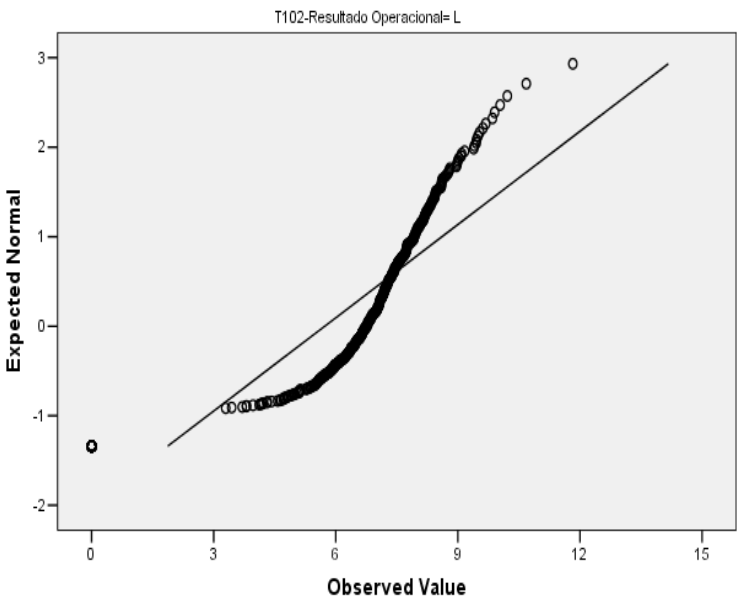

Normal Q-Q Plot of LnRLV209-ISI-Creches ou auxilio-creche

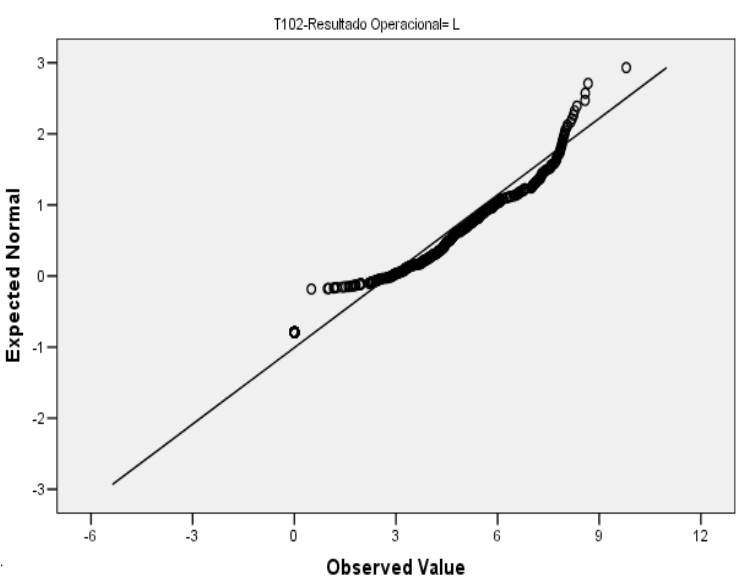

Normal Q-Q Plot of LnRLV210-ISI-Participação lucros/resultados

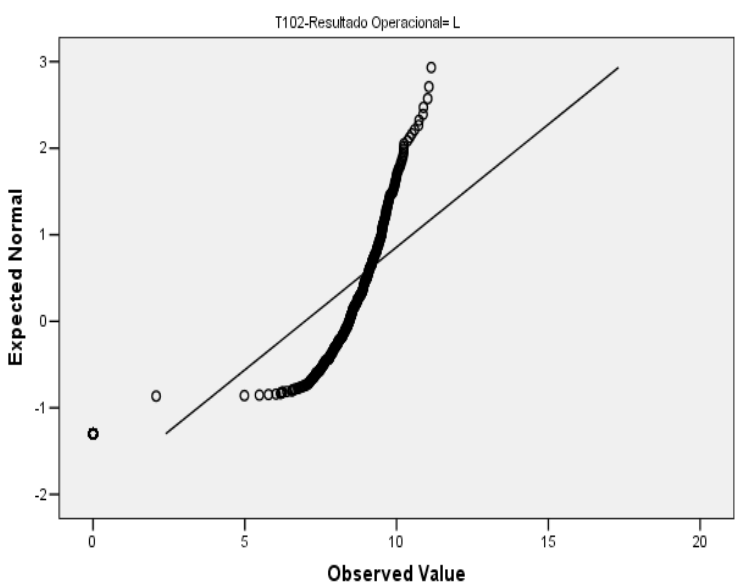


Normal Q-Q Plot of LnRLV211-ISI-Outros

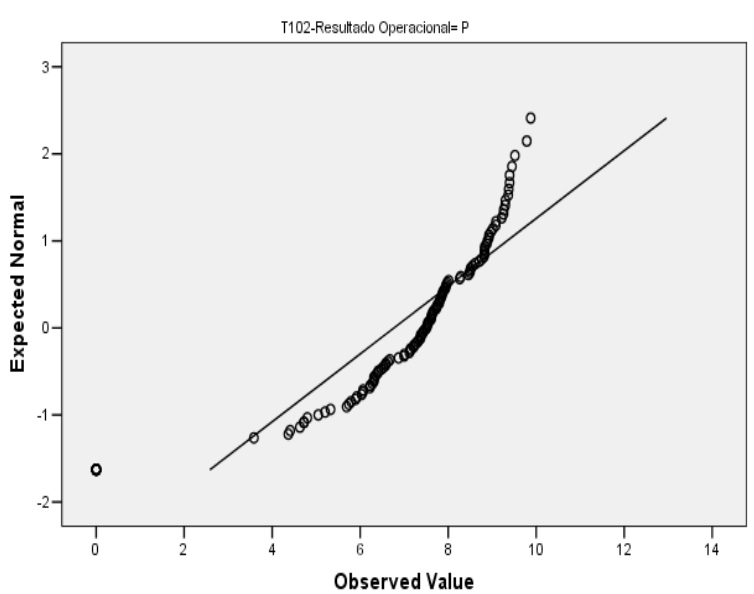

Normal Q-Q Plot of LnRLV213-ISI-Total com compulsório

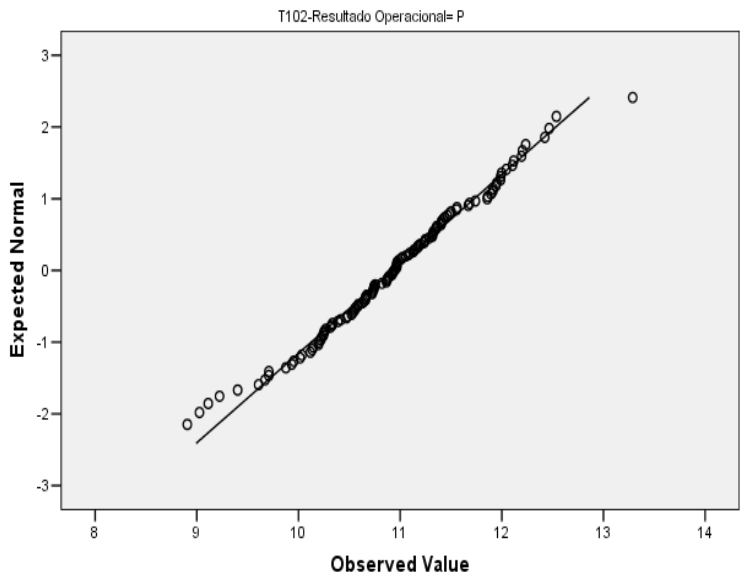

Normal Q-Q Plot of LnRLV214-ISI-Total sem compulsorio

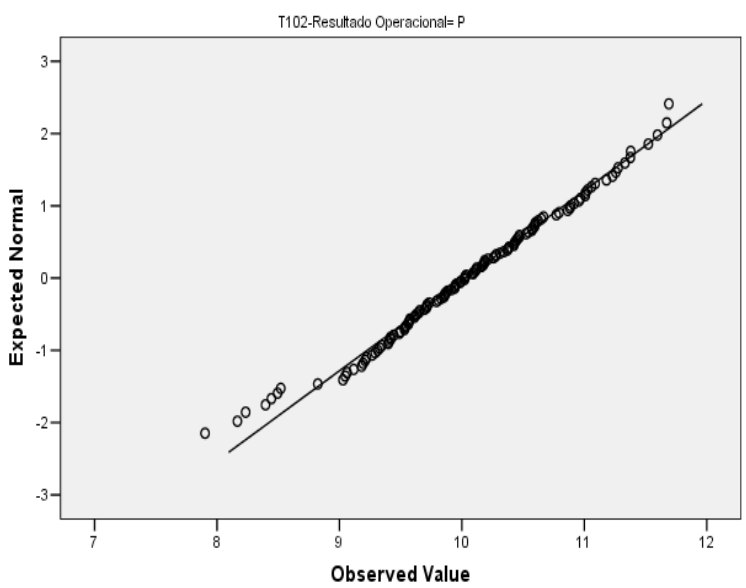

Normal Q-Q Plot of LnRLV211-ISI-Outros

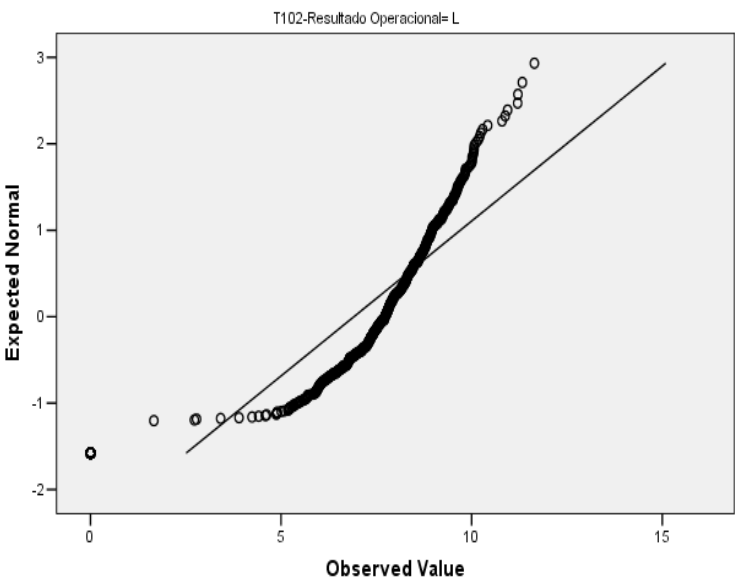

Normal Q-Q Plot of LnRLV213-ISI-Total com compulsório

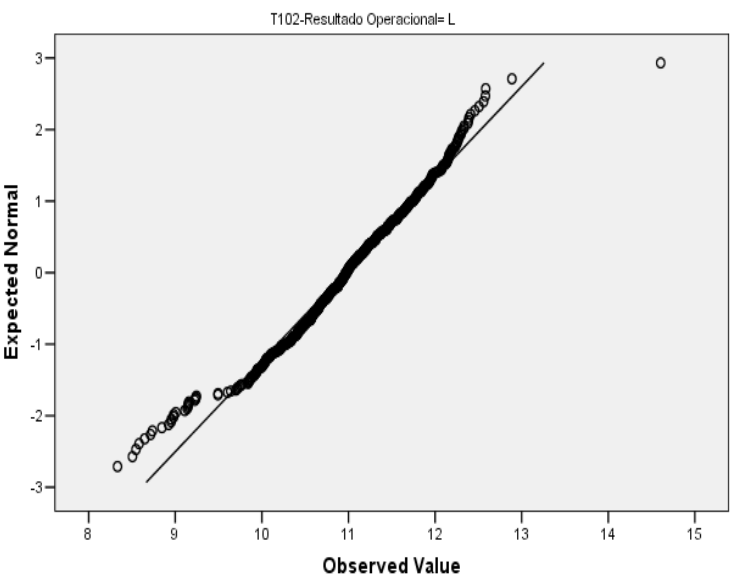

Normal Q-Q Plot of LnRLV214-ISI-Total sem compulsorio

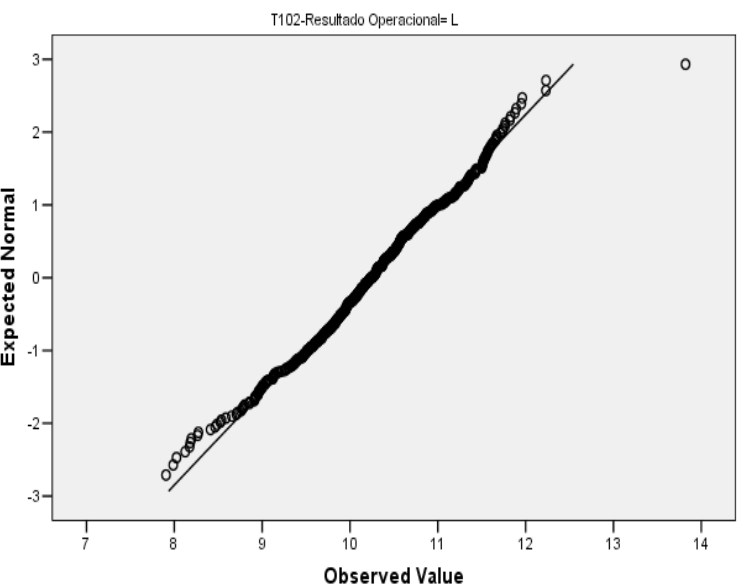




\subsubsection{Variáveis Indicadores Sociais Externos dessensibilizadas do porte das empresas}

Normal Q-Q Plot of LnRLV301-ISE-Educação

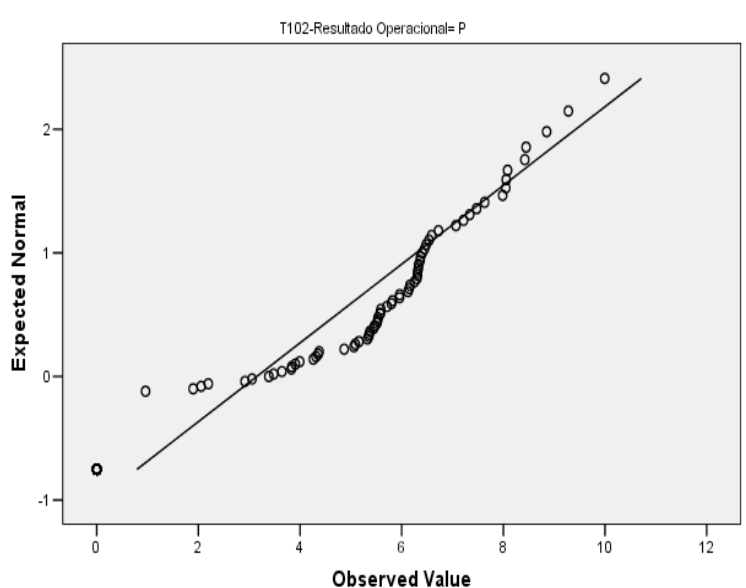

Normal Q-Q Plot of LnRLV302-ISE-Cultura

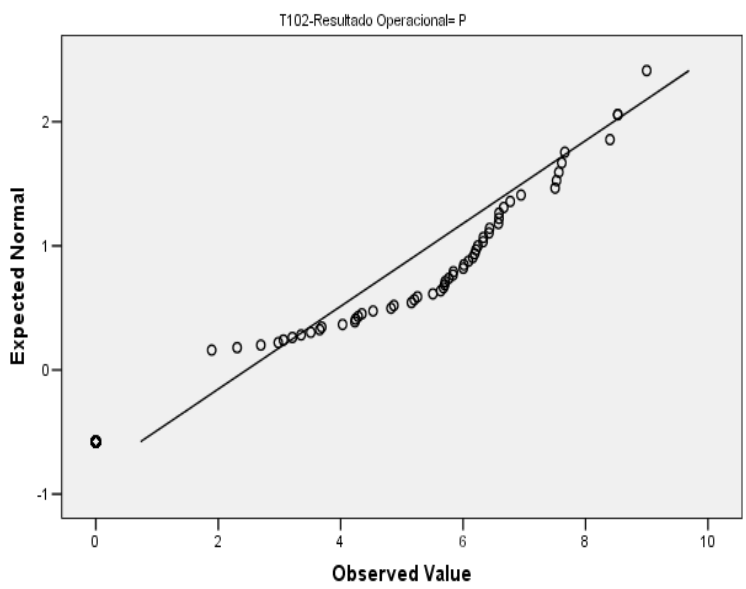

Normal Q-Q Plot of LnRLV301-ISE-Educação

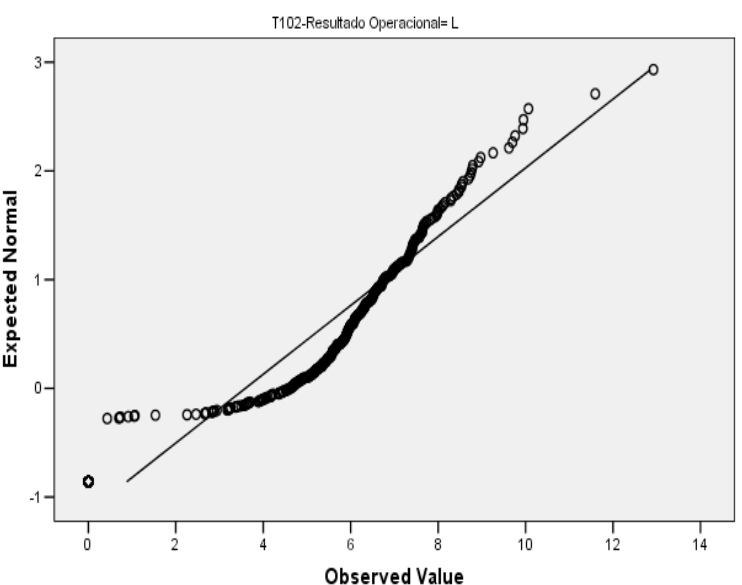

Normal Q-Q Plot of LnRLV302-ISE-Cultura

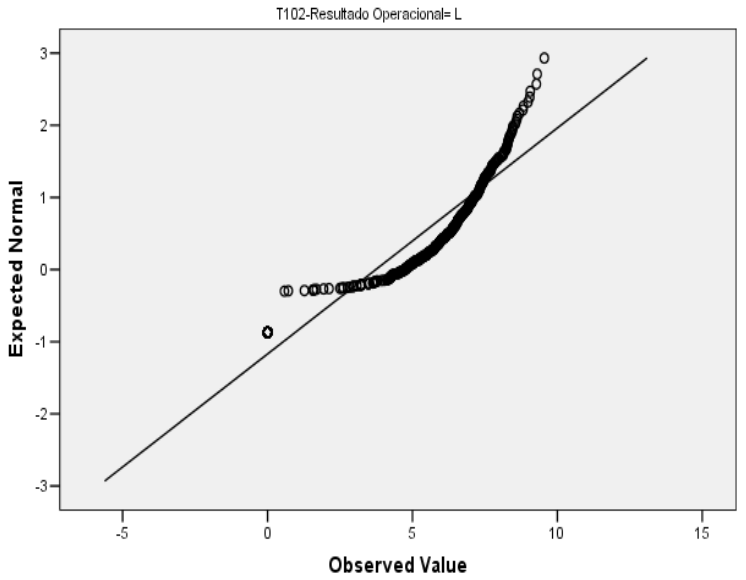


Normal Q-Q Plot of LnRLV303-ISE-Saúde e saneamento

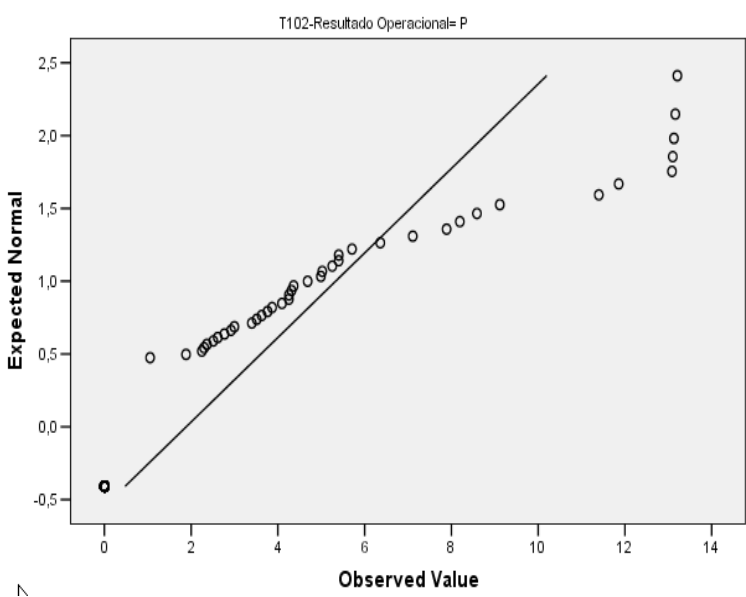

Normal Q-Q Plot of LnRLV304-ISE-Habitação

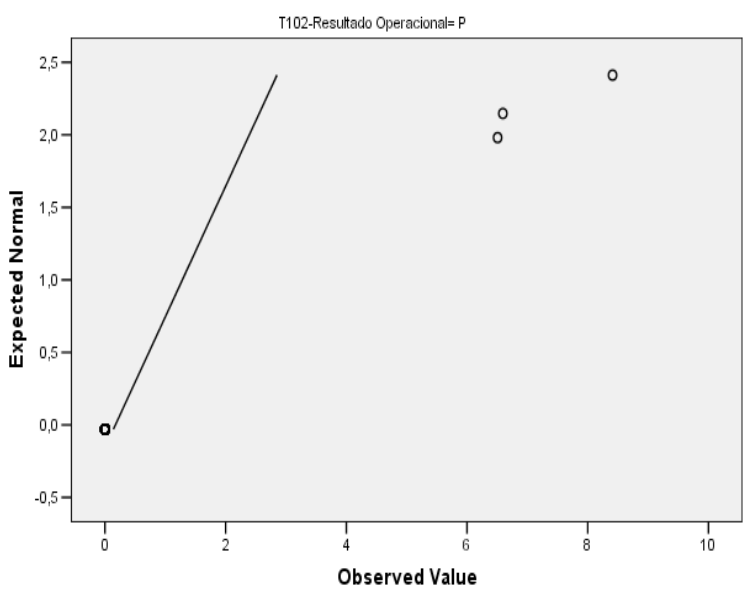

Normal Q-Q Plot of LnRLV305-ISE-Esporte

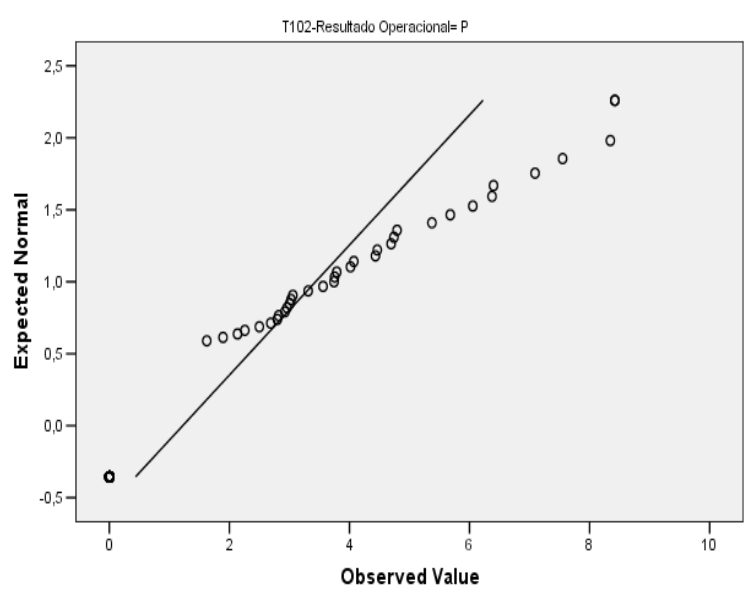

Normal Q-Q Plot of LnRLV303-ISE-Saúde e saneamento

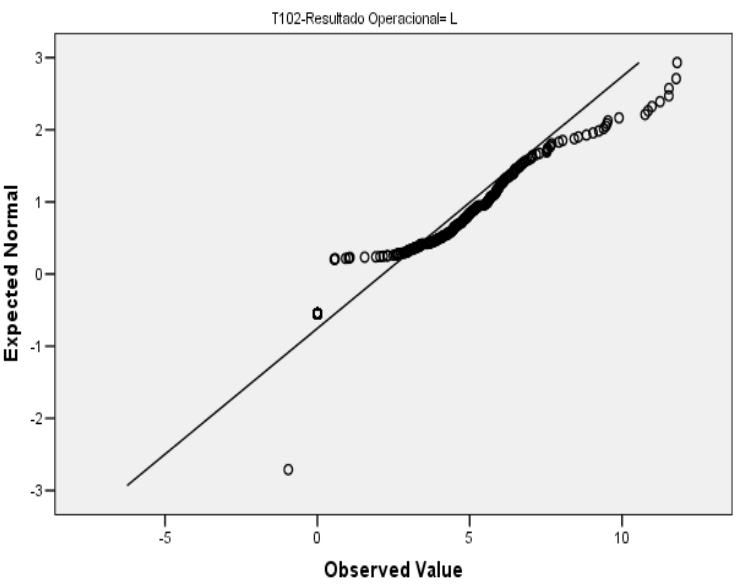

Normal Q-Q Plot of LnRLV304-ISE-Habitação

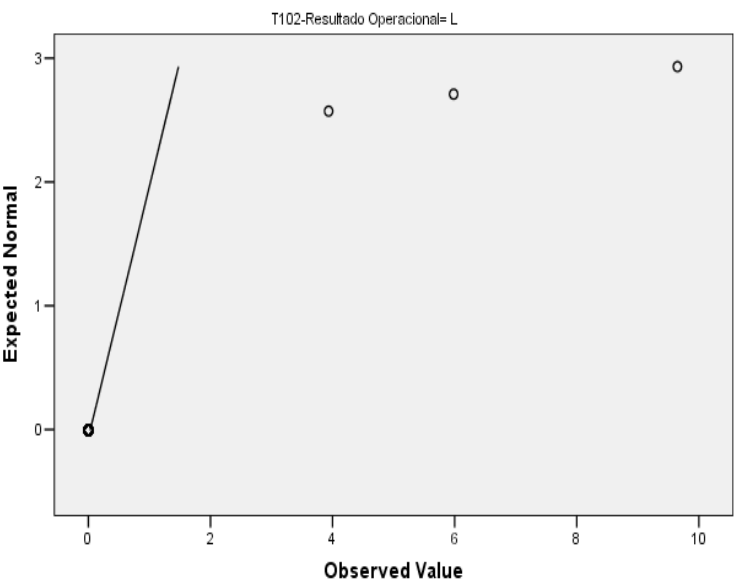

Normal Q-Q Plot of LnRLV305-ISE-Esporte

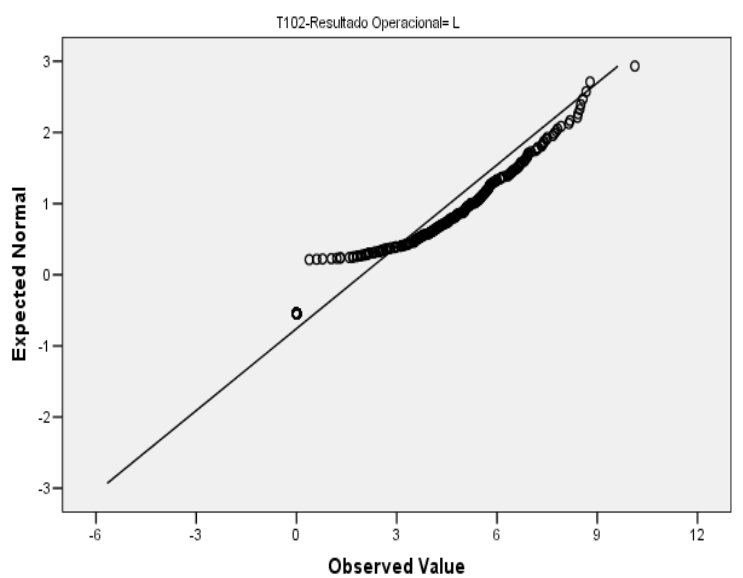


Normal Q-Q Plot of LnRLV306-ISE-Lazer e diversão

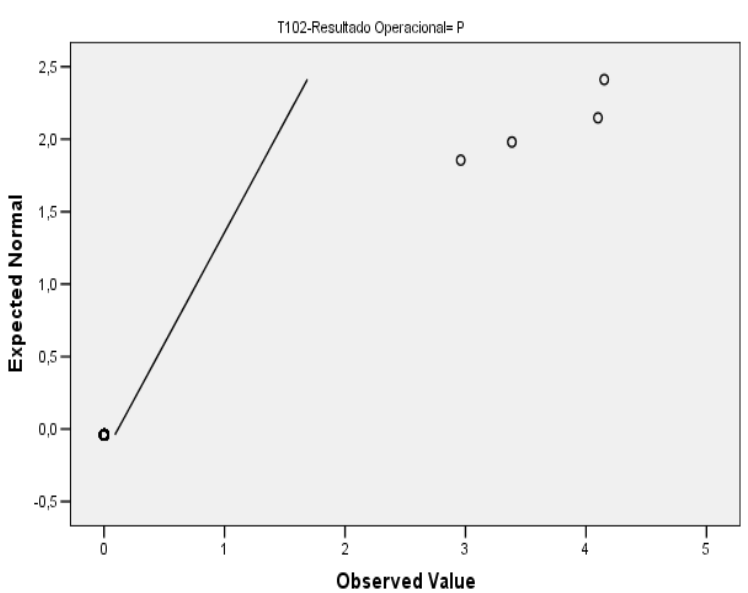

Normal Q-Q Plot of LnRLV307-ISE-Creches

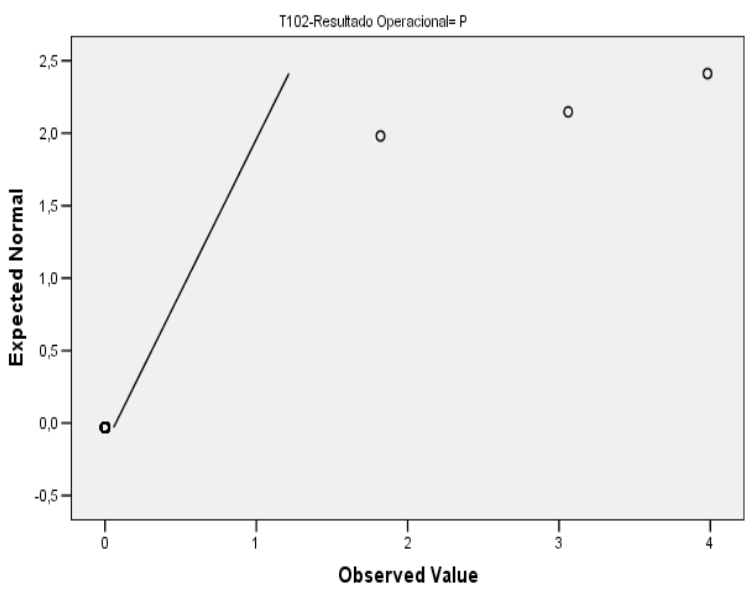

Normal Q-Q Plot of LnRLV308-ISE-Alimentação

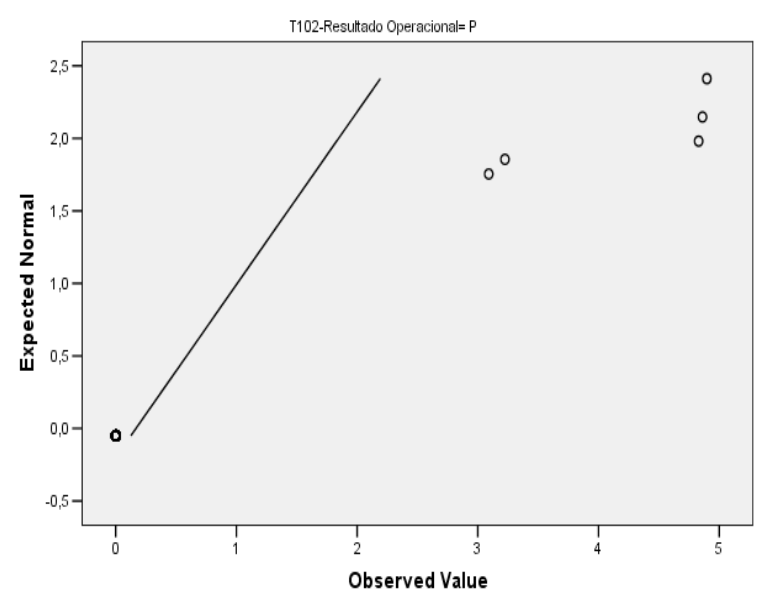

Normal Q-Q Plot of LnRLV306-ISE-Lazer e diversão

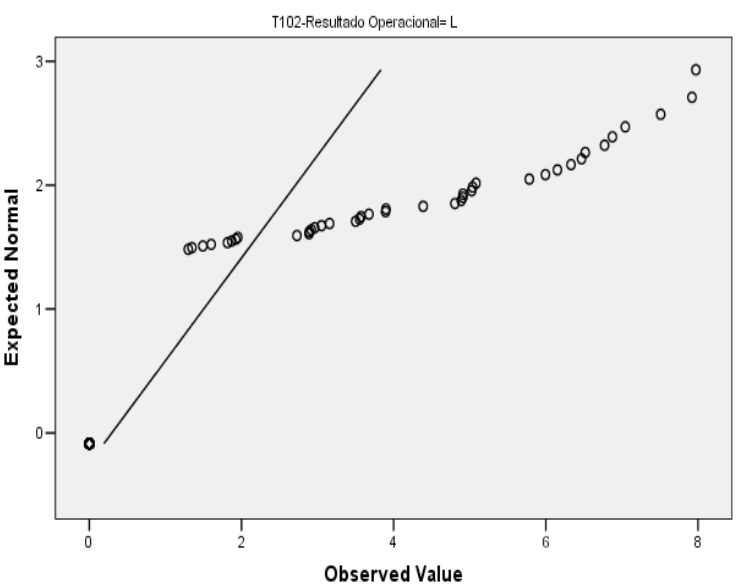

Normal Q-Q Plot of LnRLV307-ISE-Creches

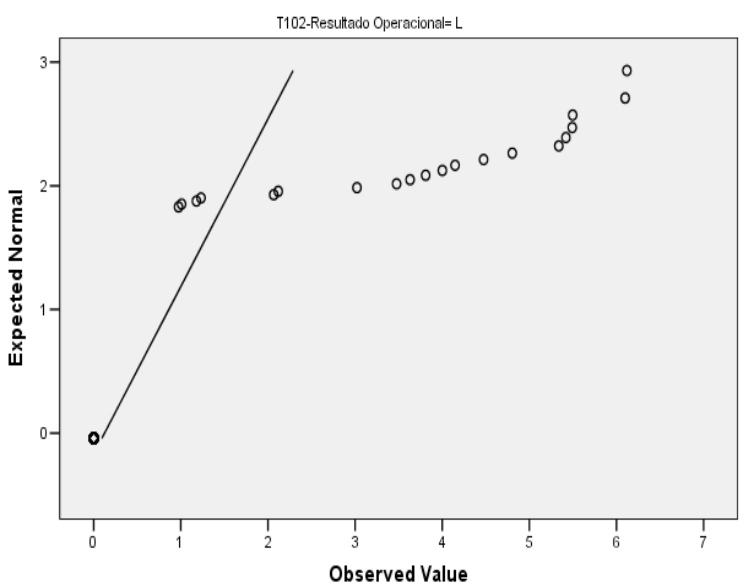

Normal Q-Q Plot of LnRLV308-ISE-Alimentação

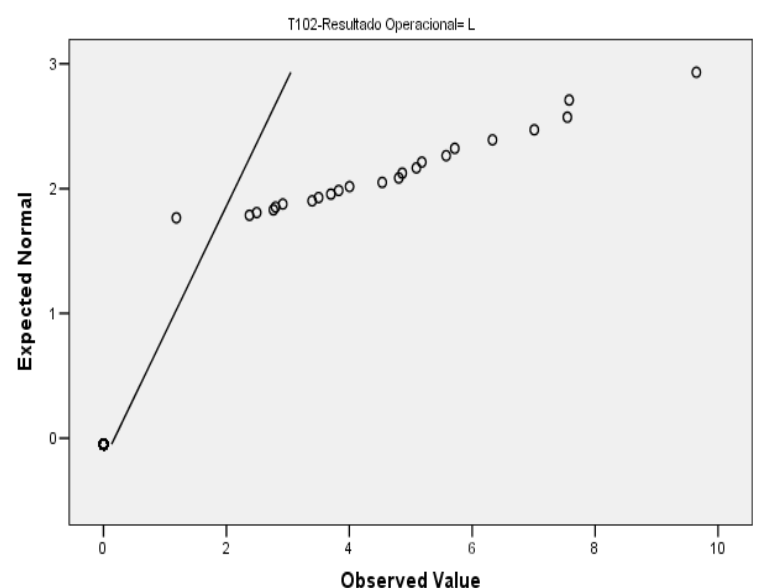


Normal Q-Q Plot of LnRLV309-ISE-Combate fome...

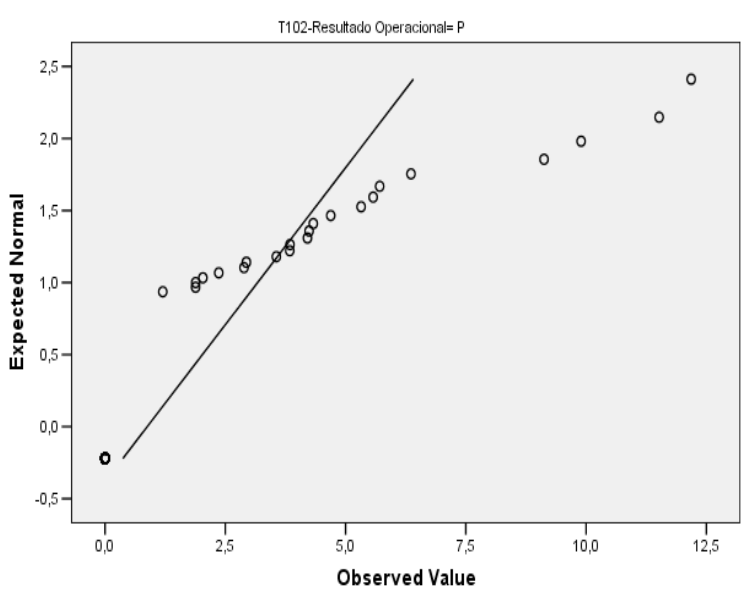

Normal Q-Q Plot of LnRLV310-ISE-Outros

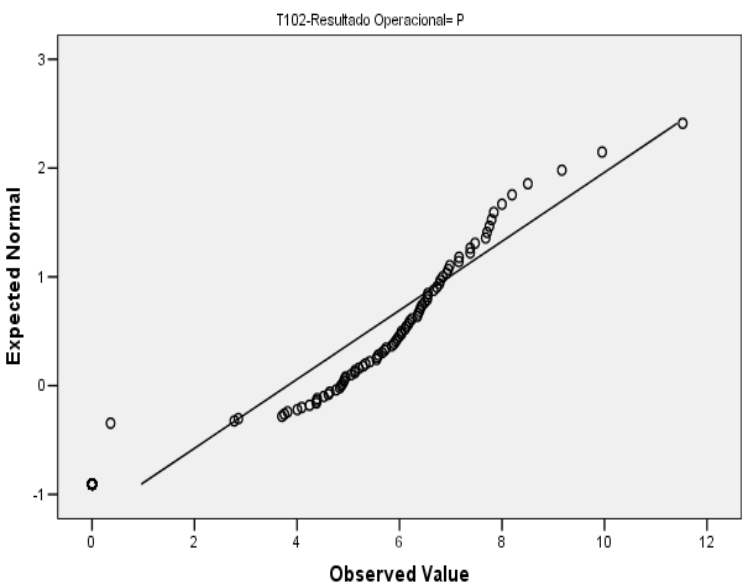

Normal Q-Q Plot of LnRLV311-ISE-Agregados

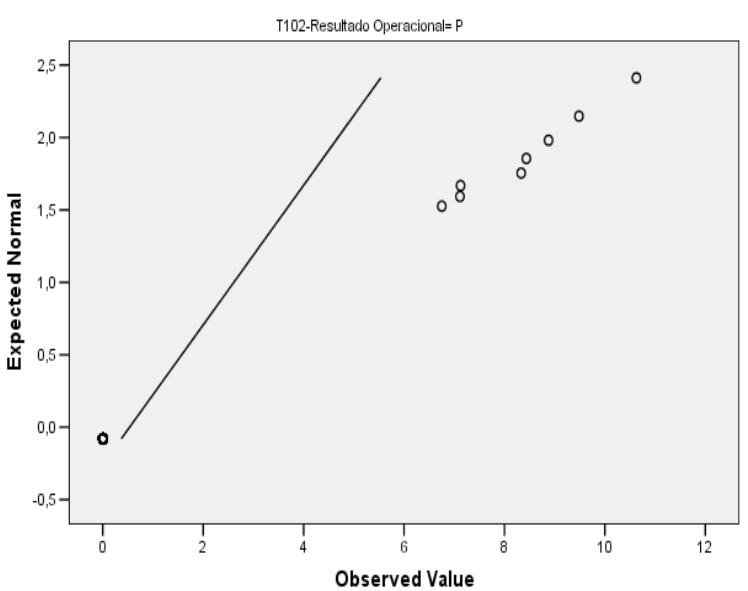

Normal Q-Q Plot of LnRLV309-ISE-Combate fome.

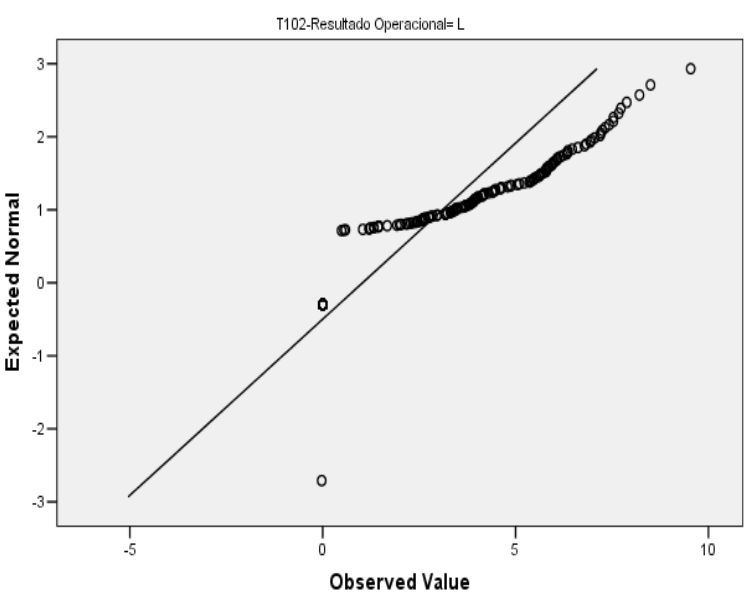

Normal Q-Q Plot of LnRLV310-ISE-Outros

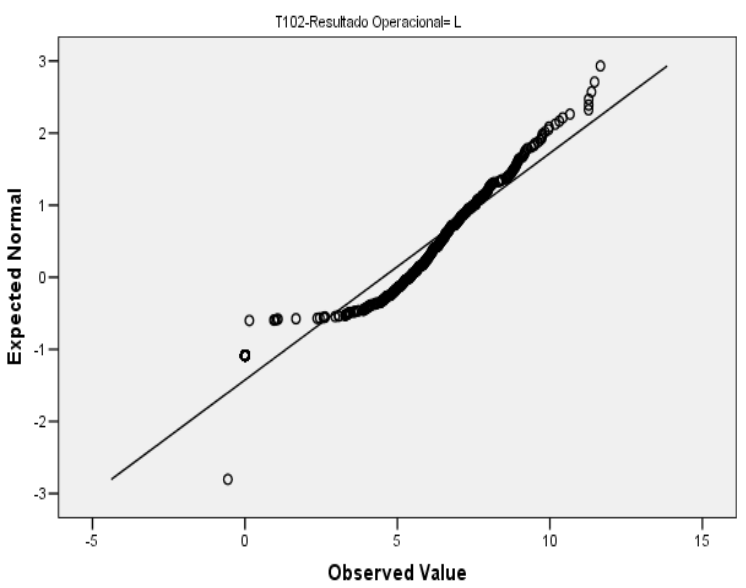

Normal Q-Q Plot of LnRLV311-ISE-Agregados

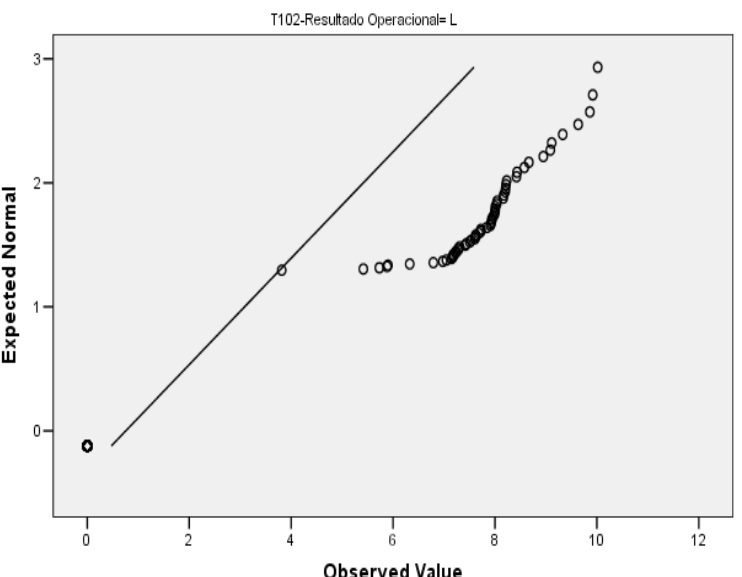


Normal Q-Q Plot of LnRLV312-ISE-Total sem compulsório

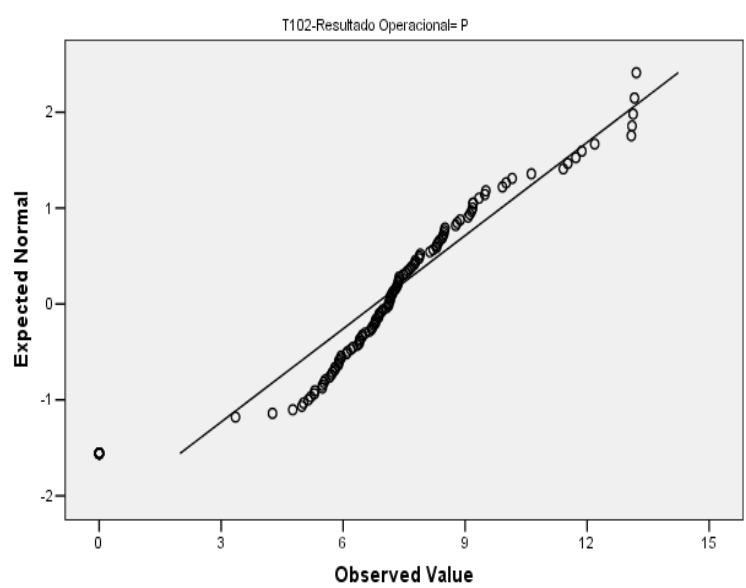

Normal Q-Q Plot of LnRLV313-Tributos (excluidos encargos sociais)

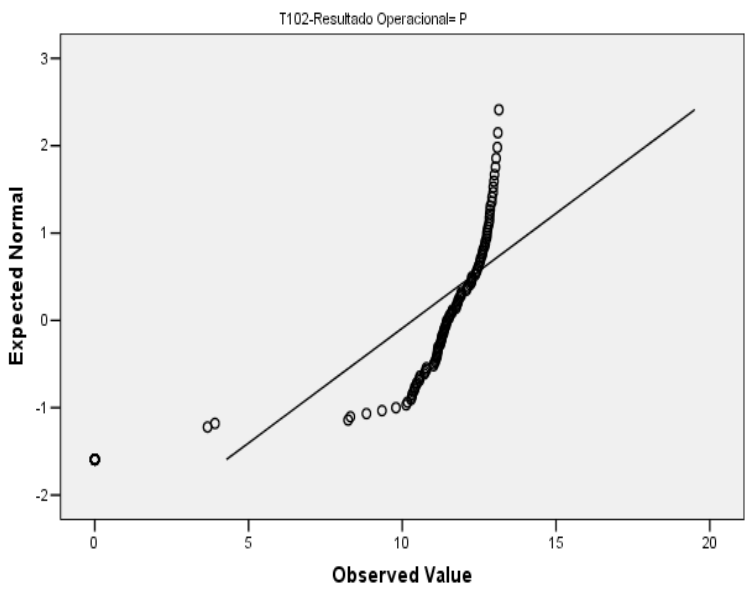

Normal Q-Q Plot of LnRLV314-ISE-Total com compulsório

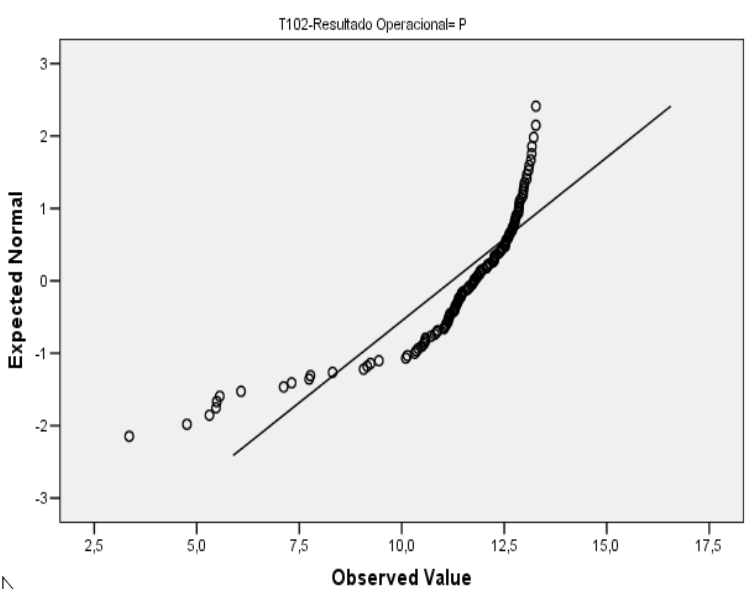

Normal Q-Q Plot of LnRLV312-ISE-Total sem compulsório

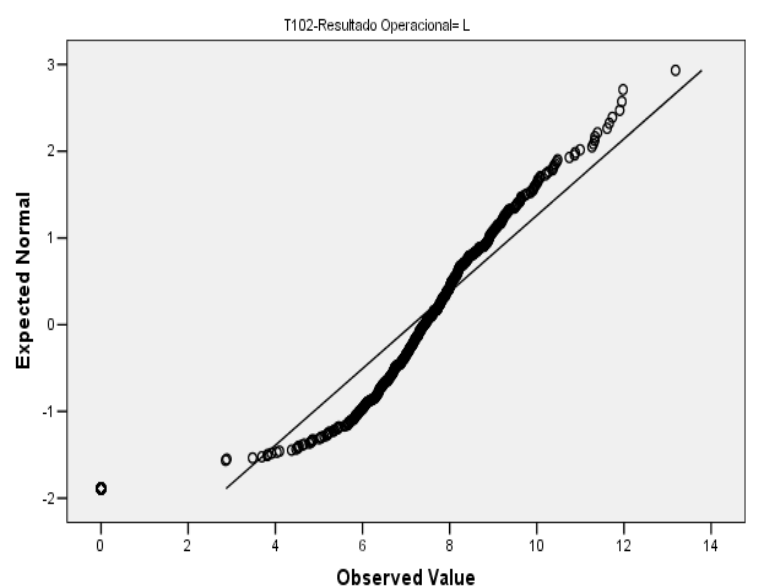

Normal Q-Q Plot of LnRLV313-Tributos (excluídos encargos sociais)

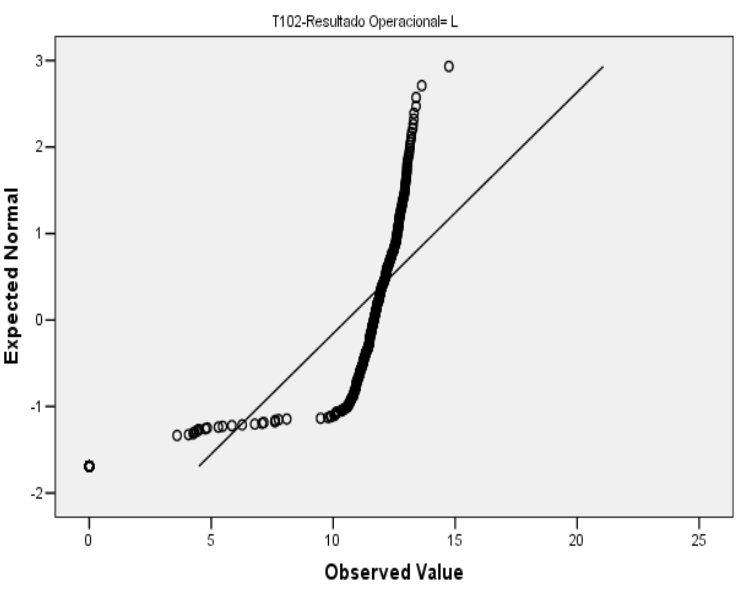

Normal Q-Q Plot of LnRLV314-ISE-Total com compulsório

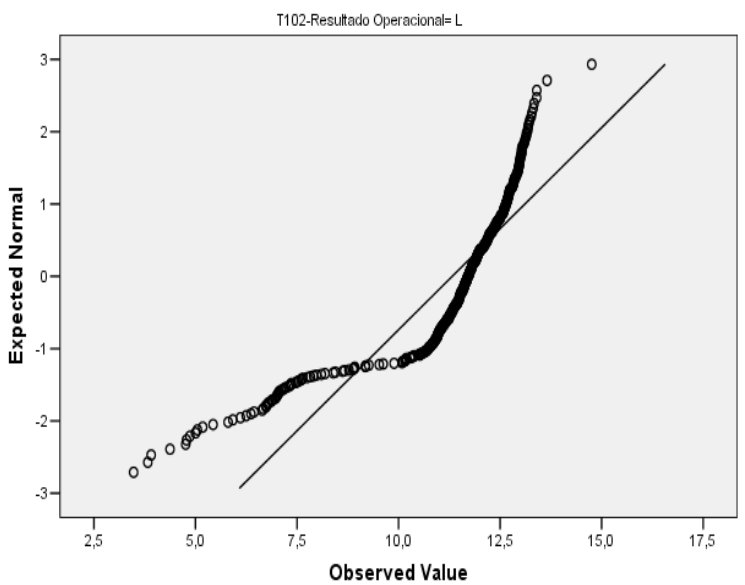




\subsubsection{Variáveis Indicadores Ambientais dessensibilizadas do porte das empresas}

Normal Q-Q Plot of LnRLV401-IA-Invest relacionados prodloperação

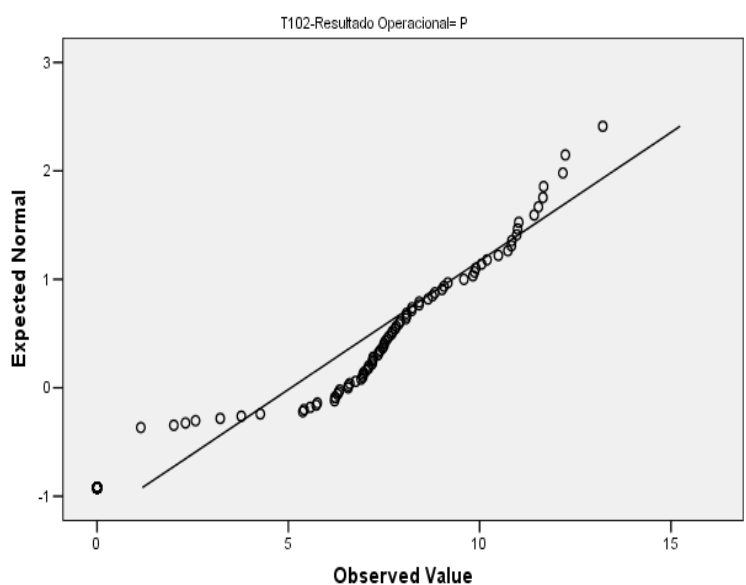

Normal Q-Q Plot of LnRLV402-IA-Invest programas \& proj. externos

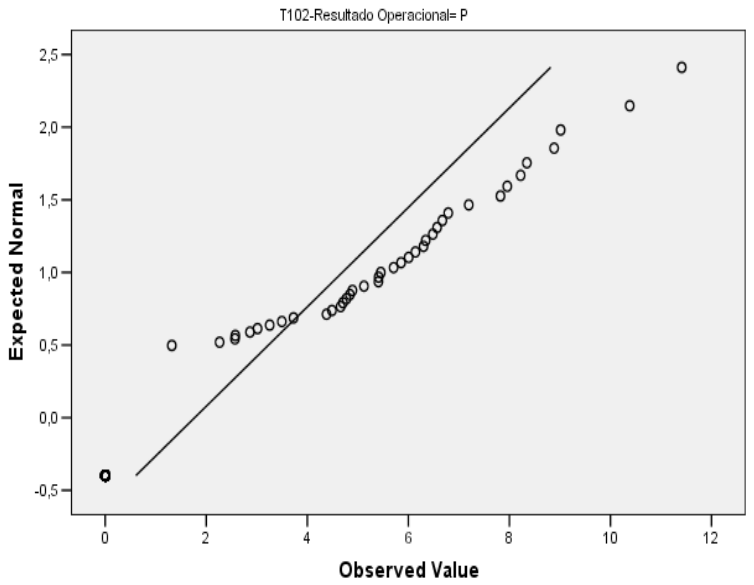

Normal Q-Q Plot of LnRLV401-IA-Invest relacionados prod/operação

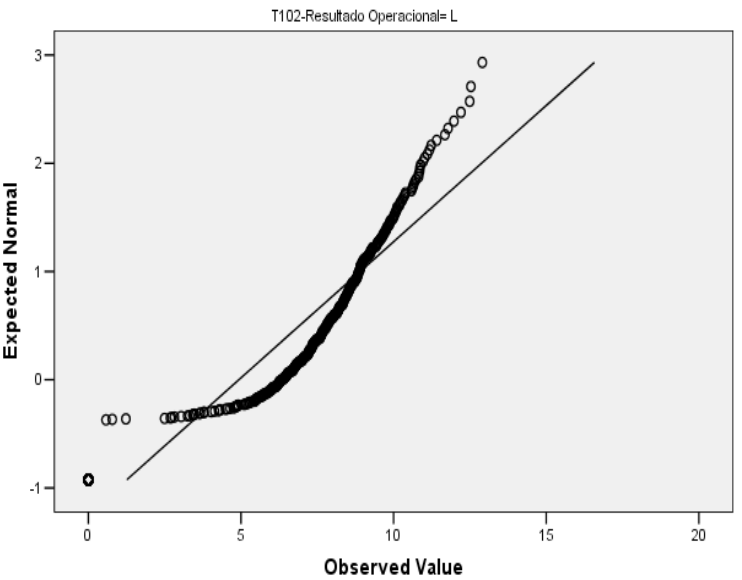

Normal Q-Q Plot of LnRLV402-IA-Invest programas \& proj. externos

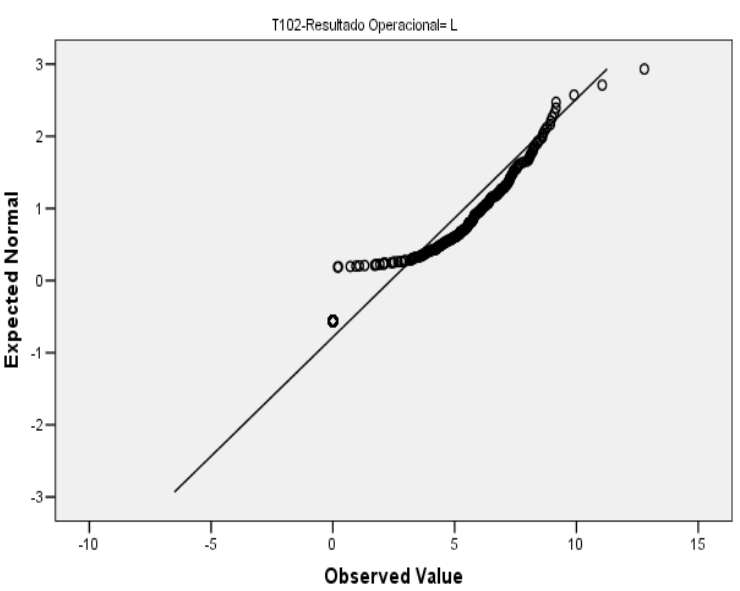


Normal Q-Q Plot of LnRLV403-IA-Agregado

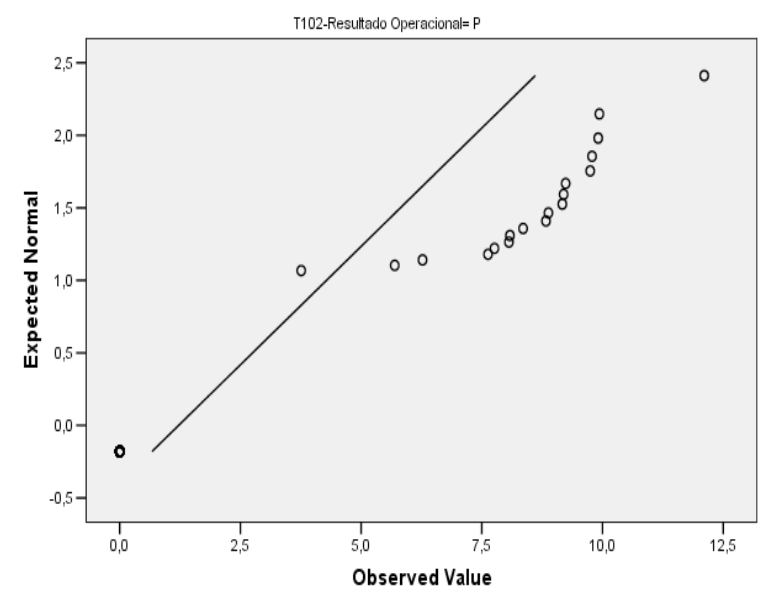

Normal Q-Q Plot of LnRLV404-IA-Total

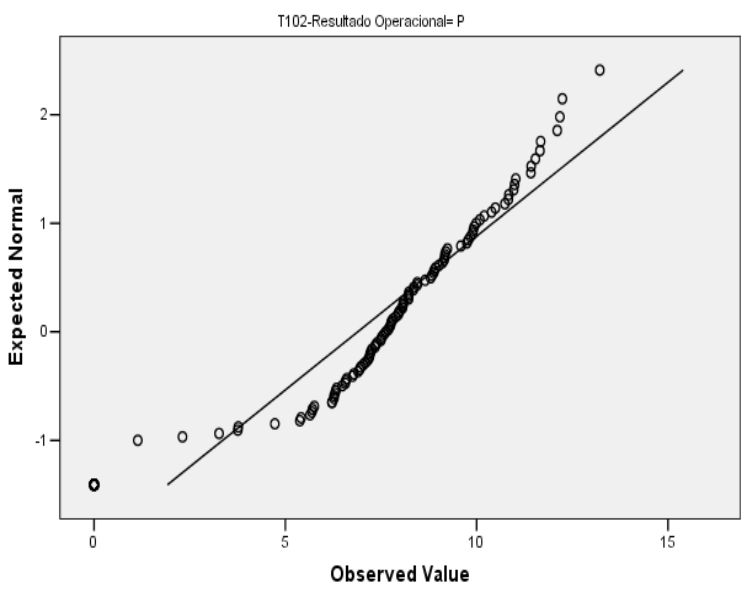

Normal Q-Q Plot of LnRLV403-IA-Agregado

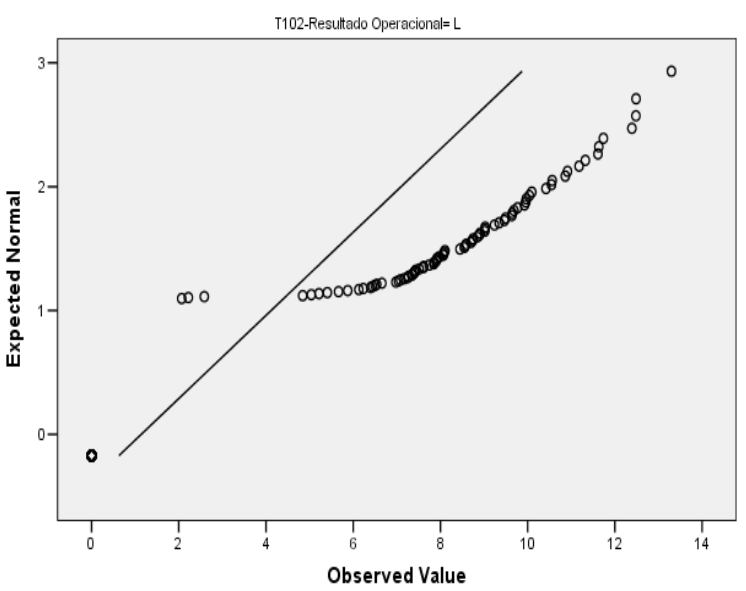

Normal Q-Q Plot of LnRLV404-IA-Total

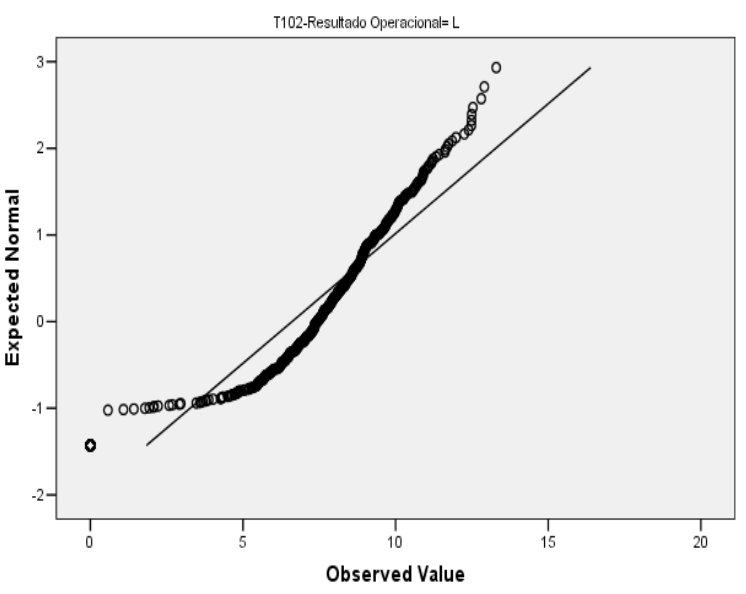




\subsubsection{Variáveis Investimentos Totais dessensibilizadas do porte das empresas}

Normal Q-Q Plot of LnR RSE Voluntario

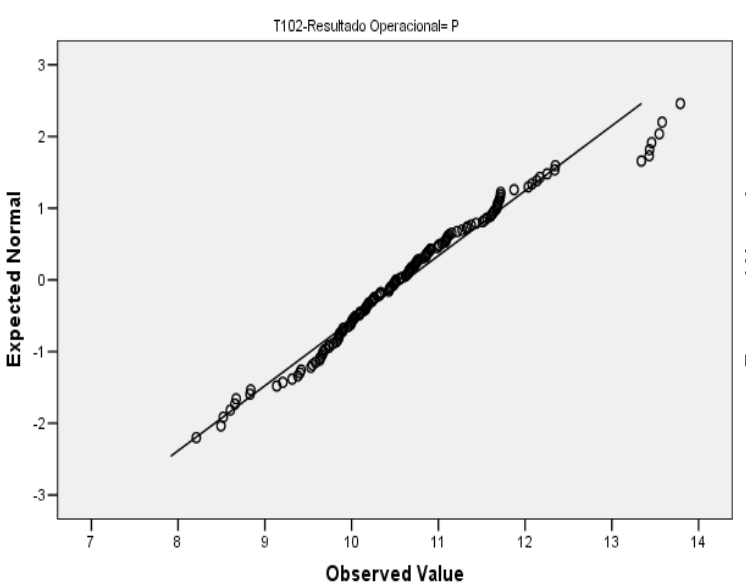

Normal Q-Q Plot of LnR_RSE_Total

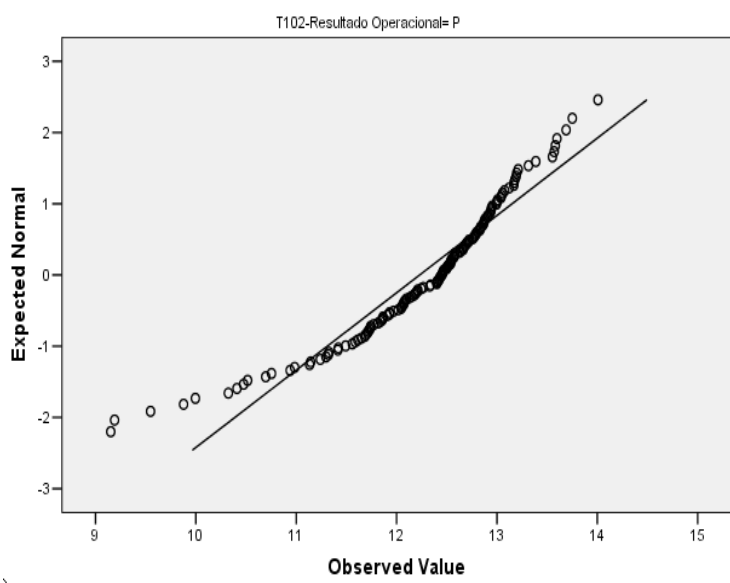

Normal Q-Q Plot of LnR_RSE_Voluntario

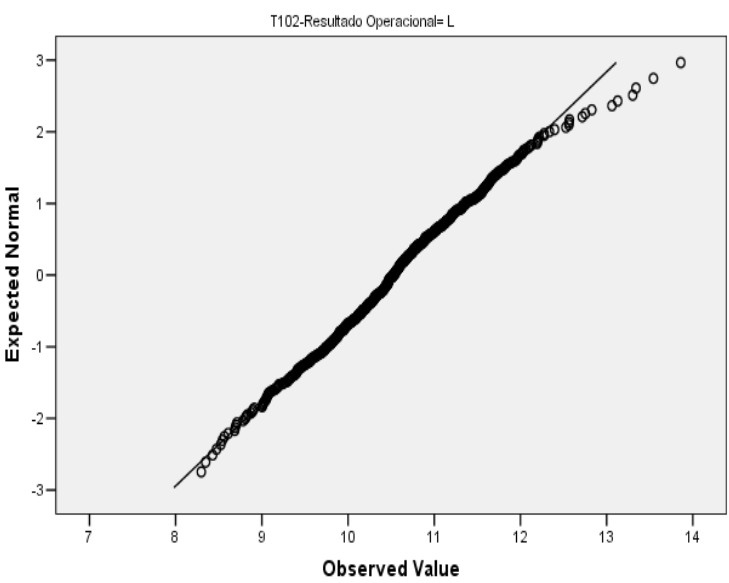

Normal Q-Q Plot of LnR_RSE_Total

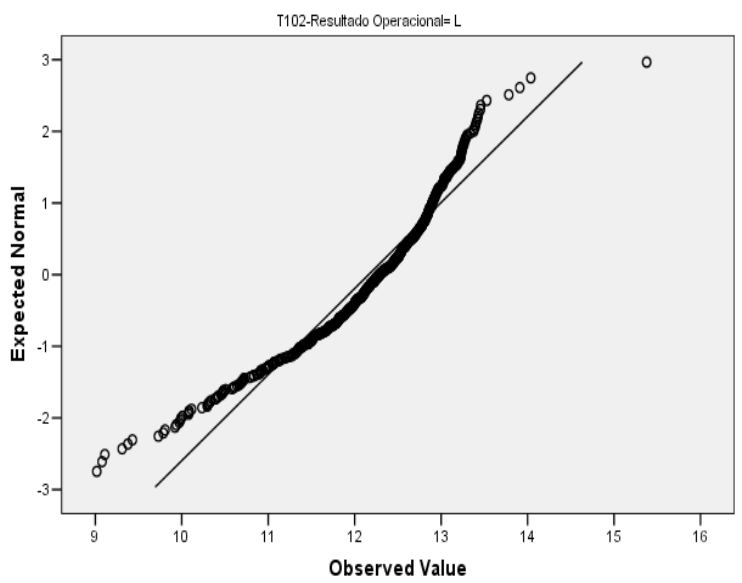

7.5 Resultados da análise GLM dessensibilizada do porte das empresas e utilizando fator de escala igual a 1000

Ainda que os resultados entre os modelos dessensibilizados do porte das empresas que utilizaram fatores de escala 1.000 e 1.000 .000 não tenham sido substantivamente diferentes, alguns modelos que utilizaram a escala 1.000 apresentaram algumas configurações nos quais os níveis de 
assertividades dos modelo estiveram abaixo do valor limite de 5,0\%, fazendo com que algumas variáveis tivessem de ser retiradas do modelo para que esse limite pudesse ser atendido. A seleção foi feita manualmente pelo autor, com o critério de seleção das variáveis menos significativas do cálculo GLM, seguido de sua retirada do modelo.

A melhor configuração obtida por essa metodologia em cada modelo está apresentada nas tabelas que seguem e foram desenvolvidas para os modelos que consideram os fatores Ano e Setor. A transformação dessas variáveis está comentada na Tabela 11.

Notar que todos os modelos com RO positivo (L) não passaram no Teste de Levene.

\begin{tabular}{|c|c|c|c|c|}
\hline & \multicolumn{2}{|c|}{ Modelo 3A-P } & \multicolumn{2}{|r|}{ Modelo 3A-L } \\
\hline & Sig & Eta quadrado parcial & Sig & Eta quadrado parcial \\
\hline Teste de Levene & 0,661 & & 0,020 & \\
\hline Assertividade do modelo (R-Sqr) & 0,009 & 0,156 & 0,000 & 0,082 \\
\hline Intercepto & $\mathbf{0 , 0 0 0}$ & 0,257 & 0,000 & 0,403 \\
\hline LnRSE_Voluntario & 0,082 & 0,026 & 0,001 & 0,020 \\
\hline Ano & 0,060 & 0,074 & 0,723 & 0,004 \\
\hline Setor & 0,047 & 0,066 & 0,000 & 0,055 \\
\hline \multirow[t]{3}{*}{ Ano * Setor } & & & & \\
\hline & \multicolumn{2}{|c|}{ Modelo 3B-P } & \multicolumn{2}{|r|}{ Modelo 3P-L } \\
\hline & Sig & Eta quadrado parcial & Sig & Eta quadrado parcial \\
\hline Teste de Levene & 0,446 & & 0,010 & \\
\hline Assertividade do modelo (R Sqr) & 0,004 & 0,197 & 0,000 & 0,095 \\
\hline Intercept & $\mathbf{0 , 0 0 0}$ & 0,106 & 0,000 & 0,423 \\
\hline LnRLV214 & 0,004 & 0,070 & 0,019 & 0,009 \\
\hline LnRLV312 & 0,784 & 0,001 & 0,006 & 0,013 \\
\hline LnRLV404 & 0,317 & 0,009 & 0,412 & 0,001 \\
\hline Ano & 0,031 & 0,087 & 0,765 & 0,003 \\
\hline Setor & 0,009 & 0,094 & 0,000 & 0,055 \\
\hline Ano * Setor & & & & \\
\hline
\end{tabular}




\begin{tabular}{|c|c|c|c|c|}
\hline & \multicolumn{2}{|c|}{ Modelo 3C-P (não calculado) } & \multicolumn{2}{|c|}{ Modelo 3C-L } \\
\hline & Sig & Eta quadrado parcial & Sig & Eta quadrado parcial \\
\hline Teste de Levene & & & 0,001 & \\
\hline Assertividade do modelo (R Sqr) & & & 0,000 & 0,201 \\
\hline Intercepto & & & 0,000 & 0,721 \\
\hline LnRLV201 & & & 0,002 & 0,018 \\
\hline \multicolumn{5}{|l|}{ LnRLV202 } \\
\hline LnRLV203 & & & 0,001 & 0,019 \\
\hline LnRLV204 & & & 0,609 & 0,000 \\
\hline LnRLV205 & & & 0,702 & 0,000 \\
\hline \multicolumn{5}{|l|}{ LnRLV206 } \\
\hline \multicolumn{5}{|l|}{ LnRLV207 } \\
\hline LnRLV208 & & & 0,001 & 0,021 \\
\hline LnRLV209 & & & 0,140 & 0,004 \\
\hline LnRLV210 & & & 0,000 & 0,039 \\
\hline LnRLV211 & & & 0,992 & 0,000 \\
\hline LnRLV301 & & & 0,216 & 0,003 \\
\hline \multicolumn{5}{|l|}{ LnRLV302 } \\
\hline LnRLV303 & & & 0,218 & 0,003 \\
\hline LnRLV304 & & & 0,002 & 0,017 \\
\hline LnRLV305 & & & 0,351 & 0,002 \\
\hline LnRLV306 & & & 0,005 & 0,014 \\
\hline LnRLV307 & & & 0,669 & 0,000 \\
\hline LnRLV308 & & & 0,374 & 0,001 \\
\hline LnRLV309 & & & 0,659 & 0,000 \\
\hline LnRLV310 & & & 0,328 & 0,002 \\
\hline \multicolumn{5}{|l|}{ LnRLV311 } \\
\hline \multicolumn{5}{|l|}{ LnRLV313 } \\
\hline LnRLV401 & & & 0,057 & 0,006 \\
\hline \multicolumn{5}{|l|}{ LnRLV402 } \\
\hline \multicolumn{5}{|l|}{ LnRLV403 } \\
\hline Ano & & & 0,918 & \\
\hline Setor & & & 0,018 & \\
\hline \multicolumn{5}{|l|}{ Ano * Setor } \\
\hline & \multicolumn{2}{|c|}{ Modelo 4A-P } & \multicolumn{2}{|c|}{ Modelo 4A-L } \\
\hline & Sig & Eta quadrado parcial & Sig & Eta quadrado parcial \\
\hline Teste de Levene & 0,667 & & 0,030 & \\
\hline Assertividade do modelo (R-Sqr) & $\mathbf{0 , 0 2 0}$ & 0,140 & 0,000 & 0,068 \\
\hline Intercepto & $\mathbf{0 , 0 0 0}$ & 0,107 & 0,000 & 0,238 \\
\hline LnR_RSE_Total & 0,346 & 0,008 & 0,080 & 0,005 \\
\hline Ano & 0,082 & 0,068 & 0,768 & 0,003 \\
\hline Setor & 0,117 & 0,049 & 0,000 & 0,058 \\
\hline Ano * Setor & & & & \\
\hline
\end{tabular}




\begin{tabular}{|c|c|c|c|c|}
\hline & \multicolumn{2}{|c|}{ Modelo 4B-P } & \multicolumn{2}{|c|}{ Modelo 4B-L } \\
\hline & Sig & Eta quadrado parcial & Sig & Eta quadrado parcial \\
\hline Teste de Levene & $\mathbf{0 , 4 8 2}$ & & 0,018 & \\
\hline Assertividade do modelo (R Sqr) & 0,019 & 0,165 & 0,000 & 0,071 \\
\hline Intercepto & 0,004 & 0,068 & 0,000 & 0,346 \\
\hline LnRLV213 & 0,051 & 0,033 & 0,295 & 0,002 \\
\hline LnRLV314 & 0,824 & 0,000 & 0,416 & 0,001 \\
\hline LnRLV404 & 0,397 & 0,006 & 0,129 & 0,004 \\
\hline Ano & 0,059 & 0,075 & 0,797 & 0,003 \\
\hline Setor & 0,024 & 0,078 & 0,000 & 0,058 \\
\hline \multicolumn{5}{|l|}{ Ano * Setor } \\
\hline & \multicolumn{2}{|c|}{ Modelo 4C-P (não calculado) } & \multicolumn{2}{|c|}{ Modelo 4C-L } \\
\hline & Sig & Eta quadrado parcial & Sig & Eta quadrado parcial \\
\hline Teste de Levene & & & 0,001 & \\
\hline Assertividade do modelo (R Sqr) & & & 0,000 & 0,200 \\
\hline Intercepto & & & 0,000 & 0,524 \\
\hline LnRLV201 & & & 0,005 & 0,014 \\
\hline LnRLV202 & & & 0,491 & 0,001 \\
\hline LnRLV203 & & & 0,001 & 0,019 \\
\hline LnRLV204 & & & 0,497 & 0,001 \\
\hline LnRLV205 & & & 0,562 & 0,001 \\
\hline LnRLV206 & & & 0,738 & 0,000 \\
\hline LnRLV207 & & & 0,930 & 0,000 \\
\hline LnRLV208 & & & 0,001 & 0,020 \\
\hline LnRLV209 & & & 0,108 & 0,005 \\
\hline LnRLV210 & & & 0,000 & 0,037 \\
\hline LnRLV211 & & & 0,939 & 0,000 \\
\hline LnRLV301 & & & 0,057 & 0,006 \\
\hline \multicolumn{5}{|l|}{ LnRLV302 } \\
\hline \multicolumn{5}{|l|}{ LnRLV303 } \\
\hline LnRLV304 & & & 0,001 & 0,018 \\
\hline \multicolumn{5}{|l|}{ LnRLV305 } \\
\hline LnRLV306 & & & 0,009 & 0,012 \\
\hline \multicolumn{5}{|l|}{ LnRLV307 } \\
\hline LnRLV308 & & & 0,399 & 0,001 \\
\hline LnRLV309 & & & 0,641 & 0,000 \\
\hline LnRLV310 & & & 0,361 & 0,001 \\
\hline \multicolumn{5}{|l|}{ LnRLV311 } \\
\hline LnRLV313 & & & 0,347 & 0,002 \\
\hline LnRLV401 & & & 0,044 & 0,007 \\
\hline LnRLV402 & & & 0,682 & 0,000 \\
\hline \multicolumn{5}{|l|}{ LnRLV403 } \\
\hline Ano & & & 0,942 & 0,001 \\
\hline Setor & & & 0,051 & 0,017 \\
\hline Ano * Setor & & & & \\
\hline
\end{tabular}


7.6 Resultados completos da análise GLM referente às empresas que operaram com RO negativo

Seguem os resultados detalhados do processamento dos modelos lineares considerando os fatores Ano e Setor. Essas são as tabelas completas referentes às descrições do item 4.2 (Análise dos modelos referentes às empresas que operaram com RO negativo).

\begin{tabular}{|c|c|c|c|}
\hline Modelo 1A-P & Sig & Eta Quadrado Parcial & Poder Observado \\
\hline Teste de Levene & 0,142 & & \\
\hline Assertividade do modelo (R-Sqr) & $\mathbf{0 , 0 0 0}$ & 0,566 & 1,000 \\
\hline Intercepto & 0,004 & 0,076 & 0,834 \\
\hline LnRSE_Voluntario & $\mathbf{0 , 0 0 0}$ & 0,407 & 1,000 \\
\hline Ano & 0,046 & 0,086 & 0,695 \\
\hline Setor & $\mathbf{0 , 0 1 7}$ & 0,091 & 0,773 \\
\hline Ano * Setor & 0,835 & 0,064 & 0,327 \\
\hline Modelo 1B-P & Sig & Eta Quadrado Parcial & Poder Observado \\
\hline Teste de Levene & 0,422 & & \\
\hline Assertividade do modelo (R Sqr) & $\mathbf{0 , 0 0 0}$ & 0,654 & 1,000 \\
\hline Intercepto & 0,461 & 0,005 & 0,114 \\
\hline LnV214 & $\mathbf{0 , 0 0 0}$ & 0,482 & 1,000 \\
\hline LnV312 & 0,080 & 0,029 & 0,417 \\
\hline LnV404 & 0,196 & 0,016 & 0,252 \\
\hline Ano & 0,026 & 0,100 & 0,762 \\
\hline Setor & $\mathbf{0 , 0 0 3}$ & 0,125 & 0,903 \\
\hline Ano * Setor & 0,783 & 0,071 & 0,360 \\
\hline Modelo 1C-P (não calculado) & Sig & Eta Quadrado Parcial & Poder Observado \\
\hline Modelo 2A-P & Sig & Eta Quadrado Parcial & Poder Observado \\
\hline Teste de Levene & $\mathbf{0 , 2 5 3}$ & & \\
\hline Assertividade do modelo (R-Sqr) & $\mathbf{0 , 0 0 0}$ & 0,553 & 1,000 \\
\hline Intercepto & 0,902 & 0,000 & 0,052 \\
\hline LnRSE_Total & $\mathbf{0 , 0 0 0}$ & 0,390 & 1,000 \\
\hline Ano & 0,176 & 0,057 & 0,483 \\
\hline Setor & 0,356 & 0,030 & 0,288 \\
\hline Ano * Setor & 0,922 & 0,052 & 0,258 \\
\hline
\end{tabular}




\begin{tabular}{l|c|c|c}
\hline \multicolumn{1}{c|}{ Modelo 2B-P } & Sig & Eta Quadrado Parcial & Poder Observado \\
\hline Teste de Levene & $\mathbf{0 , 1 8 6}$ & & \\
\hline Assertividade do modelo (R Sqr) & $\mathbf{0 , 0 0 0}$ & 0,613 & 1,000 \\
\hline Intercepto & 0,642 & 0,002 & 0,075 \\
\hline LnV213 & $\mathbf{0 , 0 0 0}$ & 0,387 & 1,000 \\
\hline LnV314 & 0,767 & 0,001 & 0,060 \\
\hline LnV404 & 0,156 & 0,019 & 0,294 \\
\hline Ano & 0,107 & 0,070 & 0,571 \\
\hline Setor & $\mathbf{0 , 0 0 2}$ & 0,132 & 0,921 \\
\hline Ano * Setor & 0,929 & 0,051 & 0,251 \\
\hline
\end{tabular}

Modelo 2C-P (não calculado) \begin{tabular}{l|l} 
Sig & Eta Quadrado Parcial \\
\hline
\end{tabular}

Poder Observado

Seguem os resultados detalhados do processamento dos modelos lineares considerando os fatores Ano e Setor. As variáveis dessensibilizadas do porte das empresas usaram o fator de escala 1.000 .000 .

\begin{tabular}{l|c|c|c}
\hline \multicolumn{1}{c|}{ Modelo 3A-P (1) } & Sig & Eta Quadrado Parcial & Poder Observado \\
\hline Teste de Levene & $\mathbf{0 , 9 5 5}$ & & \\
\hline Assertividade do modelo (R-Sqr) & $\mathbf{0 , 2 4 2}$ & 0,168 & 0,819 \\
\hline Intercepto & 0,000 & 0,224 & 1,000 \\
\hline LnR_RSE_Voluntario & 0,151 & 0,017 & 0,300 \\
\hline Ano & 0,095 & 0,062 & 0,592 \\
\hline Setor & 0,104 & 0,049 & 0,524 \\
\hline Ano * Setor & $\mathbf{0 , 9 8 8}$ & 0,029 & 0,168 \\
\hline
\end{tabular}

Como o modelo 3A-P (1) não apresentou assertividade significativa, pois o Sig foi igual a 24,2\%, maior que 5,0\%, ele foi reprocessado retirando o fator de menor significância (Ano * Setor). O modelo 3A-P (2) que segue ajustou a assertividade que se tornou significativa. Essa mesma operação foi repetida em outros modelos que seguem e que estão identificados por (1) e (2) referentes às condições "antes" e "depois" do ajuste.

\begin{tabular}{l|c|c|c}
\hline \multicolumn{1}{c|}{ Modelo 3A-P (2) } & Sig & Eta Quadrado Parcial & Poder Observado \\
\hline Teste de Levene & $\mathbf{0 , 9 6 1}$ & & \\
\hline Assertividade do modelo (R-Sqr) & $\mathbf{0 , 0 0 7}$ & 0,143 & 0,932 \\
\hline Intercepto & $\mathbf{0 , 0 0 0}$ & 0,243 & 1,000 \\
\hline LnR_RSE_Voluntario & 0,115 & 0,018 & 0,350 \\
\hline Ano & $\mathbf{0 , 0 3 0}$ & 0,076 & 0,747 \\
\hline Setor & $\mathbf{0 , 0 4 2}$ & 0,059 & 0,665 \\
\hline
\end{tabular}




\begin{tabular}{|c|c|c|c|}
\hline Modelo 3B-P & Sig & Eta Quadrado Parcial & Poder Observado \\
\hline Teste de Levene & $\mathbf{0 , 5 2 2}$ & & \\
\hline Assertividade do modelo (R Sqr) & $\mathbf{0 , 0 1 3}$ & 0,294 & 0,978 \\
\hline Intercept & $\mathbf{0 , 0 2 1}$ & 0,051 & 0,644 \\
\hline LnRLV214 & $\mathbf{0 , 0 0 1}$ & 0,108 & 0,938 \\
\hline LnRLV312 & 0,056 & 0,035 & 0,482 \\
\hline LnRLV404 & 0,128 & 0,022 & 0,330 \\
\hline Ano & 0,040 & 0,092 & 0,714 \\
\hline Setor & 0,017 & 0,094 & 0,775 \\
\hline Ano * Setor & 0,774 & 0,073 & 0,366 \\
\hline Modelo 3C-P (não calculado) & Sig & Eta Quadrado Parcial & Poder Observado \\
\hline Modelo 4A-P (1) & Sig & Eta Quadrado Parcial & Poder Observado \\
\hline Teste de Levene & 0,915 & & \\
\hline Assertividade do modelo (R-Sqr) & $\mathbf{0 , 3 1 4}$ & 0,158 & 0,782 \\
\hline Intercepto & 0,000 & 0,168 & 0,999 \\
\hline LnR_RSE_Total & 0,417 & 0,005 & 0,127 \\
\hline Ano & 0,104 & 0,060 & 0,577 \\
\hline Setor & 0,192 & 0,038 & 0,413 \\
\hline Ano * Setor & 0,986 & 0,030 & 0,174 \\
\hline Modelo 4A-P (2) & Sig & Eta Quadrado Parcial & Poder Observado \\
\hline Teste de Levene & 0,961 & & \\
\hline Assertividade do modelo (R-Sqr) & $\mathbf{0 , 0 1 3}$ & 0,132 & 0,903 \\
\hline Intercepto & $\mathbf{0 , 0 0 0}$ & 0,169 & 0,999 \\
\hline LnR_RSE_Total & 0,380 & 0,006 & 0,141 \\
\hline Ano & $\mathbf{0 , 0 3 6}$ & 0,073 & 0,727 \\
\hline Setor & 0,107 & 0,044 & 0,521 \\
\hline Modelo 4B-P (1) & Sig & Eta Quadrado Parcial & Poder Observado \\
\hline Teste de Levene & $\mathbf{0 , 3 9 0}$ & & \\
\hline Assertividade do modelo (R Sqr) & $\mathbf{0 , 1 2 7}$ & 0,232 & 0,894 \\
\hline Intercepto & 0,007 & 0,068 & 0,776 \\
\hline LnRLV213 & 0,036 & 0,042 & 0,560 \\
\hline LnRLV314 & 0,892 & 0,000 & 0,052 \\
\hline LnRLV404 & 0,063 & 0,033 & 0,462 \\
\hline Ano & 0,093 & 0,074 & 0,593 \\
\hline Setor & 0,026 & 0,086 & 0,727 \\
\hline Ano * Setor & $\mathbf{0 , 8 9 8}$ & 0,057 & 0,279 \\
\hline Modelo 4B-P (2) & Sig & Eta Quadrado Parcial & Poder Observado \\
\hline Teste de Levene & 0,500 & & \\
\hline Assertividade do modelo (R Sqr) & $\mathbf{0 , 0 0 7}$ & 0,185 & 0,948 \\
\hline Intercepto & $\mathbf{0 , 0 0 4}$ & 0,069 & 0,826 \\
\hline LnRLV213 & $\mathbf{0 , 0 3 0}$ & 0,040 & 0,588 \\
\hline LnRLV314 & 0,939 & 0,000 & 0,051 \\
\hline LnRLV404 & 0,063 & 0,030 & 0,461 \\
\hline Ano & 0,053 & 0,078 & 0,679 \\
\hline Setor & 0,008 & 0,096 & 0,835 \\
\hline
\end{tabular}




\begin{tabular}{|l|l|l|l|}
\hline Modelo 4C-P (não calculado) & Sig & Eta Quadrado Parcial & Poder Observado \\
\hline
\end{tabular}

\subsection{Resultados completos da análise GLM referente às empresas que operaram com RO positivo, sem homocedasticidade}

Foram considerados os fatores Ano e Setor nos modelos e nenhum deles apresentou homocedasticidade, pois os Sigs dos Testes de Levene tiveram valor abaixo de 5,0\%, como se pode observar nas tabelas que seguem. O objetivo foi deixar registrado os resultados obtidos na investigação, ainda que não úteis aos resultados finais.

\begin{tabular}{|c|c|c|c|}
\hline Modelo 1A-L & Sig & Eta Quadrado Parcial & Poder Observado \\
\hline Teste de Levene & 0,000 & & \\
\hline Assertividade do modelo (R-Sqr) & 0,000 & 0,761 & 1,000 \\
\hline Intercepto & 0,000 & 0,032 & 0,991 \\
\hline LnRSE_Voluntario & 0,000 & 0,702 & 1,000 \\
\hline Ano & 0,667 & 0,004 & 0,197 \\
\hline Setor & 0,047 & 0,017 & 0,696 \\
\hline Ano * Setor & 0,267 & 0,032 & 0,784 \\
\hline Modelo 1B-L & Sig & Eta Quadrado Parcial & Poder Observado \\
\hline Teste de Levene & 0,000 & & \\
\hline Assertividade do modelo (R Sqr) & 0,000 & 0,780 & 1,000 \\
\hline Intercepto & 0,000 & 0,064 & 1,000 \\
\hline LnV214 & 0,000 & 0,471 & 1,000 \\
\hline LnV312 & 0,000 & 0,030 & 0,988 \\
\hline LnV404 & 0,424 & 0,001 & 0,126 \\
\hline Ano & 0,779 & 0,003 & 0,154 \\
\hline Setor & 0,023 & 0,020 & 0,777 \\
\hline Ano $*$ Setor & 0,161 & 0,037 & 0,845 \\
\hline
\end{tabular}




\begin{tabular}{|c|c|c|c|}
\hline Modelo 1C-L & Sig & Eta Quadrado Parcial & Poder Observado \\
\hline Teste de Levene & 0,000 & & \\
\hline Assertividade do modelo (R-Sqr) & 0,000 & 0,799 & 1,000 \\
\hline Intercept & 0,000 & 0,488 & 1,000 \\
\hline LnV201 & 0,200 & 0,003 & 0,249 \\
\hline LnV202 & n.a. & n.a. & n.a. \\
\hline LnV203 & 0,000 & 0,080 & 1,000 \\
\hline LnV204 & 0,000 & 0,049 & 1,000 \\
\hline LnV205 & 0,150 & 0,004 & 0,302 \\
\hline LnV206 & 0,029 & 0,009 & 0,591 \\
\hline LnV207 & 0,318 & 0,002 & 0,169 \\
\hline LnV208 & 0,460 & 0,001 & 0,114 \\
\hline LnV209 & 0,227 & 0,003 & 0,226 \\
\hline LnV210 & 0,000 & 0,119 & 1,000 \\
\hline LnV211 & 0,086 & 0,005 & 0,403 \\
\hline LnV301 & 0,023 & 0,009 & 0,626 \\
\hline LnV302 & 0,000 & 0,038 & 0,996 \\
\hline LnV303 & 0,916 & 0,000 & 0,051 \\
\hline LnV304 & 0,794 & 0,000 & 0,058 \\
\hline LnV305 & 0,247 & 0,002 & 0,212 \\
\hline LnV306 & 0,703 & 0,000 & 0,067 \\
\hline LnV307 & 0,177 & 0,003 & 0,271 \\
\hline LnV308 & 0,203 & 0,003 & 0,246 \\
\hline LnV309 & 0,056 & 0,007 & 0,481 \\
\hline LnV310 & 0,005 & 0,014 & 0,797 \\
\hline LnV311 & 0,000 & 0,089 & 1,000 \\
\hline LnV313 & n.a. & n.a. & n.a. \\
\hline LnV401 & 0,363 & 0,002 & 0,149 \\
\hline LnV402 & 0,000 & 0,026 & 0,970 \\
\hline LnV403 & 0,039 & 0,008 & 0,543 \\
\hline Ano & 0,512 & 0,006 & 0,264 \\
\hline Setor & 0,015 & 0,022 & 0,814 \\
\hline Ano * Setor & 0,210 & 0,036 & 0,815 \\
\hline Modelo 2A-L & Sig & Eta Quadrado Parcial & Poder Observado \\
\hline Teste de Levene & 0,010 & & \\
\hline Assertividade do modelo (R-Sqr) & 0,000 & 0,756 & 1,000 \\
\hline Intercepto & 0,669 & 0,000 & 0,071 \\
\hline LnRSE_Total & 0,000 & 0,696 & 1,000 \\
\hline Ano & 0,453 & 0,006 & 0,293 \\
\hline Setor & 0,000 & 0,039 & 0,983 \\
\hline Ano $*$ Setor & 0,621 & 0,023 & 0,598 \\
\hline
\end{tabular}




\begin{tabular}{|c|c|c|c|}
\hline Modelo 2B-L & Sig & Eta Quadrado Parcial & Poder Observado \\
\hline Teste de Levene & 0,001 & & \\
\hline Assertividade do modelo (R Sqr) & 0,000 & 0,758 & 1,000 \\
\hline Intercepto & 0,151 & 0,004 & 0,300 \\
\hline LnV213 & 0,000 & 0,410 & 1,000 \\
\hline LnV314 & 0,001 & 0,019 & 0,910 \\
\hline LnV404 & 0,074 & 0,006 & 0,432 \\
\hline Ano & 0,573 & 0,005 & 0,236 \\
\hline Setor & 0,084 & 0,014 & 0,616 \\
\hline Ano * Setor & 0,286 & 0,032 & 0,774 \\
\hline Modelo 2C-L & Sig & Eta Quadrado Parcial & Poder Observado \\
\hline Teste de Levene & 0,000 & & \\
\hline Assertividade do modelo (R-Sqr) & 0,000 & 0,808 & 1,000 \\
\hline Intercept & 0,000 & 0,361 & 1,000 \\
\hline LnV201 & 0,430 & 0,001 & 0,124 \\
\hline LnV202 & 0,000 & 0,038 & 0,996 \\
\hline LnV203 & 0,000 & 0,080 & 1,000 \\
\hline LnV204 & 0,000 & 0,034 & 0,992 \\
\hline LnV205 & 0,098 & 0,005 & 0,380 \\
\hline LnV206 & 0,029 & 0,009 & 0,590 \\
\hline LnV207 & 0,298 & 0,002 & 0,180 \\
\hline LnV208 & 0,631 & 0,000 & 0,077 \\
\hline LnV209 & 0,089 & 0,005 & 0,399 \\
\hline LnV210 & 0,000 & 0,114 & 1,000 \\
\hline LnV211 & 0,580 & 0,001 & 0,086 \\
\hline LnV301 & 0,020 & 0,010 & 0,642 \\
\hline LnV302 & 0,000 & 0,035 & 0,993 \\
\hline LnV303 & 0,992 & 0,000 & 0,050 \\
\hline LnV304 & 0,848 & 0,000 & 0,054 \\
\hline LnV305 & 0,157 & 0,004 & 0,293 \\
\hline LnV306 & 0,837 & 0,000 & 0,055 \\
\hline LnV307 & 0,387 & 0,001 & 0,139 \\
\hline LnV308 & 0,115 & 0,005 & 0,351 \\
\hline LnV309 & 0,050 & 0,007 & 0,499 \\
\hline LnV310 & 0,024 & 0,009 & 0,618 \\
\hline LnV311 & 0,000 & 0,073 & 1,000 \\
\hline LnV313 & 0,229 & 0,003 & 0,225 \\
\hline LnV401 & 0,750 & 0,000 & 0,062 \\
\hline LnV402 & 0,000 & 0,029 & 0,981 \\
\hline LnV403 & 0,180 & 0,003 & 0,268 \\
\hline Ano & 0,489 & 0,006 & 0,274 \\
\hline Setor & 0,025 & 0,020 & 0,769 \\
\hline Ano * Setor & 0,142 & 0,039 & 0,856 \\
\hline
\end{tabular}




\begin{tabular}{l|c|c|c}
\hline \multicolumn{1}{c|}{ Modelo 3A-L } & Sig & Eta Quadrado Parcial & Poder Observado \\
\hline Teste de Levene & 0,005 & & \\
\hline Assertividade do modelo (R-Sqr) & 0,000 & 0,120 & 1,000 \\
\hline Intercepto & 0,000 & 0,328 & 1,000 \\
\hline LnR_RSE_Voluntario & 0,000 & 0,027 & 0,988 \\
\hline Ano & 0,177 & 0,010 & 0,491 \\
\hline Setor & 0,000 & 0,052 & 0,999 \\
\hline Ano * Setor & 0,334 & 0,027 & 0,750 \\
\hline
\end{tabular}

\begin{tabular}{l|c|c|c}
\hline \multicolumn{1}{c|}{ Modelo 3B-L } & Sig & Eta Quadrado Parcial & Poder Observado \\
\hline Teste de Levene & 0,004 & & \\
\hline Assertividade do modelo (R Sqr) & 0,000 & 0,120 & 1,000 \\
\hline Intercept & 0,000 & 0,311 & 1,000 \\
\hline LnRLV214 & 0,003 & 0,015 & 0,838 \\
\hline LnRLV312 & 0,072 & 0,006 & 0,436 \\
\hline LnRLV404 & 0,146 & 0,004 & 0,307 \\
\hline Ano & 0,821 & 0,003 & 0,139 \\
\hline Setor & 0,001 & 0,034 & 0,963 \\
\hline Ano * Setor & 0,314 & 0,031 & 0,759 \\
\hline
\end{tabular}




\begin{tabular}{|c|c|c|c|}
\hline Modelo 3C-L & Sig & Eta Quadrado Parcial & Poder Observado \\
\hline Teste de Levene & 0,000 & & \\
\hline Assertividade do modelo (R Sqr) & 0,000 & 0,243 & 1,000 \\
\hline Intercepto & 0,000 & 0,605 & 1,000 \\
\hline LnRLV201 & 0,055 & 0,007 & 0,485 \\
\hline LnRLV202 & n.a. & n.a. & n.a. \\
\hline LnRLV203 & 0,000 & 0,038 & 0,996 \\
\hline LnRLV204 & 0,510 & 0,001 & 0,101 \\
\hline LnRLV205 & 0,149 & 0,004 & 0,303 \\
\hline LnRLV206 & 0,369 & 0,001 & 0,146 \\
\hline LnRLV207 & 0,263 & 0,002 & 0,201 \\
\hline LnRLV208 & 0,562 & 0,001 & 0,089 \\
\hline LnRLV209 & 0,006 & 0,014 & 0,791 \\
\hline LnRLV210 & 0,007 & 0,013 & 0,775 \\
\hline LnRLV211 & 0,856 & 0,000 & 0,054 \\
\hline LnRLV301 & 0,235 & 0,003 & 0,221 \\
\hline LnRLV302 & 0,013 & 0,011 & 0,705 \\
\hline LnRLV303 & 0,602 & 0,000 & 0,082 \\
\hline LnRLV304 & 0,029 & 0,009 & 0,589 \\
\hline LnRLV305 & 0,015 & 0,011 & 0,681 \\
\hline LnRLV306 & 0,455 & 0,001 & 0,116 \\
\hline LnRLV307 & 0,959 & 0,000 & 0,050 \\
\hline LnRLV308 & 0,174 & 0,003 & 0,274 \\
\hline LnRLV309 & 0,149 & 0,004 & 0,303 \\
\hline LnRLV310 & 0,028 & 0,009 & 0,595 \\
\hline LnRLV311 & 0,000 & 0,027 & 0,972 \\
\hline LnRLV313 & n.a. & n.a. & n.a. \\
\hline LnRLV401 & 0,598 & 0,001 & 0,082 \\
\hline LnRLV402 & 0,002 & 0,017 & 0,860 \\
\hline LnRLV403 & 0,958 & 0,000 & 0,050 \\
\hline Ano & 0,829 & 0,003 & 0,136 \\
\hline Setor & 0,046 & 0,018 & 0,699 \\
\hline Ano * Setor & 0,189 & 0,037 & 0,827 \\
\hline Modelo 4A-L & Sig & Eta Quadrado Parcial & Poder Observado \\
\hline Teste de Levene & 0,005 & & \\
\hline Assertividade do modelo (R-Sqr) & 0,000 & 0,102 & 1,000 \\
\hline Intercepto & 0,000 & 0,273 & 1,000 \\
\hline LnR_RSE_Total & 0,028 & 0,008 & 0,595 \\
\hline Ano & 0,166 & 0,010 & 0,503 \\
\hline Setor & 0,000 & 0,054 & 0,999 \\
\hline Ano $*$ Setor & 0,425 & 0,025 & 0,703 \\
\hline
\end{tabular}




\begin{tabular}{|c|c|c|c|}
\hline Modelo 4B-L & Sig & Eta Quadrado Parcial & Poder Observado \\
\hline Teste de Levene & 0,004 & & \\
\hline Assertividade do modelo (R Sqr) & 0,000 & 0,103 & 1,000 \\
\hline Intercepto & 0,000 & 0,323 & 1,000 \\
\hline LnRLV213 & 0,279 & 0,002 & 0,191 \\
\hline LnRLV314 & 0,606 & 0,000 & 0,081 \\
\hline LnRLV404 & 0,023 & 0,009 & 0,625 \\
\hline Ano & 0,819 & 0,003 & 0,139 \\
\hline Setor & 0,000 & 0,042 & 0,989 \\
\hline Ano * Setor & 0,396 & 0,029 & 0,716 \\
\hline Modelo 4C-L & Sig & Eta Quadrado Parcial & Poder Observado \\
\hline Teste de Levene & 0,000 & & \\
\hline Assertividade do modelo (R Sqr) & 0,000 & 0,245 & 1,000 \\
\hline Intercepto & 0,000 & 0,548 & 1,000 \\
\hline LnRLV201 & 0,076 & 0,006 & 0,426 \\
\hline LnRLV202 & 0,246 & 0,002 & 0,213 \\
\hline LnRLV203 & 0,000 & 0,039 & 0,997 \\
\hline LnRLV204 & 0,559 & 0,001 & 0,090 \\
\hline LnRLV205 & 0,143 & 0,004 & 0,310 \\
\hline LnRLV206 & 0,367 & 0,001 & 0,147 \\
\hline LnRLV207 & 0,256 & 0,002 & 0,206 \\
\hline LnRLV208 & 0,666 & 0,000 & 0,072 \\
\hline LnRLV209 & 0,004 & 0,015 & 0,814 \\
\hline LnRLV210 & 0,006 & 0,014 & 0,790 \\
\hline LnRLV211 & 0,731 & 0,000 & 0,064 \\
\hline LnRLV301 & 0,227 & 0,003 & 0,226 \\
\hline LnRLV302 & 0,015 & 0,011 & 0,684 \\
\hline LnRLV303 & 0,575 & 0,001 & 0,087 \\
\hline LnRLV304 & 0,036 & 0,008 & 0,557 \\
\hline LnRLV305 & 0,016 & 0,011 & 0,673 \\
\hline LnRLV306 & 0,472 & 0,001 & 0,111 \\
\hline LnRLV307 & 0,966 & 0,000 & 0,050 \\
\hline LnRLV308 & 0,176 & 0,003 & 0,273 \\
\hline LnRLV309 & 0,143 & 0,004 & 0,310 \\
\hline LnRLV310 & 0,033 & 0,008 & 0,569 \\
\hline LnRLV311 & 0,000 & 0,025 & 0,962 \\
\hline LnRLV313 & 0,914 & 0,000 & 0,051 \\
\hline LnRLV401 & 0,665 & 0,000 & 0,072 \\
\hline LnRLV402 & 0,002 & 0,017 & 0,868 \\
\hline LnRLV403 & 0,878 & 0,000 & 0,053 \\
\hline Ano & 0,817 & 0,003 & 0,140 \\
\hline Setor & 0,051 & 0,017 & 0,688 \\
\hline Ano $*$ Setor & 0,176 & 0,038 & 0,835 \\
\hline
\end{tabular}




\title{
7.8 Resultados completos da análise GLM referente às empresas que operaram com RO
}

\author{
positivo, com homocedasticidade
}

Tendo em vista a heterocedasticidade dos modelos utilizados pela sub-amostra das empresas com RO positivo e que incorporavam os fatores Ano e Setor, as tabelas que seguem são o resultado da segmentação do modelo pelo fator Setor, resultando em homocedasticidade, conforme detalhado no item 4.3 (Análise dos modelos referentes às empresas que operaram com RO positivo).

\begin{tabular}{|c|c|c|c|c|c|c|c|c|c|c|c|c|c|c|c|}
\hline \multirow{2}{*}{ Modelo 1A-L } & \multicolumn{3}{|c|}{ IND } & \multicolumn{3}{|c|}{ SRV } & \multicolumn{3}{|c|}{ ELE } & \multicolumn{3}{|c|}{ AGI } & \multicolumn{3}{|c|}{ FIN } \\
\hline & Sig & EQP & PO & Sig & EQP & PO & Sig & EQP & PO & Sig & EQP & PO & Sig & EQP & PO \\
\hline $\begin{array}{l}\text { Teste de } \\
\text { Levene }\end{array}$ & 0,692 & & & 0,717 & & & 0,749 & & & 0,300 & & & 0,150 & & \\
\hline $\begin{array}{l}\text { Assertividade } \\
\text { do modelo } \\
\text { (R-Sqr) } \\
\end{array}$ & 0,000 & 0,792 & 1,000 & 0,000 & 0,695 & 1,000 & 0,000 & 0,602 & 1,000 & 0,000 & 0,735 & 1,000 & 0,000 & 0,825 & 1,000 \\
\hline Intercepto & 0,052 & 0,018 & 0,496 & 0,184 & 0,013 & 0,263 & 0,000 & 0,171 & 0,998 & 0,698 & 0,002 & 0,067 & 0,005 & 0,242 & 0,837 \\
\hline $\begin{array}{l}\text { LnRSE_- } \\
\text { Voluntario }\end{array}$ & 0,000 & 0,789 & 1,000 & 0,000 & 0,683 & 1,000 & 0,000 & 0,561 & 1,000 & 0,000 & 0,728 & 1,000 & 0,000 & 0,815 & 1,000 \\
\hline Ano & 0,607 & 0,013 & 0,218 & 0,439 & 0,028 & 0,294 & 0,187 & 0,053 & 0,472 & 0,017 & 0,119 & 0,776 & 0,234 & 0,135 & 0,355 \\
\hline \multirow{2}{*}{ Modelo 1B-L } & \multicolumn{3}{|c|}{ IND } & \multicolumn{3}{|c|}{ SRV } & \multicolumn{3}{|c|}{ ELE } & \multicolumn{3}{|c|}{ AGI } & \multicolumn{3}{|c|}{ FIN } \\
\hline & Sig & EQP & PO & Sig & EQP & PO & Sig & EQP & PO & Sig & EQP & PO & Sig & EQP & PO \\
\hline $\begin{array}{l}\text { Teste de } \\
\text { Levene }\end{array}$ & 0,925 & & & 0,713 & & & 0,620 & & & 0,460 & & & 0,250 & & \\
\hline $\begin{array}{l}\text { Assertividade } \\
\text { do modelo } \\
\text { (R Sqr) }\end{array}$ & 0,000 & 0,810 & 1,000 & 0,000 & 0,711 & 1,000 & 0,000 & 0,677 & 1,000 & ,, 000 & 0,753 & 1,000 & 0,000 & 0,815 & 1,000 \\
\hline Intercepto & 0,016 & 0,028 & 0,680 & 0,014 & 0,045 & 0,693 & 0,000 & 0,262 & 1,000 & 0,148 & 0,027 & 0,303 & 0,004 & 0,267 & 0,856 \\
\hline LnV214 & 0,000 & 0,500 & 1,000 & 0,000 & 0,423 & 1,000 & 0,000 & 0,288 & 1,000 & $\mathbf{0 , 0 0 0}$ & 0,449 & 1,000 & 0,000 & 0,572 & 1,000 \\
\hline LnV312 & 0,301 & 0,005 & 0,178 & 0,003 & 0,064 & 0,845 & 0,009 & 0,060 & 0,751 & 0,208 & 0,020 & 0,241 & 0,319 & 0,037 & 0,165 \\
\hline LnV404 & 0,428 & 0,003 & 0,124 & 0,895 & 0,000 & 0,052 & 0,844 & 0,000 & 0,054 & 0,104 & 0,034 & 0,369 & 0,485 & 0,018 & 0,105 \\
\hline Ano & 0,622 & 0,013 & 0,212 & 0,485 & 0,026 & 0,270 & 0,288 & 0,044 & 0,385 & ,010 & 0,135 & 0,824 & 0,272 & 0,132 & 0,323 \\
\hline
\end{tabular}




\begin{tabular}{|c|c|c|c|c|c|c|c|c|c|c|c|c|c|c|c|}
\hline \multirow{2}{*}{ Modelo 1C-L } & \multicolumn{3}{|c|}{ IND } & \multicolumn{3}{|c|}{ SRV } & \multicolumn{3}{|c|}{ ELE } & \multicolumn{3}{|c|}{ AGI } & \multicolumn{3}{|c|}{ FIN } \\
\hline & Sig & EQP & PO & Sig & EQP & PO & Sig & EQP & PO & Sig & EQP & PO & Sig & EQP & PO \\
\hline $\begin{array}{l}\text { Teste de } \\
\text { Levene }\end{array}$ & 0,365 & & & 0,910 & & & 0,238 & & & 0,358 & & & 942 & & \\
\hline $\begin{array}{l}\text { Assertividade } \\
\text { do modelo } \\
\text { (R-Sqr) }\end{array}$ & 0,000 & 0,828 & 1,000 & 0,000 & 0,808 & 1,000 & 0,000 & 0,745 & 1,000 & 0,000 & 0,868 & 1,000 & 0,000 & 0,972 &, 000 \\
\hline Intercept & 0,000 & 0,511 & 1,000 & 0,000 & 0,361 & 1,000 & 0,000 & 0,394 & 1,000 & 0,000 & 0,602 & 1,000 & 0,003 & 0,639 & 0,943 \\
\hline LnV201 & 0,038 & 0,023 & 0,546 & 0,430 & 0,001 & 0,124 & 0,625 & 0,003 & 0,077 & 0,550 & 0,006 & 0,091 & 0,038 & 0,395 & 0,580 \\
\hline LnV202 & n.a. & n.a. & n.a. & n.a. & n.a. & n.a. & n.a. & n.a. & n.a. & n.a. & n.a. & n.a. & n.a. & n.a. & n.a. \\
\hline LnV203 & 0,000 & 0,104 & 0,995 & 0,000 & 0,038 & 0,996 & 0,001 & 0,121 & 0,933 & 0,000 & 0,220 & 0,980 & 0,546 & 0,042 & 0,087 \\
\hline LnV204 & 0,221 & 0,008 & 0,231 & 0,000 & 0,080 & 1,000 & 0,156 & 0,023 & 0,294 & 0,370 & 0,014 & 0,144 & 0,064 & 0,332 & 0,471 \\
\hline LnV205 & 0,694 & 0,001 & 0,068 & 0,000 & 0,034 & 0,992 & 0,993 & 0,000 & 0,050 & 0,869 & 0,000 & 0,053 & 0,085 & 0,294 & 0,408 \\
\hline LnV206 & 0,033 & 0,025 & 0,571 & 0,098 & 0,005 & 0,380 & 0,917 & 0,000 & 0,051 & 0,815 & 0,001 & 0,056 & 0,614 & 0,030 & 0,076 \\
\hline LnV207 & 0,256 & 0,007 & 0,205 & 0,029 & 0,009 & 0,590 & 0,902 & 0,000 & 0,052 & 0,051 & 0,063 & 0,499 & 0,600 & 0,032 & 0,078 \\
\hline LnV208 & 0,732 & 0,001 & 0,063 & 0,298 & 0,002 & 0,180 & 0,368 & 0,009 & 0,146 & 0,374 & 0,013 & 0,143 & 0,869 & 0,003 & 0,053 \\
\hline LnV209 & 0,034 & 0,024 & 0,565 & 0,631 & 0,000 & 0,077 & 0,061 & 0,039 & 0,466 & 0,006 & 0,121 & 0,801 & 0,328 & 0,106 & 0,153 \\
\hline LnV210 & 0,000 & 0,152 & 1,000 & 0,089 & 0,005 & 0,399 & 0,038 & 0,047 & 0,548 & 0,000 & 0,208 & 0,972 & 0,273 & 0,131 & 0,182 \\
\hline LnV211 & 0,032 & 0,025 & 0,573 & 0,000 & 0,114 & 1,000 & 0,261 & 0,014 & 0,201 & 0,441 & 0,010 & 0,119 & 0,860 & 0,004 & 0,053 \\
\hline LnV301 & 0,043 & 0,022 & 0,528 & 0,580 & 0,001 & 0,086 & 0,969 & 0,000 & 0,050 & 0,917 & 0,000 & 0,051 & 0,836 & 0,005 & 0,054 \\
\hline LnV302 & 0,020 & 0,029 & 0,644 & 0,020 & 0,010 & 0,642 & 0,240 & 0,016 & 0,216 & 0,851 & 0,001 & 0,054 & 0,362 & 0,093 & 0,138 \\
\hline LnV303 & 0,222 & 0,008 & 0,230 & 0,000 & 0,035 & 0,993 & 0,397 & 0,008 & 0,134 & 0,652 & 0,003 & 0,073 & 0,876 & 0,003 & 0,052 \\
\hline LnV304 & 0,003 & 0,046 & 0,840 & 0,992 & 0,000 & 0,050 & & 0,000 & & $\dot{.}$ & 0,000 & & & 0,000 & \\
\hline LnV305 & 0,779 & 0,000 & 0,059 & 0,848 & 0,000 & 0,054 & 0,685 & 0,002 & 0,069 & 0,968 & 0,000 & 0,050 & 0,531 & 0,045 & 0,090 \\
\hline LnV306 & 0,111 & 0,014 & 0,357 & 0,157 & 0,004 & 0,293 & 0,595 & 0,003 & 0,083 & . & 0,000 & . & 0,282 & 0,127 & 0,176 \\
\hline LnV307 & 0,510 & 0,002 & 0,101 & 0,837 & 0,000 & 0,055 & . & 0,000 & & $\cdot$ & 0,000 & . &. & 0,000 & \\
\hline $\operatorname{Ln}$ & 0,961 & 0,000 & 0,050 & 0,387 & 0,001 & 0,139 & 0,119 & 0,027 & 0,344 & 0,117 & 0,041 & 0,347 & 0,040 & 0,390 & 0,572 \\
\hline LnV309 & 0,941 & 0,000 & 0,051 & 0,115 & 0,005 & 0,351 & 0,544 & 0,004 & 0,093 & 0,248 & 0,023 & 0,209 & 0,233 & 0,153 & 0,208 \\
\hline LnV310 & 0,137 & 0,012 & 0,318 & 0,050 & 0,007 & 0,499 & 0,176 & 0,021 & 0,271 & 0,133 & 0,038 & 0,322 & 0,440 & 0,068 & 0,112 \\
\hline LnV311 & 0,000 & 0,111 & 0,997 & 0,024 & 0,009 & 0,618 & 0,029 & 0,053 & 0,595 & 0,709 & 0,002 & 0,066 & . & 0,000 & $\cdot$ \\
\hline LnV313 & n.a. & n.a. & n.a. & n.a. & n.a. & n.a. & n.a. & n.a. & n.a. & n.a. & n.a. & n.a. & n.a. & n.a. & n.a. \\
\hline LnV401 & 0,050 & 0,021 & 0,500 & 0,000 & 0,073 & 1,000 & 0,221 & 0,017 & 0,230 & 0,001 & 0,167 & 0,923 & 0,692 & 0,018 & 0,066 \\
\hline LnV402 & 0,002 & 0,050 & 0,866 & 0,229 & 0,003 & 0,225 & 0,501 & 0,005 & 0,103 & 0,595 & 0,005 & 0,082 & 0,371 & 0,090 & 0,135 \\
\hline LnV403 & 0,002 & 0,049 & 0,863 & 0,750 & 0,000 & 0,062 & 0,195 & 0,019 & 0,252 & 0,843 & 0,001 & 0,054 & 0,692 & 0,018 & 0,066 \\
\hline Ano & 0,903 & 0,006 & 0,106 & 0,000 & 0,029 & 0,981 & 0,255 & 0,057 & 0,407 & 0,017 & 0,157 & 0,774 & 0,477 & 0,231 & $p, 177$ \\
\hline \multirow{2}{*}{ Modelo 2A-L } & \multicolumn{3}{|c|}{ IND } & \multicolumn{3}{|c|}{ SRV } & \multicolumn{3}{|c|}{ ELE } & \multicolumn{3}{|c|}{ AGI } & \multicolumn{3}{|c|}{ FIN } \\
\hline & Sig & EQP & $\mathbf{P O}$ & Sig & EQP & PO & Sig & EQP & PO & Sig & EQP & PO & Sig & EQP & PO \\
\hline $\begin{array}{l}\text { Teste de } \\
\text { Levene }\end{array}$ & 633 & & & 0,267 & & & 0,990 & & & 0,743 & & & 0,281 & & \\
\hline $\begin{array}{l}\text { Assertividade } \\
\text { do modelo } \\
\text { (R-Sqr) }\end{array}$ & 0,000 & 0,760 & 1,000 & 0,000 & 0,725 & 1,000 & 0,000 & 0,567 & 1,000 & 0,000 & 0,686 & 1,000 & 0,000 & 0,825 & 1,000 \\
\hline Intercepto & 0,229 & 0,007 & 0,225 & 0,442 & 0,004 & 0,119 & 0,290 & 0,010 & 0,184 & 0,539 & 0,005 & 0,094 & 0,011 & 0,201 & 0,742 \\
\hline LnRSE_Total & 0,000 & 0,755 & 1,000 & 0,000 & 0,715 & 1,000 & 0,000 & 0,524 & 1,000 & 0,000 & 0,677 & 1,000 & 0,000 & 0,814 & 1,000 \\
\hline Ano & 0,970 & 0,003 & 0,078 & 0,868 & 0,009 & 0,119 & 0,211 & 0,050 & 0,448 & 0,061 & 0,087 & 0,609 & 0,115 & 0,182 & 0,492 \\
\hline
\end{tabular}




\begin{tabular}{|c|c|c|c|c|c|c|c|c|c|c|c|c|c|c|c|}
\hline \multirow{2}{*}{ Modelo 2B-L } & \multicolumn{3}{|c|}{ IND } & \multicolumn{3}{|c|}{ SRV } & \multicolumn{3}{|c|}{ ELE } & \multicolumn{3}{|c|}{ AGI } & \multicolumn{3}{|c|}{ FIN } \\
\hline & Sig & EQP & PO & Sig & EQP & PO & Sig & EQP & PO & Sig & EQP & PO & Sig & EQP & PO \\
\hline Levene & 993 & & & 644 & & & 680 & & & ,754 & & & 0,101 & & \\
\hline $\begin{array}{l}\text { Assertividade } \\
\text { do modelo } \\
\text { (R Sqr) }\end{array}$ & 0,000 & 0,795 & 1,000 & 0,000 & 0,670 & 1,000 & 0,000 & 0,659 & 1,000 & 0,000 & 0,713 & 1,000 & 0,000 & 0,824 & 1,000 \\
\hline Interc & 425 & 0,003 & 125 & 0,653 & 0,002 & 0,073 & 0,014 & 0,053 & 0,696 & 0,451 & 0,007 & 0,116 & 0,028 & 0,151 & 0,609 \\
\hline LnV213 & 000 & 0,444 & 1,000 & 0,000 & 0,272 & 1,000 & 0,000 & 0,327 & 1,000 & 0,000 & 0,445 & 1,000 & 0,000 & 0,661 & 1,000 \\
\hline LnV314 & 110 & 0,013 & 0,358 & 0,010 & 0,050 & 0,738 & 0,244 & 0,012 & 0,213 & 0,847 & 0,000 & 0,054 & 0,518 & 0,014 & 0,097 \\
\hline LnV404 & 0,132 & 0,011 & 0,324 & 0,798 & 0,000 & 0,057 & 0,994 & 0,000 & 0,050 & 0,013 & 0,077 & 0,714 & 0,393 & 0,024 & 0,134 \\
\hline Ano & 877 & 0,006 & 0,117 & 0,719 & 0,016 & 0,173 & 0,196 & 0,053 & 0,463 & 0,007 & 0,142 & 0,848 & 0,348 & 0,134 & 0,319 \\
\hline \multirow{2}{*}{ Modelo 2C-L } & \multicolumn{3}{|c|}{ IND } & \multicolumn{3}{|c|}{ SRV } & \multicolumn{3}{|c|}{ ELE } & \multicolumn{3}{|c|}{ AGI } & \multicolumn{3}{|c|}{ FIN } \\
\hline & Sig & EQP & PO & Sig & EQP & PO & Sig & EQP & PO & Sig & EQP & PO & Sig & EQP & PO \\
\hline & 0,295 & & & 0,871 & & & 0,222 & & & 0,209 & & & ,601 & & \\
\hline elo & 0,000 & 0,854 & 1,000 & 0,000 & 0,838 & 1,000 & 0,000 & 0,748 & 1,000 & 0,000 & 0,875 & 1,000 & 0,000 & 0,985 & 1,000 \\
\hline & & 0,252 & 1,000 & 0,000 & 0,296 & 1,000 & 0,000 & 0,316 & 1,000 & 0,000 & 0,593 & 1,000 & 0,479 & 0,074 & 0,100 \\
\hline & 08 & 0,014 & 0,361 & 0,300 & 0,010 & 0,178 & 0,835 & 0,000 & 0,055 & 0,976 & 0,000 & 0,050 & 0,501 & 0,067 & 0,095 \\
\hline & 0,000 & 0,141 & 1,000 & 0,316 & 0,009 & 0,170 & 0,301 & 0,012 & 0,177 & 0,079 & 0,053 & 0,420 & 0,147 & 0,276 & 0,292 \\
\hline & 0,000 & 0,102 & 0,994 & 0,076 & 0,029 & 0,427 & & 71 & 0,720 & 0,000 & & 0,972 & 91 & 57 & 0,168 \\
\hline & 314 & 0,006 & 0,171 & 0,000 & 0,116 & 0,963 & 0,120 & 0,028 & 0,342 & 0,183 & 0,031 & 0,263 & 0,845 & 0,006 & 0,054 \\
\hline & 992 & 0,000 & 0,050 & 0,967 & 0,000 & 0,050 & 0,902 & 0,000 & 0,052 & 0,864 & 0,001 & 0,053 & 0,024 & 0,538 & 0,690 \\
\hline & 246 & 0,007 & 0,212 & 0,343 & 0,008 & 0,157 & 0,715 & 0,002 & 0,065 & 0,923 & 0,000 & 0,051 & 0,328 & 0,136 & 0,150 \\
\hline & 463 & 0,003 & 0,113 & 0,024 & 0,046 & 0,624 & 0,970 & 0,000 & 0,050 & 0,048 & 0,067 & 0,510 & 0,597 & 0,042 & 0,077 \\
\hline & & 0,000 & 0,051 & 0,973 & 0,000 & 0,050 & 0,501 & 0,005 & 0,103 & 0,224 & 0,026 & 27 & 25 & 01 & 0,051 \\
\hline & 01 & 0,062 & 0,928 & 0,796 & 0,001 & 0,058 & 0,070 & 0,037 & 0,443 & 0,008 & 0,117 & 0,769 & 303 & 0,150 & 0,162 \\
\hline & & 0,122 & 0,999 & 0,031 & 0,042 & 0,581 & 0,032 & 0,052 & 0,577 & 0,000 & 0,218 & 0,975 & 383 & 110 & 0,128 \\
\hline 11 & 729 & 0,001 & 0,064 & 0,317 & 0,009 & 0,169 & 0,243 & 0,016 & 0,214 & 0,284 & 0,020 & 0,186 & 0,411 & 0,098 & 0,118 \\
\hline & 75 & 0,010 & 0,273 & 0,587 & 0,003 & 0,084 & 0,894 & 0,000 & 0,052 & 0,945 & 0,000 & 0,051 & 0,769 & 0,013 & 0,058 \\
\hline & & 0,029 & 0,643 & 0,002 & 0,084 & 0,880 & 0,196 & 0,019 & 0,252 & 0,569 & 0,006 & 0,087 & 0,990 & 0,000 & 0,050 \\
\hline & 91 & 0,004 & 0,137 & 0,875 & 0,000 & 0,053 & 0,440 & 0,007 & 0,120 & 0,555 & 0,006 & 0,090 & 0,259 & 0,177 & 0,187 \\
\hline & & 0,042 & 0,799 & & 0,000 & & & 0,000 & & - & 0,000 & & & 0,000 & \\
\hline & 24 & 0,000 & 0,051 & 0,006 & 0,068 & 0,797 & 0,859 & 0,000 & 0,054 & 0,697 & 0,003 & 0,067 & 0,751 & 0,015 & 0,060 \\
\hline & 68 & 0,018 & 0,447 & 0,108 & 0,024 & 0,362 & 0,579 & 0,004 & 0,085 & . & 0,000 & 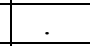 & 0,097 & 0,344 & 0,381 \\
\hline LnV307 & 319 & 0,000 & 0,056 & 0,208 & 0,015 & 0,242 & - & 0,000 & & . & 0,000 & & . & 0,000 & \\
\hline 308 & 714 & 0,001 & 0,065 & 0,822 & 0,000 & 0,056 & 0,129 & 0,026 & 0,329 & 0,079 & 0,053 & 0,421 & 0,415 & 0,097 & 0,117 \\
\hline & & 0,000 & 0,051 & 0,590 & 0,003 & 0,083 & 0,431 & 0,007 & 0,123 & 0,284 & 0,020 & 0,186 & 0,931 & 0,001 & 0,051 \\
\hline LnV310 & 0,520 & 0,002 & 0,098 & 0,871 & 0,000 & 0,053 & 0,212 & 0,018 & 0,238 & 0,166 & 0,033 & 0,281 & 0,128 & 0,298 & 0,320 \\
\hline & 000 & 0,089 & 0,987 & 0,000 & 0,121 & 0,970 & 0,025 & 0,057 & 0,617 & 0,686 & 0,003 & 0,068 & & 0,000 & \\
\hline & 532 & 0,001 & 0,076 & 0,650 & 0,002 & 0,074 & 0,999 & 0,000 & 0,050 & 0,821 & 0,001 & 0,056 & 0,304 & 0,149 & 0,161 \\
\hline 401 & 0,368 & 0,004 & 0,146 & 0,726 & 0,001 & 0,064 & 0,140 & 0,025 & 0,313 & 0,001 & 0,179 & 0,934 & 0,743 & 0,016 & 0,060 \\
\hline & 0,003 & 0,049 & 0,854 & 0,316 & 0,009 & 0,169 & 0,531 & 0,005 & 0,095 & 0,854 & 0,001 & 0,054 & 0,830 & 0,007 & 0,054 \\
\hline LnV403 & 0,060 & 0,020 & 0,470 & 0,043 & 0,037 & 0,530 & 0,145 & 0,024 & 0,306 & 0,812 & 0,001 & 0,056 & 0,422 & 0,094 & 0,115 \\
\hline Ano & 0,878 & 0,007 & 0,116 & 0,592 & 0,025 & 0,221 & 0,286 & 0,055 & 0,384 & 0,033 & 0,141 & 0,697 & 0,722 & 0,163 & 0,104 \\
\hline
\end{tabular}




\begin{tabular}{|c|c|c|c|c|c|c|c|c|c|c|c|c|c|c|c|}
\hline \multirow{2}{*}{ Modelo 3A-L } & \multicolumn{3}{|c|}{ IND } & \multicolumn{3}{|c|}{ SRV } & \multicolumn{3}{|c|}{ ELE } & \multicolumn{3}{|c|}{ AGI } & \multicolumn{3}{|c|}{ FIN } \\
\hline & Sig & EQP & PO & Sig & EQP & $\mathbf{P O}$ & Sig & EQP & PO & Sig & EQP & PO & Sig & EQP & PO \\
\hline $\begin{array}{l}\text { Teste de } \\
\text { Levene }\end{array}$ & 0,753 & & & 0,180 & & & 0,772 & & & 0,955 & & & 0,267 & & \\
\hline $\begin{array}{l}\text { Assertividade } \\
\text { do modelo } \\
\text { (R-Sqr) }\end{array}$ & 0,085 & 0,043 & 0,656 & 0,100 & 0,057 & 0,629 & 0,419 & 0,037 & 0,349 & 0,006 & 0,147 & 0,885 & 0,000 & 0,753 & 1,000 \\
\hline Intercepto & 0,000 & 0,325 & 1,000 & 0,000 & 0,350 & 1,000 & 0,000 & 0,469 & 1,000 & 0,000 & 0,238 & 0,999 & 0,218 & 0,049 & 0,230 \\
\hline $\begin{array}{l}\text { LnR_RSE_- } \\
\text { Voluntario }\end{array}$ & 0,089 & 0,013 & 0,397 & 0,183 & 0,011 & 0,265 & 0,898 & 0,000 & 0,052 & 0,003 & 0,095 & 0,859 & 0,000 & 0,750 & 1,000 \\
\hline Ano & 0,137 & 0,031 & 0,534 & 0,110 & 0,047 & 0,570 & 0,297 & 0,036 & 0,380 & 0,043 & 0,086 & 0,661 & 0,310 & 0,108 & 0,300 \\
\hline \multirow{2}{*}{ Modelo 3B-L } & \multicolumn{3}{|c|}{ IND } & \multicolumn{3}{|c|}{$\overline{\text { SRV }}$} & \multicolumn{3}{|c|}{ ELE } & \multicolumn{3}{|c|}{$\overline{A G I}$} & \multicolumn{3}{|c|}{ FIN } \\
\hline & Sig & EQP & PO & Sig & EQP & PO & Sig & EQP & PO & Sig & EQP & PO & Sig & EQP & PO \\
\hline $\begin{array}{l}\text { Teste de } \\
\text { Levene }\end{array}$ & 0,906 & & & 0,267 & & & 0,897 & & & 0,378 & & & 0,395 & & \\
\hline $\begin{array}{l}\text { Assertividade } \\
\text { do modelo } \\
\text { (R Sqr) }\end{array}$ & 0,341 & 0,038 & 0,484 & 0,336 & 0,058 & 0,480 & 0,426 & 0,061 & 0,420 & 0,013 & 0,184 & 0,874 & 0,000 & 0,732 & 1,000 \\
\hline Intercepto & 0,000 & 0,314 & 1,000 & 0,000 & 0,417 & 1,000 & 0,000 & 0,305 & 1,000 & 0,000 & 0,276 & 1,000 & 0,155 & 0,073 & 0,292 \\
\hline LnRLV214 & 0,063 & 0,017 & 0,460 & 0,603 & 0,002 & 0,081 & 0,293 & 0,010 & 0,182 & 0,716 & 0,002 & 0,065 & 0,000 & 0,676 & 1,000 \\
\hline LnRLV312 & 0,666 & 0,001 & 0,071 & 0,252 & 0,010 & 0,207 & 0,209 & 0,014 & 0,241 & 0,176 & 0,023 & 0,271 & 0,682 & 0,006 & 0,069 \\
\hline LnRLV404 & 0,662 & 0,001 & 0,072 & 0,217 & 0,012 & 0,234 & 0,533 & 0,004 & 0,095 & 0,053 & 0,047 & 0,493 & 0,564 & 0,012 & 0,087 \\
\hline Ano & 0,461 & 0,018 & 0,285 & 0,406 & 0,030 & 0,312 & 0,455 & 0,032 & 0,284 & 0,029 & 0,108 & 0,712 & 0,370 & 0,108 & 0,261 \\
\hline
\end{tabular}




\begin{tabular}{|c|c|c|c|c|c|c|c|c|c|c|c|c|c|c|c|}
\hline \multirow{2}{*}{ Modelo 3C-L } & \multicolumn{3}{|c|}{ IND } & \multicolumn{3}{|c|}{ SRV } & \multicolumn{3}{|c|}{ ELE } & \multicolumn{3}{|c|}{ AGI } & \multicolumn{3}{|c|}{ FIN } \\
\hline & Sig & EQP & PO & Sig & EQP & PO & Sig & EQP & PO & Sig & EQP & PO & Sig & EQP & PO \\
\hline Levene & 620 & & & 0,360 & & & 0,872 & & & 0,609 & & & 415 & & \\
\hline $\begin{array}{l}\text { Assertividade } \\
\text { do modelo } \\
\text { (R-Sqr) }\end{array}$ & 0,000 & 0,466 & 1,000 & 0,008 & 0,323 & 0,991 & 0,373 & 0,241 & 0,800 & 0,003 & 0,504 & 0,993 & 0,007 & 0,934 & 0,967 \\
\hline Interc & 0,000 & 0,739 & 1,000 & 0,000 & 0,453 & 1,000 & 0,000 & 0,352 & 1,000 & 0,000 & 0,494 & 1,000 & 0,065 & 0,328 & 0,465 \\
\hline LnRLV201 & 0,058 & 0,020 & 0,477 & 0,936 & 0,000 & 0,051 & 0,719 & 0,001 & 0,065 & 0,259 & 0,022 & 0,202 & 0,705 & 0,017 & 0,064 \\
\hline LnRLV202 & n.a. & n.a. & n.a. & n.a. & n.a. & n.a. & n.a. & n.a. & n.a. & n.a. & n.a. & n.a. & n.a. & n.a. & n.a. \\
\hline LnRI & 0,000 & 0,109 & 0,997 & 0,033 & 0,041 & 0,574 & 0,036 & 0,049 & 0,560 & 0,001 & 0,160 & 0,910 & 0,326 & 0,107 & 0,154 \\
\hline LnRLV204 & 0,888 & 0,000 & 0,052 & 0,124 & 0,021 & 0,336 & 0,669 & 0,002 & 0,071 & 0,826 & 0,001 & 0,055 & 0,394 & 0,082 & 0,126 \\
\hline LnR & 0,122 & 0,013 & 0,339 & 0,748 & 0,001 & 0,062 & 0,520 & 0,005 & 0,098 & 0,870 & 0,000 & 0,053 & 0,728 & 0,014 & 0,062 \\
\hline LnRI & 0,000 & 0,067 & 0,950 & 0,831 & 0,000 & 0,055 & 0,861 & 0,000 & 0,053 & 0,604 & 0,005 & 0,081 & 0,624 & 0,028 & 0,074 \\
\hline 207 & 0,476 & 0,003 & 0,109 & 0,041 & 0,037 & 0,534 & 0,386 & 0,008 & 0,138 & 0,214 & 0,026 & 0,235 & 0,737 & 0,013 & 0,061 \\
\hline LnR & 0,372 & 0,004 & 0,145 & 0,837 & 0,000 & 0,055 & 0,541 & 0,004 & 0,093 & 0,361 & 0,014 & 0,148 & 0,031 & 0,421 & 0,627 \\
\hline $\mathrm{LnR}$ & 0,000 & 0,078 & 0,974 & 0,290 & 0,010 & 0,184 & 0,078 & 0,035 & 0,423 & 0,006 & 0,123 & 0,807 & 0,763 & 0,011 & 0,059 \\
\hline & 0,001 & 0,054 & 0,894 & 0,827 & 0,000 & 0,055 & 0,559 & 0,004 & 0,089 & 0,008 & 0,113 & 0,769 & 0,756 & 0,011 & 0,060 \\
\hline & 0,088 & 0,016 & 0,400 & 0,981 & 0,000 & 0,050 & 0,364 & 0,009 & 0,147 & 0,381 & 0,013 & 0,140 & 0,107 & 0,262 & 0,359 \\
\hline 01 & 0,334 & 0,005 & 0,161 & 0,951 & 0,000 & 0,050 & 0,934 & 0,000 & 0,051 & 0,676 & 0,003 & 0,070 & 0,343 & 0,100 & 0,146 \\
\hline 02 & 635 & 0,001 & 0,076 & 0,002 & 0,086 & 0,892 & 0,175 & 0,021 & 0,272 & 0,584 & 0,005 & 0,084 & 0,679 & 0,020 & 0,067 \\
\hline & 293 & 0,006 & 0,182 & 0,901 & 0,000 & 0,052 & 0,665 & 0,002 & 0,071 & 0,834 & 0,001 & 0,055 & 0,726 & 0,014 & 0,062 \\
\hline & 0,000 & 0,120 & 0,999 & & 0,000 & & & 0,000 & & . & 0,000 & 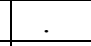 & & 0,000 & \\
\hline 05 & 545 & 0,002 & 0,093 & 0,004 & 0,071 & 0,825 & 0,874 & 0,000 & 0,053 & 0,516 & 0,007 & 0,098 & 0,562 & 0,039 & 0,084 \\
\hline 06 & 0,018 & 0,030 & 0,658 & 0,067 & 0,030 & 0,450 & 0,744 & 0,001 & 0,062 &. & 0,000 &. & 0,791 & 0,008 & 0,057 \\
\hline 07 & 0,380 & 0,004 & 0,141 & 0,926 & 0,000 & 0,051 & & 0,000 & & . & 0,000 & 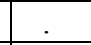 & & 0,000 & \\
\hline & 0,266 & 0,007 & 0,199 & 0,134 & 0,020 & 0,322 & 0,020 & 0,059 & 0,647 & 0,042 & 0,068 & 0,534 & 0,365 & 0,092 & 0,137 \\
\hline 309 & 869 & 0,000 & 0,053 & 0,567 & 0,003 & 0,088 & 0,773 & 0,001 & 0,059 & 0,777 & 0,001 & 0,059 & 0,762 & 0,011 & 0,059 \\
\hline & 0,067 & 0,018 & 0,449 & 0,502 & 0,004 & 0,102 & 32 & 0,001 & 0,055 & 0,722 & 0,002 & 0,064 & 0,986 & 0,000 & 0,050 \\
\hline 11 & 0,000 & 0,092 & 0,990 & 0,004 & 0,071 & 0,820 & 0,734 & 0,001 & 0,063 & 0,964 & 0,000 & 0,050 & . & 0,000 & . \\
\hline 313 & n.a. & n.a. & n.a. & n.a. & n.a. & n.a. & n.a. & n.a. & n.a. & n.a. & n.a. & n.a. & n.a. & n.a. & n.a. \\
\hline & 715 & 0,001 & 0,065 & 0,180 & 0,016 & 0,267 & 0,091 & 0,032 & 0,393 & 0,000 & 0,210 & 0,974 & 0,655 & 0,023 & 0,070 \\
\hline 402 & 23 & 0,028 & 0,628 & 0,151 & 0,019 & 0,300 & 0,837 & 0,000 & 0,055 & 0,425 & 0,011 & 0,124 & 0,686 & 0,019 & 0,066 \\
\hline & 572 & 0,001 & 0,071 & 0,776 & 0,001 & 0,059 & & 0,026 & 0,335 & 0,990 & 0,000 & 0,050 & 0,011 & 0,535 & 0,816 \\
\hline & 27 & 0,017 & 0,2 & 0,278 & 0,044 & 0,392 & 0,343 & 0,049 & 0,345 & 0,040 & 0,130 & 0,671 & 0,684 & 0,146 & 0,118 \\
\hline \multirow{2}{*}{ Modelo 4A-L } & \multicolumn{3}{|c|}{ IND } & \multicolumn{3}{|c|}{ SRV } & \multicolumn{3}{|c|}{ ELE } & \multicolumn{3}{|c|}{ AGI } & \multicolumn{3}{|c|}{ FIN } \\
\hline & Sig & EQP & PO & ig & EQP & PO & ig & EQP & PO & Sig & EQP & PO & Sig & EQP & PO \\
\hline $\begin{array}{l}\text { Te } \\
\text { Le } \\
\end{array}$ & 791 & & & 240 & & & 701 & & & 900 & & & 0,396 & & \\
\hline $\begin{array}{l}\text { Assertividade } \\
\text { do modelo } \\
\text { (R-Sqr) }\end{array}$ & 0,108 & 0,040 & 0,619 & 0,172 & 0,048 & 0,538 & 0,334 & 0,042 & 0,401 & 0,167 & 0,069 & 0,491 & 0,000 & 0,709 & 1,000 \\
\hline Intercepto & 0,000 & 0,317 & 1,000 & 0,000 & 0,284 & 1,000 & 0,000 & 0,369 & 1,000 & 0,000 & 0,306 & 1,000 & 0,882 & 0,001 & 0,052 \\
\hline $\begin{array}{l}\text { LnR_RSE_ } \\
\text { Total }\end{array}$ & 134 & 0,010 & 0,322 & 0,598 & 0,002 & 0,082 & 0,385 & 0,006 & 0,139 & 0,312 & 0,011 & 0,172 & 0,000 & 0,705 & 1,000 \\
\hline Ano & 167 & 0,029 & 0,498 & 0,108 & 0,047 & 0,573 & 0,352 & 0,033 & 0,343 & 0,106 & 0,065 & 0,519 & 0,323 & 0,105 & 0,292 \\
\hline
\end{tabular}




\begin{tabular}{|c|c|c|c|c|c|c|c|c|c|c|c|c|c|c|c|}
\hline \multirow{2}{*}{ Modelo 4B-L } & \multicolumn{3}{|c|}{ IND } & \multicolumn{3}{|c|}{ SRV } & \multicolumn{3}{|c|}{ ELE } & \multicolumn{3}{|c|}{ AGI } & \multicolumn{3}{|c|}{ FIN } \\
\hline & Sig & EQP & PO & Sig & EQP & PO & Sig & EQP & PO & Sig & EQP & PO & Sig & EQP & PO \\
\hline $\begin{array}{l}\text { Teste de } \\
\text { Levene }\end{array}$ & 0,914 & & & 0,253 & & & 0,978 & & & 0,618 & & & 0,895 & & \\
\hline $\begin{array}{l}\text { Assertividade } \\
\text { do modelo (R } \\
\text { Sqr) } \\
\end{array}$ & 0,380 & 0,036 & 0,458 & 0,180 & 0,073 & 0,604 & 0,369 & 0,065 & 0,455 & 0,025 & 0,165 & 0,821 & 0,000 & 0,724 & 1,000 \\
\hline Intercepto & 0,000 & 0,348 & 1,000 & 0,000 & 0,457 & 1,000 & 0,000 & 0,235 & 1,000 & 0,000 & 0,340 & 1,000 & 0,344 & 0,033 & 0,153 \\
\hline $\begin{array}{l}\text { LnV213 } \\
\text {. }\end{array}$ & 0,892 & 0,000 & 0,052 & 0,089 & 0,022 & 0,397 & 0,153 & 0,018 & 0,297 & 0,812 & 0,001 & 0,056 & 0,000 & 0,686 & 1,000 \\
\hline 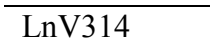 & 0,083 & 0,015 & 0,411 & 0,642 & 0,002 & 0,075 & 0,208 & 0,014 & 0,241 & 0,673 & 0,002 & 0,070 & 0,700 & 0,006 & 0,066 \\
\hline LnV404 & 0,527 & 0,002 & 0,097 & 0,065 & 0,026 & 0,455 & 0,641 & 0,002 & 0,075 & 0,005 & 0,095 & 0,808 & 0,337 & 0,034 & 0,156 \\
\hline Ano & 0,599 & 0,013 & 0,222 & 0,398 & 0,030 & 0,316 & 0,403 & 0,036 & 0,312 & 0,048 & 0,096 & 0,646 & 0,466 & 0,089 & 0,215 \\
\hline \multirow{2}{*}{ Modelo 4C-L } & \multicolumn{3}{|c|}{$\overline{\text { IND }}$} & \multicolumn{3}{|c|}{ SRV } & \multicolumn{3}{|c|}{$\overline{\text { ELE }}$} & \multicolumn{3}{|c|}{ AGI } & \multicolumn{3}{|c|}{ FIN } \\
\hline & Sig & EQP & PO & Sig & EQP & PO & Sig & EQP & PO & Sig & EQP & $\mathbf{P O}$ & Sig & EQP & PO \\
\hline $\begin{array}{l}\text { Teste de } \\
\text { Levene }\end{array}$ & 724 & & & 471 & & & 628 & & & 0,734 & & & 0,344 & & \\
\hline $\begin{array}{l}\text { Assertividade } \\
\text { do modelo } \\
\text { (R-Sqr) }\end{array}$ & 00 & 0,490 & 1,000 & 0,011 & 0,333 & 0,990 & 0,137 & 0,306 & 0,916 & 0,002 & 0,540 & 0,996 & 0,003 & 0,972 & 0,995 \\
\hline Intercept & 0,000 & 0,611 & 1,000 & 0,000 & 0,439 & 1,000 & 0,000 & 0,380 & 1,000 & 0,000 & 0,501 & 1,000 & 0,376 & 0,113 & 0,130 \\
\hline $\begin{array}{l}\text { LnV201 } \\
\end{array}$ & 0,121 & 0,013 & 0,342 & 0,859 & 0,000 & 0,054 & 0,154 & 0,023 & 0,295 & 0,552 & 0,006 & 0,091 & 0,228 & 0,200 & 0,209 \\
\hline $\begin{array}{l}\text { LnV202 } \\
\text { L }\end{array}$ & 0,434 & 0,003 & 0,122 & 0,487 & 0,004 & 0,106 & 0,006 & 0,085 & 0,801 & 0,069 & 0,057 & 0,446 & 0,017 & 0,579 & 0,758 \\
\hline LnV203 & 0,000 & 0,119 & 0,998 & 0,053 & 0,034 & 0,492 & 0,283 & 0,013 & 0,187 & 0,001 & 0,171 & 0,921 & 0,262 & 0,175 & 0,185 \\
\hline $\begin{array}{l}\text { LnV204 } \\
\end{array}$ & 0,950 & 0,000 & 0,050 & 0,090 & 0,026 & 0,397 & 0,420 & 0,007 & 0,126 & 0,972 & 0,000 & 0,050 & 0,482 & 0,073 & 0,099 \\
\hline $\begin{array}{l}\text { LnV205 } \\
\text { nat }\end{array}$ & 0,152 & 0,011 & 0,299 & 0,771 & 0,001 & 0,060 & 0,593 & 0,003 & 0,083 & 0,808 & 0,001 & 0,057 & 0,199 & 0,223 & 0,233 \\
\hline LnV206 & 0,004 & 0,045 & 0,824 & 0,940 & 0,000 & 0,051 & 0,987 & 0,000 & 0,050 & 0,583 & 0,005 & 0,084 & 0,050 & 0,443 & 0,529 \\
\hline LnV207 & 0,580 & 0,002 & 0,085 & 0,038 & 0,039 & 0,547 & 0,379 & 0,009 & 0,141 & 0,264 & 0,022 & 0,199 & 0,523 & 0,061 & 0,090 \\
\hline LnV208 & 0,468 & 0,003 & 0,112 & 0,998 & 0,000 & 0,050 & 0,302 & 0,012 & 0,177 & 0,289 & 0,020 & 0,183 & 0,797 & 0,010 & 0,056 \\
\hline LnV209 & 0,000 & 0,079 & 0,974 & 0,412 & 0,006 & 0,129 & 0,081 & 0,035 & 0,415 & 0,015 & 0,099 & 0,689 & 0,146 & 0,277 & 0,294 \\
\hline $\begin{array}{l}\text { LnV210 } \\
\text { nat }\end{array}$ & 0,001 & 0,057 & 0,908 & 0,939 & 0,000 & 0,051 & 0,269 & 0,014 & 0,196 & 0,008 & 0,118 & 0,773 & 0,648 & 0,031 & 0,070 \\
\hline LnV211 & 0,486 & 0,003 & 0,107 & 0,858 & 0,000 & 0,054 & 0,332 & 0,011 & 0,162 & 0,201 & 0,029 & 0,246 & 0,664 & 0,029 & 0,068 \\
\hline LnV301 & 0,236 & 0,008 & 0,219 & 0,788 & 0,001 & 0,058 & 0,875 & 0,000 & 0,053 & 0,420 & 0,011 & 0,126 & 0,307 & 0,148 & 0,160 \\
\hline LnV302 & 0,621 & 0,001 & 0,078 & 0,002 & 0,084 & 0,880 & 0,163 & 0,022 & 0,285 & 0,625 & 0,004 & 0,077 & 0,944 & 0,001 & 0,050 \\
\hline LnV303 & 0,323 & 0,005 & 0,166 & 0,892 & 0,000 & 0,052 & 0,438 & 0,007 & 0,120 & 0,584 & 0,005 & 0,084 & 0,132 & 0,293 & 0,314 \\
\hline LnV304 & 0,000 & 0,120 & 0,998 & & 0,000 & & & 0,000 & & & 0,000 & & & 0,000 & \\
\hline LnV305 & 0,276 & 0,007 & 0,193 & 0,009 & 0,061 & 0,753 & 0,710 & 0,002 & 0,066 & 0,363 & 0,015 & 0,147 & 0,882 & 0,003 & 0,052 \\
\hline LnV306 & 0,010 & 0,037 & 0,741 & 0,102 & 0,024 & 0,372 & 0,845 & 0,000 & 0,054 & & 0,000 & & 0,208 & 0,216 & 0,225 \\
\hline $\begin{array}{l}\text { LnV307 } \\
\text { L }\end{array}$ & 0,713 & 0,001 & 0,065 & 0,986 & 0,000 & 0,050 & & 0,000 & & . & 0,000 & & & 0,000 & \\
\hline LnV308 & 0,357 & 0,005 & 0,151 & 0,108 & 0,024 & 0,363 & 0,006 & 0,083 & 0,794 & 0,012 & 0,106 & 0,724 & 0,813 & 0,009 & 0,055 \\
\hline LnV309 & 0,902 & 0,000 & 0,052 & 0,514 & 0,004 & 0,099 & 0,969 & 0,000 & 0,050 & 0,541 & 0,007 & 0,093 & 0,328 & 0,136 & 0,149 \\
\hline LnV310 & 0,176 & 0,010 & 0,272 & 0,483 & 0,005 & 0,107 & 0,881 & 0,000 & 0,053 & 0,829 & 0,001 & 0,055 & 0,543 & 0,055 & 0,086 \\
\hline $\begin{array}{l}\text { LnV311 } \\
\text {. }\end{array}$ & 0,000 & 0,074 & 0,966 & 0,003 & 0,076 & 0,843 & 0,824 & 0,001 & 0,056 & 0,943 & 0,000 & 0,051 & & 0,000 & \\
\hline $\begin{array}{l}\text { LnV313 } \\
\end{array}$ & 0,014 & 0,033 & 0,695 & 0,413 & 0,006 & 0,129 & 0,761 & 0,001 & 0,060 & 0,316 & 0,018 & 0,169 & 0,888 & 0,003 & 0,052 \\
\hline LnV401 & 0,458 & 0,003 & 0,115 & 0,137 & 0,020 & 0,317 & 0,016 & 0,065 & 0,684 & 0,000 & 0,232 & 0,983 & 0,263 & 0,175 & 0,184 \\
\hline LnV402 & 0,011 & 0,035 & 0,722 & 0,158 & 0,018 & 0,291 & 0,993 & 0,000 & 0,050 & 0,184 & 0,031 & 0,262 & 0,930 & 0,001 & 0,051 \\
\hline LnV403 & 0,461 & 0,003 & 0,114 & 0,631 & 0,002 & 0,076 & 0,037 & 0,049 & 0,555 & 0,988 & 0,000 & 0,050 & 0,958 & 0,000 & 0,050 \\
\hline Ano & 0,565 & 0,016 & 0,236 & 0,213 & 0,051 & 0,446 & 0,392 & 0,046 & 0,315 & 0,096 & 0,104 & 0,534 & 0,788 & 0,132 & 0,091 \\
\hline
\end{tabular}




\subsection{Mapa dos BSs da amostra por ano de publicação}

Segue a distribuição anual dos BSs publicados e que compõe a amostra de estudo.

\begin{tabular}{|c|c|c|c|c|c|c|c|c|c|c|}
\hline Razão Social & Setor & 1996 & 1997 & 1998 & 1999 & 2000 & 2001 & 2002 & 2003 & 2004 \\
\hline 1001 Recargas e Cartuchos & SRV & & & & & & & $\mathrm{x}$ & $\mathrm{x}$ & \\
\hline Acesita S/A & IND & & & & $\mathrm{x}$ & $\mathrm{x}$ & $\mathrm{x}$ & $\mathrm{x}$ & $\mathrm{x}$ & $\mathrm{x}$ \\
\hline Aché - Laboratórios Farmacêuticos S/A & IND & & & & $\mathrm{x}$ & $\mathrm{x}$ & $\mathrm{x}$ & $\mathrm{x}$ & & \\
\hline Açúcar Guarani & AGI & & & & & & & $\mathrm{x}$ & $\mathrm{x}$ & $\mathrm{x}$ \\
\hline Açucareira Corona & AGI & & & & & & & $\mathrm{x}$ & $\mathrm{x}$ & $\mathrm{x}$ \\
\hline AES Sul Dist Gaúcha de Energia & ELE & & & & $\mathrm{x}$ & $\mathrm{x}$ & $\mathrm{x}$ & $\mathrm{x}$ & $\mathrm{x}$ & $\mathrm{x}$ \\
\hline Agco & IND & & & & & & & & $\mathrm{x}$ & \\
\hline Agrícola Fraiburgo & AGI & & & & & $\mathrm{x}$ & $\mathrm{x}$ & & & \\
\hline Agro Pecuária Campo Alto & AGI & & & & & & & $\mathrm{x}$ & $\mathrm{x}$ & $\mathrm{x}$ \\
\hline Agro Pecuária Mongre & AGI & & & & & & & & $\mathrm{x}$ & $\mathrm{x}$ \\
\hline Albras & IND & & & & & & & $\mathrm{x}$ & $\mathrm{x}$ & $\mathrm{x}$ \\
\hline ALL & SRV & & & & & & & & $\mathrm{x}$ & $\mathrm{x}$ \\
\hline Alphaville Urbanismo & SRV & & & & & & & & $\mathrm{x}$ & $\mathrm{x}$ \\
\hline Alternex & SRV & & $\mathrm{x}$ & $\mathrm{x}$ & & & & & & \\
\hline Alunorte & IND & & & & & & & $\mathrm{x}$ & $\mathrm{x}$ & $\mathrm{x}$ \\
\hline Amazônia Celular & SRV & & & & & $\mathrm{x}$ & $\mathrm{x}$ & $\mathrm{x}$ & $\mathrm{x}$ & $\mathrm{x}$ \\
\hline Ampla & ELE & & & & & & & & $\mathrm{x}$ & $\mathrm{x}$ \\
\hline Araupel & AGI & & & & & & & $\mathrm{x}$ & $\mathrm{x}$ & \\
\hline Asbace ATP & SRV & & & $\mathrm{x}$ & $\mathrm{x}$ & & & & & \\
\hline Bahia Sul Celulose & AGI & & & & & $\mathrm{x}$ & $\mathrm{x}$ & $\mathrm{x}$ & & \\
\hline Bahiagas & SRV & & & & & & & & $\mathrm{x}$ & $\mathrm{x}$ \\
\hline Banco Bradesco & FIN & & & & & & $\mathrm{x}$ & $\mathrm{x}$ & $\mathrm{x}$ & $\mathrm{x}$ \\
\hline Banco da Amazônia-BASA & FIN & & & & & $\mathrm{x}$ & $\mathrm{x}$ & $\mathrm{x}$ & $\mathrm{x}$ & \\
\hline Banco do Brasil & FIN & & $\mathrm{x}$ & $\mathrm{x}$ & $\mathrm{x}$ & $\mathrm{x}$ & $\mathrm{x}$ & $\mathrm{x}$ & $\mathrm{x}$ & $\mathrm{x}$ \\
\hline Banco do Nordeste do Brasil & FIN & & & & & & & $\mathrm{x}$ & $\mathrm{x}$ & \\
\hline Banco Itaú & FIN & & & $\mathrm{x}$ & $\mathrm{x}$ & $\mathrm{x}$ & $\mathrm{x}$ & $\mathrm{x}$ & $\mathrm{x}$ & $\mathrm{x}$ \\
\hline Banco Regional de Desenv. do Extremo Sul & FIN & & & & & $\mathrm{x}$ & $\mathrm{x}$ & $\mathrm{x}$ & $\mathrm{x}$ & $\mathrm{x}$ \\
\hline Banco Rural & FIN & & & & & & & & $\mathrm{x}$ & \\
\hline Bandeirante Energia & ELE & & & & & $\mathrm{x}$ & $\mathrm{x}$ & $\mathrm{x}$ & $\mathrm{x}$ & $\mathrm{x}$ \\
\hline Bank Boston & FIN & & & & & & & $\mathrm{x}$ & & \\
\hline Banrisul & FIN & & & & & $\mathrm{x}$ & $\mathrm{x}$ & $\mathrm{x}$ & $\mathrm{x}$ & $\mathrm{x}$ \\
\hline BASF & IND & & & & & & $\mathrm{x}$ & & & \\
\hline Belcar Caminhões e Máquinas & SRV & & & & & & $\mathrm{x}$ & $\mathrm{x}$ & $\mathrm{x}$ & $\mathrm{x}$ \\
\hline Belgo Mineira (Empresas Belgo Mineira) & IND & & & & $\mathrm{x}$ & $\mathrm{x}$ & $\mathrm{x}$ & $\mathrm{x}$ & & \\
\hline BNDES & FIN & & & & & & $\mathrm{x}$ & $\mathrm{x}$ & $\mathrm{x}$ & $\mathrm{x}$ \\
\hline Boa Vista Energia & ELE & & & & & & & & $\mathrm{x}$ & $\mathrm{x}$ \\
\hline BR Distribuidora & IND & & & & $\mathrm{x}$ & $\mathrm{x}$ & $\mathrm{x}$ & & & \\
\hline Brasil Telecom & SRV & & & $\mathrm{x}$ & $\mathrm{x}$ & $\mathrm{x}$ & $\mathrm{x}$ & $\mathrm{x}$ & $\mathrm{x}$ & $\mathrm{x}$ \\
\hline BrasilSaude & SRV & & & & & & & & $\mathrm{x}$ & $\mathrm{x}$ \\
\hline
\end{tabular}




\begin{tabular}{|c|c|c|c|c|c|c|c|c|c|c|}
\hline Razão Social & Setor & 1996 & 1997 & 1998 & 1999 & 2000 & 2001 & 2002 & 2003 & 2004 \\
\hline Caesb & IND & & & & $\mathrm{x}$ & $\mathrm{x}$ & $\mathrm{x}$ & $\mathrm{x}$ & $\mathrm{x}$ & $\mathrm{x}$ \\
\hline Cagece & IND & & & & & & & $\mathrm{x}$ & $\mathrm{x}$ & $\mathrm{x}$ \\
\hline Caiuá-Serviços de Eletricidade & ELE & & $\mathrm{x}$ & $\mathrm{x}$ & $\mathrm{x}$ & $\mathrm{x}$ & $\mathrm{x}$ & $\mathrm{x}$ & $\mathrm{x}$ & \\
\hline Calçados Azaléia & IND & & $\mathrm{x}$ & $\mathrm{x}$ & $\mathrm{x}$ & $\mathrm{x}$ & $\mathrm{x}$ & $\mathrm{x}$ & $\mathrm{x}$ & $\mathrm{x}$ \\
\hline Calçados Bibi & IND & & & & & $\mathrm{x}$ & $\mathrm{x}$ & & & \\
\hline Camargo Corrêa & IND & & & & & & $\mathrm{x}$ & $\mathrm{x}$ & $\mathrm{x}$ & $\mathrm{x}$ \\
\hline Cambará Produtos Florestais & AGI & & & & & $\mathrm{x}$ & $\mathrm{x}$ & & & \\
\hline Canguru Embalagens & IND & & & & & & $\mathrm{x}$ & $\mathrm{x}$ & $\mathrm{x}$ & $\mathrm{x}$ \\
\hline CAO - Cia Industrial e Agrícola Ometto & AGI & & & & & & $\mathrm{x}$ & $\mathrm{x}$ & $\mathrm{x}$ & $\mathrm{x}$ \\
\hline Caramuru Alimentos & AGI & & & & & & & & $\mathrm{x}$ & $\mathrm{x}$ \\
\hline Carioca Engenharia & SRV & & & & & & & & $\mathrm{x}$ & $\mathrm{x}$ \\
\hline CBTU - Cia Bras Trens Urbanos & SRV & & & & & $\mathrm{x}$ & $\mathrm{x}$ & & & \\
\hline CEA - Cia de Eletricidade do Amapá & ELE & & & & & $\mathrm{x}$ & $\mathrm{x}$ & & & \\
\hline CEAGESP & SRV & & & & & & & & $\mathrm{x}$ & $\mathrm{x}$ \\
\hline CEB - Cia Energética de Brasília & ELE & $\mathrm{x}$ & $\mathrm{x}$ & & & $\mathrm{x}$ & $\mathrm{x}$ & $\mathrm{x}$ & $\mathrm{x}$ & $\mathrm{x}$ \\
\hline Cecrisa & IND & & & $\mathrm{x}$ & $\mathrm{x}$ & $\mathrm{x}$ & & & & \\
\hline Cedae & IND & & & & & $\mathrm{x}$ & $\mathrm{x}$ & $\mathrm{x}$ & $\mathrm{x}$ & $\mathrm{x}$ \\
\hline Cedro & IND & & & & & & & & $\mathrm{x}$ & $\mathrm{x}$ \\
\hline CEF - Caixa Econômica Federal & FIN & $\mathrm{x}$ & $\mathrm{x}$ & $\mathrm{x}$ & & & & & $\mathrm{x}$ & $\mathrm{x}$ \\
\hline CELB - Cia Energética da Borborema & ELE & & & & & $\mathrm{x}$ & $\mathrm{x}$ & & $\mathrm{x}$ & $\mathrm{x}$ \\
\hline Celesc & ELE & & & & & & & $\mathrm{x}$ & $\mathrm{x}$ & $\mathrm{x}$ \\
\hline Celg - Centrais Elétricas de Goiás & ELE & $\mathrm{x}$ & $\mathrm{x}$ & & & $\mathrm{x}$ & $\mathrm{x}$ & $\mathrm{x}$ & $\mathrm{x}$ & $\mathrm{x}$ \\
\hline Celpa - Centrais Elétricas do Pará & ELE & & $\mathrm{x}$ & $\mathrm{x}$ & $\mathrm{x}$ & $\mathrm{x}$ & $\mathrm{x}$ & $\mathrm{x}$ & $\mathrm{x}$ & \\
\hline Celpe - Centrais Elétricas de Pernambuco & ELE & & & & & $\mathrm{x}$ & $\mathrm{x}$ & $\mathrm{x}$ & $\mathrm{x}$ & $\mathrm{x}$ \\
\hline Celtins - Cia de Energia Elétrica Tocantins & ELE & & $\mathrm{x}$ & $\mathrm{x}$ & $\mathrm{x}$ & $\mathrm{x}$ & $\mathrm{x}$ & & & \\
\hline Cemat - Centrais Elétricas Matogrossenses & ELE & $\mathrm{x}$ & $\mathrm{x}$ & $\mathrm{x}$ & & $\mathrm{x}$ & $\mathrm{x}$ & $\mathrm{x}$ & $\mathrm{x}$ & \\
\hline Cemig & ELE & & & & & $\mathrm{x}$ & $\mathrm{x}$ & $\mathrm{x}$ & $\mathrm{x}$ & $\mathrm{x}$ \\
\hline CENF - Cia de Eletricidade de Nova Friburgo & ELE & & & & & $\mathrm{x}$ & $\mathrm{x}$ & & $\mathrm{x}$ & $\mathrm{x}$ \\
\hline Central Álcool de Lucélia & AGI & & & & & & $\mathrm{x}$ & $\mathrm{x}$ & & \\
\hline Cepisa - Cia Energética do Piauí & ELE & & & & $\mathrm{x}$ & $\mathrm{x}$ & & & & \\
\hline Cesp - Companhia Energética de São Paulo & ELE & $\mathrm{x}$ & $\mathrm{x}$ & & & $\mathrm{x}$ & $\mathrm{x}$ & & $\mathrm{x}$ & $\mathrm{x}$ \\
\hline CET - Cia de Eng de Tráfego de São Paulo & SRV & & & & $\mathrm{x}$ & $\mathrm{x}$ & $\mathrm{x}$ & & & \\
\hline CFLCL & ELE & & & & & & & $\mathrm{x}$ & $\mathrm{x}$ & $\mathrm{x}$ \\
\hline CGTEE-Cia Geração Térmica Energia Elétrica & ELE & & & & & & & & $\mathrm{x}$ & $\mathrm{x}$ \\
\hline CHESF - Cia Hidro Elétrica do S.Francisco & ELE & & & & & $\mathrm{x}$ & $\mathrm{x}$ & $\mathrm{x}$ & $\mathrm{x}$ & $\mathrm{x}$ \\
\hline Cia Carris Porto-Alegrense & SRV & & & & & & $\mathrm{x}$ & $\mathrm{x}$ & $\mathrm{x}$ & \\
\hline Cia Energética de Alagoas - CEAL & ELE & & & & & $\mathrm{x}$ & $\mathrm{x}$ & & & \\
\hline Cia Energética Santa Elisa & ELE & & & & & & & $\mathrm{x}$ & $\mathrm{x}$ & $\mathrm{x}$ \\
\hline Cia Força e Luz do Oeste & ELE & & $\mathrm{x}$ & $\mathrm{x}$ & $\mathrm{x}$ & & & & & \\
\hline Cia Ind. Cataguases & IND & & & & & & $\mathrm{x}$ & $\mathrm{x}$ & $\mathrm{x}$ & $\mathrm{x}$ \\
\hline Cia Nacional de Energia Elétrica & ELE & & $\mathrm{x}$ & $\mathrm{x}$ & $\mathrm{x}$ & $\mathrm{x}$ & $\mathrm{x}$ & & & \\
\hline Cia Província & SRV & & & & & $\mathrm{x}$ & $\mathrm{x}$ & & & \\
\hline Claro & SRV & & & & & & & & $\mathrm{x}$ & $\mathrm{x}$ \\
\hline CLFSC - Cia Força e Luz Santa Cruz & ELE & & & & $\mathrm{x}$ & $\mathrm{x}$ & $\mathrm{x}$ & $\mathrm{x}$ & $\mathrm{x}$ & $\mathrm{x}$ \\
\hline Cocal Açúcar e Álcool & AGI & & & & & & $\mathrm{x}$ & $\mathrm{x}$ & $\mathrm{x}$ & \\
\hline Cocel - Cia Campolarguense de Energia & ELE & & & & & $\mathrm{x}$ & $\mathrm{x}$ & & & \\
\hline
\end{tabular}




\begin{tabular}{|c|c|c|c|c|c|c|c|c|c|c|}
\hline Razão Social & Setor & 1996 & 1997 & 1998 & 1999 & 2000 & 2001 & 2002 & 2003 & 2004 \\
\hline Coelba & ELE & & & & & $\mathrm{x}$ & $\mathrm{x}$ & $\mathrm{x}$ & $\mathrm{x}$ & $\mathrm{x}$ \\
\hline Coelce - Cia Energética do Ceará & ELE & & & & & & $\mathrm{x}$ & $\mathrm{x}$ & $\mathrm{x}$ & $\mathrm{x}$ \\
\hline Cohab-PA - Cia de Habitação do Est do Pará & SRV & & & & $\mathrm{x}$ & $\mathrm{x}$ & & & & \\
\hline Comgas & SRV & & & & & & & $\mathrm{x}$ & $\mathrm{x}$ & $\mathrm{x}$ \\
\hline Conpasul Construção e Serviços & SRV & & & & & & $\mathrm{x}$ & $\mathrm{x}$ & $\mathrm{x}$ & $\mathrm{x}$ \\
\hline Construtora Queiroz Galvão & SRV & & & & & & & & $\mathrm{x}$ & $\mathrm{x}$ \\
\hline COPAG & IND & & & & & & & & $\mathrm{x}$ & $\mathrm{x}$ \\
\hline Copasa-Saneamento MG & SRV & & & & & & & & $\mathrm{x}$ & $\mathrm{x}$ \\
\hline Copel - Cia Paranaense de Energia Elétrica & ELE & & & $\mathrm{x}$ & $\mathrm{x}$ & $\mathrm{x}$ & $\mathrm{x}$ & $\mathrm{x}$ & $\mathrm{x}$ & $\mathrm{x}$ \\
\hline COPEL Distribuição - Cia Paranaense Energia & ELE & & & & & & & & $\mathrm{x}$ & $\mathrm{x}$ \\
\hline COPEL Geração - Cia Paranaense Energia & ELE & & & & & & & & $\mathrm{x}$ & $\mathrm{x}$ \\
\hline COPEL Transmissão - Cia Paranaense Energia & ELE & & & & & & & & $\mathrm{x}$ & $\mathrm{x}$ \\
\hline Copesul - Cia Petroquímica doSul & IND & & & & $\mathrm{x}$ & $\mathrm{x}$ & $\mathrm{x}$ & $\mathrm{x}$ & $\mathrm{x}$ & $\mathrm{x}$ \\
\hline Copiadora Cidade & SRV & & & & & & & & $\mathrm{x}$ & $\mathrm{x}$ \\
\hline Corsan-Cia Riograndense Saneamento & SRV & & & & & & & $\mathrm{x}$ & $\mathrm{x}$ & $\mathrm{x}$ \\
\hline $\begin{array}{l}\text { Cosern - Cia Energética do Rio Grande do } \\
\text { Norte }\end{array}$ & ELE & & & & & $\mathrm{x}$ & $\mathrm{x}$ & $\mathrm{x}$ & $\mathrm{x}$ & \\
\hline Cosipa & IND & & & & $\mathrm{x}$ & $\mathrm{x}$ & $\mathrm{x}$ & $\mathrm{x}$ & $\mathrm{x}$ & $\mathrm{x}$ \\
\hline CPFL Cia Piratininga de Força e Luz & ELE & & & & & & $\mathrm{x}$ & & & \\
\hline CPFL Energia & ELE & & & & & & & & $\mathrm{x}$ & $\mathrm{x}$ \\
\hline CPFL Geração de Energia & ELE & & & & & $\mathrm{x}$ & $\mathrm{x}$ & & & \\
\hline CPTM - Cia Paulista de Trens Metropolitanos & SRV & & & & $\mathrm{x}$ & $\mathrm{x}$ & $\mathrm{x}$ & & $\mathrm{x}$ & $\mathrm{x}$ \\
\hline CSN - Companhia Siderúrgica Nacional & IND & & & & $\mathrm{x}$ & $\mathrm{x}$ & $\mathrm{x}$ & $\mathrm{x}$ & $\mathrm{x}$ & $\mathrm{x}$ \\
\hline CST - Cia Siderúrgica de Tubarão & IND & & & & & & $\mathrm{x}$ & $\mathrm{x}$ & $\mathrm{x}$ & $\mathrm{x}$ \\
\hline CTEEP - Cia de Trans Energia Elétrica Paulista & ELE & & & & $\mathrm{x}$ & $\mathrm{x}$ & $\mathrm{x}$ & $\mathrm{x}$ & $\mathrm{x}$ & $\mathrm{x}$ \\
\hline Cummins & IND & & & & & & & $\mathrm{x}$ & $\mathrm{x}$ & $\mathrm{x}$ \\
\hline CVI Refrigerantes & IND & & & & & & & & $\mathrm{x}$ & $\mathrm{x}$ \\
\hline CVRD - Companhia Vale do Rio Doce & IND & & & $\mathrm{x}$ & $\mathrm{x}$ & $\mathrm{x}$ & $\mathrm{x}$ & $\mathrm{x}$ & $\mathrm{x}$ & $\mathrm{x}$ \\
\hline De Nadai Alimentação & IND & & & & $\mathrm{x}$ & $\mathrm{x}$ & & $\mathrm{x}$ & $\mathrm{x}$ & $\mathrm{x}$ \\
\hline Della Coletta Usina de Açúcar e Álcool & AGI & & & & & & & $\mathrm{x}$ & $\mathrm{x}$ & $\mathrm{x}$ \\
\hline Descartáveis Zanatta & IND & & & & & & & $\mathrm{x}$ & $\mathrm{x}$ & $\mathrm{x}$ \\
\hline Disoft & SRV & & & & & & & & $\mathrm{x}$ & $\mathrm{x}$ \\
\hline Dori Alimentos & IND & & & & & & & $\mathrm{x}$ & $\mathrm{x}$ & $\mathrm{x}$ \\
\hline DuPont & IND & & & & & & & $\mathrm{x}$ & $\mathrm{x}$ & \\
\hline Duratex & IND & & & & & & & $\mathrm{x}$ & $\mathrm{x}$ & $\mathrm{x}$ \\
\hline EBAL - Empresa Baiana de Alimentos & SRV & & & & & & & $\mathrm{x}$ & $\mathrm{x}$ & $\mathrm{x}$ \\
\hline ECT - Dir Reg RS & SRV & & & & $\mathrm{x}$ & $\mathrm{x}$ & $\mathrm{x}$ & & & \\
\hline ECT Nacional & SRV & & & & & $\mathrm{x}$ & $\mathrm{x}$ & $\mathrm{x}$ & $\mathrm{x}$ & $\mathrm{x}$ \\
\hline EFLUL - Empresa Força e Luz Urussanga & ELE & & & & & $\mathrm{x}$ & $\mathrm{x}$ & & & \\
\hline El Paso & ELE & & & & & & & $\mathrm{x}$ & $\mathrm{x}$ & $\mathrm{x}$ \\
\hline Elektro Eletricidade e Serviço & ELE & & & & & & $\mathrm{x}$ & $\mathrm{x}$ & $\mathrm{x}$ & $\mathrm{x}$ \\
\hline Eletroacre - Cia de Eletricidade do Acre & ELE & & & & & $\mathrm{x}$ & $\mathrm{x}$ & & $\mathrm{x}$ & $\mathrm{x}$ \\
\hline Eletrobrás - Centrais Elétricas Brasileiras & SRV & & & $\mathrm{x}$ & $\mathrm{x}$ & $\mathrm{x}$ & $\mathrm{x}$ & $\mathrm{x}$ & $\mathrm{x}$ & $\mathrm{x}$ \\
\hline Eletronorte - Centrais Elétricas Norte Brasil & ELE & & $\mathrm{x}$ & $\mathrm{x}$ & & $\mathrm{x}$ & $\mathrm{x}$ & $\mathrm{x}$ & $\mathrm{x}$ & $\mathrm{x}$ \\
\hline Eletronuclear - Eletrobrás Termonuclear & ELE & & & $\mathrm{x}$ & $\mathrm{x}$ & $\mathrm{x}$ & $\mathrm{x}$ & $\mathrm{x}$ & $x$ & $\mathrm{x}$ \\
\hline $\begin{array}{l}\text { Eletropaulo Metropolitana Eletricidade São } \\
\text { Paulo }\end{array}$ & ELE & & & $\mathrm{x}$ & & $\mathrm{x}$ & $\mathrm{x}$ & $\mathrm{x}$ & $\mathrm{x}$ & \\
\hline
\end{tabular}




\begin{tabular}{|c|c|c|c|c|c|c|c|c|c|c|}
\hline Razão Social & Setor & 1996 & 1997 & 1998 & 1999 & 2000 & 2001 & 2002 & 2003 & 2004 \\
\hline Eletrosul & ELE & & & & & & $\mathrm{X}$ & $\mathrm{X}$ & $\mathrm{X}$ & $\mathrm{X}$ \\
\hline Eli Lilly do Brasil & IND & & & & & $\mathrm{x}$ & $\mathrm{x}$ & $\mathrm{x}$ & $\mathrm{x}$ & $\mathrm{x}$ \\
\hline Embraco - Emp. Bras. de Compressores & IND & & & & & & $\mathrm{x}$ & $\mathrm{x}$ & $\mathrm{x}$ & $\mathrm{x}$ \\
\hline Embraer & IND & & & & $\mathrm{x}$ & $\mathrm{x}$ & $\mathrm{x}$ & $\mathrm{x}$ & $\mathrm{x}$ & $\mathrm{x}$ \\
\hline Embrapa - Emp. Bras. Pesquisa Agropecuária & SRV & & $\mathrm{x}$ & $\mathrm{x}$ & $\mathrm{x}$ & $\mathrm{x}$ & $\mathrm{x}$ & $\mathrm{x}$ & $\mathrm{x}$ & $\mathrm{x}$ \\
\hline Embratel & SRV & & & & $\mathrm{x}$ & $\mathrm{x}$ & $\mathrm{x}$ & $\mathrm{x}$ & & \\
\hline Emepa & SRV & & & & $\mathrm{x}$ & $\mathrm{x}$ & $\mathrm{x}$ & & & \\
\hline Emp. de Eletricidade Vale Paranapanema & ELE & & $\mathrm{x}$ & $\mathrm{x}$ & & & & & & \\
\hline Emp. Elétrica Bragantina & ELE & & $\mathrm{x}$ & $\mathrm{x}$ & $\mathrm{x}$ & $\mathrm{x}$ & $\mathrm{x}$ & & & \\
\hline Emparn & SRV & & & & $\mathrm{x}$ & $\mathrm{x}$ & $\mathrm{x}$ & & & \\
\hline Energipe & ELE & & & & & $\mathrm{x}$ & $\mathrm{x}$ & & & \\
\hline Enersul & ELE & & & & & $\mathrm{x}$ & $\mathrm{x}$ & & & \\
\hline Epamig - Emp. de Pesquisa Agropecuária MG & SRV & & & & $\mathrm{x}$ & $\mathrm{X}$ & & & & \\
\hline EPTE - Emp Paulista Trans Energia Elétrica & ELE & & & & $\mathrm{x}$ & $\mathrm{x}$ & & & & \\
\hline Esc de Turismo e Hotelaria Barreira Roxa & SRV & & & & $\mathrm{x}$ & $\mathrm{x}$ & $\mathrm{x}$ & & & \\
\hline Escelsa - Espírito Santo Centrais Elétricas & ELE & & & $\mathrm{x}$ & $\mathrm{x}$ & $\mathrm{x}$ & $\mathrm{x}$ & $\mathrm{x}$ & $\mathrm{x}$ & $\mathrm{x}$ \\
\hline Expresso Caxiense & SRV & & & & & & $\mathrm{x}$ & $\mathrm{x}$ & $\mathrm{x}$ & \\
\hline Faber Castell & IND & & & & & & & & $\mathrm{x}$ & \\
\hline Fersol Ind e Com Ltda & IND & & & & $\mathrm{x}$ & $\mathrm{x}$ & $\mathrm{x}$ & $\mathrm{x}$ & $\mathrm{x}$ & \\
\hline Florestal Alimentos & IND & & & & & & $\mathrm{x}$ & $\mathrm{x}$ & & \\
\hline Fonte Ijui & IND & & & & & & & & $\mathrm{x}$ & $\mathrm{x}$ \\
\hline Fras-le & IND & & & & & $\mathrm{x}$ & $\mathrm{x}$ & & $\mathrm{x}$ & $\mathrm{x}$ \\
\hline Furnas Centrais Elétricas & ELE & & & $\mathrm{x}$ & $\mathrm{x}$ & $\mathrm{x}$ & $\mathrm{x}$ & $\mathrm{x}$ & $\mathrm{x}$ & $\mathrm{x}$ \\
\hline Gafisa & SRV & & & & & & $\mathrm{x}$ & $\mathrm{x}$ & $\mathrm{x}$ & \\
\hline GCS Energia & ELE & & & & & & & $\mathrm{x}$ & $\mathrm{x}$ & \\
\hline General Motors do Brasil & IND & & & & $\mathrm{x}$ & $\mathrm{x}$ & $\mathrm{x}$ & $\mathrm{x}$ & $\mathrm{x}$ & \\
\hline Geraldo J Coan & SRV & & & & & & & & $\mathrm{x}$ & $\mathrm{x}$ \\
\hline Gerdau - Metalúrgica Gerdau & IND & & & & & $\mathrm{x}$ & $\mathrm{x}$ & $\mathrm{x}$ & $\mathrm{x}$ & $\mathrm{x}$ \\
\hline Globo Cabo & SRV & & & & & $\mathrm{x}$ & & & & \\
\hline Granvitur Fretamento e Turismo & SRV & & & & & $\mathrm{x}$ & $\mathrm{x}$ & & & \\
\hline Grupo Algar & SRV & & & & & & & $\mathrm{x}$ & $\mathrm{x}$ & $\mathrm{x}$ \\
\hline Grupo Dimed & SRV & & & & & & & $\mathrm{x}$ & $\mathrm{x}$ & $\mathrm{x}$ \\
\hline Grupo Eberle Mundial & IND & & & & & $\mathrm{x}$ & $\mathrm{x}$ & $\mathrm{x}$ & & \\
\hline Grupo Inepar & IND & $\mathrm{x}$ & $\mathrm{x}$ & $\mathrm{x}$ & $\mathrm{x}$ & $\mathrm{x}$ & $\mathrm{x}$ & $\mathrm{x}$ & $\mathrm{x}$ & $\mathrm{x}$ \\
\hline Grupo José Pessoa & AGI & & & & & & $\mathrm{x}$ & $\mathrm{x}$ & & \\
\hline Grupo Maeda & AGI & & & & & & $\mathrm{x}$ & $\mathrm{x}$ & $\mathrm{x}$ & $\mathrm{x}$ \\
\hline Grupo Pão de Açúcar & SRV & & & $\mathrm{x}$ & $\mathrm{x}$ & $\mathrm{x}$ & $\mathrm{x}$ & $\mathrm{x}$ & $\mathrm{x}$ & $\mathrm{x}$ \\
\hline Grupo Skill & SRV & & & & & & & & $\mathrm{x}$ & $\mathrm{x}$ \\
\hline Hidrelétrica Xanxerê & ELE & & & & & $\mathrm{x}$ & $\mathrm{x}$ & & & \\
\hline Hidropan (Hidroelétrica Panambi) & ELE & & & & & $\mathrm{x}$ & $\mathrm{x}$ & & & \\
\hline Hospital das Clínicas de Porto Alegre & SRV & & & & & & $\mathrm{x}$ & $\mathrm{x}$ & $\mathrm{x}$ & $\mathrm{x}$ \\
\hline Hospital e Maternidade Brasil & SRV & & & & & & & & $\mathrm{x}$ & $\mathrm{x}$ \\
\hline Hospital Mater Dei & SRV & & & & & & & $\mathrm{x}$ & $\mathrm{x}$ & $\mathrm{x}$ \\
\hline Iberdrola & ELE & & & & & & & $\mathrm{x}$ & $\mathrm{x}$ & \\
\hline IBS - Inst Bras de Siderurgia & & & & & & $\mathrm{x}$ & $\mathrm{x}$ & & & \\
\hline
\end{tabular}




\begin{tabular}{|c|c|c|c|c|c|c|c|c|c|c|}
\hline Razão Social & Setor & 1996 & 1997 & 1998 & 1999 & 2000 & 2001 & 2002 & 2003 & 2004 \\
\hline Imbralit & IND & & & & & & $\mathrm{x}$ & $\mathrm{x}$ & $\mathrm{x}$ & $\mathrm{x}$ \\
\hline Infraero & SRV & & & & & & & $\mathrm{x}$ & $\mathrm{x}$ & \\
\hline Intelbras & IND & & & & & $\mathrm{x}$ & $\mathrm{x}$ & $\mathrm{x}$ & & \\
\hline Intermédica Saúde & SRV & & & & $\mathrm{x}$ & $\mathrm{x}$ & $\mathrm{x}$ & $\mathrm{x}$ & & \\
\hline Intervias & SRV & & & & & & $\mathrm{x}$ & $\mathrm{x}$ & $\mathrm{x}$ & \\
\hline Ipanema Agrícola & AGI & & & & & & & $\mathrm{x}$ & $\mathrm{x}$ & $\mathrm{x}$ \\
\hline IRB & SRV & & & & & & & $\mathrm{x}$ & $\mathrm{x}$ & $\mathrm{x}$ \\
\hline Itapebi Geração de Energia & ELE & & & & & & & & $\mathrm{x}$ & \\
\hline Itausa & FIN & & & & & $\mathrm{x}$ & & & $\mathrm{x}$ & $\mathrm{x}$ \\
\hline Itautec Philco & IND & & & & & & $\mathrm{x}$ & $\mathrm{x}$ & $\mathrm{x}$ & $\mathrm{x}$ \\
\hline Jari Celulose & AGI & & & & & $\mathrm{x}$ & $\mathrm{x}$ & $\mathrm{x}$ & $\mathrm{x}$ & $\mathrm{x}$ \\
\hline Kepler Weber & IND & & & & & & & & $\mathrm{x}$ & $\mathrm{x}$ \\
\hline Kraton Polymers & IND & & & & & & & & $\mathrm{x}$ & $\mathrm{x}$ \\
\hline Laboratório Sabin de Análises Clínicas & SRV & & & & & & $\mathrm{x}$ & $\mathrm{x}$ & $\mathrm{x}$ & $\mathrm{x}$ \\
\hline Leili Eletro Eletronica & SRV & & & & & & & & $\mathrm{x}$ & $\mathrm{x}$ \\
\hline Light - Serviços de Eletricidade & ELE & $\mathrm{x}$ & $\mathrm{x}$ & $\mathrm{x}$ & & $\mathrm{x}$ & $\mathrm{x}$ & $\mathrm{x}$ & $\mathrm{x}$ & $\mathrm{x}$ \\
\hline Lupatech & IND & & & & & $\mathrm{x}$ & $\mathrm{x}$ & $\mathrm{x}$ & $\mathrm{x}$ & $\mathrm{x}$ \\
\hline Manaus Energia & ELE & & & & & $\mathrm{x}$ & $\mathrm{x}$ & & & \\
\hline Marcopolo & IND & & & & & $\mathrm{x}$ & $\mathrm{x}$ & $\mathrm{x}$ & $\mathrm{x}$ & $\mathrm{x}$ \\
\hline Marelli Moveis & IND & & & & & & & $\mathrm{x}$ & $\mathrm{x}$ & $\mathrm{x}$ \\
\hline Marisol & IND & & & & $\mathrm{x}$ & $\mathrm{x}$ & $\mathrm{x}$ & $\mathrm{x}$ & $\mathrm{x}$ & $\mathrm{x}$ \\
\hline MBR - Minerações Brasileiras Reunidas & IND & & & $\mathrm{x}$ & $\mathrm{x}$ & & & & & \\
\hline Meridional de Tabacos & IND & & & & & $\mathrm{x}$ & $\mathrm{x}$ & $\mathrm{x}$ & $\mathrm{x}$ & \\
\hline Metrô SP & SRV & & & & & $\mathrm{x}$ & $\mathrm{x}$ & & & \\
\hline Milênia Agro Ciências & IND & & & & & & $\mathrm{x}$ & $\mathrm{x}$ & $\mathrm{x}$ & $\mathrm{x}$ \\
\hline Millennium Inorganic & IND & & & & & & & & $\mathrm{x}$ & $\mathrm{x}$ \\
\hline MNA - Metalúrgica Nova Americana & IND & & & & & & $\mathrm{x}$ & $\mathrm{x}$ & $\mathrm{x}$ & $\mathrm{x}$ \\
\hline Multibrás da Amazônia & IND & & & & & & $\mathrm{x}$ & $\mathrm{x}$ & $\mathrm{x}$ & $\mathrm{x}$ \\
\hline Multibras Eletrodomesticos & IND & & & & & & & & $\mathrm{x}$ & $\mathrm{x}$ \\
\hline Muri Linhas de Montagem & IND & & & & & & & $\mathrm{x}$ & $\mathrm{x}$ & \\
\hline Muxfeldt, Marin \& Cia & ELE & & & & & $\mathrm{x}$ & $\mathrm{x}$ & & & \\
\hline Nestlé & IND & & & & & & & $\mathrm{x}$ & $\mathrm{x}$ & $\mathrm{x}$ \\
\hline Nitroquímica & IND & & & & $\mathrm{x}$ & $\mathrm{x}$ & & & & \\
\hline Norvinco & IND & & & & & & & & $\mathrm{x}$ & $\mathrm{x}$ \\
\hline Novitá Fiat & SRV & & & & & $\mathrm{x}$ & $\mathrm{x}$ & & & \\
\hline O Boticário - Grupo & IND & & & & & & $\mathrm{x}$ & $\mathrm{x}$ & & \\
\hline O Boticário - Indústria & IND & & & & & $\mathrm{x}$ & $\mathrm{x}$ & $\mathrm{x}$ & & \\
\hline $\begin{array}{l}\text { Organon do Brasil Ind Com Ltda de Akzo } \\
\text { Nobel }\end{array}$ & IND & & & & $\mathrm{x}$ & $\mathrm{x}$ & & & & \\
\hline Orsa Celulose, Papel e Embalagens & AGI & & & & & $\mathrm{x}$ & $\mathrm{x}$ & $\mathrm{x}$ & $\mathrm{x}$ & $\mathrm{x}$ \\
\hline Orsa Florestal & AGI & & & & & & & & & $\mathrm{x}$ \\
\hline Otis & IND & & & & & & $\mathrm{x}$ & $\mathrm{x}$ & $\mathrm{x}$ & \\
\hline Pará Pigmentos & IND & & & & & & & $\mathrm{x}$ & $\mathrm{x}$ & \\
\hline Paraíso Bionergia & AGI & & & & & & $\mathrm{x}$ & $\mathrm{x}$ & $\mathrm{x}$ & $\mathrm{x}$ \\
\hline Parks SA Comunicações Digitais & IND & & & & & $\mathrm{x}$ & $\mathrm{x}$ & & & \\
\hline Perdigão & IND & & & & & $\mathrm{x}$ & $\mathrm{x}$ & $\mathrm{x}$ & $\mathrm{x}$ & $\mathrm{x}$ \\
\hline Pesagro-Rio & IND & & & & $\mathrm{x}$ & $\mathrm{x}$ & & & & \\
\hline Peter Chemical & IND & & & & & $\mathrm{x}$ & $\mathrm{x}$ & & & \\
\hline
\end{tabular}




\begin{tabular}{|c|c|c|c|c|c|c|c|c|c|c|}
\hline Razão Social & Setor & 1996 & 1997 & 1998 & 1999 & 2000 & 2001 & 2002 & 2003 & 2004 \\
\hline Petrobras & IND & & & $\mathrm{x}$ & $\mathrm{x}$ & $\mathrm{x}$ & $\mathrm{x}$ & $\mathrm{x}$ & $\mathrm{x}$ & $\mathrm{x}$ \\
\hline PetroFlex - Suzano Petroq. & IND & & & & $\mathrm{x}$ & $\mathrm{x}$ & $\mathrm{x}$ & $\mathrm{x}$ & $\mathrm{x}$ & $\mathrm{x}$ \\
\hline Petróleo Ipiranga & IND & & & & & $\mathrm{x}$ & $\mathrm{x}$ & $\mathrm{x}$ & $\mathrm{x}$ & \\
\hline Petroquímica Triunfo & IND & & & & & & & $\mathrm{x}$ & & \\
\hline Polibrasil - Suzano Petroq. & IND & & & & & & $\mathrm{x}$ & $\mathrm{x}$ & & \\
\hline Politec & SRV & & & & & & & $\mathrm{x}$ & $\mathrm{x}$ & \\
\hline Politeno - Suzano Petroq. & IND & & & & & & $\mathrm{x}$ & $\mathrm{x}$ & & \\
\hline Randon & IND & & & & $\mathrm{x}$ & $\mathrm{x}$ & $\mathrm{x}$ & $\mathrm{x}$ & $\mathrm{x}$ & $\mathrm{x}$ \\
\hline RBS - Rede RBS de Comunicações & SRV & & & & & & $\mathrm{x}$ & & & \\
\hline REFAP & IND & & & & & & $\mathrm{x}$ & $\mathrm{x}$ & & \\
\hline Refrigerante Marajá & IND & & & & & & & & & $\mathrm{x}$ \\
\hline RGE - Rio Grande Energia & ELE & & & & & & & $\mathrm{x}$ & $\mathrm{x}$ & $\mathrm{x}$ \\
\hline RRJ Transp Valores, Segurança e Vigilância & SRV & & & & & & & $\mathrm{x}$ & $\mathrm{x}$ & \\
\hline Sabesp - Cia Saneamento Básico de SP & IND & & $\mathrm{x}$ & $\mathrm{x}$ & & & & $\mathrm{x}$ & $\mathrm{x}$ & $\mathrm{x}$ \\
\hline Sadia & IND & & & & $\mathrm{x}$ & $\mathrm{x}$ & $\mathrm{x}$ & $\mathrm{x}$ & $\mathrm{x}$ & $\mathrm{x}$ \\
\hline Saganor & SRV & $\mathrm{x}$ & $\mathrm{x}$ & & & $\mathrm{x}$ & $\mathrm{x}$ & & & \\
\hline Saint-Gobain Canalização & IND & & & & & & $\mathrm{x}$ & $\mathrm{x}$ & $\mathrm{x}$ & $\mathrm{x}$ \\
\hline Samarco & IND & & & & & & $\mathrm{x}$ & $\mathrm{x}$ & $\mathrm{x}$ & $\mathrm{x}$ \\
\hline Sanepar & SRV & & & & & & & $\mathrm{x}$ & $\mathrm{x}$ & \\
\hline Santander Banespa & FIN & & & & & & $\mathrm{x}$ & $\mathrm{x}$ & $\mathrm{x}$ & $\mathrm{x}$ \\
\hline SAR - Sul América Refrigeração & IND & & & $\mathrm{x}$ & $\mathrm{x}$ & & & & & \\
\hline Serasa - Centralização de Serviços dos Bancos & SRV & & & & & & $\mathrm{x}$ & $\mathrm{x}$ & $\mathrm{x}$ & $\mathrm{x}$ \\
\hline Sercomtel Celular & SRV & & & & & $\mathrm{x}$ & $\mathrm{x}$ & $\mathrm{x}$ & $\mathrm{x}$ & $\mathrm{x}$ \\
\hline Sercomtel SA Telecomunicações & SRV & & & & & $\mathrm{x}$ & $\mathrm{x}$ & $\mathrm{x}$ & $\mathrm{x}$ & $\mathrm{x}$ \\
\hline Shell & IND & & & & & & & $\mathrm{x}$ & $\mathrm{x}$ & $\mathrm{x}$ \\
\hline Sidesc Club Card & SRV & & & & & & & & $\mathrm{x}$ & \\
\hline Souza Cruz & AGI & & & & & & & $\mathrm{x}$ & $\mathrm{x}$ & \\
\hline Springer Carrier & IND & & & & & $\mathrm{x}$ & $\mathrm{x}$ & & & \\
\hline Sul América Seguros & SRV & & & & & & $\mathrm{x}$ & $\mathrm{x}$ & $\mathrm{x}$ & \\
\hline Sulcatarinense & SRV & & & & & & & & $\mathrm{x}$ & $\mathrm{x}$ \\
\hline Suzano de Papel e Celulose & AGI & & & & & $\mathrm{x}$ & $\mathrm{x}$ & $\mathrm{x}$ & $\mathrm{x}$ & $\mathrm{x}$ \\
\hline TAM & SRV & & & & & & & & $\mathrm{x}$ & $\mathrm{x}$ \\
\hline Tecno Moageira & IND & & & & & & & & $\mathrm{x}$ & \\
\hline Tecnum \& Corporate Empreend Imobiliários & SRV & & & & & & $\mathrm{x}$ & & & \\
\hline Tele Celular Sul Participações & SRV & & & & & & & $\mathrm{x}$ & $\mathrm{x}$ & \\
\hline Tele Norte Celular & SRV & & & & & & & $\mathrm{x}$ & $\mathrm{x}$ & \\
\hline Telemar & SRV & & & & & & $\mathrm{x}$ & $\mathrm{x}$ & $\mathrm{x}$ & $\mathrm{x}$ \\
\hline Telemig Celular & SRV & & & & & $\mathrm{x}$ & $\mathrm{x}$ & $\mathrm{x}$ & $\mathrm{x}$ & $\mathrm{x}$ \\
\hline Termoaçu & ELE & & & & & & & $\mathrm{x}$ & $\mathrm{x}$ & \\
\hline Termope - Termopernambuco & ELE & & & & & & & $\mathrm{x}$ & $\mathrm{x}$ & \\
\hline Texon Indústria Farmacêutica & IND & & & & & $\mathrm{x}$ & $\mathrm{x}$ & $\mathrm{x}$ & $\mathrm{x}$ & \\
\hline TIM Nordeste & SRV & & & & & & & & $\mathrm{x}$ & $\mathrm{x}$ \\
\hline TIM Sul & SRV & & & & & & & & $\mathrm{x}$ & $\mathrm{x}$ \\
\hline Todeschini Ind. Com. & IND & & & & & $\mathrm{x}$ & $\mathrm{x}$ & & & \\
\hline Torre Empreendimento Rural e Construção & SRV & & & & & $\mathrm{x}$ & $\mathrm{x}$ & $\mathrm{x}$ & $\mathrm{x}$ & $\mathrm{x}$ \\
\hline
\end{tabular}




\begin{tabular}{|c|c|c|c|c|c|c|c|c|c|c|}
\hline Razão Social & Setor & 1996 & 1997 & 1998 & 1999 & 2000 & 2001 & 2002 & 2003 & 2004 \\
\hline Tractebel Energia & ELE & & & & & & $\mathrm{x}$ & $\mathrm{x}$ & $\mathrm{x}$ & $\mathrm{x}$ \\
\hline Transportadora Americana & SRV & & & & & $\mathrm{x}$ & $\mathrm{x}$ & & & \\
\hline Trensurb - Empresa de Trens Urbanos Ltda & SRV & & & & $\mathrm{x}$ & $\mathrm{x}$ & & & & \\
\hline Tropical Imóveis & SRV & & & & & & $\mathrm{x}$ & & & \\
\hline TRW Automotive & IND & & & & & & & $\mathrm{x}$ & & \\
\hline Tupy & IND & & & $\mathrm{x}$ & & & & $\mathrm{x}$ & $\mathrm{x}$ & $\mathrm{x}$ \\
\hline Uberlândia Refrescos & IND & & & & & & $\mathrm{x}$ & & & \\
\hline Ultrapar Participações & IND & & & & & & $\mathrm{x}$ & $\mathrm{x}$ & $\mathrm{x}$ & $\mathrm{x}$ \\
\hline Unialco & AGI & & & & & & $\mathrm{x}$ & $\mathrm{x}$ & & \\
\hline Unibanco & FIN & & & & & $\mathrm{x}$ & $\mathrm{x}$ & $\mathrm{x}$ & $\mathrm{x}$ & $\mathrm{x}$ \\
\hline Univias & SRV & & & & & & $\mathrm{x}$ & $\mathrm{x}$ & $\mathrm{x}$ & \\
\hline Usiminas - Usinas Siderúrgicas de MG & IND & $\mathrm{x}$ & $\mathrm{x}$ & $\mathrm{x}$ & $\mathrm{x}$ & $\mathrm{x}$ & $\mathrm{x}$ & $\mathrm{x}$ & $\mathrm{x}$ & $\mathrm{x}$ \\
\hline Usina Alvorada & AGI & & & & & & & & $\mathrm{x}$ & $\mathrm{x}$ \\
\hline Usina Antônio Ruette & AGI & & & & & & & & $\mathrm{x}$ & $\mathrm{x}$ \\
\hline Usina Cerradinho & AGI & & & & & & $\mathrm{x}$ & $\mathrm{x}$ & $\mathrm{x}$ & $\mathrm{x}$ \\
\hline Usina Ferrari & AGI & & & & & & $\mathrm{x}$ & $\mathrm{x}$ & $\mathrm{x}$ & $\mathrm{x}$ \\
\hline Usina Jalles Machado & AGI & & & & & & $\mathrm{x}$ & $\mathrm{x}$ & $\mathrm{x}$ & $\mathrm{x}$ \\
\hline Usina Mandu & AGI & & & & & & $\mathrm{x}$ & $\mathrm{x}$ & $\mathrm{x}$ & $\mathrm{x}$ \\
\hline Usina Santa Cruz & AGI & & & & & & & $\mathrm{x}$ & $\mathrm{x}$ & $\mathrm{x}$ \\
\hline Usina São Domingos & AGI & & & & & & $\mathrm{x}$ & $\mathrm{x}$ & $\mathrm{x}$ & $\mathrm{x}$ \\
\hline Usina São José da Estiva & AGI & & & & & & $\mathrm{x}$ & $\mathrm{x}$ & $\mathrm{x}$ & $\mathrm{x}$ \\
\hline Usina São Manoel & AGI & & & & & & & $\mathrm{x}$ & $\mathrm{x}$ & $\mathrm{x}$ \\
\hline Usina São Martinho & AGI & & & & & & $\mathrm{x}$ & $\mathrm{x}$ & $\mathrm{x}$ & $\mathrm{x}$ \\
\hline Usina Virgolino de Oliveira & AGI & & & & & & & & $\mathrm{x}$ & $\mathrm{x}$ \\
\hline Usina Vista Alegre & AGI & & & & & & & $\mathrm{x}$ & $\mathrm{x}$ & $\mathrm{x}$ \\
\hline USJ Açúcar e Álcool & AGI & & & & & & & $\mathrm{x}$ & $\mathrm{x}$ & $\mathrm{x}$ \\
\hline Vale do Ivai Açúcar e Álcool & AGI & & & & & & & & $\mathrm{x}$ & $\mathrm{x}$ \\
\hline Vega Engenharia Ambiental & SRV & & & & & & & $\mathrm{x}$ & & \\
\hline Viação Campos Gerais & SRV & & & & & & $\mathrm{x}$ & $\mathrm{x}$ & $\mathrm{x}$ & \\
\hline Viação Grande Vitória & SRV & & & & & $\mathrm{x}$ & $\mathrm{x}$ & & & \\
\hline Viamao & & & & & & & & $\mathrm{x}$ & $\mathrm{x}$ & \\
\hline Vivo & SRV & & & & & & & & $\mathrm{x}$ & $\mathrm{x}$ \\
\hline Votorantim - Grupo & IND & & & & & & & & $\mathrm{x}$ & $\mathrm{x}$ \\
\hline Votorantim Celulose e Papel & AGI & & & $\mathrm{x}$ & $\mathrm{x}$ & $\mathrm{x}$ & $\mathrm{x}$ & $\mathrm{x}$ & $\mathrm{x}$ & $\mathrm{x}$ \\
\hline Zanzini Móveis & IND & & & & & & $\mathrm{x}$ & $\mathrm{x}$ & $\mathrm{x}$ & \\
\hline Zen & & & & & & & & & $\mathrm{x}$ & $\mathrm{x}$ \\
\hline Zivi/Hércules & IND & & & & & $\mathrm{x}$ & $\mathrm{x}$ & $\mathrm{x}$ & & \\
\hline
\end{tabular}




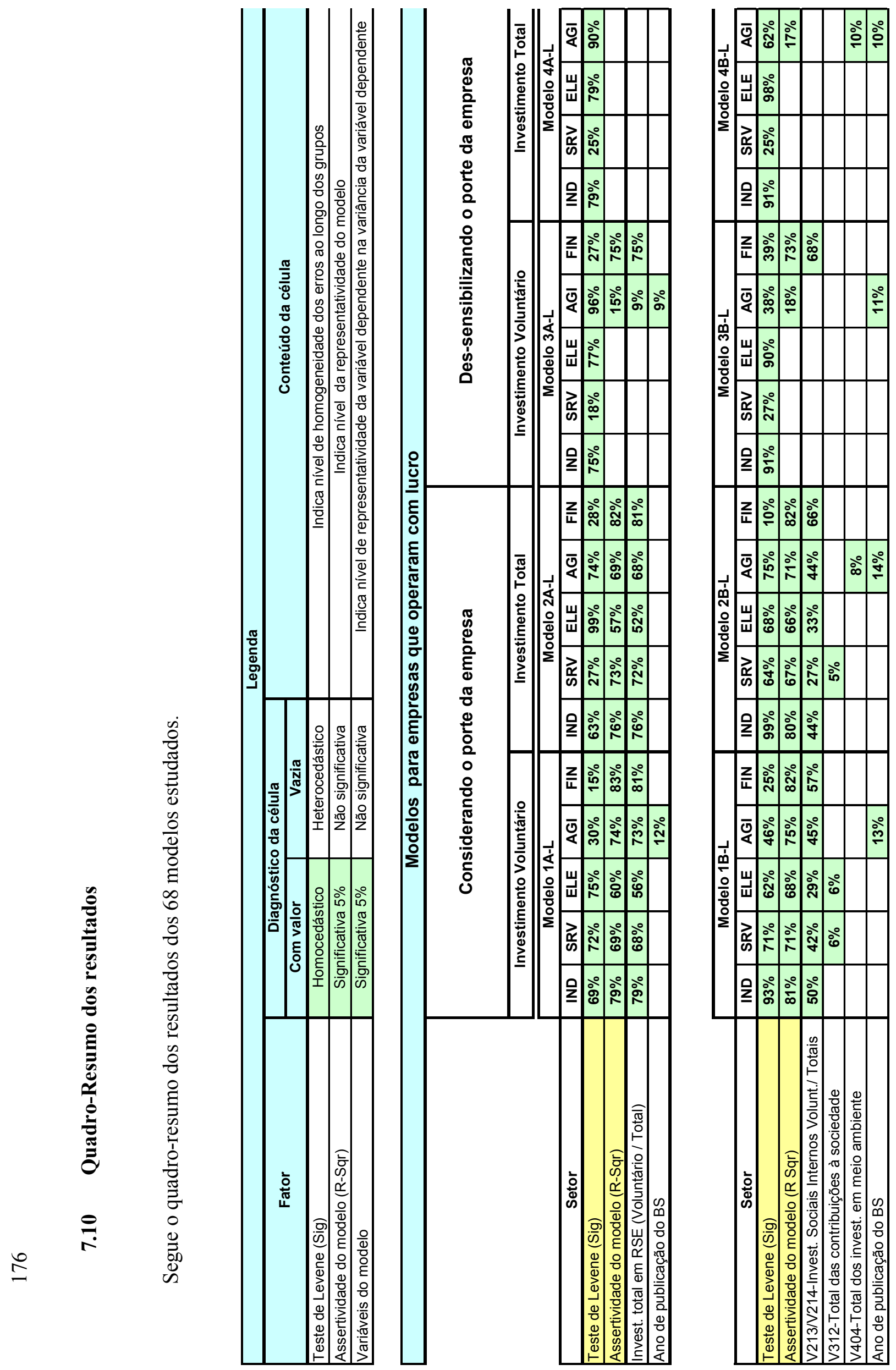




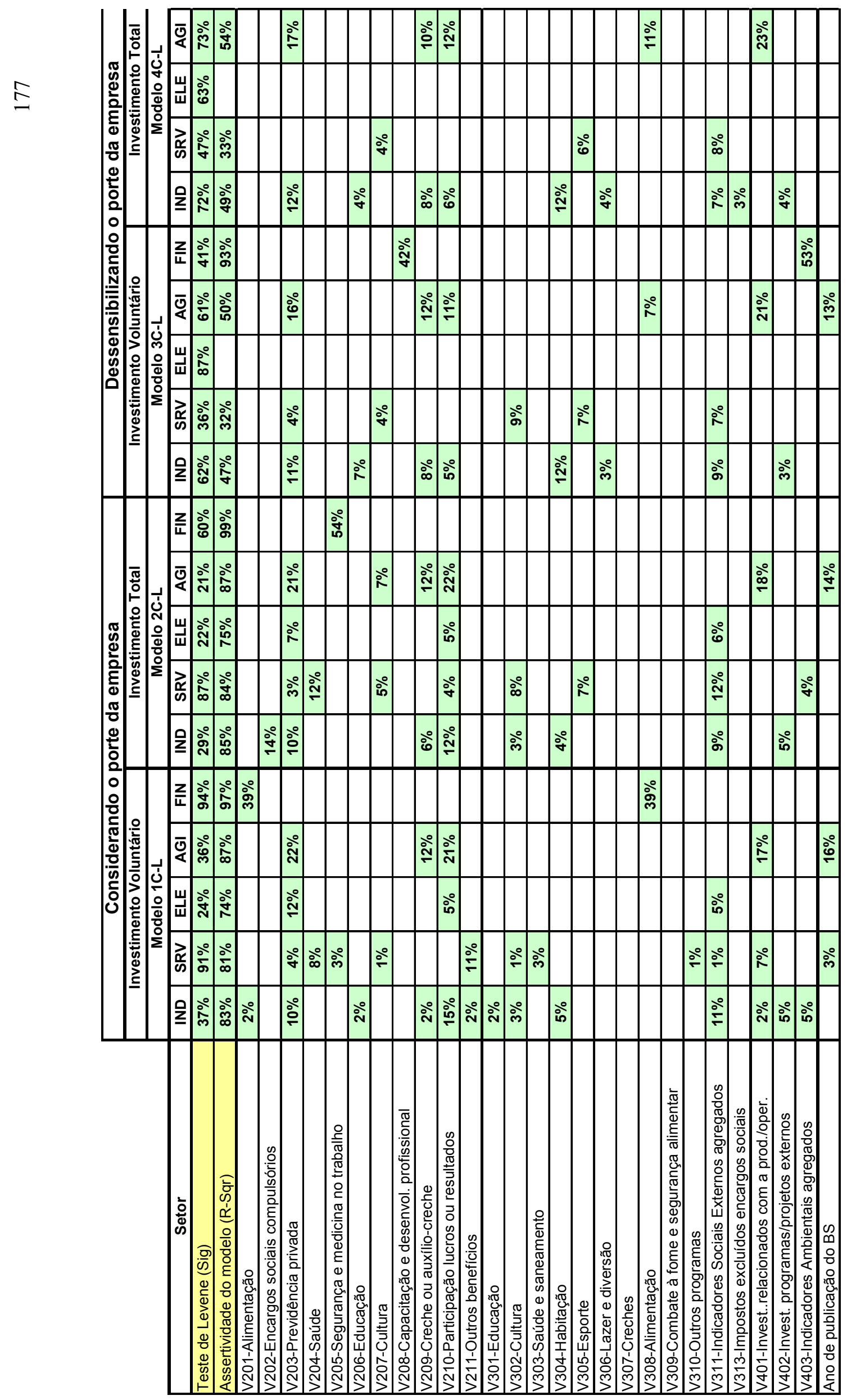


Modelos para empresas que operaram com prejuízo

\begin{tabular}{|c|c|c|c|c|}
\hline & \multicolumn{2}{|c|}{$\begin{array}{c}\text { Considerando o } \\
\text { porte }\end{array}$} & \multicolumn{2}{|c|}{$\begin{array}{c}\text { Dessensibilizando o } \\
\text { porte }\end{array}$} \\
\hline & Volunt & Total & Volunt & Total \\
\hline Modelo & 1A-P & 2A-P & 3A-P & 4A-P \\
\hline Teste de Levene (Sig) & $14 \%$ & $25 \%$ & $95 \%$ & $96 \%$ \\
\hline Assertividade do modelo (R-Sqr) & $57 \%$ & $55 \%$ & & $13 \%$ \\
\hline Invest. total em RSE (Voluntário / Total) & $41 \%$ & $39 \%$ & & \\
\hline Ano de publicação do BS & $9 \%$ & & & $7 \%$ \\
\hline Setor & $9 \%$ & & & \\
\hline Ano * Setor & & & & \\
\hline
\end{tabular}

\begin{tabular}{|l|c|c|c|c|}
\hline \multicolumn{1}{|c|}{ Modelo } & 1B-P & 2B-P & 3B-P & 4B-P \\
\hline Teste de Levene (Sig) & $42 \%$ & $19 \%$ & $52 \%$ & $50 \%$ \\
\hline Assertividade do modelo (R Sqr) & $65 \%$ & $61 \%$ & $\mathbf{2 9} \%$ & $\mathbf{1 8 \%}$ \\
\hline V213/V214-Invest. Sociais Internos Volunt./ Totais & $\mathbf{4 8 \%}$ & $\mathbf{3 9 \%}$ & $\mathbf{1 1 \%}$ & $\mathbf{4 \%}$ \\
\hline V312-Total das contribuições à sociedade & & & & \\
\hline V404-Total dos invest. em meio ambiente & & & & \\
\hline Ano de publicação do BS & $10 \%$ & & $\mathbf{9 \%}$ & \\
\hline Setor & $12 \%$ & $13 \%$ & $\mathbf{9 \%}$ & $\mathbf{1 0 \%}$ \\
\hline Ano * Setor & & & & \\
\hline
\end{tabular}

\begin{tabular}{|c|c|c|c|c|}
\hline Modelo & $1 C-P$ & 2C-P & $3 C-P$ & 4C-P \\
\hline Teste de Levene (Sig) & \multirow{31}{*}{\multicolumn{4}{|c|}{$\begin{array}{l}\text { Tamanho da amostra foi considerado } \\
\text { insuficiente para cálculo desses modelos }\end{array}$}} \\
\hline Assertividade do modelo (R-Sqr) & & & & \\
\hline V201-Alimentação & & & & \\
\hline V202-Encargos sociais compulsórios & & & & \\
\hline V203-Previdência privada & & & & \\
\hline V204-Saúde & & & & \\
\hline V205-Segurança e medicina no trabalho & & & & \\
\hline V206-Educação & & & & \\
\hline V207-Cultura & & & & \\
\hline V208-Capacitação e desenvol. profissional & & & & \\
\hline V209-Creche ou auxílio-creche & & & & \\
\hline V210-Participação lucros ou resultados & & & & \\
\hline V211-Outros benefícios & & & & \\
\hline V301-Educação & & & & \\
\hline V302-Cultura & & & & \\
\hline V303-Saúde e saneamento & & & & \\
\hline V304-Habitação & & & & \\
\hline V305-Esporte & & & & \\
\hline V306-Lazer e diversão & & & & \\
\hline V307-Creches & & & & \\
\hline V308-Alimentação & & & & \\
\hline V309-Combate à fome e segurança alimentar & & & & \\
\hline V310-Outros programas & & & & \\
\hline V311-Indicadores Sociais Externos agregados & & & & \\
\hline V313-Impostos excluídos encargos sociais & & & & \\
\hline V401-Invest. relacionados com a prod./oper. & & & & \\
\hline V402-Invest. programas/projetos externos & & & & \\
\hline V403-Indicadores Ambientais agregados & & & & \\
\hline Ano de publicação do BS & & & & \\
\hline Setor & & & & \\
\hline Ano * Setor & & & & \\
\hline
\end{tabular}

